Fabio Armao

Inside War

Understanding the Evolution of Organised Violence in the Global Era 



\section{Fabio Armao}

\section{Inside War}

Understanding the Evolution of Organised Violence in the Global Era

Managing Editor: Magdalena Randall-Schab

Langueage Editor: Adam Tod Leverton

Translated by Kora E. Bättig von Wittelsbach and Emilia Bianca Pisani 
Published by De Gruyter Open Ltd, Warsaw/Berlin

Part of Walter de Gruyter GmbH, Berlin/Munich/Boston

\section{(cc) BY-NC-ND}

This work is licensed under the Creative Commons Attribution-NonCommercial-NoDerivs 3.0 license, which means that the text may be used for non-commercial purposes, provided credit is given to the author. For details go to http://creativecommons.org/licenses/by-nc-nd/3.0/.

Copyright $\odot 2015$ Fabio Armao

ISBN: 978-3-11-047119-9

e-ISBN: 978-3-11-047124-3

Bibliographic information published by the Deutsche Nationalbibliothek The Deutsche Nationalbibliothek lists this publication in the Deutsche Nationalbibliografie; detailed bibliographic data are available in the Internet at http://dnb.dnb.de.

Managing Editor: Magdalena Randall-Schab

Langueage Editor: Adam Tod Leverton

www.degruyteropen.com

Cover illustration: @ Fabio Armao 


\title{
Contents
}

\author{
Introduction $-\mathbf{X}$ \\ Acknowledgments —XVII
}

\section{Part I}

1 Old Wars, New Wars - 2

1.1 A Trick of Nature - 3

1.2 The Role of 'American Social Science' -5

1.3 The Foundations of a New Paradigm - 8

1.3.1 Ontology 8

1.3.2 Epistemology - $\mathbf{1 1}$

1.3.3 Methodology - 14

1.4 The Post-Cold War Scenario - 16

1.4.1 The End and the Beginning — 17

1.4.2 The De-construction of the State -19

1.4.3 The Revenge of the Peripheries - 20

1.4.4 The New Cleavage Structures - 22

1.5 On Changes in War -23

Part II

2 Violence and the Human Factor -28

$2.1 \quad$ The Military and the Problem of Legitimacy - 28

2.2 The Education and Training Process of Soldiers - 32

2.3 Witting and Unwitting Victims - 38

$3 \quad$ Military Apparatuses - 46

3.1 The Variants of Professionalism -47

3.2 Recruitment and Career - 54

3.3 Esprit-de-corps -61

$4 \quad$ Battlefields -66

4.1 Permanent and Temporary Spaces - 68

4.2 Urban and Rural Spaces - 74

4.3 Spaces of Concealment $-\mathbf{8 0}$

5 The Propaganda Machine — 85

5.1 The Elements of Propaganda $-\mathbf{8 6}$

5.1.1 The Propagandist -86

5.1.2 The Audience $\mathbf{-} \mathbf{8 8}$ 


\begin{tabular}{|c|c|}
\hline 5.1 .3 & The Content -89 \\
\hline 5.1 .4 & The Media -91 \\
\hline 5.2 & Inventing the Enemy - 93 \\
\hline 5.3 & News Management \\
\hline 5.4 & Heroes and Survivors -105 \\
\hline 6 & War Political Economy — 110 \\
\hline 6.1 & State, Capitalism, and War — 111 \\
\hline 6.2 & The Global Market of Violence — 117 \\
\hline 6.3 & Shadow Economy and Finance -125 \\
\hline
\end{tabular}

\section{Part III}

7 Perspectives on the Coming World - 136

7.1 A New Geography of Cities and States — 137

7.2 Clusters of Sovereignty $-\mathbf{1 4 0}$

7.3 The Rule of the Clan - 146

7.3.1 Imagined Family - 147

7.3.2 Social Control and Informal Justice - $\mathbf{1 4 8}$

7.3.3 Neopatrimonialism $-\mathbf{1 4 9}$

8 Conclusion. Urban Resistance to Violence - 151

Bibliography 158

Index -192 
To my son, remembering my father 

Looking back over the centuries, or even if looking only at the present, we can clearly observe that many men have made their living, often a very good living, from their special skill in applying weapons of violence, and that their activities have had a very large part in determining what uses were made of scarce resources.

F. C. Lane, Profits from Power.

War makes states, I shall claim. Banditry, piracy, gangland rivalry, policing, and war making all belong on the same continuum - that I shall claim as well. For the historically limited period in which national states were becoming the dominant organizations in Western countries, I shall also claim that mercantile capitalism and state making reinforced each other.

C. Tilly, War Making and State Making as Organized Crime. 


\section{Introduction}

War is a social construction. There is no greater artifact - in its literal sense of a product of human genius - than the planning and execution of a massacre. Infantry emerging from the trenches around the Somme River only to be mowed down in the tens of thousands by enemy machine guns, suicide terrorists who blow themselves up on the streets of Jerusalem or in the subways of London and Madrid, are all guided by an idea (and an order), not by instinct. Every type of society has developed within itself more or less sophisticated apparatuses composed of individuals specialised in the use of armed force. Human history is also the history of violence, its evolution and the attempts to limit it.

For the last five centuries, states, more than any other institution, have excelled in the art of war, showing an extraordinary capability to create military organisations that guaranteed sufficient obedience and were thus compatible with their own foundations of legitimacy. It is not a coincidence that absolute monarchs, whose power derived from God or tradition, demonstrated a marked predilection for mercenary troops and, when finances and the consolidation of the bureaucracies made it possible, for armies composed of professional soldiers. In the same way, only a revolutionary regime such as that of 1792 in France could have conceived of the idea of the nation armée and resort to mass conscription without fearing for its own survival as a political entity - this is demonstrated by the fact that a few years later Prussia adopted the principle of universal conscription, but was careful not to maintain the policy once Napoleon had been defeated. This historical cycle reached its apex during the total wars of the early twentieth century, which saw the citizens of belligerent states involved first as soldiers and then in their capacity as civilians as well, as the targets of 'terror bombings' in the cities. After that, the USA and the USSR in particular, engaged in the development of the largest arsenal in human history, accumulating thermonuclear weapons whose use was limited (thankfully for all involved) to strategy simulations or war games. The two superpowers certainly did not remain inactive, but rather utilised their immense conventional military resources in wars against third parties, or to feed proxy wars entrusted to their allies on the periphery of the international system.

Over these same centuries, none of this would have been possible if the state had not been able to count on the help of capitalism. The evolution of a military apparatus in the political sphere requires a similar capacity for innovation in the economic sphere: from the production and sale of weapons, to the collection and allocation of capital. Even with regard to war, the historical vicissitudes of the state and capitalism appear in reality to be inseparable. It is enough to reflect on the age of the first great transoceanic enterprises, when long distance trade in precious metals developed in order to satisfy the growing needs of powers such as Spain; or the later colonial adventures of England, France, and the Netherlands, when it seemed instead that it was the governments placing themselves at the service of private interests. Politics 
assumes the responsibility of determining who will be killed and why, of finding the 'just cause' for war - from the civilizing mission of colonialism to the Global War on Terror (GWOT). The market, on the other hand, occupies itself with supplying the instruments of slaughter. For centuries war has carried out a political, and therefore, public, function; but private actors have always claimed wide margins of manoeuvre, and profit, in all the activities connected to its management. Besides this, the military sector as such has revealed itself many times to be an extraordinary factor in progress, allowing for civilian applications of its inventions as well, once the need for secrecy has been eliminated or enemy adversaries have bridged the technological gap. The push given to civilian transport by successive arms races, first naval, then air and missiles comes to mind; or the role played by inventions such as radar or computers in the daily life of common citizens.

The year 1989 marks an unprecedented cleavage with the past. The international system has struggled since then to establish new rules of conduct and clear hierarchies. The fall of the USSR deprived the American administration of an enemy which, on an international level, had actually revealed itself to be an excellent governing partner. The two superpowers had succeeded, in fact, in constructing a vast network of patron-client relationships that allowed developing countries in particular to play their changing positions between the two blocks like a card for procuring ever greater resources. The immediate dismantling of that network damaged the USA capacity for leadership, and its pretense to continue to exercise authority over the entire planet. At least until the appearance of a new enemy gives new life to the strategy of alliances.

However, 1989 marked an even more significant cleavage in the relationship between politics and the market. The previously mentioned anomaly of the Cold War - the fact that confrontation could not go beyond the threshold of the rhetoric of deterrence without risking the extermination of the human race - shifts the competition from the military plane to the technological and industrial planes. And therefore the primary beneficiary was an economic system rather than a political system. The cleavage of 1989 owed far more to the competitive nature of American capitalism - the author of the failure of the planned economy of the Soviet state than to the penetration of democratic values. This is further demonstrated by the fact that, while capitalism has not encountered obstacles to its own expansion since then, in many countries (and not only in those of the former Soviet block) democracy is a conquest more in form than in substance. Actually, capitalism has established itself often to the detriment of democracy, imposing extremely elevated social costs to a growing multitude of men and women.

In other words, the fall of the Berlin Wall eventually liberated the forces of capitalism from the geopolitical restraints that characterised the Cold War era. As if the bulwarks had suddenly given way, the free market flooded into eastern Europe, Russia, even China, washing away previously existing institutions or, at the least, subjecting them to its own uses. In the course of just a few years, the expansion of the free market accomplished a feat that overshadows, for the rapidity with which it 
was realised and for the vast number of countries involved, the numerous efforts at conquest which until then had characterised the history of capitalism. Furthermore, as a consequence of that event, states assumed to be legitimised to dramatically improve the privatisation process in a growing number of sectors which until then had been under public management - from education to healthcare to the armed forces. That choice, meant as a remedy to help bring down growing budget deficits, ended up calling into question the very idea of democracy as a mechanism for the redistribution of resources, heightening inequalities instead of diminishing them.

With regard to war, in particular, this privatisation process has resulted in the freeing up of growing spaces for a vast range of violent non-state actors (VNSAs). Figures that seemed to have been relegated to the past now begin to recapture substantial segments of warfare arena. Mercenarism is a common practice in many wars where even children are forced to fight, on the African continent, in some Asian peripheries, and in Latin America; and piracy has made a comeback as a lucrative activity, especially in Asia and the Pacific.

The reappearance on the world scene of these kind of players, state rivals with respect to the use of violence - and, more recently, of groups such as mafias, terrorist networks, and private military corporations (PMCs) - seems destined to contradict the universalist character of the state experience which is generally taken for granted. The fact that there is no place left on earth which is not part of one state or another, promoted the idea of a world that was fairly stable or that, at the least, had completed a necessary and decisive phase of its consolidation. And the slow, but constant progress in the number of democratic regimes, the end of the clashes between rival ideologies, the globalisation of the economy, all contributed to strengthening this idea. The fact that between those same states there was a propensity for the pacific instruments of law enforced by an ever tighter network of international organisations, also seemed to confirm that within a short time violence would be confined to residual areas of the planet where, in the end, war itself would finally be replaced by a more moderate use of force by an 'international police corps'.

Whether this was a kind of new 'Great Illusion' - after that of the nineteenth century which held that free commerce would render war obsolete - cannot yet be determined, but the repeated bursts of violence in daily life even in the privileged West are challenging the faith of even the most optimistic. This evolution could be interpreted as a return to the state of nature. According to this hypothesis, even within many states the very premises of civil coexistence, and in particular, that pactum subiectionis upon which rests the sovereign authority's claim to the monopoly of the legitimate use of physical force, seems to be questioned anew. The lexicon of political science has been enriched by expressions such as 'failed state' and 'rogue state'; and there are even those who theorize the return to fealty and organizing principles of feudalism.

This book seeks to oppose this idea of a return to an original, pre-political condition, by assuming that new wars are the product of the blurring of the public- 
private divide. Going back again to history, we could observe in fact that, particularly in Europe, the exit from the feudal system and the entire state-making process can be considered in terms of the pretense of monarchies to gradually enlarge their sources of legitimacy, and to define themselves (also against other competing political authorities) in terms of the legitimate holders of the monopoly in the use of force. This process entailed the creation of a certain, limited, number of public spaces of sovereignty - the states, with their own armed forces and police apparatuses - and also a gradual ban on private violent actors, such as warlords, mercenaries, pirates, and so on. We assume that the end of the Cold War, together with globalisation, inverted this process, and that the public-private border is now again blurred. As a consequence, internal and external factors are blurred and the border between war and crime is becoming ever more permeable and elusive. The main fact that new wars are both local and global, and that they are different from both classic inter-state wars and classic civil wars, implies a growing uncertainty as to which law, domestic or international, applies; and which legitimate authority is supposed to enforce it.

It is worth stressing this main point: the post-Cold War period was, and still is, characterised by both the recurrence of state wars and the spread of forms of organised violence other than wars. Asymmetric warfare between alliances led by the USA and groups of insurgents, such as those witnessed in Afghanistan and Iraq, coexist alongside conflicts, such as that of former Yugoslavia; and others managed by ethnic or terrorist groups, gangs, and narco-traffickers, among others. The massive militaryindustrial complexes conceived in the context of the threat of nuclear Armageddon are still there of course, but they now coexist with irregular armies of insurgents capable of carrying out massacres through the use of light weapons and improvised explosives devices. This book intends to cover - and to include in its model of analysis - events ranging from state wars to conflicts with and among VNSAs, assuming that:

1. organised violence, in all its manifestations, is a complex process involving different actors whose main characteristic is the professional practice of violence;

2. politics and market - over the past five centuries, mainly the state and capitalism - both concur in perpetrating the empirical evidence of organised violence: from the pain suffered by the victims, to the environmental ravages of fighting and bombings;

3. organised violence, from wars between states to conflicts among the different VNSAs, is politically motivated. In this sense, we assume that war is still intrinsically Clausewitzian, in so far as it still pretends to be the pursuit of politics with other means. War evolves simply because politics is changing, in particular, and at present, going through a process of privatisation and de-democratisation.

In sum, Inside War goes beyond a state-centered analysis and adopts a multifaceted perspective capable of surpassing these simplistic representations of war, which risk pushing the social sciences into a renewed form of reductionism, by forcing dialogue among researchers from different fields. Part I is intended to confront the ongoing 
inadequacy of the war studies, and to outline the new scientific paradigm on which the research was based. The first section of chapter 1 examines the persistence in social sciences of the 'human nature' prejudice, typically cited as the main cause of war. The second offers an account of the specific role assumed in the study of war by the discipline of International Relations (IR) in the USA in the aftermath of World War II. The third section lays the foundations of the new paradigm deemed necessary for the development of a comprehensive analysis of war. The fourth outlines the post-Cold War scenario following the methodological prerequisites of the new paradigm, but also defines the peculiar contribution of IR to the study of war - which compliments the input of other disciplines such as sociology or history. The fifth and final section confronts with the ongoing debate on the changes in twenty-first century war, proposing this book as a tentative way out of this theoretical stalemate.

Part II reflects the basic elements of war: from the human factor to military institutions; from the spatial dimensions of battles to the methods adopted for building public consent around the main actors' recourse to violence; and, finally, to the intertwined role of politics and economy. But in order to give more substance to the new wars debate, the aim is to apply these same elements to VNSAs, and to look at their evolution - with particular attention, of course, to the post Cold War period. Chapter 2 begins by examining the background of those who engage in organised forms of physical violence (soldiers, contractors, terrorists, gang, and mafia members), and explores how this background eventually influences these individuals' perceptions of their relationship with their enemies. The first section confronts the problem of legitimacy as the foundational prerequisite of any military institution. The second section examines more closely the different phases of the education and training process which is needed to gain obedience from individual soldiers, and to overcome their inhibition to kill, and analyses the extreme cases of torturers and suicide terrorists. The third section is intended to bring to the forefront the victims of violence: to distinguish the willing and unwilling; and investigating how they perceive the physical trauma and the process of dehumanisation suffered specifically, through the examination of three representative cases: women, civilians, and torture victims.

Chapter 3 looks at military institutions, the professional groups to which political systems have always subcontracted the administration of violence - their structures, functions, goals, and motivations. The first section analyses the evolution of the role of the officer in state armed forces: a figure that is increasingly required to take on competences typical of freelance professionals, and attenuate the traditional martial traits associated with their role - traits paradoxically re-discovered by VNSAs. The second section explores more in depth the problems of recruitment and career, stressing the fact that the combined effects of voluntary enlistment and outsourcing inevitably put emphasis on the delegation of military functions, as well as the renunciation by political institutions of the prerogative both to determine the strategic dimensions of the conflict, and verify their correct application. The third section 
compares the internal cohesion of the primary groups in public armed forces and in VNSAs, stressing how the latter have re-discovered all those symbolic dimensions from the honour code to the initiation rites - that democratisation had made more and more implausible for members of the military.

Chapter 4 is devoted to the spaces where violence is carried out. The locations where violence takes place determine the distance (both physical and psychological) between soldiers and civilians, and consequently the degree of civilian participation in the event: a battle on an open field is quite different from urban guerrilla warfare. The first section distinguishes between permanent and temporary spaces: battlefields, military bases, even walls, underlining how these spaces change as a consequence of the growing privatisation of violence. The second section analyses how urban or rural settings condition (and suffer the consequences of) war and organised violence, as well as how the ongoing spreading of VNSAs impacts on these two different environments. The third section investigates a peculiar dimension of space, the shady areas characteristic of both autocracies and democracies which are destined to grow in the era of terrorists, mafia, and private military corporations (PMCs).

Chapter 5 confronts the problem of how both states and non-state actors legitimise their use of violence through propaganda, adopting different languages depending on their audiences and the different phases of the conflict involved. The first section is intended to outline a definition of the concept of propaganda, based on four elements: the propagandist, the audience, the content, and the media. The second section analyses the process of enemy-making before the war, stressing the phases and variables involved. The third section looks at the evolving role of the media during the conflict - in particular, examining how the media affects the 'aesthetics' of violence; and considers the possible consequences of the privatisation of both violence and the media. The fourth section dwells on the role of memory and the emergence of different narratives following the end of a conflict.

Chapter 6 analyses the interplay between politics and market forces in the waging of war. In the first section, the historical process of the monopolisation of force in the state is reinterpreted, starting from the public-private dichotomy and distinguishing between two factors: the armed forces, both the troops and the officer corps; and the armament industry. The second section defines the characteristics of the global market of violence generated by the end of the Cold War and the proliferation of VNSAs. The third section analyses in more detail the enlarging shadow areas of both the economic and financial spheres.

Part III builds on the consequences of the proliferation of VNSAs, and the changing relationship between the city and the state with regard to coercion, finally sketching an hypothetical scenario of the new world coming. The first section of chapter 7 is intended to resume the results of the research, with particular regard to VNSAs, and to stress how their ongoing proliferation is radically changing the relationship between the city and the state, subverting the results of the long statemaking process, and bringing back the city at the forefront in the competition for the 
control of coercive resources. The second section proposes a redefinition of the very concept of sovereignty, until now considered a condition intrinsic and exclusive to the state. The third section analyses the revival of the clan as a form of social organisation, as a 'new imagined community'. The Conclusion prefigures the advent of a world of cities confronting the risk of a permanent global civil war, conveying the proposal to convert the current debate on war into a new one, devoted to elaborating on how to foster urban resilience to chronic violence.

Considering the multidimensionality of organised violence, Inside war draws upon authors from different disciplines: Military History, Sociology, Psychology and Anthropology, Political Science, and International Relations. It focuses mainly on Western states, first of all on the USA; but it also draws on events and empirical evidence from other countries, whenever this is helpful to reinforce theoretical arguments. The narrative core of this book is the organised violence of the last century, from the World Wars until today; and yet, when necessary, the arguments in the different chapters will be sustained with historical illustrations from previous epochs. The aim of the book, however, is not to offer an exhaustive history of the events of the period under scrutiny; let alone establish a ranking of the horrors of violence by comparing the destructiveness of twentieth century state military apparatuses to that of post-Cold War VNSAs. Inside war has rather the ambition to offer the reader a conceptual toolkit for the study of war. 


\section{Acknowledgments}

Since 2004 I have had the privilege of conducting my research at Cornell University, which has placed at my disposal the inexhaustible bibliographical resources of its libraries, as well as an intellectual (and natural) environment that is extremely favourable to research. Over the course of these sojourns, I have also had the opportunity, in the context of various seminars, to discuss parts of the book with both colleagues and students whom I thank for the observations and encouragement they offered me. I also wish to thank Judy Virgilio, Administrative Manager of the Department of Government, who, with kindness and efficiency, has always helped me solve problems that, in reality, were caused more by my awkward efforts than by actual bureaucratic difficulties. My expressions of gratitude go also to Kora E. Bättig von Wittelsbach and Emilia Bianca Pisani for their discerning translation.

During this time, Matthew Evangelista - President White Professor of History and Political Science at Cornell University and Chair of the Department of Government from 2008 to 2011 - and his wife Joanie have shown themselves to be wonderfully generous friends. Getting to know them better did nothing but increase my affection for them, and our association quickly transcended the limits of my time at Cornell, thanks to their frequent trips to Italy, a country for which by now they manifest a far more unconditional love than can I. To Matt, I also owe an immense debt of gratitude for having edited the first English version of the manuscript.

My wife Anna has been my companion in this undertaking as well, following its development step by step, bearing the full weight of my frustrations and the frequent moments of discouragement which were aggravated by my inability to show her the full scope of my gratitude. A special thanks also goes to Marina Longo who, at a moment when doubts and difficulties seemed to gain the upper hand, read and critiqued the entire manuscript, guiding me through the ford with determination and affection; and to Francesco Tuccari, who exterted his influential criticism as a renowned historian on the final manuscript.

Since the beginning, I imagined that my research should attempt to recompose on a single canvas two seemingly incompatible worlds: that of my father, born in 1914, the year that the Great War began, and that of my son, born just after September 11, 2001. I believed that my generation should at least attempt to explain to him and his peers how it was possible that the patrimony of ideals in defense of which wars and revolutions had been fought was squandered precisely at the moment when finally it seemed that no obstacles stood in the way of their definitive realization. How was it possible that democracy, a mere utopia when my father fought in Africa, managed to defeat two totalitarian regimes only to have doubt cast on it by the proliferation today, in nearly every part of the world, of violent non-state actors that we academics had underestimated, dismissing them as anti- or ahistoric and therefore destined to disappear or at least to be relegated to the margins of society. 

Part I 


\section{Old Wars, New Wars}

In the Introduction of his renowned A Study of War - first published in 1942, and in an abridged edition in 1964 - Quincy Wright asserted that war was a problem to be debated and not an event to be taken for granted, a view which had gained consensus over the previous century, finally becoming the accepted opinion of the vast majority of the human race. Wright attributed this evolution in the interpretation of war to four main developments.

The first is represented by the shrinking of the world: 'modern technology has made the world of today smaller in travel and transport time [...] and smaller in communication time'. The second development is the acceleration of history: 'the progress of science and invention and the rapid intercommunication of ideas and techniques have conspired to accelerate the speed of social change'. The third is the progress of military invention, such as the industrialisation of military transport and equipment, and the development of national propaganda, among other things. 'As a result of this change in the character of war and of the increased economic interdependence of peoples', Wright observed, 'war has tended to spread more rapidly, to destroy larger proportions of life and property, and to disorganise the economy of states more than ever before'. Finally, the fourth change is the rise of democracy: 'Foreign policies and wars have ceased to be mysteries but have become human acts which people can influence if not control. [...] Democracy has stimulated the will of people to eliminate war, although it has not yet enlightened their intelligence as to the means'. Wright concludes: 'Because the world is getting smaller, because changes occur more rapidly, because wars are more destructive, and because peoples are more impressed by the human responsibility for war, the recurrence of war has become a problem for a larger number of people, an increasing number of whom have come to believe that the elimination of war from international relations is not only desirable but also possible' (Wright, 1964: 4-5).

It is worth noting how Wright's observations resound, sometimes with incredibly similar words, in the ongoing debates on the changing character of war in the twentyfirst century. For example, when today's authors link the 'newness' of war to the forces of economic globalisation, or to new technological advancements induced, at least in Western-style warfare, by the revolution in military affairs. We may also observe in Wright's statements a certain idealistic optimism about the role of democracy in contributing to the elimination of war. But the main reason to focus on this long and evocative citation is to stress how, almost a century after Wright began to research the causes of war (an area upon which he began to focus in 1926), we are still debating the same topics, adopting more or less the same concepts, and still lamenting the lack of an interdisciplinary approach and the need for new knowledge. As it has been stated, a 'conceptual black hole' still surrounds the very notion of war: 'What is it? How ought we to think about it, inquire into it, and situate it in relation to other social 
phenomena? [...] What is missing is a scholarly project that takes war as its central object of analysis and is adequate to it' (Barkawi \& Brighton, 2011: 527).

\subsection{A Trick of Nature}

Over the course of history every type of society has developed internal structures composed of individuals specialising in the use of violence and weapons. These structures can vary in complexity, from primitive hunters to members of the thousands of military professions of the modern age. Every type of society has also used these kinds of specialists again and again to defend itself or to attack other groups. This central fact has led the overwhelming majority of scholars in the social sciences to maintain that aggressiveness is somehow 'natural' - that violence is written in the genetic code of humanity (Lorenz, 2002; Ardrey, 1966). Almost all scientific debates on war have floundered upon this anthropological assumption. Only some idealists have attempted to criticise this argument by putting forward the opposite claim that humans are naturally sociable. And yet, not even Voltaire was able to avoid this mindset when he wrote: 'what becomes of humanity, modesty, temperance, gentleness, wisdom, piety; and what do I care about them, while half a pound of lead, shot from six hundred feet away, shatters my body, and while I die at the age of twenty in inexpressible torments in the midst of five or six thousand dying men; while my eyes, opening for the last time, see the town in which I was born destroyed by iron and fire, and while the last sounds in my ears are the cries of women and children expiring under the ruins - all for the alleged interest of a man whom we don't know?'; adding, however: 'what is worse is that war is an inevitable scourge' (Voltaire, 1962: 305).

The fact is that both aggressiveness and sociability seem to be part of the genetic code of individuals, together with the millions of other factors which combine to define the human species. Put in these terms, the argument about aggressiveness seems so obvious that it ends up being totally irrelevant for explaining war. People may be violent under some circumstances and sociable under others. However, all this inevitably leads us back to the context of organised violence; and this context is society itself, in all of its most varied historical manifestations.

Sovereign states, in particular, have built their claims of defining themselves in opposition to others and therefore in potential conflict with them on this naturalistic prejudice. From this perspective, Hobbes's metaphor of the state of nature as the original condition of the war of all against all (bellum omnium contra omnes) turns out to be much more effective, for example, than Rousseau's opposite and equally plausible metaphor of the noble savage (Hobbes, 1997; Rousseau, 1984). The reason is that Hobbes's metaphor allows war to survive outside the borders of the pactum societatis. War both precedes society and exists outside of it, precedes the state and exists outside of it. According to Hobbes, the Leviathan has the right to hold his subjects in bondage and bind them in fear to respect agreements. At the same time, 
however, that same Leviathan, just because of its absolute sovereignty, has the right to make war and peace with other states; that is to say, of judging when war (or peace) should be pursued for the sake of the commonwealth. For Hobbes, and for all those of the realist tradition that followed him, there is no contradiction in the fact that people may abandon the state of nature in order to guarantee their survival, while at the same time finding themselves forced to rekindle their 'natural passions' in order to fight a war that the sovereign wants (or better, requires) them to fight.

When all is said and done, external war against other states is the argument most frequently (and most successfully) adopted in order to reinforce domestic cohesion. Moreover, the centralisation process of the means of coercion as well as of the administrative and judicial functions which define state sovereignty, is also - if not principally - determined by the needs of war: 'if the state was born from war, it gives tit for tat, generating war in turn. They progress at the same pace' (Caillois, 1990: 106).

But still, this is not enough. In the state-making process, a ruler must obtain the recognition of other states in order to become truly sovereign; and this recognition ends up coinciding with passing the test of a great war - that is, with the state seeing itself recognised in the role of a belligerent by its enemies as well as by its allies. In other terms, a state's sovereignty cannot be considered complete until it achieves formal or de facto recognition by the entire international community or at least by a significant part of its members. This recognition does not always happen peacefully. A recent example is that of the acknowledgment of Croatia and Slovenia at the moment of the break-up of Yugoslavia in January 1992, and the consequences this had on the following Bosnian Wars.

Besides being useful to the state and society, the concept of violence and war as something intrinsic to human nature helps individuals exorcise the problem of guilt and responsibility. And the more intolerable the violence becomes, the more often this occurs. The statement 'war is hell' is usually pronounced to justify even the most horrendous crimes. What else does it represent but the last attempt to protect an escape route - that is, the possibility of drawing a line beyond which everything is allowed?

In the end, the social sciences have tried to buttress themselves with conclusions about human destructiveness obtained from biology, ethology, or psychoanalysis in order to offer yet another naturalistic interpretation of war. However, this comes across like a stubborn rejection of the task of studying war for what it really is - i.e. a problem intrinsic to society, and not to man. In fact, societies have invested immense resources and energies to the planning and managing of war, incomparably more than those dedicated to the well-being and cultural advancement of their citizens. Even those political regimes that prove to be incapable of securing the economic survival of the state have frequently demonstrated that they are fit to wage war. Ultimately, 'this view that war is caused by man's aggression is not only unrealistic but harmful. It detracts attention from the real causes and thus weakens the opposition to them' (Fromm, 1973: 211). 


\subsection{The Role of 'American Social Science'}

In the aftermath of World War I, a new discipline successfully claimed the right to study international politics and war, asserting its independence from other wellestablished disciplines - such as International Law and Diplomatic History - which had until that time monopolised the field of international studies. Born as a branch of Political Science, International Relations also had to distinguish itself from the study of domestic politics. IR existed in a context ruled by anarchy, and not by order. Beside that, the only possible equivalent to government change in the international system was war. It was precisely IR's specific proficiency on the subject of war which gave the discipline an undisputed competitive advantage over its older rivals, and which secured its enduring allure for governments, in particular those of the great powers.

It is not by chance, therefore, that IR won prominence firstly, and above all, in the USA. The story of what Stanley Hoffmann (1977) tellingly defined as 'an American social science', and of the overwhelming role realism played in American academic institutions, deserves our attention precisely because of the consequences it had on the study of war.

In his essay, Hoffmann weighs the 'first thirty years' of the discipline in an appraisal which, for at least two reasons, is still of great interest today. The first reason is his revealing, and almost certainly deliberate, choice of postponing the birth of IR until just after World War II; that is, the moment of the school of realism's sudden triumph. In this way, Hoffmann seems to relegate the liberal utopia of IR's founding fathers, to whom other official stories attribute the merit of having instituted the first chair in International Politics, to the limbo of prescientific (and British) thought. ${ }^{1}$ It is worth taking a moment to reflect on this detail of the naming of the discipline. Edward H. Carr also defines it as the 'Science of International Politics' (Carr, 1981); however, in crossing the Atlantic, it changes its name to International Relations, the appellation which will eventually be adopted in Europe as well.

Economics evokes the laws (nomos) of domestic administration; sociology, discourse (logos) on society; and law, the research of that which is just (directum). Political Science aspired to transform the art of city governance (techne politike) into knowledge (scire). History declared its desire to observe: the Greek historia is a derivative of istor, 'he who has seen'. IR, on the other hand, has at most the rhetorical efficacy of a synecdoche: using the part (relations among nations) to represent the whole (IR as a discipline) - but then, as has been observed, it would be more

1 As it is well-known, the chair in question was established in 1919 at the University College of Wales in Aberystwyth and entrusted to Alfred Zimmern. The idea of its founder, David Davies, was that the chair's holder should travel the world spreading the message that war is not an irreversible phenomenon, but rather, something which could be gradually eradicated through the contribution of scientific research (Smith, Booth, \& Zalewski, 1996). 
correct to speak of 'interstate relationships' (Burton, 1972: 19). This choice can likely be explained in one of two ways. First, in recalling the desire expressed from the beginning even by idealists to apply the scientific method, it may be that, from this point of view, the term 'politics' carried too many ideological overtones. Or on the other hand, it may be that the same term 'politics' could be perceived as redundant when applied to a system such as the international one, which - to use the words of an heterodoxical realist - is destined to live perennially in the shade of war (Aron, 1966).

Today, in view of IR's success, one might easily maintain that the name was wisely chosen. For sure, this low-profile strategy had a further notable advantage: by defining itself as 'realist', this American school was attributing the label of 'idealist' to whomever did not conform to its precepts. The consequences of this decision on the methodological development of the discipline have yet to be fully considered. Certainly it contributed to making the boundary between doctrine and scientific research, between the practice of international politics and the way it is represented, somewhat ephemeral.

Exacerbating the difficulties inherent to keeping reality and its interpretations distinct from one another - and here we come to the second point of interest raised in Hoffman's article - IR presented itself from the beginning as strongly policy-oriented. To use the extraordinarily efficacious words of Hoffmann: 'What the scholars offered, the policy-makers wanted' (Hoffmann, 1977: 47). The USA, Hoffmann explains, became IR's elect nation thanks to an intellectual predisposition towards social science research confirmed by the successes achieved during the same years in other fields as well; ${ }^{2}$ but mainly due to two factors of a political nature: historical circumstances, or the role of superpower assumed by the USA at the end of World War II, and institutional opportunities. With regard to the latter, the factor which merits most attention is certainly 'the most direct and visible tie between the scholarly world and the world of power: the 'in-and-outer' system of government, which puts academics and researchers not merely in the corridors but also in the kitchens of power' (Hoffmann, 1977: 49).

In the USA, the relationship between intellectuals and power had assumed systemic dimensions already during the course of World War II, with the Manhattan Project aimed at the development and construction of the first atomic bomb (Jungk, 1958). During the Cold War, however, the mobilisation of the intellectual and university worlds gave life to a 'politico-academic complex', the neat complement to the far more frequently cited 'military-industrial complex' (Chomsky, et al., 1997; Martino-Taylor,

2 Especially in Economics, which (like Sociology and Political Science) IR has always viewed as a reference model. And yet economics is the only discipline in the world which is still allowed to claim as valid a theory, that of the free market, which has never received empirical confirmation - in this way absolving its champions of the numerous sins committed in the attempt to apply it. 
2008; Simpson, 1998). On the academic side of things, this complex featured two types of actors, at first glance quite distinct from each other: think tanks and universities. From the beginning, the former were conceived as places of privilege where ideas were contaminated by political, as well as military and industrial, interests. ${ }^{3}$ The latter, on the other hand, had long asserted a separate set of entitlements and their own autonomy, including economic independence: some of the foremost private academic institutions, for example, refused any form of public finance for research, even in dramatic economic circumstances such as those provoked by the Great Depression.

In the end, however, even these institutions had to adapt to the laws imposed by the new balance of terror. ${ }^{4}$ This is the case, for example, of Stanford University, which finally has accepted (even if after a bitter internal debate) becoming increasingly dependent on government funding for research aimed mainly at military ends (Lowen, 1997). From this moment on, the nature of the 'complex' tended to manifest itself principally through the increasingly open nature of the boundaries between the institutions involved: today think tanks lend their most authoritative intellectuals, indiscriminately, to politics or to the academic world; and universities do the same, competing to earn the favour of the President of the USA and his staff, and ever more willing to construct their own autonomous centres of study, removing them from the control (both managerial and scientific) of academic authorities.

For those who benefit from this unusual marketplace, the undisputed advantage is the ability to pass effortlessly from an intellectual to a political career and vice versa, putting credibility earned in one field to work in another. If and when this permits intellectuals to maintain their own freedom of thought and, consequently, guarantee the scientific plausibility of their own theories, is a judgment which should be left to their biographers. ${ }^{5}$ From the point of view of the academic community as a whole and of the research that it produces, however, the predominance of political interests over scientific interests may have extremely significant consequences. The behaviourist revolution that occurred in the wake of World War II, for example, took place not only (and not primarily) thanks to the presumed superiority of statistical methods, but rather as a result of a growing climate of intellectual conformism, if not fear, generated by the Cold War and artfully fed by McCarthyism. Campus administrators not only marginalised controversial professors who threatened to estrange the institution from

3 One thinks of the Rand Corporation and its peculiar relationship with the USA Air Force and its relative industrial sector (Robin, 2001; Smith, J. A., 1991).

4 These events, however, should be considered quite separate from those linked to actual recruitment, in particular by the CIA, of intellectuals to be employed in covert activities (Wilford, 2008).

5 See, for example, the biography of Henry L. Stimson, a predecessor of that particular category of intellectuals for which Henry Kissinger will be the most long-lived and noted interpreter. From this book the importance of academic membership as a criteria for selection of the civil servants destined to occupy the highest posts in the USA government emerges clearly, and this is at the beginning of the twentieth century (Malloy, 2008). 
the good graces of its financial backers, but also, and for the same reasons, promoted those scholars willing to adopt quantitative approaches which did not have political overtones in their courses and research (Lowen, 1997).

A further example: the fact that the theory of war as the product of a random chain of uncontrolled events was confirmed at the same time that the development of thermonuclear arms was implemented, legitimises (at the very least) the doubt that the theory might be able to respond to the political leadership's need for a preformed alibi, allowing them to avoid assuming the responsibility of having caused the end of the civilised world. ${ }^{6}$ In more general terms, this mechanism of revolving doors between research centres (universities and think tanks) and the halls of government of the world's greatest power should have received more attention in order to analyse the consequences that it may have had in terms of research strategy and, more significantly, the methodology employed.

One can legitimately wonder, for example, whether the realist school would have been able to enjoy all the credit that it received (even from its keenest opponents) if it had been judged solely on the basis of its own capacity for heuristics, and if its doctrine had not been shown to be so well-suited to the needs of American leadership. And, in any case, it is still the realist hegemony that comes to mind when we agree that 'farreaching transformations in the contemporary world system make a new paradigm for academic teaching and research necessary, but deeply entrenched traditional ways of thinking block the needed changes' (Riggs, 2004: 344).

\subsection{The Foundations of a New Paradigm}

In order to establish a new paradigm, we preliminarily assume that it is necessary to start from the three admissible dimensions of the theoretical debate: ontology, epistemology, and methodology. In fact, methodology requires the guarantee of an epistemology, while ontological hypotheses that lack an epistemological basis are dogmas and, as such, cannot legitimise any methodology (Smith, S., 1996).

\subsubsection{Ontology}

Ontology concerns judging the nature of international politics. From this perspective, we might imagine that the debate expresses $n$ positions along a continuum which

6 The fact, moreover, that it was the Rand Corporation which guaranteed the scientific credibility of this theory through the writings of one of the most important American strategists of the age, Bernard Brodie, does make one think that the immense economic interests in play contributed too to sanctioning its success (Kuklick, 2006: chpt. 3). 
has anarchy and order at its extremes. On one hand, there are those who consider the absence of an independent, authoritative, third party a condition that is both indispensable and logically inferred from the fact of the intangibility of state sovereignty. The golden rule that power politics is the only useful instrument for the pursuit of one's own interest - and according to some, as a result of this, the only morally valid choice - derives from this view. In its most renowned formulation: 'The main signpost that helps political realism to find its way through the landscape of international politics is the concept of interest defined in terms of power. [...] Political realism refuses to identify the moral aspirations of a particular nation with the moral laws that govern the universe. [...] The lighthearted equation between a particular nationalism and the counsels of Providence is morally indefensible [...]. On the other hand, it is exactly the concept of interest defined in terms of power that saves us from both the moral excess and the political folly' (Morgenthau \& Thompson, 1985: 5, 13).

On the other hand, we have those who do not consider the state to be a permanent institution, but rather one that is historically determined and as such, superable. This also means assuming that we can envisage a global government capable of guaranteeing order with the same efficacy and, above all, with the same legitimacy, as the state. With respect to realism, what changes is the language, in terms of both grammar and syntax: federalism substitutes nationalism, the national interest surrenders its place to the common good of humanity; and the time lost (history's lesson) is supplanted by the future (utopia, in the sense of 'that which has not yet occurred' - though it still might).

Several authors have grappled with the construction of typologies based on this ontological component. For example, Martin Wight, the recognised forefather of the so-called English school, acknowledges three traditions: realists (or Machiavellists), rationalists (or Grotians) and revolutionists (or Kantians). The first see international politics as a potential state of nature in which it is 'all against all'; the second see it as a reality of conflict and cooperation; and the third as the civitas maxima of humanity (Wight, 1991). Similarly, in one of the most noted IR manuals the distinction is made between realists, transnationalists (the heirs of the idealists), and radicals (mainly neo-marxists) (Kinsella, Russett \& Starr, 2013). The flaw in these classifications is the fact that they tend to lead back to what are effectively eclectic positions within the same category. But if one adopts a theoretical perspective, between the two extremes of anarchy and order it is possible to discern a much wider range of gradations.

It may be assumed that international anarchy is in fact mitigated by a legal component. And, within this position, those who maintain that the moderating effect can be attributed exclusively to the state, in particular democratic regimes, may be distinguished from those who instead look favourably upon the process of institutionalisation, which transpires on an international level as well. In this second case, only formal institutions (governmental and nongovernmental) or even so-called international regimes - forms of cooperation which are issue-specific and not haphazard but which do not imply an attenuation of the idea of sovereignty - may 
be judged relevant (Hasenclever, Mayer, \& Rittberger, 1997; Krasner, 1983; Rittberger, 1993). There are also those who, although they do not believe in the existence of an order in the full, legal meaning of the term, replace anarchy with the principle of hierarchy, attributing the function of discriminating between rulers and their subjects to hegemonic war, which in this way determines the roles, functions and rules of the international system (Gilpin, 1981; Goldstein, 1988; Levy, 1983; Modelski, 1987).

And even within this group different threads may be discerned: for example, according to the belief in, or negation of, the inevitability of the decline of leader states (in which case we achieve cyclical reconstructions of history); or the role attributed to economic, in addition to military, resources. In this last case, a distinction may still be made between those who believe that hegemony is the source of international tensions; and those who, conversely, believe that the differential in economic power favours collaboration and the reciprocal satisfaction of the two parts, assuming that the hegemonic player has the ability to coordinate the production of public collective goods in short supply (Gilpin, 2001; Keohane, 1984; Ravenhill, 2014).

The fact that all of the viewpoints are 'legitimate' and 'arguable' - all may be confirmed in history but no single one is 'true' in the absolute sense - demonstrates that they are ontological positions (judgements). Their importance, and therefore the opportunity to make them more clear or explicit, derives from the realisation that by starting from similar assumptions it becomes possible to establish which sphere or area should be subject to research, and how far the boundaries of that which we define as 'international reality' go. Determining the instruments to be employed in the study of this reality brings us to the facets of epistemology and methodology.

Even when IR effectively forces itself to 'think systematically about how the logic of politics and the functioning of power may be transformed by the "thickening" of the international realm', it does not reject the 'formal realist conception of politics as power struggle', but rather stretches the meaning in order to include the new, postmodernist players (Neumann, \& Sending 2007: 690, 700). On the contrary, our new paradigm is based on the assumption of the increased permeability of internalexternal boundaries, and the presumption that global and local dimensions and venues intersect, inventing geographies of power which, until yesterday, were unimaginable. The state is no longer at the centre of the political universe and the centripetal force which for almost five centuries produced the concentration within itself of military and civil administration, fiscal and juridical functions, seems to have reversed its direction, giving life to an opposite, centrifugal motion that, as if in a big bang, is generating the fragmentation of power to institutions which are external to the state, and geographically sub- or superordinate to it - as we will see in more detail later on in this same chapter when we delineate the post-Cold War scenario.

Tearing down the wall between internal and external means restoring to the concept of politics a wealth of nuance - an area of denotation and connotation - 
which the ontological anarchy of IR had taken away. ${ }^{7}$ As previously asserted, this does not necessarily mean creating an opposite or conflicting idealistic vision of the world of one's own. On the contrary. Obviously, there still exists a sphere of interstate politics in which phases of hegemonic unipolarity tend to alternate with phases of aperture to multilateralism - contingent, nevertheless, more on the inclination of the USA (as the unquestionably hegemonic player) to participate in dialogue than any real competition from other states. ${ }^{8}$ But there is also the sphere of action of transnational corporations, which are relevant whenever they make choices that have political consequences for citizens throughout the world. And there are macro regions and global city networks that, at times, are capable of carrying out elaborate strategies of foreign policy in complete autonomy from their states of origins.

\subsubsection{Epistemology}

Epistemology is intended to chart the general criteria for validity (its foundations, basic nature and limits) of scientific knowledge. Perhaps the most comprehensive way to summarise the variety of positions present within the discipline according to this dimension - which has been making strides, especially since the 1980 s - is to trace a continuum which has at its extremes the explanatory theory and the constitutive theory (Smith, S., 1995). ${ }^{9}$ On one side there are those who maintain that facts can and must be distinguished from values, and that only the former, neutral and, by their nature, objective, can be the aim of scientific knowledge; on the other, are those who are convinced that nonpartisan science does not exist, given that it does not even presume an objective reality but only a 'reality as social construction'. In other words, the very language of the theory contributes to 'constructing' the world. And in this way the theory shows itself to be an act of power that the researcher should, ideally, declare, revealing (and thereby deconstructing) its internal structure (Vasquez, 1995).

In this case as well, the continuum allows important differences to be highlighted. With regard to explanatory theory, the variety of positions is determined above all by that which one accepts to understand within the reality that is to be subjected to scientific examination: whether it should comprise only that which is observable and of which therefore we may have a direct perception; or also, for example, invisible

\footnotetext{
7 Going so far as to waste, in the neorealist interpretation of Kenneth Waltz (1979), a concept of extraordinary heuristic potential like 'system'. In reality, Waltz, subverting the rules of syntax, is satisfied with making the system an attribute of the anarchy.

8 Attributing the role of a monolithic player to the European Union, as they frequently are prone to do on the other side of the Atlantic, still seems very premature.

9 The most common way to portray these two positions is through the use of the positivism-postpositivism dichotomy which refers to a philosophical debate that is extrinsic to the discipline of IR and which to a large extent transcends its contents.
} 
structures and interrelations which nonetheless influence the results of international social action. Secondly, the positions change according to the space assigned to interpretation, that is, to reason and theory; even, we may say, to the intuitions of the researcher.

As it is easy to imagine, these are choices that have immediate consequences with regard to methodology as well, but it is equally important not to lose sight of the purely epistemological side. Explanatory theory may therefore witness the internal contrast between at least three different approaches: the empiricism of those who are convinced that scientific knowledge concerns only those single phenomena of which we have direct experience; the rationalism of those who maintain that the laws that govern reality might escape direct experience and must therefore be logically deduced; and pragmatism, which attempts to combine the notion that the mind is always active in any given interpretation of reality with the idea that revisions to our beliefs must necessarily derive from experience (Smith, S., 1996). All three formulations share a strong, objective concept of truth, the existence of which is never doubted, only the way to reach it.

With regard to constitutive theory, a common denominator among its different forms - in addition, naturally, to the accepted refusal of the notion of objective truth may be traced back to the centrality of the role attributed to intangible factors: values, ideas, expectations, in as much as these represent the same essential components of the reality that we are attempting to explain. But the position these different factors should occupy within the theory is a point upon which opinion among internationalists differs, and not by a little. We may limit ourselves to considering them an intervening variable on a level with the material forces in play: we might say, and not entirely as a joke, that what the players are is also what the players believe and say they are (constructivism) (Kratochwil, 1989; Onuf, 1989; Wendt, 1987 and 1999). Alternatively, we might place these factors at the base of epistemology, maintaining that knowledge and awareness cannot avoid mirroring the politico-ideological interests of the analyst. In that case, we may perceive the difference between conservative theories - aimed at resolving immediate problems and at maintaining the status quo - and emancipative theories - designed to improve the human condition (critical theory) (Cox, R., 1981; Linklater, 1992). And finally, we might reach the extreme of considering all theories, even those described as emancipative, as narrative, pure and simple, and science as a discursive phenomenon to be decrypted (postmodernism) (Der Derian, \& Shapiro, 1989; Rosenau, 1992). Paradoxically, this last position eventually adopts an attitude similar to that of the most radical empiricists; that is, the habit of circumscribing reality as much as possible, subjecting it to an accurate, but partial, analysis. The difference is that attention is directed at words rather than facts: reality consumes itself in the text which is interpreted through language analysis.

In the mainstream of constitutive theory epistemology can also take on a particular connotation of gender if it is assumed not only that science is not neutral, but instead entirely lacks a female perspective and adopts typically male ideas and 
values (Enloe, 2000 and 2004; Sylvester, 2001). In this case, it is plausible to assert that the development of a distinctly female form of research would require its own specific ontology, a new vision of the world (feminist theory). In general, however, it would be an error to infer that to each ontological position one - and only one - epistemological (or methodological) option must correspond. The fact that traditionally the great majority of the supporters of anarchic ontology have opted for explanatory theories does not prevent us from hypothesising that this ontology is compatible with, for example, a postmodern epistemology: anarchy (like order) may be considered an objective reality, but also a metanarrative (if not a founding myth) about the nature of international politics.

The idea, widely diffused in IR, that a theory must offer a simplified representation of reality has no epistemological foundation: 'Parsimony comes after, not before, an analysis of complex causal possibilities’ (Bernstein, Lebow, Stein, \& Weber, 2007: 238). On the contrary, we assume that reality is a social construction and that its main prerogative is complexity (Berger, \& Luckman, 1989; Elder-Vass, 2012). Furthermore, we must assume the importance of intangible factors in the analysis of social reality, and of language as the main instrument by which values, rules and choices are spread within society: 'Some facts exist independently of any human institution. I call these brute facts. But some facts require human institutions in order to exist at all. [...] An institution is a system of constitutive rules, and such a system automatically creates the possibility of institutional facts. All institutional facts [...] are created by speech acts' (Searle, 2010: 10 and 11). And more than any other social reality, politics, even international politics, is consubstantial with discourse. It is worth remembering what Hannah Arendt wrote in her analysis of the public sphere in ancient Greece: 'Speech and action were considered to be coeval and coequal, of the same rank and the same kind; and this originally meant not only that most political action, in so far as it remains outside the sphere of violence, is indeed transacted in words, but more fundamentally that finding the right words at the right moment, quite apart from the information or communication they may convey, is action' (Arendt, 1958: 26). Compare, for example, the ancients' appreciation for rhetoric with its current-day application by political leaders, and their armies of ghost writers and spin doctors, whose main task today, as in the past, is not to produce 'great thoughts' but 'great words' - and, when necessary, even being 'professionals in lying' (Arendt, 1972).

The acceptance of these premises does not necessarily imply the adoption of a postmodernist epistemology that reduces politics to a narrative. ${ }^{10}$ Rather, these suppositions serve as a means of marking the boundaries of a theory that is certainly constructive, allowing us to explain the behaviour of political players within the

10 And which would probably make more sense in an ontology of language and not of politics which is exactly what Searle proposes when even he takes on the question of political power (Searle, 2010: chpt. 7). 
context in which they operate. This means assuming as well that the players (agents) are somehow restricted or bound by the context (structure) in which they function, that they can respond in a different manner to different circumstances at different times, and that their choices may also influence or modify the context itself (Wendt, 1987; Guzzini, \& Leander, 2006). Nevertheless, the question which must be posed is not whether a causal connection between agent and structure exists, nor the nature of its directionality (which of the two defines the other). Rather, the problem is one of conceiving systemic models capable of accounting for the ways in which agents and structures can interact and transform themselves reciprocally.

\subsubsection{Methodology}

Finally, we come to the last dimension of IR's internal debate: methodology. According to the reconstructions commonly found in the literature, this dispute takes the form of the well-known controversy in realism between traditionalists and behaviourists sparked by the publication of Hedley Bull's essay in defence of the classic approach (based on the contributions of history, philosophy and law), and against the excesses of purely statistical-quantitative analysis (Bull, 1966). In fact, within IR, the methodological issue has been far and away the most neglected, with two repercussions of enormous dimensions for the fate of the discipline. The first has been the inability to understand the consequences that methodological choices can have on the ontological and epistemological levels (and vice versa); and second, the tendency to give rise to a true terminological Babel. ${ }^{11}$

In an attempt to abstract the terms of the debate for the last time, we might imagine a third continuum which has induction and deduction at its extremes. In an initial estimation, this means setting the logic of those who start with the analysis of individual cases in order to arrive at the formulation of empirical generalisations, against that of those who, on the contrary, proceed from the universal to the particular, forming hypotheses whose correspondence with reality will be verified afterwards (if at all). In even more operative terms, the position on the continuum is determined by each researcher's attitude towards empirical analysis and the theory; clearly recognising, however, that there is no way to establish once and for all which of the two should prevail over the other, given that the advancement of knowledge is the product of the interaction between them both. The inductive-experimental method, especially (but not exclusively) in the social sciences, requires a theoretical context of reference. In the absence of such a context, the choice of variables to be analysed proves to be completely arbitrary, and the results thereby obtained may not

11 It is enough to consider the different meanings of 'theory' (Burchill, \& Linklater, 1996) or of 'levels of analysis' (Buzan, 1995; Yurdusev, 1993) which appear on a recurring basis in IR literature. 
be generalised - in fact, theoretical assumptions are detectable in any example of empirical research, even when they are not declared or the researcher him/herself fails to recognise them. On the other hand, the theoretical-deductive method, even in its most elegant and parsimonious forms, may be considered an end in itself if it is never compared to (or verified or refuted by) the data supplied by reality. On closer inspection, therefore, the only authentic hierarchy of priorities possible is that determined by the attitudes, approaches and interests of the single researcher.

For decades, the mystique surrounding empirical research and the inductive method has conditioned IR research as well, blocking the possibility of coming to terms with the growing complexity of international politics and war. This approach can easily conceal normative aims: 'There is no more normative theorist than one who proudly boasts that he or she will simply deal with "the facts"' (Smith, S., 1995: 30). Social sciences, on the contrary, should proceed through 'the development of scenarios, or narratives with plot lines that map a set of causes and trends in future time' (Bernstein, Lebow, Stein, \& Weber, 2007: 236). The production of scenarios entails specific choices with regard to at least four aspects of research: the degree of abstraction, the levels of analysis, the levels of comprehension and time.

With regard to the degree of abstraction, our new paradigm does not appear in a severely inductive light, limiting itself to the empirical study of a few facts or to detecting the existence (or non-existence) of correlations between single variables. Neither does it seek predictive theories based on logically correlated and coherent hypothetical systems. Constructing scenarios means having to move continuously along the ladder of abstraction: formulating hypotheses and verifying their plausibility through empirical research in order to then correct the initial assumptions, if necessary.

The levels of analysis probably represent the facet of research which most distinguishes our new paradigm. First of all, we assume that these levels should not be limited to the three traditionally recognised by the literature: the individual, the state, and the international system (Waltz, 1954). Ethnic groups or clans, and regions may be easily identified in between the individual and state levels; and in between the state and international levels, the geopolitical subsystems created by alliances or processes of transnational politico-economic integration. But, according to research requirements, others can also be imagined. Secondly, levels of analysis must be considered as cumulative, and not alternative or mutually exclusive. The need to explain the dynamics of political reality as a social construction is theoretically irreconcilable with the assumption that there is only one relevant level of analysis, and what's more, that it can be chosen a priori. Thirdly, the systemic character does not appertain to a single level of analysis, let alone represent an exclusive element of the international system. The nature of the system complies with the entire scenario that we are creating. It is the logic governing the dynamic between agents and structures that we recognised in our research design - incidentally, the only 
one capable of expressing the interactions and explaining how agents and structures form on a mutually dependent basis. ${ }^{12}$

The third aspect of research is that which Raymond Aron defined as levels of comprehension (Aron, 1966). The idea is that, in order to explain politics and war in a time of globalisation, we cannot limit ourselves to considering only the choices made by states but must also draw on disciplines which can offer additional insight. Even before approaching the question of choosing the elements to be analysed (the variables), the research design demands in fact that a choice be made relative to the sources that are to be used (the levels of comprehension).

Just as an example, the study of the recrudescence of the so-called ethnic conflicts that followed the end of the Cold War means that the global context of reference, that is, the end of bipolarism and the international client state system to which it gave rise, is definitely considered. But in order to explain why these conflicts break out in certain countries and not in others, it is necessary to switch to the level of analysis of the state, drawing on the contributions offered by Political Science and Area Studies. And finally, in order to understand precisely how the presumed ethnic character of those conflicts manifests itself, it is necessary to come down another level and scrutinise intra-group dynamics through the use of contributions from the fields of Anthropology and Psychology.

The fourth and final dimension of research is time. What should be noted here, with regard to the research design, is that time is not a unilinear projection for which we must set only the $a$ quo and ad quem limits. On the contrary, time can also develop in terms of depth. By artificially slowing down time, the longue durée allows for the rethinking of history in its totality, and for the highlighting of the persistent frameworks of thought and action (Braudel, 1980). Our new paradigm cannot count on only a simple chronicle of events, but must seek to widen the perspective as much as possible, guaranteeing its research the necessary depth of field.

\subsection{The Post-Cold War Scenario}

War is embedded in politics and society; it is one of the possible instruments for the authoritative allocation of resources at both the local and global level. The specific and preliminary contribution that IR may offer to the ongoing debate on new wars

12 The need to abandon the traditional way of understanding the levels of analysis finds authoritative confirmation in the conclusion of a book which recently re-proposed in its title the main political question - who governs the globe?: 'The framework we sketch does not fit neatly into some single "level of analysis" expected by standard IR theory. The processes we investigate in this volume cross levels. They weave back and forth among levels. They may involve the creation of new levels' (Avant, Finnemore, \& Sell, 2010: 368). 
consists in sketching out the background global scenario where wars occur. In accordance with our new paradigm, we refuse the anarchical ontology to assume instead that the international system is governed by an order. Secondly, to decrypt this order, we assert that a constitutive epistemology must be adopted, one capable of guaranteeing the appropriate significance to intangible factors, and more effectively comparing different and intertwined levels of analysis and levels of comprehension.

\subsubsection{The End and the Beginning}

Two days, November 9, 1989 and September 11, 2001, are competing markers of the beginning of the new era, at least if we adopt the kinds of cyclic theories that look at major wars in order to shed light on the functioning of the international political system (Goldstein, 1988; Modelski, 1987). Leaving aside the ambitious and overly deterministic presumption of using cycles to predict the occurrence of the next world war, these theories still have a fascinating trait: they seem to offer us the chance to interpret the structure of power as well as the rules and values of each international political system by focusing on the outcomes of the major war to which it gave birth. It is worth remembering that this was a significant methodological revolution. Studying the outcomes of wars rather than their causes means uncovering the hierarchical rather than anarchical nature of international politics. Assigning the correct meaning to victory is a more plausible explanation for (if not always a justification of) the issue of the loss of men and resources in war than is the search for a mere balance among powers. According to this perspective, adopting 1989 or 2001 as the starting point of a new world order can make a difference. This topic has been largely debated (Clark, I., 2001; Ikenberry, 2001 and 2011; Parsi, 2006), but here we wish to stress the logical, rather than historical, consequences of our choice, as well as formulate three different hypotheses.

1. November 9,1989 - the day of that extraordinarily symbolic event that was the downfall of the Berlin Wall - is the correct starting point because of the collapse of the USSR and of the end of the old bipolar system. This 'year zero' marks the triumph of liberal democracies and the end of ideologies (Fukuyama, 1992). Furthermore, it denotes a telling mutation in the nature of the international system, as, for the first time in history, it changed its structure by means of a basically peaceful event, without fighting a true major war (Bonanate, 2009). Starting with these assumptions, we soon run into trouble interpreting the period of disorder which followed unless we basically admit we were either wrong or, at the least, overly optimistic. Firstly, we could find in the events following the end of the Cold War a confirmation of the law that only wars fought on the battlefield with widespread bloodshed may give rise to stable, if not actually peaceful, orders. Secondly, the spread of world disorder could also mean that Cold War was not really World War III or that it ended without a clear winner, or that the winner 
did not possess the power needed to enforce its rules. Finally, we could concede that we are experiencing a sort of crisis of development. If Rome was not built in a day, if the fortunes of modern states have not yet ended after five centuries, then a new legitimate international order could still be built in the foreseeable future.

2. September 11, 2001 - with the terrorist attack on the Twin Towers and the Pentagon - marks the real turning point in the life of international system. It indicates the declaration of war, by an enemy who was not easily identified against the only superpower that had survived the end of the Cold War. In this case, we should simply assume that we are now experiencing a major war - a Global War on Terror (GWOT) - and that it is almost impossible to predict its end, let alone the contents of a subsequent new world order. We could debate strategy, the justifications of the doctrine of preventive war, or the legitimacy of exporting democracy through war. In fact, this is precisely what happened both within the discipline of IR and in the media. However, we cannot say anything about the structure and the rules of the coming international system. At best we might investigate the challenge to the concept of sovereignty posed by new violent nonstate actors (VNSAs), or debate whether the retreat of the state might result in the emergence of a neofeudal system (Strange, 1996). Nevertheless, this does not help us make a choice.

3. November 9, 1989 initiates a new world order and September 11, 2001 is one of the main consequences of the rules adopted. This means that we have misrepresented the events of the whole period and that we need a different interpretation instead. In this context, the words Fernand Braudel wrote as early as 1977 seem eerily prophetic: 'breaks inevitably occur from time to time, but at long intervals; for example, following the Age of Discovery of the late fifteenth century, or in 1689, when Peter the Great opened Russia to the European economy. Imagine the sort of break that would occur in the West as we know it today were a free, total, and definitive opening of the Soviet and Chinese and Russian economies to occur' (Braudel, 1977: 81). This is precisely the break we experienced in 1989.

The tearing down of the wall which had been built in August 1961 really signified the shattering of a boundary which embraced a much wider area than the wall itself, and which, paradoxically, was even less permeable to infiltration than the real wall. Surely, the market is what suffered the most. Its search for profits was hemmed in by geopolitical constraints that cut it off from a significant portion of the globe, as well as by class conflicts provoked even inside the capitalist states by the very existence of Communism. In contrast, politics benefitted from the ideological confrontation that the wall represented. Among other things, politics achieved its goal of glorifying the virtues of democracies, even if those democracies had already largely shown their limits in the areas of civil rights and, especially, guaranteeing their citizens equal opportunity. In other words, the Berlin Wall blocked the market, but supported a political system. The end of the bipolar system did not designate a winner. Instead, it 
left two losers on the field. What collapsed was an entire global system with its rules of dominance, rather than a system of mutual control between the superpowers. This is the reason why some scholars, perhaps even those who spent years developing advanced models of brinkmanship (Schelling, 1966), could end up nostalgic for the stability of nuclear deterrence and deeply concerned for the fate of an 'out of control' world (Brzezinski, 1993).

\subsubsection{The De-construction of the State}

The state in the post-Cold War era is going through a process of dispersion of its prerogatives induced by globalisation as well as by the states themselves, which seek to externalize the growing and unsustainable costs of their apparatuses - from welfare to security, domestic and foreign. After 1989 we had to confront a re-ordering of the different levels of analysis, favouring multiples and, much more frequently, fractions of the social unit of reference, which means the state. With respect to the state-making process, the flows appear to have been inverted. As a consequence, the centripetal force that had made the centralisation of military and civil administrations, fiscal and judicial functions and so forth possible, has been replaced by a centrifugal force that generates fragmentation.

In order to render the subject less indeterminate, it may be useful to review the 'basic model' of Stein Rokkan's political development based on four primary components: force, culture, law and economy. If we analyse the recent processes of functional differentiation of each of these components, it is easy to establish: a) that each tends to be dispersed to an increasing degree in institutions different from the state; and b) that these institutions are geographically superordinate or subordinate according to a scale which, by placing the state at its centre, distinguishes, on the one hand, the macro-regional and global and, on the other, the regional and urban levels of analysis. By adopting a diachronic focus, we see that, after a long historical period during which the four components were structured within the borders of the state, now we are confronting an opposite tendency, still at work, which appears to invert the four temporal phases which, according to Rokkan, define the ideal-typical sequence of modern state formation (Rokkan, 1999).

1. In our case, therefore, Phase I will be that of the de-construction of the state, characterised by a clear tendency for an administrative decentralisation that re-evaluates local cultures. However, it also revitalises claims for autonomy (if not for secession) and the rebirth of true local authorities. These local authorities reacquire (or, at the very least, claim for themselves) the power both of tax collection and of the use of force; pretend to become the spokesmen for the rights and privileges of their citizens; and manage infrastructures and essential services (schools, hospitals, etc.). At the same time, the de-construction of the state receives further incentives thanks to the development of supranational organisations which claim 
the legitimate authority to produce norms and to make them effective (think about the subsidiarity principle of the European Union) or pretend to enforce models of social and economic development (as in the case of the International Monetary Fund or the World Bank). They may even violate the principles of sovereignty in order to defend the right of survival of threatened minorities (as in the various forms taken by the humanitarian interventions of the United Nations). Finally, even the revival of the universalistic ambitions of religious institutions contribute to reshaping the role and the main idea of the state.

2. Phase II will see the expulsion, from the socio-political system, of increasingly large sectors of the masses, deprived of access to essential services, ignored by the new mechanisms of representation, and therefore destined to come up against the impossibility of both claiming their rights and continuing to identify with the culture and symbols of the state. In this case as well, the effects of local dynamics, which cause a polarisation of income brackets, are added to those generated by migration flows and the consequent creation of a new, impoverished, and marginalised global caste of 'untouchables.'

3. Phase III will lead these expelled masses to rediscover forms of parasitic participation based on patronage relationships and/or forms of sectarian and violent associations; entrusting, for example, the fate of immigrants and other marginalised groups to transnational organised crime groups, terrorist networks, gangs, and so on.

4. Finally, Phase IV will force the state to abandon its management of public welfare and the redistribution of incomes 'through transfers from the betteroff strata to the poorer, from the richer to the backwards regions' (Rokkan, 1999: 133). As a consequence, we will witness the resurrection of privatised and violent accumulation and allocation of resources, with the state committed to maintaining an appearance of legality - for example, by playing the managing role in the huge market of public contracts.

\subsubsection{The Revenge of the Peripheries}

A second aspect of Rokkan's development model which is also extremely effective for the study of the new political geographies outlined by globalisation, is represented by the attention he pays to the notion of territory: 'we cannot study [the variations among political systems] - he claims - without looking into the structure of the space over which they exert some control' (Rokkan, 1999: 108). To sum up, this means: a) identifying and studying the centres where the actors ruling the system exert their power and where the main decisions are taken; b) understanding which the peripheries, or the areas controlled by these centres and depending on them, are; c) recording the transactions among the individual centres and between each of these and their peripheries.

This is, undoubtedly, a difficult task for a comparative analysis of the formation of European states, but it becomes almost impossible in the contemporary world, where 
the proliferation of political groups creates new galaxies and new centre-periphery constellations which differ according to the perspective adopted. In fact, we should imagine a different constellation for each of the levels of analysis (multiples or fractions of the state), in relation to the primary component under scrutiny (force, culture, law or economy). Again, Rokkan's model helps us find the way, by reminding us to pay the necessary attention to territory. Despite the propaganda of those who identify globalisation fundamentally as the movements of world finance capital or with the virtual networks of web surfers, politics maintains the intrinsically physical nature of a geographical space. At the same time, however, politics redesigns its boundaries, favouring a much wider variety of actors equipped with more or less conspicuous resources of violence. As a consequence, Rokkan's model helps us to highlight a sort of historical nemesis absolutely consistent with the previously hypothesised process of dispersion of primary components of the state. While for Rokkan 'the essential point is that the periphery depends upon one or more centres' (Rokkan, 1999: 114), the exact opposite is true today: increasing numbers of centres find themselves dependent on the peripheries.

Furthermore, what had habitually been considered the structural weaknesses of the periphery with respect to the centre, now become its strengths. If we consider the global level of analysis, it seems evident that, in the military field, the missing 'nationalisation of the masses' (Mosse, 1974) - the 'new politics' of the early twentieth century which found its full expression in the Fascist and Nazi dictatorships - makes enough recruits available to transnational terrorist networks to keep the world powers in a position of stalemate. In the cultural field, the inability to differentiate between secular and religious institutions transforms the churches, mosques, and other religious centres into the most powerful agents of mobilisation and resistance to marginalisation (as in the case of radical Islamists). In the judicial field, the failure of states to promote rights and justice feeds the private protection market, to the great advantage of social mediators both new and old (from the groups who revive ethnic or clan identities to mafias and gangs) who impose their own model of political participation even upon communities transplanted in 'lands overseas'. In the field of economics, the conditions of dependency or exploitation, and the occasional inability to guarantee even a minimum level of production for survival generates migratory flows which feed whole sectors, both legal and not, of the economy. It is no coincidence that these 'points of strength' - in as much as they bring the peripheries back into play and help them free themselves from their role as subjects - are perceived as a threat by the centres. ${ }^{13}$

13 The choice of using the Rokkan model rather than the possibly betterknown Wallerstein model, depends on the fact that the latter limits itself to taking into consideration the economic variables while ignoring, on the other hand, military-administrative, juridical, and cultural dimensions (Wallerstein, 1974, 1980 and 1989). 


\subsubsection{The New Cleavage Structures}

A third element of Rokkan's development model which makes it particularly suited to the processes in question, is the concept of cleavage, understood as a particularly heavy and prolonged conflict rooted in social structure and capable of determining political polarisation within a particular system. Similar conflicts, which are often found at latent levels, are destined to explode at particular points in time (critical junctures) and to differentiate themselves along two dimensions (cleavage structures). The first, functional dimension relates to oppositions of ideology and interest, and are, therefore, of a cultural and economic nature. The second, territorial dimension relates to the conflicts between elites competing for central power, which can also mirror antithetic concepts with regard to both domestic and foreign politics or, more simply, local opposition to the centre (Rokkan, 1999: 278, and ff). Rokkan had in mind, for example, national revolutions (such as the French Revolution) which produced cleavages between central and local cultures and between state and church; and the Industrial Revolution which saw land and industrial interests in opposition, with entrepreneurs against landowners on the one side, and workers against labourers on the other.

The current functional cleavage structures appear to be dependent on two new conflicts. The first, given the dramatic downsizing of the primary economy, sees the opposition of residual industrial interests - which, to some degree, propose an exceptional alliance between workers and entrepreneurs (or, rather, a drastic reduction of the conflicts determined for the most part by the workers' loss of contractual power, imposed by globalisation) - and financial and speculative interests. These are represented by a new 'transnational professional class' of top managers and highly specialised technicians characterised by an high degree of mobility, and by a inevitable alliance with the service sector, which owes its fortune to the appearance of this class (Sassen, 2007). In some contexts, and in the presence of a widespread employment crisis, the traditional class conflict between entrepreneurs and workers can take the form of a clash, entirely within the workers' front, between the unemployed and immigrants, who are perceived as unfair competitors because they accept wage and safety conditions which the local labor force consider intolerable. The second conflict proposes, once again, the old oppositions on a global scale: between the culture of the western model of development and local cultures and traditions on the one hand; and between church and state on the other. This last opposition, in particular, appears to cut across the world system, finding true believers in the political function of faith on both shores: among the neoconservative and evangelical movements in the USA, as well as among the militants of the opposing radical Islamist movements.

Moving on to the territorial cleavage structure, at least two conflicts in this area may be highlighted. The first is the clash between two different views of international politics: one which privileges unilateralism and the use of force - so-called hard power - as instruments of hegemonic power; and one which, on the contrary, insists 
on the advantages of multilateralism, the juridification of international relations, and the centrality of a third party - a reformed United Nations - as a means of resolving controversies. The second is the global conflict between the North and the South, documented by periodic reports published by the United Nations Development Program (UNDP) ${ }^{14}$ which demonstrate the exponential (and by now pathological) growth of the differential between both income and consumption for an increasingly small elite of highly industrialised countries and a mass of states which are semiindustrialised or have never even reached the thresholds of development.

In conclusion, and returning to the levels of analysis with which we began, it is worth noting that, when moving from the abstractions of globalisation to a material and, as previously mentioned, territorial (or geographical) level, it becomes evident that even the international level of analysis ends up coinciding with the local level of analysis. The city reclaims its position over the state and reacquires its own sovereign autonomy. The world's foremost international organisations are established in Brussels, Strasburg, Geneva or New York and end up identifying themselves with those cities. The financial districts of the main capitals (and the most anonymous streets of the offshore centres preferred by those who wish to avoid taxation or conceal illicit profits) constitute the hub of international financial transactions. At the same time, ports and airports remain the junction points of commercial capitalism and from those intersections spread the routes that constitute the new 'diasporic networks' (Sassen, 2007: 16) of migrants but also of mafia members and terrorists. In the cities, finally, it is even possible to find the centre-periphery relationship reproduced on a small scale (Sassen, 1994: chpt. 7). The banlieues, the slums of today's megalopoli, are the new ghettos in which the destinies of the masses expelled by a manufacturing industry in crisis are intertwined with those of the new migrants called upon to perform the many bit-parts globalisation reserves them. These are the places where new urban violence is concentrated and, at times, explodes; but also where unexpected forms of cohabitation and civil society may develop (Davis, M., 2006; Mehta, 2004).

\subsection{On Changes in War}

The debate on the changing character of war in the twenty-first century is already well established, and has been efficaciously resumed in the following terms: are new wars 'New' and are new wars 'War'? (Kaldor, 2013). Contenders on both sides of this continuity-discontinuity debate have already advanced a plethora of good arguments and empirical evidence in defence of their opinions. In fact, every aspect of the supposed 'newness' of post-Cold War conflicts has been measured and compared with

14 The UNDP reports can all be found on the website: www.undp.org. On the subject see also Held, \& Kaya (2007). 
their historical precedents: the growing involvement of civilians, with the annexed toll in terms both of death and forced displacement; or the economic underpinnings, such as the combatants' propensity to self-finance through remittances from diaspora communities or illicit trafficking, which, especially in the latter case, increasingly blurs the border between war and crime. And the ideological motivations as well: nationalism, ethnicity, and religion; not to mention the competing exegesis of Clausewitzian theory (Strachan, \& Herberg-Rothe, 2007).

It is plausible to assert, for example, that we, as social scientists, tend towards 'an overemphasis on present events and our own depiction of the past, but [that] we are not immune to a presentist interpretation of the future either' and, consequently, 'instead of historically novel forms of violence, one encounters processes that have been intensifying since the birth of the modern era' (Malešević, 2010: 311 and 312). At the same time, however, it seems equally legitimate to reassert that 'new wars have a logic that is different from the logic of [the] "old wars" - the idea of war that predominated in the nineteenth and twentieth centuries', because in the new era of globalisation 'the distinction between state and non-state, public and private, external and internal, economic and political, and even war and peace are breaking down' (Kaldor, 2013: 2).

The fact is that this debate, like the previous debate on the nature of international politics, prefigures a vast range of arguable ontological positions (judgements), all of them capable of finding some confirmation in history, but in the end dependant on the (hopefully cognisant) assumptions of each single researcher - which, as we said before, are relevant in so far as they determine both the area subjected to the research and the methods adopted. The background (and too often undeclared) opinion about the intrinsic anarchical nature of international politics and the persistent uniqueness of the state experience, for example, is common to most followers of the continuity side of the debate on changes in war. This sort of prejudice causes some of them not only to underestimate the devastating role of VNSAs in contemporary organised violence and thereby limit understanding of the reality of war, but even to put the congruence of their research at risk by forcing an 'over-generalisation' of their results. ${ }^{15}$ Conversely, those who join the discontinuity side of the debate on changes in war may overestimate the role of globalisation market forces and/or of international institutions while ignoring the enduring importance of the states - hence pretending that we have entered a post-Clausewitzian era. ${ }^{16}$

15 It seems pointless, for example, to read in a recent and truly innovative book: 'There has been no dramatic shift in the causes and objectives of contemporary violent conflict; indeed, in most respects, recent warfare follows the already established tracks that have been on the increase since the dawn of modernity: the cumulative bureaucratisation of coercion and centrifugal ideologisation' (Malešević, 2010: 14).

16 This is mainly because "'new wars" tend to be mutual enterprises rather than a contest of wills. The warring parties are interested in the enterprise of war rather than winning or losing, for both political and economic reasons. The inner tendency of such wars is not war without limits, but war without end' (Kaldor, 2013: 13). 
In these terms, the debate cannot have any real solution. As social scientists involved in the study of war in this new century, we might agree on some very broad preliminary assumptions. The first pertains to (the philosophy of) history, and the shareable demand to 'moderate' the very idea of newness in war with historical contextualisation. 'Change in the practice of war - as has been observed - can also take the form of a pendulum swinging back and forth' (Strachan, \& Scheipers, 2011: 16). I would rather propose the spiral as a metaphor for the historical longue durée, an image that both brings together and blends the traditional linear and cyclical philosophies of history. A spiral in itself evokes the idea of progress, but its circular motion also makes room for discontinuity - the phases of slowing down, stalling, and actually going backwards. A spiral reproduces cyclical motion but never passes the same point twice. Instead of closing, the circle gets bigger and goes up to slightly higher and higher planes, as if we could hypothesise a sort of a collective ability of mankind to learn, which would allow people to periodically repeat experiences that they already made but never in the exact same form.

The second preliminary assumption pertains to the definition of war, an area in which Clausewitz may still legitimately be our beacon, but for his today rarely quoted and yet fundamental citation: 'We see, therefore, that war is not merely an act of policy but a true political instrument, a continuation of political intercourse carried on with other means. What remains peculiar to war is simply the peculiar nature of its means' (Clausewitz, 1976: 87). The third and final assumption pertains to the opportunity to allow for a plurality of political actors capable of waging war, beyond the state (Ruzza, Jacobi, \& Geisler, 2015).

The aim of stressing the need for a new paradigm and, in particular, proposing a methodology based on the building of scenarios may resound here as a plea to the community of researchers not to waste any more time and resources to contrasting others opinions. It would be far more fruitful to opt for an inclusive research strategy, capable of taking the greatest possible advantage of the insights of different authors from different fields. This book is intended to move in this direction, placing war at the core of analysis, and drawing on the assumption - argued in the previous pages - that the reality of war is what we make of it, that the only insurmountable limit to our comprehension of war is our way of knowing and representing it. 



\section{Part II}




\section{Violence and the Human Factor}

As sophisticated as military apparatuses, and weapons, may be, the fact remains that those wielding the weapons are the millions of men (and, increasingly, women and children, as well) throughout the world who - through necessity, greed or conviction - make killing other men, women, and children their profession and their business. Violence can always be reduced to a personal act: those who kill are as much individuals as their victims. The heroes, martyrs, torturers, and countless others war's extras, so to speak - are all individuals. Military leaders and the academics who advise them are well aware of this truth, and it is therefore no coincidence that these two groups have always attributed the utmost importance to the human factor in conflict. Among academic disciplines, Military Sociology has been most interested in these kinds of problems, but focused from the very beginning essentially on the cohabitation of the military apparatus, the political system and society, and in particular on the relationship between the professionalisation of the military and its propensity to intervene in politics through a coup d'état (Huntington, 1957; Janowitz, 1960; Vagts, 1967).

Outside of those particular professional spheres, however, few have ventured beyond the well-worn observation that war reduces men to savages by offering them the opportunity to fully express the propensity for cruelty and domination which is supposedly present on a subconscious level in each of us: 'Warfare and barbarity have been inseparable from each other throughout history, which we should have learned long ago. From Sparta in the 5th century BC to Darfur in the 21st century AD the use of indiscriminate terror, ethnic cleansing, genocide, and rape as familiar and effective tools of war-making has continued uninterrupted [...]. The propensity for cruelty is in all of us, and it rises to the surface in many when they are given complete authority over other human beings. Add the unique environment of war, in which culture, religion, race, ethnicity and ideology often separate guards from prisoners and abuse becomes the norm instead of the exception' (Kassimeris, 2006a: 3 and 14). ${ }^{1}$ The ways in which different societies have organised and managed collective violence is, on the other hand, something which has received much lesser attention.

\subsection{The Military and the Problem of Legitimacy}

All modern societies are characterised by a division of roles which stipulates that the individuals who bear the arms are not the same who hold political power. If it is true that the state is the particular authority that successfully claims the monopoly of the

1 War history was also a succession of tentative bids, mostly failed, to cointain barbarity. See, for an historical and juridical analysis respectively, Afflerbach, \& Strachan (2012); and Koskenniemi (2002). 
legitimate use of physical force within a given territory (Weber, 1978), it is also true that the effectiveness of that monopoly does not depend on the actual ability of rulers to personally exercise force; but rather, resides in their power to inspire the obedience of those who carry the weapons. The political relationships of power develop through a complex process of constructing disciplinary regimes in which the efficacy of command depends on the capacity of those who govern to substantiate the idea that their power is legitimate (Weber, 1978; Foucault, 1977). Government could not exist without that concentration of myths, symbols, and traditions that it produces and disseminates, first through the church and the family, then through schools and universities, and finally, through military academies, where discipline is elevated to dogma.

Throughout history, states in particular set aside considerable portions of their budget and proposed different models of military institutions for regulating the use of both domestic and foreign violence, holding it in check, and rousing and employing it for conquest or repression when necessary. Soldiers are only the intermediaries of death because they perform their operations on behalf of a third party. On the one hand, soldiers respond to a command imparted to them by a hierarchical superior and, ultimately, by the government. On the other hand, their own force is directed downwards, onto the victims. As will be seen in the next section, the education and training of soldiers is designed also to prevent the possibility that the flow of violence could be inverted and directed upwards, at the authority. In order to obtain obedience, however, those in power must first justify their own claims of legitimacy.

Every age has constructed its own civic and political culture drawing on elements of tradition, the charismatic power of a particular leader, or simply, referencing the rule of law (Weber, 1978: 212-301). As proof of the fact that nothing is more tangible and unambiguous than the exercise of power, the medieval origins of monarchy reference claims to sacredness, and even to the invulnerability (and the unavailability) of the sovereign's body as proof of the superhuman origins of his power (Bertelli, 1990; Bertelli \& Grottanelli, 1990; Kantorowicz, 1957). The king is completely out of reach, at times even invisible; but when he decides to reveal himself, he must at least show that he possesses miraculous powers (Bloch, 1973). Since medieval times, the myth of the inviolability of the political body has re-echoed, even in the nineteenth-century doctrines propelled by fascism and communism which called for the annulment of the single person in favour of the common spirit of the people; in the various nationalist movements of the twentieth century in which people claimed the right to affirm their own identities with regard to (and often to the detriment of) other peoples; and even in the idea of popular sovereignty of modern democratic constitutions.

Starting from this common matrix of the sacredness of sovereign power, the ability of rulers to secure the obedience of military institutions has been guaranteed by idiosyncratic blends of the different foundations of legitimacy. The soldier of an army that calls upon tradition claims to possess a social status that guarantees his right-duty to bear arms; and he will continue to believe it until the 
sovereign, by necessity or convenience, confirms this opinion. The typical case is that of someone of noble birth who, from medieval times up through the definitive establishment of absolutism, claims a monopoly on the use of violence; and he does so successfully, at least as long as he can allow himself the luxury of a horse, armor, and the time for training in the art of the duel. At the other extreme, a volunteer conscript in a levée en masse responds to the call of a leader whose appeal is centered on his own heroic character or the exemplary value of an idea or set of values that he represents: the homeland, the nation, the revolution. In an intermediary position is the figure of the military professional, prevalent today, who operates within political systems that base their legitimacy on a belief in the legality of a juridical system.

Historically, traditional or charismatic leaderships were more fleeting than leaderships imbued with a legal-rational basis. Traditional leaderships tend to contaminate references to the past with the adoption of economic - rather than legal - rationales: a heavy reliance on mercenary troops and the practice of selling officer's commissions to the sons of the emerging middle class are instruments adopted by absolute monarchies to free themselves from the nobility's control of the resources of violence. Charismatic leaderships, on the other hand, ends up substituting the leader's ephemeral call to greatness or the allure of an ideal with a solid juridical (rather than economic) rationale: the more coherent evolution of the levée en masse and of people's armies is an institutionalised system of universal conscription.

The question is no different if approached from the perspective of the individual soldier. The nobleman who claims the birthright to bear arms, and the volunteer whose beliefs or whose faith in a leader move him to enroll, both choose either to adapt to the renewed military institutions by becoming part of them - the nobleman going through a professionalisation process in the newborn military academies, the volunteer agreeing to enlist in the institutionalised army - or face the consequences: marginalisation, if not criminalisation. In post-Cold War conflicts, most soldiers tend to place their own professionalism above any principles of loyalty or sense of belonging, and the only valid criteria for distinguishing those employed by the state from those employed by private military corporations (PMCs), are the previously mentioned predominantly legal rationale or predominantly economic rationale. The problematic nature of this division is evidenced by the frequency with which the boundary between the categories is crossed: at the public level, each time a government chooses to subcontract part of its defence to a corporation; and on the individual level, when an officer of an elite state corps chooses to accept a significantly better paid position with PMCs.

Especially since the end of the Cold War, in fact, a growing number of governments have accepted PMCs as partners for the management of domestic security as well as for wars. But that's not all. Other governments, more and more frequently, brush off terrorism or gangs as criminal phenomena without realising that these groups 
enjoy a certain level of approval and consensus among the people; or even tolerate the presence of mafias, believing that it is possible to share their resources without paying any additional political cost. And yet, the long process of state- and nationbuilding - and the squandering of intellectual and material resources which, especially in the European experience, has revealed itself essential to strengthen the rulers claims for legitimacy - should make us aware of the fact that the delegation of even just a small portion of the state's monopoly of the legitimate use of physical force to private actors constitutes a threat on the integrity of the 'sovereign body'. On the contrary, both developed and emerging countries, democratic and rogue states alike, all seem too often incapable of seeing these organisations for what they really are: rivals competing against the state for shares in legitimacy. Violent non-state actors (VNSAs), for their part, do not demonstrate any reverence for the state, and instead adopt a strongly competitive attitude, offering their employees-affiliates an opposing identity and sense of belonging. If anything, these players emulate and reinterpret in their own original ways the strategies adopted by the state over the centuries for building and strengthening sovereign power.

For example, mafias and terrorist organisations show a marked propensity for charismatic leadership; loyalty to a boss, who is spontaneously recognised by his followers to be a person endowed with extraordinary powers, is valued above all else: 'What is alone important is how the individual is actually regarded by those subject to charismatic authority, by his "followers" or "disciples"' (Weber, 1978: 242). Beside that, in daily life, both mafias and terrorist organisations may reinforce their internal cohesion through frequent references to tradition (even developing their own origin myths). For example, Cosa Nostra, Japanese Yakuza, Chinese Triads or even the more recently formed Russian mafiyas, all feed the ancient myth that they originated in the secret societies defending the weak from abuse by the powerful or in fighting against an illegitimate power, or at least in local banditries. And all claim that their group is ruled by an honour code (Armao, 2000: 69-74; Hobsbawm, 2000). In other circumstances, those same actors may prefer to reinforce their cohesion offering affiliates regular wages and, in the case of their detention or death, some form of economic assistance for family members. These 'social welfare' practices enacted by the mafias and terrorist groups should not be neglected, because they contribute to widen the consensus base of these organisations.

PMCs, for their part, also propose a peculiar mix of these elements: on the one hand, their founding members often include individuals who are considered to be legendary 'dogs of war'; on the other, these firms seek to incorporate the glorious past of the soldiers' original units into the corporation's brand name, using it as a commercial reference and a guarantee of the quality of its services. Beside that, PMCs can offer to their soldiers, and their family members, a much more remunerative death insurance coverage than the one the state guarantees to its soldiers. In any case, the main foundation of military corporations' legitimacy remains free market rationality, based on the law of profit. 


\subsection{The Education and Training Process of Soldiers}

Up to this point, we have addressed the problem of legitimacy as a foundational prerequisite of any military institution. The second issue concerns the different phases of the education and training process which is needed to gain obedience from individual soldiers, and to overcome their inhibition to kill. As mentioned previously, the aim is to avoid the possibility that those who carry the arms might turn them against the authorities, but also to ensure that the soldiers will use their weapons against anyone, and under any circumstances, ordered by those same authorities. In order to reach these aims, different forms of education and training have been developed, but they all share the principle that obedience may be obtained only through the physical and psychological coercion of the soldier himself. In other terms, soldiers go through a process of socialisation to violence, the intensity of which varies according to the goals of the particular unit, but must in any case permit the military institution to: a) test the recruit's aptitude for service; b) educate the recruit to execute orders without questioning their content; and c) train the recruit to overcome his inhibition against killing - three strictly interrelated stages, that may be useful to distinguish for analytical reasons.

The first stage of this process, testing the individual's aptitude for service, traditionally involves a series of trials that are, at times, entirely identical to initiation rites, and that, as such, not only mark the entry into a new society, but also the abandonment of the old one. A soldier is the result of a radical modification of his social status and a radical shift in the nature of his own existence. As in primitive societies, where blood rites mark the passage from adolescence to adulthood, access to these military organisations as well require symbolic death and departure from secular (or, in this case, civilian) life in order to be reborn as a new man (Eliade, 1958; van Gennep, 1960; Guénon, 2001). ${ }^{2}$

State armed forces, in particular, have always respected this tradition, making use not only of forms of education and training aimed at preparing the recruit for what he will experience in war, but also tolerating spontaneous, and equally violent, rituals by which group elders harass the new recruits. ${ }^{3}$ After the initial phase of training is complete, baptism by fire marks another, even more fundamental passage: from the theory of combat to its practice. Similar forms of initiation may exist in criminal organisations; and even youth gangs may recognise particular rituals of life and death

2 The etymological origin of the term 'initiation' is the Latin word initium, derived from inire: to go (ire) inside (in).

3 One is here reminded of the many figures of sergeant instructor made immortal in the world of cinema, as for example in Stanley Kubrick's Full Metal Jacket (1987). The climate of structural violence present in military institutions was also effectively represented in Marco Bellocchio's Marcia trionfale (1976). 
as fundamental elements of their subculture (Armao, 2000; Hagedorn, 2008) - we will discuss this question more fully in the next chapter. But even for the members of organised crime groups, such as gangs or terrorists, the recruit's main test is baptism by fire, his first homicide. And not necessarily of an enemy. There are many accounts of mafia bosses testing recruits' trustworthiness by requiring them to kill one of their own relatives (on the pretext that the victim represents a threat to the organisation).

The second stage of the education and training process, as mentioned, is aimed at ensuring that the soldier learns to execute orders as soon as they are given. This aim has a practical justification as well: the speed with which an order is carried out can prove to be fundamental for the survival of any unit that finds itself in a combat zone. But this is not the point in this case. Here the physical and psychological conditioning seeks to inculcate respect for the principle of top-down flow of authority in the soldier: if camaraderie represents an important element of cohesion among peers, instant and absolute submission is the only admissible approach towards a superior. An order is accepted, and never questioned; the essential part of an order is not its content, but rather, who issued it. Now the institution's interest in avoiding challenges to its authority becomes obvious: if a soldier (or a mafia hit man, a terrorist, or a gang member) were left free to ponder the nature of the violence he is asked to commit - its lawfulness, whether it is proportional to the declared goal, and its consequences the integrity of the entire structure would be threatened.

However this arrangement presents undeniable advantages for the individual soldier as well, because it permits him to transfer the responsibility for his own actions onto others. The argument most frequently invoked by soldiers on trial for war crimes in Nuremberg, at the end of World War II, was that they were just obeying orders (Taylor, 1992); just like the soldiers prosecuted, more recently, at the Hague, seat of the International Criminal Tribunal for the Former Yugoslavia. Analogously, some of the people who were condemned for war crimes asserted with conviction that the sentence was unjust. The most telling representation of this argument resounds in the words of Eichmann, at the end of his trial in Jerusalem: 'Then came Eichmann's last statement: his hopes for justice were disappointed; the court had not believed him, though he had always done his best to tell the truth. The court did not understand him: he had never been a Jew-hater, and he had never willed the murder of human beings. His guilt came from his obedience, and obedience is praised as a virtue. His virtue had been abused by the Nazi leaders. But he was not one of the ruling clique, he was a victim, and only the leaders deserved punishment' (Arendt, 1963: 245).

As an institution, state armed forces have always offered their combatants, and particularly their officers, a much-needed alibi. And in most cases, it has been upheld as a justification. However, sometimes the officers themselves may have negated the alibi by, for example, refusing to execute orders they believed would result in the unnecessary massacre of their own men - even if that meant risking a court-martial, or, worse, immediate execution for insubordination. In other situations, it was the 
military institutions themselves, or the international community, who sought to preserve some margin of autonomy for the individual soldier.

The third and decisive stage of the education and training process consists in drilling the soldier to exercise violence on others. In order to achieve this, it is not sufficient to learn combat techniques and how to use weapons. 'There is within most men - it has been observed - an intense resistance to killing their fellow man. A resistance so strong that, in many circumstances, soldiers on the battlefield will die before they can overcome it'. And yet, 'with the proper conditioning and the proper circumstances, it appears that almost anyone can and will kill' (Grossman, 1995: 4; Harding, 2006). This assumption found a compelling confirmation in the Stanford Prison Experiment, conducted in the summer of 1971, in which a group of students were recruited, randomly divided into two sub-groups, and then asked to assume the roles of either inmates or guards in a mock prison. Initially conceived to last two weeks, the experiment had to be abruptly suspended at the end of the first week because of the violent, gratuitous harassment inflicted by the 'guards' on the 'inmates' at night, when they thought the experiment had been interrupted and the video cameras recording their every movement had been switched off (Zimbardo, 2007). In another famous experiment, a group of randomly selected adults was asked to inflict electrical shocks on another person. Almost half of the subjects agreed to administer shocks, even when the victims asked that they be interrupted, only because those were the orders issued (Milgram, 1974). In both cases, the outcomes confirmed beyond any doubt that it is the system of membership and belonging, and the social setting that influence the individual, rather than vice versa: 'People and situations are usually in a state of dynamic interaction. Although you probably think of yourself as having a consistent personality across time and space, that is likely not to be true. You are not the same person working alone as you are in a group; in a romantic setting versus an educational one; when you are with close friends or in an anonymous crowd; or when you are traveling abroad as when at home base'; and, beside that, 'any setting that cloaks people in anonymity reduces their sense of personal accountability and civic responsibility for their actions' (Zimbardo, 2007: 8 and 25). ${ }^{4}$

The social setting, or rather, the specific circumstances that allow a soldier to overcome his natural reticence towards killing, is an aspect which deserves further analysis. There are at least two conditions which any military apparatus must be able to satisfy: the first is to offer its members a kind of guarantee of immunity, i.e., the soldier is authorised to use violence, and his role legitimises this action. In fact, the soldier is actually obliged to use violence. By reversing one of the fundamental laws

4 See also the web site where Zimbardo, apart from reassuming the history of the experiment, has collected some of the video material made at that time, comparing it with more recent testimonials such as the images of torture in Abu Ghraib: http://www.prisonexp.org. (accessed 03/03/2015). On Abu Ghraib, see also Strasser (2004). 
of civil society - hence the centrality of initiation as the moment of transition from the old world to the new - the military apparatus punishes the soldier if he refuses to kill. It sanctions him juridically, by applying its own military codes; and morally, exposing him to the condemnation of his comrades, and even his community of origin. ${ }^{5}$ In essence, fear of disobeying the order to shoot, and the ensuing sense of guilt, must prevail over the fear and sense of guilt caused by the awareness that one has killed another individual.

The second condition is for the soldier to despise his enemy, thus making the fact of his elimination more acceptable. This always requires, in essence, a process of dehumanisation of potential victims, which can be achieved only by changing the character of the conflict from intraspecific competition (conflict among members of the same human race) to interspecific competition (conflict between members of different species). ${ }^{6}$ At times, this dehumanisation process may be radicalised: the enemy is transformed, first from a simple outsider into a barbarian; then into a representative of a different, inferior race; until finally, he is viewed as a non-human who may be subjected to the indiscriminate agonies of an extermination camp (Rousset, 1965).

Both of these conditions are essentially valid for VNSAs as well. For a terrorist, a mafia or a gang member - and, to a greater extent, for a contractor paid exclusively for that purpose - killing is an entirely legitimate act of duty. Refusing to commit this act means exposing oneself to the scorn of one's companions, expulsion from the group, or even death. The image of the enemy that they are offered (a rival boss, an infidel, the representative of an opposing class or rebel faction) is very similar to that developed by governments, though perhaps slightly less sophisticated, due to the lack of a comparable propaganda apparatus and a hired horde of "professional "problem-solvers", [...] drawn into government from the universities and the various think tanks, some of them equipped with game theories and system analysis' (Arendt, 1972: 9-10).

In any case, there are two extreme cases that represent a particularly good test of a military apparatus's ability to obtain its soldiers' obedience. The first one is torture; the second, acts of suicide. Torture, especially as a governmental practice, is not a product of chance or emergency circumstances, but rather one of the most carefully planned activities: it requires strategists capable of devising its forms, industries prepared to produce the instruments to be used, and the existence of a reliable group of

\footnotetext{
5 It is perhaps worth remembering that in a country such as Italy, conscientious objection to military service was, until 1972, punishable with imprisonment. In other democracies, too, evading military service meant falling into disrepute.

6 And yet paradoxically - as we are used to think that men in battle regress to beasts - study of animal behaviour has, in fact, demonstrated that collective conflicts among groups belonging to different species are not registered, while duels within the same species are highly ritualised and hence rarely conclude with the killing of one of the contenders (Eibl-Eibesfeldt, 1979).
} 
specialists to employ it (Sironi, 1999). Recruits destined to become torturers go through different forms of education and training that include, among other things, initiation rites that are significantly more severe than those imposed on regular soldiers. These are specifically designed to make the recruits feel different from others, even from their own comrades, as well as breaking down any authentic relationships they may have with friends and family (Huggins, Haritos-Fatouros, \& Zimbardo, 2002). The units into which these recruits are organised reproduce the secret society model: once inside, initiates will find it almost impossible to leave and betray its rules. Torturers are therefore ordinary people whose behaviour is a direct consequence of ideological indoctrination and of a particularly severe training; they are created through brutal experiences of deculturation imposed on them (Conroy, 2000). Yet, like other soldiers, they freely chose to place themselves at the disposal of the political and military system for which they operate. These ordinary people become atrocity perpetrators thanks to transformative processes induced by their institutions; it becomes easier for them 'to do evil where 1) previous moral considerations are overridden, 2) blind obedience is mandated, 3) victims are dehumanised, and 4) personal and social accountability are neutralised. In and through each of these processes, moral disengagement is activated' (Huggins, Haritos-Fatouros, \& Zimbardo, 2002: 250).

The process of the dehumanisation of the enemy must be pushed to the point of estrangement: the torturer no longer sees his victim, and neither feels nor comprehends his pain. In the torture chamber, as in the concentration camps of totalitarian regimes, through an obscene paradox, the extremes of proximity and promiscuity annihilate any residual normal social behaviour (Arendt, 1966; Sofsky, 1997). Yet this alone is not sufficient. What is also needed are the proper circumstances, a network fortified by collusion and the connivance that offers sufficient cover to the activity. Torture must be made routine, directly involving functionaries and officials, and thus making them all responsible for its practice. This was theory behind the ocean flights conducted by the Argentinean military junta between 1976 and 1977: every Wednesday, fifteen or twenty prisoners were tortured and then dumped into the ocean unconscious, but alive, so that no trace of their death would be left behind (Verbitsky, 1996). A more recent example is 'extraordinary rendition', the illegal and clandestine capture and deportation of suspected terrorists carried out by the USA secret services on behalf of the US administration and with the support of some European governments (Mayer, 2008; Paglen, \& Thompson, 2006).

Acts of suicide are the extreme opposite of torture because the soldier becomes the predestined victim. The conditioning must be directed toward creating the kind of despair and hatred of the enemy that will allow the soldier to overcome the inhibition against suicide and project all of the destructive potential of the weapons he has been trained to use against others onto himself, submitting so entirely to their power that he becomes the detonator - suicide terrorism, in particular, proves to be a very cheap technique, alternative to and competitive with more sophisticated electronic techniques (Lewis, J. W., 2007). For a soldier, killing always involves a deliberate 
choice, yet dying does not. A soldier is more aware of the possibility of his own death in battle than ordinary, unwitting citizens who find themselves involved in a conflict which is not their own; yet the soldier does not intentionally pursue death, and it is doubtful whether he can actually conceive of it: one may learn to inflict suffering on others, but no one can prepare himself for the destruction of his own body. The death to which one is subjected is characterised by a randomness and indeterminacy that is missing in the death one perpetrates. By contrast, a victim of true suicide maintains (or rather, exhibits) at least some capacity for self-determination. But even this most somber form of autonomy is denied to the soldier, whose sacrifice is imposed upon him by external forces and is deferred and/or executed according to the precise orders of his superiors. This fact helps explain the attention which the groups that exploit suicide dedicate to the sacralisation of an act, which is, in truth, a demonstration of how little each individual soldier - sold like meat to the butcher - is valued by his (and, occasionally, her) organisation.

The differences between the infantryman of the Great War, sent to attack a wall of machine guns with a bayonet, the Japanese kamikaze of World War II, and the martyr of modern terrorist organisations, all play upon varying combinations of the same two elements: the compulsion to act, surely prevalent in the first example; and the ritualisation of the act, dominant in the other two. The self-awareness of the victimised soldiers, at least as may be discerned in the records and documents which have reached us, often emerges in all its dramatic clarity. In letters to family members and in the memoirs of the combatants of the two World Wars, a sense of the inevitability of what awaits them prevails, as does an awareness of the useless nature of their sacrifice.

The best-documented case is that of the Japanese kamikaze, a group whose members included numerous university students and intellectuals, and who were far from being ignorant, fanatic nationalists as they have been represented in the West. What emerges from their testimony is the overriding sense of duty and devotion to the emperor which prevents them from engaging in any form of insubordination. Yet, these combatants are also explicit in their criticism of the strategies adopted by their military superiors; and their desperation over the squandered lives and identities of young men sent off to die in their first mission (when a different policy might have allowed these soldiers to take part in dozens of missions, killing many more of the enemy) is quite moving. Even more tragically, some kamikaze were destined to die without the possibility of completing their only mission: due to the inability of their comrades on land to guide them to their targets, many simply ran out of fuel and disappeared into the sea. Again, the social setting appears to be essential: 'The Japanese military tradition had a distinctive, almost unique element. Whereas German soldiers where told to kill, Japanese soldiers were told to die. [...] Even when entire corps of Japanese soldiers faced utterly hopeless military situations, the soldiers were told to die happily' (Ohnuki-Tierney, 2006: 4: see also Ohnuki-Tierney, 2002). 
Today suicide-terrorists too are told to die happily, but are deprived of even the last, residual margin of autonomy represented by the written word. By forcing them to recite their last will and testimony into a video camera, the organisation to which they belong appropriates even their most intimate legacy - their memory - for the purposes of propaganda.

\subsection{Witting and Unwitting Victims}

Violence is the suffering of the body (Scarry, 1985). This is demonstrated by the images of brutal death and mutilation hurled at us daily by the media, but which, in perhaps an even more vivid fashion, were made familiar to us through the pages of epochal novels from Stendhal, Tolstoy or Remarque and from a few, iconic photographs like those of Robert Capa or Eddie Adams. The burned flesh of a Vietnamese child fleeing the fields inundated by napalm; the dust-covered faces of the survivors of the collapse of the Twin Towers - all represent empirical evidence of the use of violence. And then there are the remains found in the many mass graves from Pol Pot's Cambodia, to Rwanda, to the former Yugoslavia (Gutman, \& Rieff 1999); and those traces which will never be unearthed, of the millions of Jews burned in the crematoria of AuschwitzBirkenau (Hilberg, 1985).

For many soldiers, war is a traumatic experience, a tragic parenthesis, an autonomous event that is extrinsic to civilian life, that entails the transgression of all known categories, and that creates bewilderment and a sense of detachment (Leed, 1979). A few facts are sufficient to confirm this interpretation. Among US soldiers in World War I, the number of psychiatric victims was twice as high as the number of dead. During World War II, the US army - excluding air and naval forces, and the marines - lost 504,000 men, the equivalent of fifty combat divisions, to psychiatric collapse caused by combat stress. In the Arab-Israeli war of 1973, almost one-third of all victims, on both the Israeli and the Egyptian fronts, were psychiatric cases. And in the 1982 raid on Lebanon, psychiatric victims outnumbered the dead two to one, and constituted 27 per cent of all injured. The number of all psychiatric victims in the twentieth century, starting with the Russian-Japanese war of 1905, surpassed by 100 per cent the number of soldiers killed by enemy fire (Gabriel, 1988).

In the light of this data, there is no sense feeding the myth that only the weak and the cowardly collapse when faced with the stress of combat: 'Psychiatric collapse under fire [...] is the reaction of the normally sane to an insane environment. [...] Under these circumstances, abnormality becomes normality, and the psychic nature of man along with clinical definitions of sanity are altered forever. The paradox is that in order for the soldier to be saved, he must first be mentally destroyed. And with his destruction, the human dimension of war - bravery, sacrifice, endurance, heroism 
- disappear, too' (Gabriel, 1988: 172). ${ }^{7}$ For the soldier who has developed psychiatric pathologies, at times it can be very difficult to gain awareness of the illness and seek help. For the military institution, on the other hand, admitting that a serious problem exists would mean either confronting the moral justifiability of the goal for which the military organisation itself was created, or declaring that the method adopted for inhibiting or removing the soldiers' natural reluctance to kill (the education and training process) is inadequate. ${ }^{8}$ All the more so, it is entirely plausible that the available data actually underestimates the gravity of the situation.

However, the wars of the first part of this new millennium indicate an additional factor. Among the US veterans of the Afghanistan and Iraq Wars affected by psychological disorders, there is a growing number for whom the sense of guilt for the killings committed, especially for the damage done to civilians, is greater than the pain of their own physical handicaps (Baum, 2004). As a consequence, some psychiatrists have proposed the codification of traumatic stress induced by the perpetration of violence (PITS) as a sub-category of post-traumatic stress disorder (PTSD) which long ago entered basic psychiatry manuals (MacNair, 2002). This suggests that, while violence always destroys our sense of belonging to the world, at the same time it cannot (and, in fact, expressly, does not) make us all equal. In other words, the soldiers' suffering cannot be placed on the same level as the suffering of their victims.

Each act of violence is ultimately defined as a relationship between a victim and his executioner; the medium for this relationship is the body. In reality, the roles of victim and perpetrator may also be exchanged, perhaps in later moments, but they will never be equivalent. Even in a thoroughly balanced contest between two, perfectly matched contenders - such as a medieval duel between two knights - any sense of equilibrium is lost at the moment in which one of the challengers prevails, transforming himself into an executioner and forcing his opponent into the role of the victim. As previously stated, killing entails a deliberate choice; while death does not. But this formula is not sufficient to define violence for those who are subjected to it, because not all victims are the same. The soldier who is a member of any army, public or private, consciously places his body at the disposal of his superiors and agrees to fight. On the other hand, the innocent, unwitting civilian targeted by military reprisal or aerial bombings is not allowed any freedom of choice. The fact that the combatant may not be a volunteer, but rather, has been obliged to respond to the call to arms,

7 On World War I, see also Thomas, G. M. (2009); and Watson (2008).

8 There is, however, at least in the USA, a conspicuous body of research and books designed to help the military institutions facing the psychological trauma of its veterans; this confirms the relevance of the problem. See Hancock, \& Szalma (2008); Kennedy, \& Zillmer (2006); and Tanielian, \& Jaycox (2008). 
might make his situation more similar to that of the victim in some ways, but the two roles will never be fully comparable.

Perhaps the most extreme example of assimilation between the roles of executioner and victim is that of the child soldier recruited by force, blackmail or subjugation in many theatres of war in Africa, Asia and Latin America, as well as in the urban peripheries of megalopolises, controlled by criminal organisations (Rosen, 2005; Singer, 2005a). As aware as he may be of his own actions, a child can never be considered responsible for them in the same manner as an adult. This should be kept in mind during the child's eventual reinsertion into civil society at the end of the conflict, as should the fact that during the most sensitive stages of his or her development, the child was fighting in the streets instead of studying in a classroom. However, it is also important that the child soldier not be equated with other actors, sometimes adult, whom he may have killed, tortured or raped in these scenarios.

In recent years, many professionals have concerned themselves with the question of child soldiers: from academics who seek to analyse the phenomenon, to the representatives of humanitarian organisations, psychologists and psychiatrists who are involved in the children's recovery, to the media, who have brought the matter to the attention of the world. The paradoxical effect of this overexposure has been that the victims of child soldiers, deprived of all attention, have been once again relegated to obscurity (Beneduce, 2008). In an attempt to invert this viewpoint, and, for once, afford the victims of violence the opportunity to be heard, three archetypal figures of a much vaster universe will be examined: torture victims, women, and civilians, representing, respectively, individual violence, gender violence, and collective violence.

Torture is the form of violence that represents the ultimate expression of domination imaginable: 'torture is a process which not only converts but announces the conversion of every conceivable aspect of the event and the environment into an agent of pain' (Scarry, 1985: 27-28). In torture, the estrangement of the executioner reaches paroxysmal levels. If the goal of the initiation of the torturer is to include him in a power elite, the men or women who are the victims of his violence instead undergo a form of initiation that seeks to exclude them from the group to which they belong, as well as from the entire human race. Therefore, the practice of torture is aimed providing an inverted representation of the world. In torture, the enforcer is often invisible, perhaps blindfolding his victims in order to terrify them even more. The world is reduced to a single room, the walls, ceiling, and doors of which are transformed into instruments of pain (Sironi, 1999).

'Torture consists of a primary physical act, the infliction of pain, and a primary verbal act, the interrogation. The first rarely occurs without the second. As is true of the present period, most historical episodes of torture, such as the Inquisition, have inevitably included the element of interrogation: the pain is traditionally accompanied by "the Question"' (Scarry, 1985: 28) - and the Inquisition, in particular, implied even the subversion of religion, by imposing expiation through 
the sacrifice of oneself rather than through the forgiveness of sins. More generally, the act of interrogation, which is at the core of torture, reverses the meaning of that fundamental institution of civilisation, the court trial: instead of analysing evidence that might lead to punishment, torture uses punishment to create evidence. It also reverses the institutions of medicine and psychiatry: the former is used by torturers to increase pain rather than assuage or prevent it, and they employ the latter to add psychic suffering to the physical pain (Halloff, 2008; Ojeda, 2008).

In this upside-down world, the torture victim becomes his own worst enemy: his body, physical abilities and senses are all transformed into weapons to be used against him. Pain forces the victim to betray himself by speaking, but the fact of having spoken generates new suffering (Crelinsten, \& Schmid, 1995; Levinson, 2004). Those who confess do not feel free or safe; on the contrary, they experience their lapse or breakdown as their own fault and become estranged from society and from themselves, because, for them, the very meaning of communication has been lost forever. From the human being that they once were, the victim is reduced to an inanimate object incapable of considering itself anything more than a traitor, and equally unable to see others as anything else than potential threats to their safety. Unless someone from the outside intervenes and helps them along the path toward re-humanisation, the victim may eventually become unable to perceive the world around it, and may never regain the power to choose one interlocutors autonomously (Sironi, 1999). ${ }^{9}$

Women, like those who have suffered torture, are among the least-heard victims, in spite of the fact that historically they have been (and, today, continue to be) a choice target during times of conflict. Violence is gender-specific: 'war crowds' tend to organise and define themselves also in opposition to women (Canetti, 1973: 63-67). In the main, military institutions throughout history have been constructed by and for, and composed of, men. The concept of masculinity has always been associated with the image of the warrior, and vice versa, over time, military activity has helped refine the definition of masculinity itself: 'The First World War added no new feature to the stereotype of modern manhood, but it deepened certain aspects [...]. The association of militarism and masculinity had always been present - after all, the birth of modern masculinity had culminated in Napoleonic Wars' (Mosse, 1996: 109; see also van Creveld, 1991; Ehrenreich, 1997). Even today, gender is an essential characteristic of what is usually referred to as camaraderie or, in the modern language of Military Sociology, buddyship: the interpersonal relationships that contribute to strengthening the esprit-de-corps (Little, 1964). Female soldiers continue to be excluded from fraternisation, in the sense that all military institutions either ban, or make an effort to severely limit, informal interaction between the sexes as much as

9 The debate on justifiability of torture rekindled in the USA after the terrorist attacks of September 11, 2001 (Greenberg, K. J., 2006). 
possible; even more than they seek to control or limit interactions between superiors and their subordinates. The only aspect of women in the military that is openly discussed is their performance in combat, as compared to that of men; a juxtaposition which is unlikely to risk undermining the concept of masculinity (Goldstein, 2001: chpt. 2; Moskos, 1988).

Therefore, far from having achieved integration between the sexes, all institutions to which the task of managing violence has so far been given - today even mafias, PMCs, and (albeit with significant exceptions) terrorist groups and gangs - still seem to be conditioned by that obsessive cult of force which, within a group composed strictly of males, feeds the tendency on the part of the combatant to reduce women to simple pieces of sexual equipment, or even legitimate spoils of war - a prostitute or a rape victim. Historically, the two have often overlapped. The massacre of Nanking carried out by Japanese troops in December 1937 resulted in the killing of approximately 300,000 people, and the rape of (depending on the source) between 20,000 and 80,000 women. The women who survived were recruited by the Japanese army and forced to follow the troops as prostitutes (Chang, 1997). Much more recently, rape has been 'reappraised' as an instrument of ethnic cleansing: during the Bosnian war (1992-1995), between 20,000 and 50,000 women were subjected to this violation but, for example, not less ferocious is the violence systematically exercised on women in Colombia, in particular by the paramilitaries (Amnesty International, 2004).

There are some who affirm that rape is somehow related to an archaic tradition aimed at precluding the continuity of an ethnic group: the women are raped so that they can bear children to the winners, ensuring that the blood of the subjugated people will be replaced by that of the new rulers (Codrignani, 1994). But if it were true that even today the goal is effectively to contaminate the adversary and spread one's own race by literally increasing the numbers of the winners, it still does not explain why these children are then abandoned and forgotten (Zoja, 2001). Rather, what can be said is that these female victims, even more than males, are condemned to having their identity denied by their violator. The very expression 'ethnic rape' seems to have been invented for the purpose of transforming gender violence into political and cultural violence; as well as a means for disguising the fact that the ultimate goal of this act is, in fact, to render the raped women impure and therefore also, if not almost entirely, unacceptable to their own group. The goal of rape is to transform procreation - that is, the act of union between the two sexes - into the cause for their definitive separation and (though only as a consequence) to disrupt the group by attacking the very reproducibility of their social links.

The most poorly defined category remains: the civilian victim. Strangely, the more the law attempts to codify attacks against civilians as crimes, the more popular civilians seem to become as targets. The etymology of the term 'violence', after all, also references the concept of violation. Violence is intrinsically subversive and, therefore, the more extreme it becomes, the more it tends to violate every possible system: political, moral, religious, economic and even legal. For centuries, populations have 
been involved in conflicts only in an indirect (although for this, no less devastating) manner. One only has to think of the plunder and destruction of crops and cities - the scorched earth policy adopted by all great generals - and, above all, the epidemics for which troops in disarray were the main vehicles of spread (McNeill, 1976). The first real qualitative leap was World War II, which saw the planned destruction of entire cities through the strategy of aerial bombing - also known as 'terror bombing'. Estimates vary, but we can assume: 30,000 dead in Dresden and 50,000 in Berlin (with 600,000 dead and 800,000 wounded in the whole of Germany). And then Japan: in Tokyo, 89,000 dead; in Nagoya, Kobe, Osaka, Yokohama, and Kawasaki, 260,000 dead and between 9 and 13 million homeless. Finally, Hiroshima on August 6, 1945: between 100,000 and 140,000 immediate deaths, to which at least another 100,000 presumed deaths within five years as a consequence of illnesses linked to atomic radiation must be added; and Nagasaki on August 9, 1945: 74,000 dead and 75,000 wounded (Tanaka, \& Young, 2009).

Here, civilians were included in a much broader concept of the enemy, and were identified with the enemy regime of which, in reality, many of the civilians were actually hostages. It was assumed that by moving the frontline into the cities themselves, the enemy government's basis for consensus would be undermined, thereby hastening its defeat. Yet, this was not the case, as demonstrated by the fact that the end of World War II was achieved only thanks to Allied victories in the field. The Vietnam War brought the strategy of civilian punishment back - this time they were spared radioactive contamination, but suffered chemical poisoning from Agent Orange instead. And in this case as well, targeting civilians proved itself to be a useless strategy that in any case failed to save the USA from defeat. In spite of this, the practice of bombing civilians is still regularly revived. During the four years of the siege of Sarajevo, anywhere from a minimum of 200-300 to a maximum of 800-1000 bombs were launched onto the city each day (Pirjevec, 2001: 150), and during NATO's campaign to drive Serbian forces from Kosovo, the city of Belgrade was regularly bombed (Cordesman, 2001).

For those who experience them, bombings emulate torture as applied according to the canons of an economy of scale. In many ways, the estrangement of the pilot, facilitated by the physical distance that separates him from his victims on the ground, is no less than that of the torturer. In this regard, Claude Eatherly, the pilot of the plane that dropped the Bomb on Hiroshima (who, in a famous piece of correspondence with Günther Anders made public the sense of guilt he felt for having taken part in the first atomic attack in human history), should be considered an extraordinary exception in the cold, technological world of the fighter pilot, who seem to be glorified only for their ability to strike their target with surgical precision (Anders, 1961). Yet for the civilians below, who cannot know exactly where and when it will explode, a bomb in free-fall or a guided missile represent the incarnation of a new absolute and arbitrary power: it sees you, but without showing itself, and strikes without having even established your possible guilt (Scarry, 1985). 
The perception of violence suffered by the victim of a terrorist attack is not much different; though it is aggravated by the additional senselessness of an act that is, with increasing frequency, completely decontextualised (Bonanate, 2004). Scholars of terrorism all agree that its victims do not count as individuals because, as such, they are not the real targets of the violence (Jenkins, 1975; Schmid, Jongman, et al., 2005). The victim's only role is to convey a message to a much wider audience. In other words, terrorism seems to assume a rhetorical dimension that is entirely autonomous from the coercive force associated with the violence that it expresses. This may well serve to provoke a debate between the segments of the public at which it is aimed: 'A terrorist sends a message to a target audience (the public, a state, an organisation, or the government) by engaging in an act of violence or destruction. The message is not the violence or destruction itself; rather, it is encoded within such activity' (Tuman, 2010: 32$).{ }^{10}$ But the fact is that every form of violence has always claimed this kind of rhetoric and discursive function. The ancients, and even primitive populations, linked the use of violence to a ritual symbolism that revealed a kind of awareness of death and the function of rites of passage that the modern exegetists of human sacrifice lack entirely. For centuries, the state has invested immense resources in propaganda aimed at achieving these goals - as we will see in chapter 5 . The difference, then, is that when violence is reduced to a marketplace, the victims become the currency used to acquire a presence in the mass media - the price of a communicative strategy that effectively strives to reach the widest possible audience, but in order to promote a brand name rather than to provoke a discussion.

Looking back, it seems possible to assert that the representation of the victim's world includes an odd kind of merit scale in which the dead precede the survivors, and those who are in some way responsible for or accomplices in their own fates, or rather, chose to place their own lives in jeopardy, are placed before the unwitting. It is easy to fixate (immortalise) in the collective memory the image of the fallen hero because it reassures us of the value of our cause. On the other hand, it is better to forget those who tried, even unsuccessfully, to avoid their appointment with fate by protesting, disobeying orders, or even deserting.

Those who died in vain are even more embarrassing, because they constitute the proof of the errors committed, and of the limits violated: the equality in death evoked by ossuaries, memorial stones, and military cemeteries is never extended to these civilian victims. The memory of the millions drowned, of those who never returned, is entrusted mostly to the testimony of the saved, who had the privilege of not dying (Levi, 1988). But they struggle against the tide, going up against the unconscious desire for collective repression and the revisionist leanings of institutions that sometimes act as

10 There exists a vast bibliography on the subject of terrorism and communication. It is sufficient to recall here Paletz, \& Schmid (1992); Schaffert (1992); and Schmid, \& de Graaf (1982). Most recently, on how the media have treated the events of September 11, 2001 see Greenberg, B. S. (2002). 
accomplices to the executioners. ${ }^{11}$ All too often, the only true witnesses of massacres, the survivors, have remained unheard or have been judged as untrustworthy simply because their stories did not conform to the official narratives. Today, however, at a time in which violence is being privatised, and thereby losing even those few political references which serve to explain it (although not necessarily to justify it), we are witnessing a further loss of the social meaning of life and death. One only has to think to the many people killed by that which, through a grotesque euphemism, have come to be known as 'stray bullets', fired by the members of a gang or mafia engaged in a war with their rivals. Such incidents have by now become a structural element of any given megalopolis; though they tend to be obscured in common crime statistics. And yet we should ask ourselves: to what end, and for what cause, have these victims been sacrificed?

11 A particularly significant example of collective self-censorship, with its complex implications linked to the responsibility for the extermination of Jews, concerns Germany, which for decades ignored the immense devastation that struck its cities during the bombings by the Allies in World War II. See Sebald (1999) for an analysis of the representation of these events in German literature. 


\section{Military Apparatuses}

The military profession does not begin and end with the acquisition, through the education and training process, of specific techniques designed to fight and kill. What really counts, above all else, is membership: soldiers belong to an exclusive group equipped with its own leadership and its own administrative apparatus (Janowitz, 1960). Over the course of the twentieth century, the professionalisation of the officer corps was commonly asserted to be (at the very least) a precondition of its loyalty to political institutions; just as, in many countries, universal conscription was considered a prerequisite for democratic citizenship. Having reached the final stage of a centuries-long process of acquiring the monopoly of the legitimate use of physical force, the state was finally facing the task of bridging the civilian-military gap (Feaver \& Kohn, 2001) - with parliamentary systems on the one hand, and systems based on executive power on the other, playing different roles in their relationship with military forces (Avant, 1994).

In the post-Cold War era, the far more pertinent problem is instead the proliferation of violent non-state actors (VNSAs); and, as a consequence, the questions that receive the most attention are those related to the varying and complex relationships between these actors and the state. The distance between the holders of the legitimate monopoly of force and private groups or agents of violence, which until quite recently seemed immense, has now been reduced to the point that the two realities occasionally even exchange roles, from the point of view both of military efficiency in the strict sense and in terms of capacity for legitimisation. Comparative research on different types of armed groups revealed that 'states, in many ways, are involved in the "production" of the leaders of armed groups. It is supposedly within state institutions that core skills needed for armed rebellion are transmitted. [...] Also, some degree of military expertise, usually acquired in state institutions, is a characteristic of the profile of many armed group leaders. And finally, the experience of violence in state prisons and prior political conflicts also suggests a causal relation between encounters with state violence and the resort to arms as a political strategy' (Schlichte, 2009: 249-250).

If state identity is no longer sufficient to discriminate between different apparatuses of violence, it may be helpful to distinguish them, according to their primary 'institutional' aims, in three categories (or ideal types):

1. coercive non-profit organisations: groups that use violence in the service of a cause (the nation, religious faith, ethnicity) and, as a consequence, essentially appeal to their members' sense of identity. Regular armies, militias, guerrilla movements, rebel groups (or insurgents), and terrorist organisations may be placed in this category. Soldiers who serve in these types of formations, and who also claim some form of political and ideological affiliation, face the task of preserving the remains of the warrior ethos that has accompanied the military profession for 
centuries. This does not make these soldiers better than others, but, if anything, it qualifies them as the most faithful interpreters of traditional warfare;

2. coercive commercial enterprises: groups dealing in violence that aim for profits and maintain relationships of a contractual nature both with their clients and with their own members. Today, these groups are tasked with personifying managerial military leadership in its purest form. Private military corporations (PMCs) remain the ideal, yet even some mafia groups, and other organisations dedicated to illegal trafficking (of drugs, arms, or human beings), demonstrate that they are fully suited to the task;

3. fringe armies: groups that lay outside these two mainstream categories, each time mashing up, in a peculiar and unconventional way, idealistic aspirations and economic interests. In general, these manifest as small units with limited resources, though at the same time, thanks to their brutality, they are capable of offering an original approach to the repertory of violence. This category includes: bandits and street gangs; paramilitary and self-defense groups; vigilantes and warlords.

each of these three categories tends to propose a specific interpretation of the concept of the military profession; each develops autonomous models for recruitment and career development; and each attributes its own specific meaning to that form of intragroup cohesion known as 'esprit-de-corps'. And yet, at times, it may be quite difficult to trace clear lines of demarcation between them.

\subsection{The Variants of Professionalism}

The end of the Cold War gave new connotations to the meaning of professionalism in the field of violence. One significant change concerned, above all, the characteristics and functions of state armed forces. ${ }^{1}$ The new threats faced after 1989 marked the military's entrance into a 'postmodern' phase characterised by the altered nature of the missions entrusted to them. International wars and nuclear deterrence gave way to local clan-based conflict or terrorist attacks; the defense of national territory and efforts undertaken in support of allies were replaced by peacekeeping operations and international humanitarian interventions. All this required significant evolution,

1 The fundamental text on the evolution of the armed forces in the post-Cold War period remains Moskos, Williams, \& Segal (2000). On the case of the USA, see Roxborough (2003). For a specific analysis of the evolution or the armed forces in European countries, see Forster (2006). On how the menaces coming from the domestic or international environment tend to determine the character and the function of the military apparatuses and their relationship with civil society, see, finally, Desch (1999). 
particularly in the role of the officer. Previously, during the two World Wars, an officer was defined as a combat leader capable of planning battles and motivating his men. Later, in the era of nuclear deterrence, and mainly with reference to the armies of the great powers, officers were expected to acquire technological and managerial skills. Today, this same class of soldier finds himself forced to interpret a much more complex 'hybrid' role - 'the "Hybrid" label tries to capture the idea that the range of threats faced today combines threats of earlier eras, from nuclear attack to large scale conventional war to low intensity conflict against non-state actors to subnational threats within the country' (Williams, J. A., 2008: 202) - in which, over time, he must exhibit significant organisational capabilities and a talent for diplomacy, advanced technical understanding of the weapons in use, and adequate knowledge of the historical and cultural context of his operational theatre. In addition, today's officer must also demonstrate the ability to adjust the use of force in a way that allows him to transform his men from soldiers into policemen.

Ironically, this occurs at a time when back at home police forces are increasingly undergoing a process of militarisation through the creation of special units which seek to emulate elite corps of the armed forces in both training and weaponry. For example, in the US, the Police Paramilitary Units (PPU) or Special Weapons and Tactics Teams (SWAT), directly modelled on the Navy Seals, have become widespread in the last few decades: in 1995, 89 per cent of all police departments located in communities with over 50,000 inhabitants had one of these teams, which represents a doubling of the 1980 figures (Kraska, 2001). Similar units appeared in some European countries, such as Germany and Italy, in the 1970s, mainly to combat terrorism.

In more general terms, the boundary between the military and the civilian spheres - like the distinction between combatants and noncombatants in the sphere of the victims - is ever more subtle and permeable. On one hand, soldiers begin to acquire skills that are also associated with freelance professions (and no longer exclusively with public administration). On the other, the groups of which they are a part now require more support from civilian personnel; even in combat zones, where employees of many governmental and non-governmental organisations are involved in humanitarian relief efforts. Furthermore, the growing degree of professionalism found among enlisted personnel - who often perform tasks entirely analogous to those of their officers - is steadily eroding the traditional rigidity of hierarchical relationships between the ranks. This evolution has been favoured by new means of communication, such as the Internet, which has made the spread of discussion groups and web-based blogs possible, even among the members of the military (Williams, J. A., 2008).

Ultimately, the soldier employed by the state is increasingly asked to attenuate the most pronounced warlike characteristics of the military profession. His position in society can be ascribed ever more to the particular set of technical competencies he 
has acquired in the service, rather than to his role as a soldier. ${ }^{2}$ At the same time the traditional martial traits have been rediscovered and reappraised by private groups specialising in organised violence, which propose them anew under the most varied guises: from the figure of the sterile, technologically-minded contractor, to the austere, hardscrabble guerrilla or terrorist; from the cynical and opportunistic mafia member, to the proud yet tragically naive child soldier. Within the division of global labor in the sector of violence, these actors reappropriate the tasks related to the process of extraction-accumulation-distribution of resources they already performed during the long state-making process. Beside that, the same technological progress which 'civilised' a growing number of members of the armed forces, transforming them into managers and technicians, now places new weapons - simple yet awesomely destructive - at their disposal; attributing an entirely new meaning to the very concept of the military profession. The new acceptance reassesses the profession's original link with the 'function of the warrior' (Dumézil, 1985); and yet, in so doing, it also reinterprets its traditional elitist connotations.

The proliferation of VNSAs in a certain territory, in fact, allows for the capillary diffusion of old and new figures whose professionalism is manifested, above all, in their absolute lack of inhibition towards killing - as we have seen in the previous chapter, the never fully resolved problem of old mass armies based on the draft (Grossman, 1995). At the same time, the particular nature of their organisation makes it easier to induce even simple privates to put their own expertise to work for higher collective goals, rather than limiting themselves to the pursuit of personal interests. This, in state armed forces, was peculiar of highest ranking officers, defined as military elite precisely 'to distinguish those members who use their skill to achieve social and political ends from those who are content to practice their profession for personal and immediate rewards' (Janowitz, 1960: 7).

With regard to the first point - professionalism interpreted as a lack of the inhibition to kill - until now, history has reserved the role to inflict violence in its most direct and heinous forms for elite units of totalitarian and authoritarian regimes. The anonymity of the ranks of 'willing executioners' (Goldhagen, 1996) was guaranteed by the bureaucratic nature of the extermination apparatuses of which they were indispensable pawns. In the case that they happened to be accused of committing crimes, these same characteristics allowed them to plead in their own defense that they were only obeying orders - as we have seen in the previous chapter. Today, organisations as varied as terrorist groups, mafias, gangs, and PMCs, obtain entirely identical degrees of cruelty from their affiliates (or employees), but with a far limited

2 As it had been already noted by Janowitz (1960: 64), with reference to the USA, the number of the enrolled in the army performing typically military tasks had gone down: from 93.2 per cent during the Civil War to 28.8 per cent in 1954. A similar trend was observed in the officer corps, and even more so in the Navy and the Air Force. 
deployment of resources and time. They succeed simply by keeping the physical and mental space of engagement with the enemy to a minimum. Everything is played out within the narrow confines of a neighbourhood or a street, and everything is reduced to a feud: violence exercised to right a wrong, perceived or real; or preventively, to stop the offense from being committed in the first place. The victim is no longer an abstract representative of a nation or an opposing class, but rather, any individual who, through the sole fact of his existence, constitutes a threat to one's identity and (only secondarily and not always) a threat to one's safety.

As in the torture chamber, physical proximity becomes the measure of an immense distance: between a contractor at the checkpoint and a civilian seeking to cross to the other side; between members of two gangs competing for the same piece of sidewalk; between a bomber and a passerby entering the same subway train. The dehumanisation of the enemy - once again manifested in the archaic form of fury perpetrated upon his/her body through practices such as rape, violence or mutilation - is the product of varying combinations of indoctrination, training, and coercion. Non-profit organisations still tend to rely mainly on the first aspect, coercive commercial enterprises on the second, and fringe armies on the third; but the internal interpretations of each differ in significant ways.

Among non-profit organisations, for example, the state armed forces that subcontract the training of troops to PMCs inevitably end up abdicating the job of instilling abstract values such as patriotism, institutional loyalty, and respect for the law of war in their soldiers in exchange for their mastery of weapons and combat techniques. In contrast, terrorist and guerrilla movements seem unable to do without religious or party-affiliated schools tasked with 'educating' recruits, even before they are sent to training camps. The terms of indoctrination may evolve, of course, depending on different situations. For example, 'the 1st generation of Europe's global jihadis [who] came into existence and operated within the nexus between Al Qaeda in Afghanistan [...] were required to go through substantial periods of religious studies, political indoctrination, and military (paramilitary) training before they were assigned to missions'. On the contrary, Europe's 2nd generation of activists, most of them young second-generation Muslim immigrants born in Europe, 'operated quite autonomously from the organised militant groups by which they were inspired. Some of the recent terrorist cells uncovered in Europe have been described by investigators as being mainly self-recruited, self-radicalised, and self-trained, by the use of the jihadi Internet' (Nesser, 2008: 238, 239 and 241).

In any case, non-profit organisations such as terrorist and guerrilla groups are also far more dependent on the environment in which they operate. The setting may represent a resource to be exploited, but can also throw up insurmountable obstacles and severely limit the movements' freedom of action. For example, radical Islamic groups mobilise the entire neighbourhood in an effort to strengthen the determination of candidates for martyrdom. Not only is the local community charged with the task of preserving the memory of those who are successful, but it is also responsible for 
ostracising those who fail (Reuter, 2004). On the other hand, in the case of insurgent groups, a local environment that is rich in natural or financial resources can actually undermine earlier idealistic motivations, making the groups less dependent on local support and thereby feeding indiscriminate violence toward civilians. In other words, movements that emerge in environments that are poor in resources tend towards a more selective and strategic use of violence; and their leaders are more easily able to maintain control over their troops (Weinstein, 2007).

Among coercive commercial enterprises, PMCs are those which most equate professionalism with the efficient use of weapons. In this case, the dehumanisation of the enemy consists in denying him any kind of identity and reducing him to a target: a faceless obstacle to be eliminated. The most important factor here is reaction time. The speed of engagement allows the contractor to avoid risking his own safety, and secures the investment of the PMC that hired him. A lack of scruples, or better, a lack of any real interest in the nature of the conflict or the other people involved in it, proves to be the most effective marketing strategy for these groups. ${ }^{3}$

Mafias, on the other hand, tend to contaminate their commercial enterprise nature, or their own fundamental indifference (from an ethical standpoint) toward the victims of their violence, with some of the elements typical of the other two groups. Emulating non-profit organisations, they offer their associates alibis of an ideological nature, essentially based on the claim that they incarnate the ideal of a man who is loyal to the superior principles of friendship and justice. Emulating fringe armies, mafias may resort to pressure or intimidation to obtain the obedience of their affiliates; for example, by applying the strategy of next-of-kin revenge, to deter potential witnesses to collaborate with state prosecutors.

Coercion, the act of inflicting physical suffering on a follower as a prerequisite for overcoming the inhibition to kill the enemy, becomes the dominant aspect of many fringe armies: from units (often made up of child soldiers) serving warlords to gangs. In Sierra Leone, for example, since the 1960s the odelays or 'devil societies', which in the last decades of the twentieth century became ever more violent and political, were the main secret association for youngsters: 'The initiation ceremony for new members lasted two or three days and stressed endurance to pain. Boys were beaten, kicked, cut with glass and razor blades, and sometimes hung from a tree or above a fire. Boys who were especially good fighters paid reduced membership dues' (Rosen, 2005: 69-70). Central America maras, to give another example, impose cruel initiation

3 'Professional, polite, prepared to kill' read the sign at the entrance to Camp Victory in Baghdad (Schumacher, 2006). And after the disastrous earthquake of January 2010, All Protection \& Security from Orlando, Florida, offered Haitian citizens a number of services (for payment) on its website; all were aimed at defending the resources of the island, including the vaguely stated 'high threat terminations', presenting as a guarantee of the professionalism of its employees the thousands of successfully conducted missions in Iraq and Afghanistan (Scahill, 2010). 
rites to the new members: 'When a teenager wanted to join the gang, the candidate just had to hang out with the members of the clique he wanted to join and go through an initiation rite that imitated the rites followed by the original gangs in the United States. One of the things that young people joining any Central American gang used to do [...] was to get tattooed, often on the most visible parts of their body, including the face'. But 'the formal initiation rite consisted in an endurance test. The gang wannabe must endure a 13-second (MS-13) or an 18-second (Eighteenth Street Gang) beating by five or six members of the clique. In recent years, as gangs became more organised, the initiation rite also included a "mission", this is, the murder of a rival gang member' (Cruz, 2010: 388).

Also in this case, however, an institutionalisation process may induce gangs to 'develop rituals and ceremonies that distinguish them from other similar organisations, and come up with an apocryphal organisational history' (Hagedorn, 2008: 8). They develop, in other terms, a 'system of beliefs' and 'rationalised myths', that make them more similar to coercive non-profit organisations. Finally, there are examples of vigilante groups which resort to forms of indoctrination, albeit in limited and illegitimate ways (Abrahams, 1998; Pratten, \& Sen, 2008); or of paramilitary units (Mazzei, 2009; Sluka, 2000) which, especially when they are not part of the repressive apparatus of an authoritarian state, tend to appropriate the utilitarian model of contractors or mafias - as in Colombia, where paramilitary groups and mafias overlapped (Duncan, 2006).

With regard to the second point, the goal of inducing even simple soldiers to place themselves in the service of higher collective aims is obtained by universalising the very idea of the elite, and extending it to all members of the organisation. VNSAs are aided in this effort by the limited size of their own apparatuses, and can therefore abandon the impersonal model incarnated by the state armed forces in order to strengthen the ties of personal affiliation. And in this way, the private nature of these groups acquires the additional, literal meaning of being hidden from the view (and from the oversight) of the public. But invisibility does not serve only to hide the predominantly clandestine and illegal nature of their activities; it also allows the organisation to take on all of the qualities traditionally associated with secret societies: such as cell structure as a guarantee of the safety of its members, and the initiation rites and inexhaustible patrimony of symbolic references that represent indispensable instruments for increasing internal cohesion (Armao, 2000: chpt. 3).

China is probably, today, one of the most interesting case-studies, because of its strong and long tradition of secret societies, dating back to the early Qing dynasty. In fact, 'China's secret societies of all kinds were almost completely eradicated during a relatively short period after the communists seized power in 1949. In the post-Mao era, as political control over society has loosened up with the market reform and Chinese citizens have accordingly acquired more socioeconomic freedoms, secret societies have come back and multiplied with a stunning speed. In the late 1990s, the rate of gang crime rose to account for 60-70 per cent of all criminal offenses' and 
some of these criminal secret societies 'have reportedly created a reign of terror over an increasing portion of Chinese society' and 'demonstrated a capacity to mobilise thousands of people onto the streets' (Chen, 2005: 78).

Admission to one of these groups implies a true rite of passage from the profane to the 'sacred' life under the tutelage of a 'spiritual guide'. The initiate agrees to modify his own human condition, estranging himself from society, in order to be reborn as a new man inside a confraternity. The initiation - which can assume the farcical manners typical of many mafia organisations or, as we have seen, the much more tragic forms of violence imposed on adolescents who want to become gang members - satisfies two important requirements. The first, and most immediate, is regulating access to the organisation. From this point of view, the figure of the tutor is fundamental; not only is he tasked with instructing the new follower, but he also guarantees the recruit's trustworthiness vis-à-vis the group. The role of a spiritual guide has acquired particular importance in terrorist groups that train their men for suicide missions. In this context, the guide's duties most likely extend to the eve of the attack, in order to avoid the risk of the candidate withdrawing from the proposed act of martyrdom (Horgan, 2006).

The second requirement of initiation is that it affords group leaders the opportunity to (re)legitimise themselves in the eyes of their associates and those they rule. Through the rites of initiation, leaders reinforce their charisma - a necessary, though, by itself, incomplete basis for power - by alluding to the cultural stereotypes historically attributed to secret associations, such as mystical or religious origins, and the tradition of mutual aid societies (Cazeneuve, 1971). This last aspect in particular allows leaders to claim the authority not only to administer justice, but also to exercise their peculiar 'right to robbery' that benefits the members of the group (Eliade, 1958).

The different types of non-profit organisations, coercive commercial enterprises and fringe armies present in the private market of violence all interpret the secret society model in their own way. Yet the differences between them can ultimately be traced to two fundamental dimensions: the degree of institutionalisation of the group (or the complexity of its apparatus); and its degree of secrecy (or its vulnerability to infiltration by external agents). As far as the complexity of the apparatus is concerned, scholars have given special attention to the form it has assumed over time: either hierarchical and pyramidal; or that of a horizontal network; or of the shifting sands of desert dunes - as recently suggested with regard to Al Qaeda (Mishal, \& Rosenthal, 2005). However, another factor, implicit to the initiatory nature that these organisations tend to acquire as soon as they become rooted in a territory and begin to develop an increasingly articulated network of collusion with the political, economic and social systems, is even more relevant. It is the distinction between the hierarchy of function and the hierarchy of the degree of knowledge.

The first, as in any other bureaucratic organisation, differentiates members based on the role they have been assigned within the internal division of labor. The second, categorizes members according to their access to the 'great mysteries'; or, beyond the 
metaphor, to the people and information that are truly fundamental to the pursuit of the interests and goals of the group. While the assigned function of any member may be temporary, his degree of knowledge constitutes a permanent acquisition: 'The function has so to speak only an "accidental" character with respect to the degree; the exercise of a given function may require the possession of this or that degree, but it is never bound necessarily to that degree, however elevated this may be; and what is more, the function may be only temporary and thus can come to an end for a variety of reasons, whereas the degree always constitutes a permanent acquisition, one that is obtained once and for all and which can never be lost by any means' (Guénon, 2001: 277; see also Davis, F.-L., 1977).

As far as the level of secrecy is concerned, it can vary over time, and be adjusted to satisfy the strategic requirements of the moment. On the one hand, secrecy can be functional in protecting the associates and strengthening their sense of superiority relative to those who do not belong to the same elite. On the other, however, the practice of secrecy can backfire against those who use it, fostering internal conspiracies and, above all, creating conditions in which even the smallest revelations can be fatal to the very survival of the organisation. 'Secrecy - wrote Simmel - [...] is sustained by the consciousness that it might be exploited, and therefore confers power to modify fortunes, to produce surprise, joys, and calamities, even if the latter be only misfortunes to ourselves. Hence the possibility and the temptation of treachery plays around the secret, and the external danger of being discovered is interwoven with the internal danger of self-discovery, which has the fascination of the brink of a precipice' (Simmel, 1906: 465-466; see also Koselleck, 1988). This helps to explain the danger that individuals who collaborate with justice represent for the mafia and terrorist organisations (and their usefulness to the state).

\subsection{Recruitment and Career}

One of the factors that have certainly contributed to bridging the gap between public and private managers of collective violence has been the democratic regimes' gradual abandonment of the universal draft. This happened in spite of the fact that the two World Wars confirmed its deep-seated relevance to the concept of democratic citizenship, forcing military institutions to face, in particular, the question of racial segregation. It is worth remembering that in the USA, for example, integration into the army was one of the strategies adopted by the black community to combat segregation, at least up until the Vietnam era (Cohen, E. A., 1985; Janowitz, 1991) reinforced by the universities Reserve Officers' Training Corps (ROTC) programs (Leal, 2007; Neiberg, 2000).

The universal draft and voluntary service exist on two different semantic and legal levels. The draft evokes the idea of service given in exchange for previously acquired political and social rights. It places itself within a universalist relationship 
of citizenship, which, among other things, explains why democratic regimes have gradually introduced the possibility of exchanging military for civil service, but, in the end, excluded the option of paying for a substitute to serve, which was common in past eras. Voluntary service appeals to those who are the most motivated, and the most needy. In this way, however, the system favours the idiosyncratic variable over the institutional; levelling the differences between groups (the state armed forces, PMCs, mafias, and gangs) and forcing them to compete for the greatest number of potential recruits through the use of cultural and financial incentives (identity and money).

Among Western nations, the process of abolishing the draft started in the middle of the Cold War and has not yet concluded. In some cases, the choice seems to have been dictated by particular circumstances: Great Britain abolished National Service in 1960 with the definitive extinguishment of any imperial ambition (the Suez Canal episode dates back to 1956); and the USA did the same in 1973 as a result of the Vietnam experience, marked by the birth of a genuine collective movement of draft resistance. In other European countries the decision came much later. In some cases it appeared to have been taken in the absence of any real debate about its potential implications, and yet the choice was entirely in keeping with what seemed to be the dominant aspects of the new millennium: the end of the ideological conflict, advent of new information and communication technologies which made strategists predict a new revolution in military affairs, and not lastly, an increasingly widespread intolerance among the young for the burdens and risks of military service. ${ }^{4}$

The USA illustrated the seemingly inevitable demise of conscription when the government excluded the possibility of a draft even as the Global War on Terror (GWOT) and the direct involvement of American troops on two fronts (in Iraq and Afghanistan) revealed the number of available soldiers to be thoroughly inadequate. In order to satisfy the demand, the Bush administration instead chose to lower its standard for recruitment into the all volunteer force. In fiscal year 2007, only 79 per cent of the recruits had a high-school diploma, compared to a previous average of 90 per cent. And, in a departure from the regulations in force at the time, the US Army admitted a large number of candidates with criminal records, for a total equal to 10 per cent of all recruits. Secondly, the army increasingly relied on elements of the National Guard and the Reserves - organisations that still embody the ideals of the citizen-soldier, in spite of the fact that they, too, are based on voluntary recruitment. By 2004, these units made up 33 per cent of the US military forces deployed in Iraq. The use of reservists, in particular, rose from 12.7 million work days in fiscal year 2001, to 61.3 million work days in fiscal year 2006, involving a total of almost

4 France and Spain abolished the universal draft in 2001; Italy in 2006. Only Germany continues to maintain a system based on obligatory military service. In Russia, mandatory service has been reduced from 18 to 12 months. 
600,000 men and women (Commission on the National Guard and Reserves, 2008; Lynch, \& Stover, 2008). Thirdly, the Bush administration exponentially increased the practice of subcontracting functions to PMCs, which seemed capable of remedying the vocational crisis while at the same time guaranteeing high professional standards. According to governmental data, on March 2009, contractors made up 48 per cent of the Department of Defense (DOD) workforce in Iraq, and 57 per cent in Afghanistan (Schwartz, Mo., 2009). This trend was substantially confirmed by Obama administration: on March 2011 contractors made up 58 per cent of DOD workforce in Iraq, and 48 per cent in Afghanistan (Schwartz, Mo., \& Swain, 2011); on March 2013, 62 per cent in Afghanistan (Schwartz, Mo., \& Church, 2013). The result is that 'according to government officials and analysts, the military is unable to effectively execute many operations, particularly those that are large-scale and longterm in nature, without extensive operational contract support. Even in short-term operations, contractors can play a variety of critical roles. [...] Given the extensive role of contractors in military operations, many DOD officials and analysts consider contract management a mission-essential task' (Schwartz, \& Church, 2013: 2).

The combined effect of voluntary recruitment and outsourcing may emphasise the devolution of military functions and, as a consequence, political institutions' renunciation of their prerogative both to determine the strategic dimensions of the conflict, and to verify their correct application. As far as public opinion is concerned, the lack of a mandatory draft as a requirement of citizenship and the consequent recourse to contractors risks accentuating the sense of estrangement experienced by the masses who are excluded from directly participating in war events, and often entirely ignorant of them (circumstances that also characterised the relationship between the military and civilians in the past). Among civilians, this estrangement can manifest itself either as concern about the authoritarian character of the military institution, or as an excessive faith in the ability of the armed forces to resolve any problem. After September 11, the risks of a new militarism were feared by many intellectuals in the USA at a moment in which the terrorist menace seemed to justify the attribution of unprecedented prerogatives to the armed forces, even in the domestic sphere, thus foreshadowing the birth of a new model of a 'garrison state' (Lasswell, 1941). ${ }^{5}$ Among the military forces, it tends to be exhibited in frustration over what is perceived as a lack of acknowledgement of the importance (and the danger) of their mission or, vice versa, in an almost aristocratic claim on the right of membership to a body separate from the state.

The entry of contractors into what, until that moment, had been a fully monopolised market of violence introduces an element of competitiveness that could,

5 The debate developed particularly after the publication of Bacevich (2005). On risks related to the militarisation of the terrorist menace see, most recently, Kohn (2009). For an original analysis of militarism from a gender perspective, see Enloe (2007). 
over an extended period of time, have even more significant consequences than those outlined here. In the course of combat, the involvement of private contractors complicates coordination (when it does not create actual conflicts of competencies) between the hierarchical lines of command: in addition to the traditional competition between different branches (army, air force and navy) there is now additional antagonism between these and the managers of the military corporations. The presence of soldiers and contractors in the same war theatre - all with different functions, responsibilities and rules of engagement - also produces negative effects on the cohesion and the morale of the troops (Avant, 2007).

The contention, however, generates effects of a systemic nature as well, from the point of view of career models for the officer corps, and from that of the military institution as a whole. The first case represents the possibility of exploiting the competencies and merits acquired in the public sector in order to guarantee career advancement in the private sector. For the person directly concerned, shifting from the state military apparatus to the PMCs produces undisputed benefits in terms of income, and (at times, and depending on the role) of social status. But for the state, this mechanism represents a cost without any possibility of a return, and is neither constructive nor profitable.

In the second case, the effect is that of further accentuating the tendency already observed in Western countries where, starting with the recruitment campaigns, occupational motivations prevail over the institutional: the pay, benefits, and the possibility of specialisation in fields useful in the civilian life, rather than disinterested service, patriotism, and military values (Moskos, 1977). This strategy might have made sense as an effort to widen the recruitment base in the context of the monopoly of force held by the state. Today, on the contrary, in an arena where private actors can issue offers that are far more advantageous than those made by their public counterpart, it seems entirely counterproductive.

The structural consequences caused by the abandonment of the mandatory draft should be added to those created by the end of the Cold War and the redefinition of the missions entrusted to state armed forces. A first consequence, in fact, was the drastic reduction in the size of the military apparatuses ${ }^{6}$ and their radical reorganisation into much more agile units, which are intended to compensate for reduced firepower with greater efficiency and the ability to coordinate with other branches of the military made possible by new communication technologies (Forster, 2006; Moskos, Williams, \& Segal, 2000). In the early 1990s, scholars in the field began predicting the possible

6 In the USA, military personnel (from the Army, Navy and Air Force) has diminished from over 2,130,000 men in 1989 to 1,386,000 in 1999 and 1,419,000 in 2009; civilian personnel followed a slightly different trajectory during the same three year period, going from 1,075,000 in 1989, to 691,000 in 1999, and rising to 733,000 in 2009. See http://www.usa.gov/Federal-Employees/Active-MilitaryRecords.shtml (accessed 03/06/2015). 
consequences of these structural changes, especially with regard to the armed forces of Western countries (Burk, 1994 and 1998). It was observed, for example, that the requirements for flexibility and speed of deployment implied the shortening of the hierarchical ladder and a general reduction of ranks. The overall reshaping and budget cuts, on the other hand, pushed administrations to reserve full-time contracts for fighting personnel for an indefinite time period, while all other members of the military, as well as civilians hired in the fields of administration, logistics, and other services, were limited to fixed-term contracts in accordance with the practices already adopted by private industries and the civilian sector of public service (Caforio, 2003).

In a short time, among the employees this created an increasing sense of estrangement from the traditional values of the military institutions, often compounded by frustration generated by the fact that the salaries they received were often inferior to those of their colleagues hired to work in similar positions for private corporations: 'the implementation of commercial business practices to improve efficiency, cost-effectiveness, and flexibility has a marked impact on perceptions of military employment. Not only has it fragmented military work, but it also appears to have undermined the traditional value system associated with military service based on selfless service, loyalty, and commitment to the organization' (Heinecken, 2009: 493-494). This climate, moreover, increased the fear of a possible trade unionisation of the military, which, in all countries, has so far been denied any right to collective representation (Bartle, \& Heinecken, 2006). ${ }^{7}$

All of the factors described above can help explain the difficulties in recruitment that the armed forces in Western countries occasionally face. ${ }^{8}$ But the ultimate reason for the crisis in the military vocation should be sought in the weakened ability of the state, as compared to the competing VNSAs: a) to justify the merits of violence for reaching specific objectives to their own constituencies - a true contradiction in terms for democracies, which they can try to obfuscate by lying to their citizens, as repeatedly happened in the USA during the war in Iraq in 2003 (Brewer, S. A., 2009: chpt. 6); and b) to offer soldiers benefits proportionate to the motivation that compels

7 It is worth mentioning that similar fears of a possible wave of salary claims were the argument with which the Republican Party vetoed the nomination of the White House candidate for the directorship of the Transportation Security Administration in January 2010. This agency is part of the Department of Homeland Security, created by the Bush administration in 2002 with the explicit legal provision that its 180,000 employees, like members of the military, can never be granted normal trade union rights in order to maintain the 'flexibility' considered a necessary prerequisite to combatting the war on terror (Knowlton, 2010).

8 In June 2007 in the USA, the number of young Americans interested in enrolling reached the historic minimum of just 9 per cent. The DOD, on the other hand, estimates that more than half the population between the ages of 17 and 24 years do not satisfy the minimum requirements for the armed forces (22 per cent, for example, exceed the body mass limits set for entering service) (Commission on the National Guard and Reserves, 2008). 
them to kill and even risk their own lives. With regard to the first point, the comparative advantage of VNSAs derives from the fact that most of them can easily demonstrate that violence is a necessary, and sometimes sufficient, means to achieve their ends. For others, violence can, in fact, represent an end in itself. The new coercive nonprofit organisations, for example, have no need to resort to philosophical theories about the regenerative power of war, or to refer to manuals on guerrilla warfare in order to persuade their men to follow them down the path of revolution or jihad: the objective conditions of inequality and exploitation, and the unbearable daily struggle for survival are sufficient motivators. If the inability to access the political arena and lack of normal channels of representation deprives individuals of any hope of having their voices heard, and even the possibility of escape represented by emigration is closed to them, then the only remaining option is to gather around a leader and be loyal to a cause (Hirschman, 1970).

Although hardly a justification of the violence these groups exercise, such factors contribute to explaining the support VNSAs enjoy in a given society. In the case of terrorism, for example, it has been observed that members of groups which, in one way or another, model themselves on nationalist or separatist ideals, such as the IRA (Irish Republican Army) in Northern Ireland, or Hamas in the West Bank or Gaza, do not appear to be estranged from their families or their communities in any way - while the opposite was true for members of anarchical or revolutionary groups, such as the Brigate rosse (Red Brigades) in Italy or the Rote Armee Fraktion (Red Army Fraction) in Germany in the 1970s and 1980s. For the former, the choice of becoming a member of a terrorist organisation represents a moment of transition or passage that reinforces their identity within the community of reference: the recruits are treated with respect and not labeled as terrorists; rather, if anything, they are considered rebels, freedom fighters or resistance members (Horgan, 2006: 91; Silke, 2003a). PMCs and a good portion of the fringe armies, for their part, do not even ponder the question of how to explain the purpose of the violence to their members (and in the case of corporations, to their stockholders). These organisations have been created for the express purpose of administering violence; and willingness to use it constitutes the fundamental criterion by which they select their members.

And even with regard to the second point - the ability to adapt methods of compensation to the individual motivations of the soldiers - VNSAs demonstrate a flexibility unknown to states, employing different combinations of resources related to status, economic incentives, and coercion for each individual case. Field research has shown, for example, that fringe armies such as street gangs employ three main strategies for recruitment, depending on the circumstances and the context in which they operate. The first is aimed predominantly at the sense of fraternity, the idea that becoming a member of the group represents a true social achievement despite the risks related to the obligation to fight in order to defend the interests and reputation of the gang. The second recruitment technique relies mainly on the sense of belonging to a larger community, and the duty to join a group in order to defend the values 
of this community. It can therefore be adopted only when the gang enjoys a certain legitimacy, or is at least tolerated even though it engages in illegal trafficking. The third technique, which tends to prevail during periods of greater conflict for the control of a given territory, is based on different forms of physical and psychological coercion which make it possible to increase the ranks in a relatively short time (Jankowski, 1991).

Moving to coercive commercial enterprises, an exclusively economic motivation appears to remain the prerogative only of contractors, who in any case have no difficulty obtaining guarantees of much higher compensation from PMCs than those offered by the state armed forces from which they are almost always recruited. Mafia recruiters, on the other hand, even if they primarily propose their prospective members unexpected possibilities for enrichment, at the same time can also take advantage of members' loyalty to their minority group which, especially in a migratory context, may be subjected to conditions of objective exploitation and discrimination - the propensity to foster the feeling of deprivation as an instrument to legitimise its existence among migrant communities has been observed, for example, in the Japanese Yakuza (Hill, 2003: chpt. 3). Non-profit organisations like terrorist groups, to give a further example, rely primarily on ideological involvement and indoctrination, and yet do not shy away from using money to motivate new recruits. Competition between rival terrorist networks may even occasionally foster the search for funds that will finance not only propaganda activities, but also welfare initiatives benefitting the community, including improved compensation for combatants. Among other factors, this contributes to explaining the importance of the role played by the states that sponsor terrorism (Byman, 2005: chpt. 3).

One final point concerns career prospects. The more precarious these become in public apparatuses - either as a consequence of the growing 'civility' of the military profession or the adoption of short-term contracts - the more guaranteed they prove to be among VNSAs. In fact, if PMCs represent the natural professional outlet for those with no profession other than that of the soldier, market dynamics also guarantee a future to other 'professionals' of violence, such as terrorists, guerrillas, or gang members whose rehabilitation and reinsertion into civil society are made even more impractical by the fact that they have spent a good part of their lives in clandestine activities. The solution consists in suggesting easy role reversals that allow a guerrilla or a terrorist to apply the competencies he has acquired during his years of militancy to the sector of transnational illegal trafficking (Dishman, 2001; Reuter, 2004: 10); or permit a mafia member to work for a political plan which is, if not explicitly subversive, then at least anti-democratic - as happened in postSoviet Russia (Varese, 2001; Volkov, 2002). In this game, even the 'old' state military institutions can be rediscovered and parasitically exploited by private groups: such as when, for example, gang members enlist in the army in order to perfect their use of weapons and combat techniques (Eyler, 2009). 


\subsection{Esprit-de-corps}

In comparison with state armed forces, whose transformations, no matter how important, occur within a consolidated bureaucratic structure and in compliance with decision-making processes legitimated by the government, VNSAs are characterised by a tendency to change their goals more frequently, with inevitable consequences on the personal motivations of the single 'combatants'. The ease with which elite members of an insurgent group can let themselves be corrupted by economic interests, and abandon the defence of community interests, is bound to influence the criteria for the recruitment and training of men as well as the internal discipline of the group. ${ }^{9}$ Yet, rather than constituting a weakness, these aspects of volatility and adaptability can be an extraordinary resource, and may constitute a comparative advantage when facing the state. What counts is not so much the stability and the consequent trustworthiness of the manager of the resources of violence, but his ability to guarantee the congruity between the motivation of his soldiers and the context in which they operate - in other words, to preserve the esprit-de-corps.

All the research conducted by psychologists and military sociologists since World War II has shown that the internal cohesion of the primary group constitutes the factor that most influences the performance of soldiers in combat (Grossman, 1995: 149-155; Stouffer, \& al. 1949). The group helps the individual to kill by absolving him from the guilt of having committed homicide; and it also helps him to exorcise death by not abandoning him at the moment of transition: 'Death, which in truth threatens every man all the time, must have been proclaimed as a collective sentence before people will oppose it actively. There are, as it were, declared times of death, times when it turns on a definite, arbitrarily selected group as a whole. It is "Death to the French" or "Death to the English". The enthusiasm with which men accept such declarations has its root in the individual's cowardice before death; no one likes facing it alone. It is easier in a duel, when two enemies, as it were, execute sentence on each other; and the death that thousands approach together is entirely different. The worst that can happen to men in war is to perish together; and this spares them death as individuals, which is what they most fear' (Canetti, 1973: 72-73).

In real combat, the group integrates the single member in order to guarantee his safety as much as possible, as well as exalting his aggression in the face of the enemy. It is worth remembering the echelons of pikemen in sixteenth century battles, or the line formations and outflanking maneuvers of seventeenth century battlefields, or even the more complex geometry of today's commando actions. The function of these tactical exercises is always double: to increase firepower while simultaneously protecting

9 These are the premises in the research conducted by Henriksen, \& Vinci (2008). But the topic of individual motivation, particularly as far as terrorists are concerned, has in recent years attracted the attention of a growing number of scholars. See, for example, Kimhi, \& Even (2004); and Fair (2008b). 
one's own forces to the maximum possible extent. When, on the contrary, officers indiscriminately send their own men to be massacred - as happened in many World War I trenches, where the infantry were obliged to throw themselves against a wall of machine gun fire; or in the Iran-Iraq War, when adolescents were forced to sacrifice themselves on the minefields or as human bombs - what suffers is the cohesion of the group, and the ultimate consequence is the dissolution of the entire military apparatus.

In past centuries, states historically created and nourished the esprit-decorps of their armies through the use of an intangible yet extraordinarily unifying symbolic factor: the code of honour, adjusting it to the values prevalent in a given society (Bowman, 2006; Stewart, 1994). It is therefore not a coincidence that absolute monarchies made honour a prerogative limited to the officer corps, allowing its members to proudly claim a common aristocratic origin, even beyond their own country, as if they were ante litteram representatives of a global caste. Since then, with the gradual opening of the military career to the sons of the bourgeoisie, and even, finally, to less affluent classes, the emphasis has been placed increasingly on professionalism; that is, the requirements of competence, responsibility, and, as always, sense of belonging, eventually pursued through training in military academies (Huntington, 1957). The democratisation processes have made the idea that war can constitute an activity that is honourable in and of itself, or a source of personal glory, particularly implausible. And this has increasingly obliged members of the military to face civil society, and base their self-respect on public prestige and collective recognition of the function they fulfill (Janowitz, 1960: chpt. 11).

The privatisation of violence which followed the end of the Cold War restored the honour code to the central role it had lost. Most importantly, the exercise of violence as such once again became the end in itself upon which soldiers increasingly rely for their dreams of glory, or even their hopes for immortality (as in the case of suicide terrorists). Indeed, for many of them, in a crescendo culminating in a kind of social autism, honour ends up being measured by the number of enemy killed.

Scholars have often underestimated the importance of this belief system, for both internal cohesion and for defence from external agents, by reducing it to folklore. On the contrary, the honour code represents a constitutive element of the process of selecting, and building loyalty among, the new soldiers employed by VNSAs. It also contributes to explaining the solidity of peer relationships, and, consequently, the reluctance of individuals to abandon the group - particularly in the context of terrorist organisations (Horgan, 2006: chpt. 6). The construction of the honour code is a two-phase process: narration and ritualisation (ter Haar, 1998: chpt. 1). The first consists in the elaboration of a text that situates the group - its origins, mission, and the strategies adopted for its realisation - within the framework of a larger tradition, be it cultural, political or religious. This text may vary in richness and complexity, depending on whether the prevailing need is the legitimisation of its existence and cause or the pragmatic demand to administer to its members a code of conduct that guarantees the group's governability. It can therefore range 
from an ideological or religious pamphlet associated, respectively, with guerrilla movements or fundamentalist groups, to the set of commandments dictated to new recruits by many criminal organisations and even some military corporations. The more restricted the area of action becomes - from coercive non-profit organisations, to coercive commercial enterprises, and fringe armies - the more self-referential the text becomes, until, in its most concentrated form, it is limited to mythologised representations of the group's own feats.

The ritualisation phase seeks to concretise the fiction of the tradition represented in the text: a goal it achieves through the simple repetition of acts and gestures (Cazeneuve, 1971). We have already cited the rites of initiation which accompany the entry of new members into groups that explicitly emulate the model of secret societies. To this we must now add a complex code composed of the jargon and gestures used by these same groups to feed the belief in the indissolubility of affiliative ties among their members. This reinforces the pride of having been admitted to the group, but at the same time, it heightens recruits' awareness of the risks associated with a possible betrayal. In gangs in particular, the obsessive and ostentatious repetition of these gestures has today turned into a proud reclaiming of one's social marginality, but also of brotherhood as the sole winning strategy for survival (Rodgers, \& Muggha, 2009). ${ }^{10}$

In dealing with the topic of esprit-de-corps, Military Sociology has most often emphasised the fact that values such as the warrior spirit, comradeship, and loyalty to institutions (first of all, obviously, to the armed forces themselves) are essential for guaranteeing the cohesion of the primary groups involved in combat. From this point of view, the processes of privatisation which have been underway since the end of the Cold War do not seem to have produced any significant change: even the new apparatuses of violence would have no difficulty in sharing this undertaking and recognising these same values (though of course adapted to the specific contexts of each group) in their own members. And yet, if we reexamine the long-term processes, it is obvious that the nation-state has completed a trajectory, certainly not without obstacles, of growing inclusion; while the new VNSAs are rediscovering exclusion as the fundamental criterion for guaranteeing the esprit-de-corps.

In the evolution from permanent armies to the universal draft, there has been an obvious attempt to integrate different strata and classes. In a multi-ethnic country like the USA, as we said before, the armed forces have also become a privileged space for experimentation in new forms of racial integration: for African-Americans during World War II, and for Hispanics today. ${ }^{11}$ In some cases, enlistment has become the

10 For an effective representation of this phenomenon, see the documentary by Christian Poveda, $L a$ vida loca (2009).

11 Racial segregation in the armed forces was abolished by a decree issued by President Truman in 1948; while the Civil Rights Act, which extends to African-Americans the right to vote and outlaws racial segregation in schools and the workplace, was passed only in 1964 (Moskos, 1988). 
immigrant's means to acquire citizenship. In the post-bipolar world, finally, so-called peacekeeping operations have in fact violated the last taboo, foreshadowing the formation of multinational intervention forces; though it is also worth remembering the road opened by the European Union for the formation of a true common army (Burk, 1994).

On the other hand, exclusion is the trait that distinguishes many private brands of violence, in spite of the fact that it manifests itself in different forms. Coercive non-profit organisations, such as guerrilla movements, terrorist groups and some militias, all claim loyalty to a party (in its literal sense of a 'faction'), a church, or an ethnic group, as an indispensable prerequisite for the selection of its members. The commercial enterprises of violence, PMCs and mafias, select their men on the basis of equally rigid criteria of 'professional competence' acquired through service in the elite corps of the armed forces of major powers, as is the case of military corporations; or in a criminal milieu, in the case of mafia-like organisations. Finally, fringe armies adopt one or more of these parameters - ethnic identity in the case of warlords or gangs; professionalism in the case of paramilitary units or vigilantes - though at the same time restricting the circle of belonging even more, to the point of limiting its boundaries to a specific neighbourhood.

This reversal of perspective is confirmed by the different relationship that public and private military institutions develop with their territory. For states, the national borders demarcate the legitimate area of recruitment, and the location of the garrisons and troops is determined by strategic and operative requirements. Uprooting soldiers from their regions of origin has, in fact, been the instrument adopted to instill in them the idea of belonging to a 'nation', an entity superior to the local power but which, until then, they had perceived only as an abstraction. For almost all VNSAs, on the other hand, the village or the neighbourhood becomes the physical setting for the exercise of totalitarian control. And, even when faced with an inevitable reduction in the number of potential recruits (compared to the state), the fact of knowing and following them since adolescence, and feeding their sense of loyalty to the cause, whatever it may be, constitutes a real advantage. This is true both of mafias, which seek to evaluate the predisposition for committing crimes (and also for submitting to rules) in the young men of their neighbourhood; and of terrorist groups. The latter may also exploit the fact that they are able to count on the presence of charitable organisations, hospitals, schools and mosques present in their territory, as well as use the offices of political parties as a filter, submitting potential recruits to a long internship before admitting them into the terrorist organisation itself (Silke, 2003a).

Yet the variable that, more than anything else, testifies to the passage from a strategy of growing inclusion to that of exclusion, is gender (Goldstein, 2001). The privatisation of the apparatuses of violence marks, above all, a dramatic retreat in the perception of women within the group. The model of masculinity that has always prevailed even in the traditional armed forces of democratic countries, now tends to be substituted by far more exaggerated forms of machismo and misogyny, which 
reduce women to property whose use, at most, needs to be regulated (Armao, 2000: chpt. 1; Jankowski, 1991). Secondly, the role reserved to women inside organisations is also changing. In comparison to the process which, in state armies, concluded with women standing side-by-side with men, sometimes even in combat, in the new brands of private violence women are once again pushed into the background and neglected, even when they have sacrificed their lives for the interest of the group.

In the post-Cold War era, the most relevant and complex case from this point of view is that of terrorism. Unlike the Marxist guerrilla and terrorist movements of the second part of the twentieth century, which at least confronted head on the question of how to grant women combatants the same dignity traditionally reserved for men, the brands that have affirmed themselves in the era of globalisation show a propensity to co-opt women in an instrumental fashion only if, and when, they prove to be useful in reaching the group's goals. ${ }^{12}$ If, on the one hand, this in no way implies that the recruitment of women is always a product of deceit or coercion; on the other, it is obvious that women cannot compete for honour on the same terms as men. For example, women are called to martyrdom by some fundamentalist leaders only because they were widowed and therefore deprived of a social role recognised by their community of belonging - this is the case of the 'black widows' widely exploited by the Chechen Mudjahadeen in their fight against the Russians (Bloom, 2007: chpt. 1) - or because they had been raped by the enemy and therefore required or deserved self-sacrifice as a means to 'wash off the shame'.

In conclusion, it would be a mistake to always relegate women to a subsidiary role, and yet gender equality is far from being achieved: 'Although women have historically been involved with politically violent organizations, most of their activities have been in "support" capacities; thus, their presence has been seen as passive. [...] This is not true of the "warrior" women. [...] [W]omen are pushing for expanded roles within their respective organizations, from leadership to combat, and [...] a growing number of younger women are joining organizations and staying. However, what is equally clear is that for most observers (e.g., academic, journalistic, policymakers) this choice seems so foreign and unnatural to women that there must be an explanation beyond simply that women want to fight for their respective causes. As a result, women are duped into being "cannon fodder" as they are tasked with the most dangerous missions because they are expendable to their leaders' (Cunningham, K. J., 2003: 186).

12 In recent years, the role of women in terrorist groups has been the subject of growing interest for scholars. See, among the most recent works, Gonzalez-Perez (2008); Ness (2008); Whaley Eager (2008). 


\section{Battlefields}

We assumed in the Introduction that the end of the Cold War, together with globalisation, blurred the public-private divide and, as a consequence, also internal and external borders are blurred; and the border between war and crime is becoming ever more permeable and elusive: the new wars are both local and global, and they are different from both traditional inter-state and civil wars. This evolution inevitably rebounds on the way of conceiving the spaces of war - forcing a reconsideration of the very meaning of 'battlefield'. Violence, in fact, requires spaces in which to manifest itself, and it interacts with those spaces in various ways. Throughout the twentieth century, the tendency to eliminate any residual distance between civilians and the military encouraged the protagonists of war to transcend the same physical spaces which, for centuries, states had struggled to establish; and as a result, effectively eliminated any areas which, until then, had been immune from conflict or safe from massacres. This evolution complicated the task of battle planning to the point where US military experts were forced to adopt a new concept, termed 'theater strategy', to define the arena in which a conflict will take shape; or rather, the perimeter within which the various actors will operate and the limits to which they will be subjected: 'The theater strategy should describe the regional end state and the objectives, ways, and means to achieve it. The theater strategy should begin with the strategic estimate. Although there is no prescribed format for a theater strategy, it may include the commander's vision, mission, challenges, trends, assumptions, objectives, and resources. [...] To support this goal [the advance of US interests], theater strategies normally emphasise security cooperation activities, building partner capacity, force posture, and preparation for contingencies. Theater strategies typically employ military and regional engagement, close cooperation with the Department of State (DOS), embassies, and other federal departments and agencies as ways to achieve theater objectives. Theater strategy should be informed by the means or resources available to support the accomplishment of designated end states and may include military resources, programs, policies, and available funding' (Joint Publication (JP) 5-0, 2011: II, 7).

At the end of the nineteenth century (and with the exception of some early experiments in amphibious operations), technological limitations ensured that wars were waged either on land or at sea. From World War I onwards, however, almost every geographical dimension came into play, from deep beneath the waves to high in the heavens above. As a consequence, war became an integrated exercise among the various branches of the military - the army, navy and air force - which increasingly merged and coordinated their actions, even if that meant losing, at least in part, the autonomy of their command systems (Gray, C. S., 1999; Liddell Hart, 1967). Here, we should recall one of the most well-known examples from history, operation Overlord, the landing of the Allied troops in Normandy on June 6, 1944, when the largest aerialnaval apparatus in history was deployed: around 4,000 ships (both transport and 
landing craft, and war ships); 4,900 fighter planes and 5,800 bombers; 156,000 soldiers who landed or were transported by air to the five beaches chosen for the invasion (Barbier, 2007; Wieviorka, O., 2008).

Finally, in the aftermath of Cold War, a new wave of technological innovations, especially in the area of communications between divisions on the battlefield, introduced a virtual space with the so-called 'net war'. These developments led the Pentagon, in particular, to build on the idea - which Soviet military theorists had been discussing since the mid-1970s - of a real 'revolution in military affairs' (RMA) meant to promote drastic reductions in the human cost of waging war. ${ }^{1}$ RMA is 'what occurs when the application of new technologies into a significant number of military systems combines with innovative operational concepts and organisational adaptation in a way that fundamentally alters the character and conduct of conflict [...] by producing a dramatic increase - often an order of magnitude or greater - in the combat potential and military effectiveness of armed forces' (Krepinevich, 1994: 30).

Despite this, today all wars still confront the question of territory, and thanks to the simple fact that human societies are geographically defined, and always require an outlet on dry land. To cite one of the most basic and enduring tenets of military strategy: 'land matters most'. Among other things, this offers an explanation as to why even considerable air and naval superiority are at times insufficient for a great power to defeat a much weaker enemy; and why, from Sun Tzu onwards, strategic thinking has always considered defence to be more important than offense. If the conflict is carried onto the adversary's terrain, the soldier - an infantryman - becomes the protagonist; and the main variable is the nature of the places where the battle will be fought. The 'friction' of war - that is, the difference between an ideal strategy and the one that is actually applied on the battlefield - makes itself felt and becomes an important factor in determining the outcome (Clausewitz, 1976: Book 1, chpt. 7). Any hill may represent an objective to be conquered at all costs; the hydrography of a place (the location of its rivers and lakes) and the altitude and geography of the surrounding regions can impose long deviations on carefully planned routes; and meteorological conditions - something as simple as the weather - can influence the deployment of troops. Furthermore, on the battlefield itself, much is determined by the perfection of literal and figurative geometries. Inaccuracy in artillery and air force targets can result in the massacre of one's own troops. The speed of an advance must be calibrated to avoid overextension in the logistical chain: a delay or lack of provisions could transform a prospected victory into defeat. It is worth remembering the Vietnam War's Tet offensive, which remains the most elaborate and (according to the enemy) the best planned land

1 As one can easily imagine, the body of literature on the revolution in military affairs is immense. See, most recently: Baylis, Wirtz, \& Gray (2013); Kinross (2008); Sloan (2008); Snyder (2008); Stulberg, \& Salamone (2007). 
campaign of the entire post-World War II period. North Vietnamese General Vo Nguyen Giap succeeded in what many considered to be an impossible endeavour, leading regular army divisions and the Vietcong guerillas in a fast-paced siege on Saigon, Hue, and Khe Sanh (Allison, 2008; Anderson, \& Ernst, 2007; Wilbanks, 2007).

\subsection{Permanent and Temporary Spaces}

The history of violence is a succession of attempts at regimentation - both in the sense of containing the use of force, and, when necessary, directing it toward a determined target or enemy. In order to achieve this goal, over the course of its evolution the state has defined the spaces of war with increasing clarity. Initially, these spaces were for the most part temporary. An army of mercenaries would be recruited for the occasion only to be dissolved at the end of the conflict; and during it, would live in (and at the expense of) the territory, in camps or temporary fortifications. Over time, however, the growth of monarchies allowed for the creation of permanent installations, such as military academies, garrisons (at home and in the colonies), and arsenals. Extraordinary developments in the architecture of fortifications made possible, especially from the seventeenth century onwards, by increasing revenues in state treasuries - favoured this process, which advanced in lockstep with the growing bureaucratisation of civil and military apparatuses. Battles consisted of sieges of these 'dedicated' facilities; or, more frequently, took place in the open, far from inhabited centres and citizens. The experience of the Thirty Years War, which devastated the entire continent of Europe between 1618 and 1648, perhaps served as a lesson, prompting governments to keep the places of war and peace separate (Pagès, 1970; Parker, G., 1984; Polisensky, 1971; Wedgwood, 1981).

Through World War I, the space that separated combatants from non-combatants was represented even on the battlefield as a 'no man's land' - an area where enemy soldiers could meet to agree on a ceasefire, or even to fraternise, an attitude which, unsurprisingly, was abhorred by the military leadership (Jürgs, 2003; Leed, 1979). During World War II, the aerial bombing of cities and partisan warfare once again eliminated the barriers between civilians and the military. Yet, until the end of the Cold War, military architecture - in particular that of the superpowers - remained largely unchanged. Over the past two decades, however, there has been a significant inversion of this tendency, evidenced above all by the fact that approximately seven million soldiers throughout the world have been demobilised since 1989 (Singer, 2003: 49-70). In the case of the former USSR, the dissolution of the regime brought about the total collapse of the military apparatus. The network of military bases deployed throughout Soviet satellite countries simply disappeared: the 565,000 soldiers stationed in Eastern Europe were withdrawn in the beginning of the 1990s; all 116,000 troops deployed to Afghanistan were demobilised over the course of a single year (1988-1989); and the 65,000 soldiers stationed in Mongolia returned to Russia in 1993; 
as did the divisions which had been deployed to Cuba and Vietnam - as of January 2014, Russia retained only a few bases in eight of the former Soviet republics.

In the USA, the first few years of the post-Cold War reorganisation of the military apparatus corresponded with both budget cutbacks and a reduction in the number of active service members (for example, the 244,000 soldiers deployed in Europe were reduced by more than two-thirds in 2000); but ultimately, the downsizing focussed chiefly on the closure of military installations (Calder, K. E., 2007). ${ }^{2}$ The Base Realignment and Closure Process (BRAC) was first established in 1988 and consisted of five rounds, the last of which began in 2005, well after the declaration of the GWOT. Though well-planned and executed, the process of restructuring bases was not without significant social consequences. American military bases are selfsufficient units which may include housing for members of the military and their families, as well as schools, hospitals, and barracks for the police and fire services. ${ }^{3}$ Service members lead a relatively circumscribed life with its own rules and habits, but these installations represent a significant economic resource for the surrounding communities, both in terms of employment possibilities and consumption. Each round of BRAC closures entailed high social and economic costs: military families had to be transferred and locals lost their jobs; the bases and adjacent environment were often heavily contaminated, requiring expensive cleanup and recovery.

In some cases, the USA bases were 'repurposed' as support structures for the National Guard, sites for government offices, or shopping centres. By 2006, more than one-third ( 90 out of 258) of the large bases had been closed, but the consequent savings for the Federal Government were significantly smaller than expected, raising doubts about the usefulness of the policy (Sorenson, 2007; Cooley, A., 2008). With regard to overseas USA military installations: in the decade between the end of the 1980s and the end of the 1990s, about 60 per cent of these bases - most located in Germany, South Korea, and Japan - were either closed or turned over to the host government. This trend was reversed after 2001, when the total number of overseas bases returned to Cold War-era levels, but with a difference: contemporary installations are part of a global network of smaller, more flexible facilities located mainly in new conflict areas (such as Africa, Central Asia, and the Black Sea region) (Cooley, A., 2008). ${ }^{4}$

2 France and Great Britain are no exception: the former maintains a few installations in some of its former African colonies; the latter was ahead of its time when it enacted a 'complete withdrawal East of Suez' between 1968 and 1976.

3 American bases traditionally consisted of five types - Combat-Support, Mission-Support, Training, Research, and Industrial.

4 More accurate data are available in the annual US Department of Defense Base Structure Report (www.defense.gov), but only from fiscal year 2002 forward. These reports show that the number of overseas military installations reached their highest level in 2004 (902), and then showed a continuous decline (with the exception of 2007, when the number reached 823): in 2011, when they had decreased to 611, and in 2014 to 523. 
The reduction in public war-related spaces, which attenuates the presence and visibility of the state as the holder of the monopoly of the legitimate use of physical force, can be realised only through growing reliance on outsourcing: private corporations now handle many, if not all, of the services that the government no longer manages directly, yet continues to need. It is difficult to say whether this represents a permanent change, though the fact of subcontracting services to the private sector - especially those related to research, training, and combat support - necessarily involves a loss of government know-how and skills, something that can be difficult to recover later at a sustainable cost. It should be noted as well that private corporations enjoy a double advantage: the fact that they are operating in an imperfect market - for security services - where competition is considerably reduced and lobbying is highly effective; and the fact that they can change their organisational structure and brand quickly and easily, should that be required in order to adapt to demand or evade legal responsibility (Singer, 2003). Moreover, private military corporations (PMCs) can afford a significantly lighter logistical structure: as they themselves have emphasised, all they require is a database with the names and curricula vitae of soldiers. These men are not in permanent service, but called up as needed; and they are already trained, so a short briefing is sufficient to inform them of the content of their mission and furnish them with the weapons they will be using. The procurement of combat vehicles and heavy weaponry does not officially concern them, but, rather, is the responsibility of the client, who may acquire this hardware new, directly from the manufacturer; or used, from arms dealers operating in the gray or black market.

It is worth emphasising that this public-private shift is of relevance here chiefly because of its tendency to blur the boundary between the spaces of war and the spaces of peace, scattering among the civilian headquarters of private corporations departments and functions that were previously managed exclusively by the military bureaucracy and located in designated military facilities.

Yet in the face of this substantial administrative disengagement, and amidst the globalisation processes aimed at favouring the free circulation of goods and people, the state rediscovered the strategic value of walls. And ironically, it did so only a few years after the fall of the one erected in the centre of Berlin in 1961 became the emblem of the end of the Cold War. The symbolism in this case is not without significance: the act of erecting a wall, like constructing a fortress or a prison, represents a 'display of power', which, as an instrument for the exercise of power, is as effective as the physical structures themselves (Purbrick, Aulich, \& Dawson, 2007). The Great Wall of China played this role in the third century BC; as did the Maginot line in France during World War I (though it was revealed to be entirely useless at the beginning of World War II).

Today's examples include the security barrier which separates the West Bank from the rest of Israel, and the fence in Texas which marks the border between Mexico and the USA. The former, whose final costs could reach two billion US dollars (approximately two million US\$ per kilometer), was intended to be almost 800 
kilometers long. The latter is expected to cover more than 1,000 kilometers. Along the spots considered to be at highest risk for terrorist infiltration (circa 3 per cent of the total length), the Israeli wall consists of cement blocks that are 9 meters high; along the rest of the perimeter, a chain-link fence is used, with long-range sensors buried underground. The area is controlled by remotely operated aircraft (drones) and includes trenches and mined terrain. Passage is permitted only at checkpoints controlled by Israeli soldiers. The Texan border fence, which for long stretches is nothing more than a succession of portable barriers used to block automobile traffic, is equipped with sophisticated electronic video surveillance systems, thermal sensors, and high-powered lighting. ${ }^{5}$

For the Israeli government, the West Bank barrier has achieved its objective. Since the start of construction, attacks in Israel have been reduced by more than 90 per cent; the number of Israelis killed has diminished by 70 per cent; and the number of Israeli wounded is down 85 per cent. Meanwhile, the social cost of the wall has been borne almost entirely by Palestinians. In the first place, in terms of physical containment: Palestinians are prevented from accessing their workplaces, fields, and schools beyond the wall unless they walk miles to pass through Israeli checkpoints. And secondly, in terms of time: even once the checkpoint has been reached, wait times for crossing can be many hours long (Pullan, 2007). In the case of the Mexico-US border fence, between 1995 and 2006 there were more than 350 confirmed deaths of attempted migrants each year, with an annual average that doubled between 1999 and 2005. Not visible in these statistics, are the scores of people who went missing in the desert and for whom we have no reliable figures (Nevins, 2008).

But there are many other examples both of external and internal walls barricading territories: 'Post-apartheid South Africa features a complex internal maze of walls and checkpoints and maintains a controversial electrified security barrier on its Zimbabwe border. Saudi Arabia recently finished constructing a ten-foot high concrete post structure along its border with Yemen, which will be followed by a wall at the Iraq border [...], cruder barriers have been built by India to wall out Pakistan, Bangladesh and Burma, and to wall in disputed Kashmir territory' (Brown, 2010: 8). Many other walls have been built or are under construction in Central Asia, and in Africa - the most notorious of which is the border fence in the Spanish enclaves of Ceuta and Melilla, in Morocco: profusely financed by European Union, it was intended to stop immigration and smuggling, but in fact it is nurturing human trafficking by organised crime groups, and the systematic corruption of security guards (Andersson, 2014).

These may be defined as political walls, but there are also security-related walls that delineate social spaces. For example, those which surround the privileged inhabitants of gated communities, many of whom see auto-seclusion as a mark of

5 Much more work has been undertaken on the subject of the Israeli wall. Among the most recent, see Makdisi (2008); Jacoby (2007); Kershner (2005). On the US barrier, see Dear, \& Holzer (2007). 
status as well as a source of security. The residents of gated communities entrust their security to private vigilantes; securitisation, however, may go hand-to-hand with new social control techniques. Over the past decades, many US municipalities have adopted new tools - including off-limits orders, parks exclusion laws, and other applications of trespass law - as an alternative to jail. These new social control techniques, based precisely on rendering more spaces inaccessible to people charged with those new crimes, fuse criminal and civil legal authority, actually increasing the number of behaviours and people defined as criminal (Beckett, \& Herbert, 2008).

Another example of security-related walls (mostly virtual, and yet as concrete as those that are real) are those which isolate ghettos in large Western cities or in the immense peripheries of the megalopolises in developing countries, whose inhabitants are bound to become slaves to the mafias or gangs that control their neighbourhood (Davis, M., 2006). According to United Nations World Urbanisation Prospects, 'in 1990 there were 10 cities with more than 10 million inhabitants, and these so-called "megacities" were home to 153 million people, representing less than 7 per cent of the global urban population. Today, the number of megacities has nearly tripled to 28, the population they contain has grown to 453 million, and these agglomerations now account for 12 per cent of the world's urban dwellers' (United Nations Department of Economic and Social Affairs, 2014: 13). In 2014, 54 per cent of world population resides in urban areas; and most megacities, moreover, are located in the global south: China, India, Africa, and Latin America. In these social environment, violent non-state actors (VNSAs) 'have gained effective control of the means of coercion, and impose their own forms of justice, security, and livelihoods. In such situations - most frequently in informal neighbourhoods where property rights are vague or contested - the community is fragmented and seized by a sense of powerlessness, and the state is absent or corrupted' (Davis, D. E., 2012: 9).

We will return to these, and other, considerations related to the occupation of urban and rural spaces in the next section, but here we wish to underline the fact that, at present, the process of the privatisation of organised violence does not generally produce anarchy, nor can it be dismissed as one of the many forms of de-localisation caused by globalisation (like industrial production or financial capital). Instead, it is triggering new processes of re-localisation and neo-institutionalisation governed by clans, gangs, or PMCs that have nothing in common with traditional, democratic forms of local government, but that, instead, propose updated versions of authoritarian - if not totalitarian - models of dominance.

The emphasis placed on the physicality of violence and the spaces where it is exercised serves to underscore the fact that every area conquered by private groups represents territory that has been removed from state control, and therefore weakens the state's claim on recognition of its status as the single legitimate authority. Irrespective of any judgment on the nature of the state - whether more or less democratic, more or less authoritarian, or more or less corrupt - this kind of spatial transformation entails a double acknowledgement: 1) the state's inability to successfully claim the 
monopoly of the legitimate use of physical force; and 2) its consequent inability to guarantee the rights and obligations of its citizens. This simple fact is important not because of its theoretical implications for the concept of politics, but rather because of its practical effects on the daily life of millions of men and women who, in addition to fearing for their safety during the most acute stages of the struggle between various factions, must also live with a radical sense of social insecurity, without any certainty about who is really governing, and without a clear understanding of the criteria that are being used to determine the allocation of available resources. This explains how, and why, at times the installation of authoritarian and repressive regimes may be perceived as a solution by the majority of a given population: in Afghanistan, for example, the Taliban were initially received favourably precisely because they were considered the only ones capable of bringing stability to the area after two decades of foreign occupation and civil war (Singh Deepali, 2007). Nevertheless, there are instances where not even this solution is feasible.

Colombia, which during the 1980s became the world's largest centre for the production and distribution of cocaine, is one of the most obvious examples of the compartmentalisation of national territory and rationing of its resources. Over the last thirty years, the country has witnessed conflicts among a wide variety of VNSAs: regular military forces, drug traffickers; and three guerrilla organisations: the ELN, Ejército de Liberación Nacional (National Liberation Army); the EPL, Ejército Popular de Liberación (Popular Liberation Army); and the FARC, Fuerzas Armadas Revolucionarias de Colombia (Revolutionary Armed Forces of Colombia), which is by far the largest and most active formation. In addition to these, we must also consider the numerous security groups (which in the 1990s numbered approximately 200) created by individual municipalities in order to defend themselves from guerrilla attacks. It has been estimated that in the decade between 1988 and 1998, these forces were responsible for the deaths of 24,751 people, but in reality the number of victims may actually be much higher: 3,884 are known victims of the guerrillas, while the other 20,887 people are believed to have been killed by other organisations serving a wide variety of interests. Broadly speaking, between 1999 and 2005, the average number of yearly victims was 25,000, the overwhelming majority of which were innocent civilians, who were invariably considered backers of the adversary and therefore a legitimate target for retaliation. ${ }^{6}$

In contexts of this type, not only it is impossible to distinguish the areas designated for war from the spaces for peace, but even the strategic concept of time

6 The greatest number of victims was recorded in 2002, followed by a gradual decrease linked to the process of demobilisation of the main self-defence groups, which began in 2003 and concluded in 2005 with the widely publicised handover of thousands of weapons to the government in exchange for a large-scale amnesty. Colombia has 44 million inhabitants. See Echandía Castilla (2006); Duncan (2006); and Richani (2002). 
is distorted. Military plans have always been decided by the clock. States have always idealised the concept of blitzkrieg - the only war that fit this model, however, was the Six Days War of 1967, undertaken, and won, by Israel against Egypt, Jordan, and Syria - but then had to take into account geographical distances, terrain, and weather conditions, and the precocious aging of even the most revolutionary battle plans. It is worth remembering the Schlieffen Plan for war on two fronts, adopted by the German General Staff at the beginning of the twentieth century, but aborted just a few months after the beginning of World War I. In regular warfare, time is an enemy because the longer the conflict goes on, the more evident any planning and tactical errors become; while in an irregular war, time represents an important resource to be exploited (Gray, C. S., 1999).

In places such as Colombia, chronological time no longer exists. Death is always waiting in ambush, anywhere, and at any moment. The goal of abolishing chronological time and generating a profound sense of existential insecurity was pursued with great incisiveness by (for the most part) totalitarian regimes, but only by investing immense resources into its realisation: the capillary occupation of state institutions and the militarisation of the entire society through the use of a propaganda apparatus of unprecedented proportions and the mobilisation of the entire economic and manufacturing system to run the machinery of extermination, the concentration camps. In the end, the store of accumulated violence exploded into a world-wide conflict (Arendt, 1966). By contrast, today, the same aim may be readily achieved by small groups with a limited budget.

\subsection{Urban and Rural Spaces}

The urban or rural nature of a given territory is destined to be reflected in the direction and management of a war. A propensity to cross the traditional boundaries of belligerence and reduce (or eliminate) the distance between soldiers and civilians assumes different characteristics in the two different contexts. In past centuries, states typically fought pitched battles: first, the divisions of mercenaries (the Spanish tercios) aligned in the classic square formations of pikemen prepared to resist a downpour of arrows and the devastating onslaught of cavalries; then, permanent armies better trained in tactics and linear deployment designed to outflank the enemy. With the advent of field artillery capable of breaking up the adversary's front ahead of the infantry's advance, open spaces became even more important. And they were essential to the cavalry, which was finally relieved of its cumbersome armor and was therefore able to use its speed to sow confusion in the lines of musketeers and create disturbance behind the lines, breaking the supply chain of food and ammunition (Parker, G., 1988). The dilation of distances made possible by the increased range of the weapons seemed like an unwritten, but universally accepted, law designed to delay a close encounter with the enemy, which might entail hand-to-hand combat 
or the sight of wounds and blood, as long as possible. High-altitude bombing or the transcontinental exchange of thermonuclear missiles so often simulated during the time of the Cold War, may also be interpreted as an attempt to use distance to 'sterilise' war, hiding the martyred bodies behind the reassuring and aseptic screen of technology.

Even in past centuries armies resorted to sieges, or (more often) plundering, as a means of guaranteeing soldiers their share of war booty; but events like Moscow being set ablaze in order to block Napoleon's advance, or the street by street defence of Stalingrad against the Nazis, have a special place in history precisely because of their extraordinary nature. By contrast, the sniper killings in Sarajevo or suicide attacks in Baghdad are news stories revisited on an almost daily basis, and in a manner increasingly decontextualised from the setting of war. Particularly in Iraq, suicide terrorists reinterpreted the urban dimension of combat, making it more subversive than ever, killing scores of men and women, and leaving permanent marks on the thousands of the civilians and soldiers who survive it (Cordesman, 2003 and 2008; Keegan, 2004; Murray, \& Scales, 2003). The conflicts of the late-twentieth and early part of the twenty-first centuries, significantly reduced the distance between the warring parties. This is demonstrated not only by the fact that today's so-called 'light' (short- or very short-range) weapons are responsible for the greatest number of victims throughout the world (Bourne, 2007); but also by soldiers' cruel abuse of the bodies of the enemy dead - in the European war in former Yugoslavia (Rastello, 1998) no less than in Africa.

In the absence of careful planning in open field battles and of a clear definition of who the combatants really are, the tendency for violence to concentrate in populated centres is entirely logical and predictable. Most business- and finance-related wealth is localised in the cities, where the seats of power are, and where the greatest number of potential victims live. Like real forests, these asphalt jungles offer combatants infinite possibilities for hiding, and even better opportunities for growth. Cities can reproduce violence almost ad infinitum. Sooner or later, partisans and guerrillas must come down from the mountains to eat, procure weapons and financing, and find new recruits to fill the void left by their dead comrades. Terrorists choose urban objectives if they want to acquire notoriety; rural mafias look to conquer the capital; and gangs fight for territory, block by block, street by street. Even PMCs, no matter how inclined they might be to hide their finances in tax havens, cannot do without branches in large urban centres, because that is where they find their clients. Violence may originate in the periphery, but it has an innate centripetal force that is difficult, if not impossible, to stop.

In war time, much more than in peace time, becomes evident to all the parties involved that sovereignty is linked to a particular point in space, that 'land matters most', and the capital city more than any other location: 'Capitals [...] perform an agglomerating function for all types of resources. This then creates the perception that the capital is a "prize" of significance because it contains all or the majority of the 
underlying productive value of the state. In essence, the capital is a proxy for the state's productive assets. Fundamentally however, the productive value of the capital relies on the continued existence of essential physical and human infrastructure. Bridges, ports, airstrips, lines of communication (roads, telephones, etc.), and buildings make possible the activities that set the capital apart' (Landau-Wells, 2008: 13). Beside that, capital cities 'embody national symbols and myths which act as symbolic resources for entities which can draw on them' (Paquet, 1993: 271-272).

From the end of World War II to 1989 (the time frame that defines the 'old' international system), the two principal domestic forms of organised violence were coup d'état and guerrilla insurgencies. The coup d'état - characterised by a systemic top-down dynamic - took place most often in state capitals and other important cities of a country, with the military occupation of the barracks housing divisions loyal to the regime, of the main seats of the government, and of radio and television stations. Only after having gained full control of the centre, would the leadership go about solidifying its positions in the periphery (Farcau, 1994). One only has to think of the attack on the Palacio de la Moneda and the assassination of president Salvador Allende during the Chilean coup on September 11, 1973 (Arriagada, 1991); or the occupation of the Casa Rosada in Buenos Aires during the Argentine coup, as decisive moments in the establishment of a dictatorship (Farcau, 1996; Pion-Berlin, 2001; Remmer, 1989). ${ }^{7}$

By contrast, guerrilla movements - which, even when directed by a revolutionary elite, are defined by a bottom-up directionality because they cannot survive without solid support from at least some part of the population - form in rural zones, and hide there, forcing the regular forces to come out and meet them on their own terrain. In fact, for these groups control of urban areas normally comes during the final stages of the conflict. In Vietnam, for example, the North Vietnamese People's Army and the Vietcong entered Saigon on April 30, 1975, just as the last American helicopters were plucking US personnel from the roof of the embassy (Anderson, D. L., 2005; Anderson, \& Ernst, 2007; Karnow, 1983). A similar situation repeated itself in Nicaragua, with the entry of the Sandinista troops into Managua on July 19, 1979, following the defeat of Somoza's forces in the countryside (Booth, Wade, \& Walker, 2006; Kruijt, 2008).

One further, and mostly neglected, aspect is worth mentioning, concerning the environmental consequences of wars: conflict of any kind leaves traces on the territory as indelible as those marking the bodies (and minds) of its human victims. According to an estimate from 1978, the Vietnam War produced at least 500,000 disabled individuals among US soldiers alone - nine times the number of the dead. Among them, some of the most gravely wounded were those exposed to the chemical defoliants (napalm) used to destroy the vegetation that offered cover to the enemy.

7 The execution plan of the Borghese coup in Italy in 1970 equally envisaged the occupation of the main political and communication sites in Rome (De Lutiis, 1998). 
These people suffer from severe forms of tumors, as well as the tragedy of seeing their children born with genetic malformations (Anderson, D. L., 2005). It is more difficult to calculate what the costs have been for the members of the Vietnamese population who, in addition to the effects of immediate exposure, have also paid in the form of diseases related to water and ground pollution, as well as the economic legacy of the prolonged unproductivity of lands treated with defoliants. And Vietnam is not the only case, because defoliants are still one of the preferred tools for destroying plantations in the 'war on drugs'.

Only the briefest glimpse into the past reinforces the point with almost infinite examples: from the unexploded bombs dating from World War I which still lay in French fields and, to this day, continue to maim and kill locals as well as the bombremoval experts charged with disposing of a problem created by a conflict fought a century ago; to the many zones in Africa and Asia scattered with millions of antipersonnel mines specifically designed to attract the attention of children who, mistaking them for a toy, are struck down. The minute dimensions and exquisite sensitivity of these mines have rendered any clearing operation prohibitive, both from the points of view of cost and safety (Webster, 1996).

On the one hand, the reality of such devastation forces states to come to terms with the environmental consequences of conflict: in terms of the destruction of natural habitats - in recent years, related especially to the use of depleted uranium (White, 2008) - and excessive use of resources, all factors that only perpetuate the vicious circle of deterioration and poverty. The most recent studies demonstrate that, in this case, technological progress only seems capable of proposing models of 'unsustainable development', even when the wars appear to be motivated by humanitarian goals (Cooper, \& Vargas, 2008; Shambaugh, Oglethorpe, \& Ham, 2001; Tucker, \& Russell, 2004).

On the other hand, it is important to consider what remains once the conflict is over, and the population is forced to return to places where the roads have been transformed into battlefields, the houses turned into prisons and torture chambers, and ditches made into trenches. The visible traces of death and destruction - the cement ruins of bombed-out cities, the metal wrecks of tanks or destroyed planes that every conflict leaves behind - are, in the anthropological sense of the term, contaminated. ${ }^{8}$ These disputed places will continue to generate competing interpretations and recollections, and preserve the memory of the violence that they witnessed. Some of these will become sites of public commemoration and collective rites of grief and remembrance in which the state plays the role of officiant. But the local inhabitants may have to engage in private forms of grief in order to process the

8 This is quite a new field of research whose main periodical is the Journal of Conflict Archeology, Brill, Boston. 
sorrow and suffering those places recall for them personally on a daily basis (Bevan, 2006; Purbrick, Aulich, \& Dawson, 2007).

Moving now to the environmental context in which emerging VNSAs operate, the post-Cold War era - with the obsolescence of major wars (Mueller, 1989) - presents some novel characteristics, although some of today's processes obviously have their roots in the time before the fall of the Berlin Wall. The new geography of urban spaces is characterised by a growing institutionalisation process of a series of groups, which deserve some more specification. VNSAs power to pursue the military occupation of urban spaces depends, in fact, on four main factors:

1. the ability to guarantee continuous control over the territory of settlement seen, in Weberian terms, as the effectiveness of power, measured by the ability to obtain obedience;

2. the level of structure in the group, either in strictly organisational terms, or from an 'ideological' point of view, in the broad sense of the elaboration of a subculture, original at least in part, and capable of offering an identity and a sense of belonging to potential recruits;

3. the degree of the group's interaction (or its true integration) with its surroundings, or the ability to establish relationships with representatives of the local and national political and economic systems;

4. the group's ability to penetrate international networks of the illegal economy.

Once it has been set in motion, this process of institutionalisation is difficult to reverse because preserving the organisation becomes the main priority of the groups in question. This has been observed in some Chicago gangs, but is even more evident in groups, such as mafias, that feature a particularly consolidated subculture. The need to ensure the survival of the organisation helps explain why leaders of these groups seek to consolidate consensus through a variety of methods: by assuming the role of mediator in interpersonal conflicts that arise within their territory; by taking part in (pagan or religious) rites in their community; and by practicing different forms of patronage such as the public distribution of money, financing social activities, the construction of schools and churches, and so on. Consider Pablo Escobar, for many years the undisputed head of Colombia's Medellin Cartel: in 1989 Forbes magazine declared him the seventh richest man in the world, capable, through his organisation, of controlling 80 per cent of global cocaine production (for an estimated value of $\$ 30$ billion a year).

Architecture plays a fundamental role in the VNSAs' institutionalisation process. It has been observed, that 'the rise of modern architecture and "the architect" as a god figure - and of architectural history as about the future more than the past - was partly due to the opportunities to rebuild urban centres laid flat by (mostly) Allied air forces' (Bishop, \& Clancy, 2006: 57). Since the beginning of the 1970s, in the USA, both sociologists and urbanists began to build on the idea of planning urban spaces that could be defended against crime (Paulsen, 2013). If we only give a look to 
the Vele di Scampia, on the periphery of Naples, and to all other exurbs or bedroom suburbs of the major European cities, or to the favelas in Rio de Janeiro and the slums of Mumbai, we cannot avoid observing that these programs were largely neglected - and, presumably, in the coming decades, the processes of urbanisation will only tend to intensify, not diminish the uncontrolled proliferation of slums - but we will analyse these aspects in more detail in the Part III of the book.

In the urban environment, moreover, prisons play a leading role in the new geographies of violence. In the USA, for example, the space of a prison and that of an urban ghetto tend to coincide, for the simple reason that the state's recurrent 'wars on gangs' conclude with the arrest and imprisonment of their leaders. Even in a context far removed from the USA, such as that of the Italian island of Sicily, prison has always been integrated into the urban context, maintaining a central role in cities' criminal dynamics. Rather than interrupting the process of institutionalisation of VNSAs, prisons end up supporting it, strengthening the leadership of these organisations and offering them an inexhaustible reservoir for new recruits. It seems plausible to generalise what has been stated with regard to the Brazilian carceral system: prisons 'are more akin to concentration camps for the dispossessed, or public enterprises for the industrial recycling of social refuse, than to judicial institutions serving any identifiable penological purpose - be it deterrence, neutralisation, or retribution, leaving aside rehabilitation' (Wacquant, 2008: 62).

Compared to cities, rural spaces - broadly defined as non-urbanised areas situated far from capitals - have until now offered VNSAs a greater guarantee of immunity, in addition to providing them with greater freedom of movement, either because of the central governments' inability to conquer the entire national territory, or because such a project is unfeasible, or lacks the real interest and material support necessary for its realisation. The strategic importance of these zones essentially resides in the availability of natural resources that central authorities are unable to fully exploit and adequately valorise, and for which they therefore prefer to subcontract - legally, in exchange for royalties; or illegally, by feeding their own private accounts and the corruption of public apparatus. The institutionalisation of VNSAs in this context differs from the same process as it occurs in the city. And there are two types of actors that tend to monopolise the situation: first, the PMCs in charge of defending the interests and investments of the multinational companies that control oil production and the pipeline that stretches from Algeria to Azerbaijan; or those which extract minerals (diamonds, etc.) in Congo, Sierra Leone or Angola, to mention only a few (Avant, 2005; Singer, 2003). Second, there are the numerous militias which serve the narco-dictatorships that control different zones for the cultivation of coca and the opium poppy.

One example is the Golden Triangle, the mountainous zones between Laos, Vietnam, Thailand and Burma, where defeated nationalist troops armed and financed by Europe and the USA found refuge after the 1949 Maoist victory in China. The regimes they installed were able to maintain control of the area with remarkable continuity, 
and even expanded their role in the global drug market during the war in Vietnam (Booth, 1990: chpt. 7; McCoy, 1991; Yang, 1987). Another case is Afghanistan, where opium production began to develop in the 1990s, and found particularly fertile ground among the many tribes and the local chieftains whose power had been encouraged by the central government itself, according to the well-known strategy of 'divide and rule' (Bhatia, \& Sedra, 2008). Since then, the cultivation of opium has increased at an annual rate seven times higher than that of the overall growth of the country's entire economy, thanks as well to the spread of corruption and the continuous influx of weapons and financing from the CIA and Inter-Services Intelligence (ISI), the Pakistani secret services. Despite taking an official stance against heroin, Taliban leaders have done nothing to limit its production, which in any case guarantees them an autonomous and undisclosed source of income. The global price of opium, which between 1994 and 2000 remained essentially unchanged (at US\$ 30 per kilogram), climbed to US\$ 700 per $\mathrm{kg}$ in 2001 (falling to US\$ 350 in 2002). Following the presidential elections of 2005, 13 per cent of the total population of Afghanistan still earned its living by growing opium poppies (Singh Deepali, 2007). Finally, we may cite Bolivia, Peru and, again, Colombia, where, in addition to the income generated from kidnappings and extortions, FARC derives substantial earnings from the protection 'tax' they impose on coca growers (Echandía Castilla, 2006).

\subsection{Spaces of Concealment}

The effectiveness of violence is dependent on the ability of those who manage it to elicit fear - or better, to evoke, in their followers as well as their enemies, the different emotions that reinforce their role: surprise, fascination, respect, terror. On the one hand, then, they must make a public display of their power. For any military regime, parades - as opposed to the large maneuvers reserved for a more limited audience have always served the function of building credibility in the eyes of supporters, as well as warning adversaries. From the mass demonstrations of the Fascist and Nazi regimes, to the marchpasts in Red Square or in Tiananmen Square, to the processions led by children dressed as martyrs organised by Hezbollah - all feature the same choreography of perfectly aligned divisions stepping in measured march: burlesques of violence.

On the other hand, the use of violence requires concealment and dissimulation to feed the idea of a secret apparatus capable of controlling the population's every movement, continuously generating reciprocal suspicion, and encouraging and rewarding informants. It has been observed that power tends to use secrecy to protect itself, and the sphere of secrecy tends to be as broad as the degree of autocracy is high (Bobbio, 1987). The torturer blindfolds his victim not only to protect himself from being recognised, but also to increase the victim's fear: the source of suffering is unseen and unknown, and thereby all the more daunting. Authoritarian regimes 
'disappear' their opponents (actual or imagined; present or potential), making it impossible to establish responsibility for, and erasing all evidence of, crimes that might incriminate the regime in the eyes of international public opinion. Above all, this practice dissuades everyone else from criticising the authorities: in the absence of any form of confirmation regarding their loved ones' status (whether dead or imprisoned), the family and the friends of the disappeared tend to abstain from any form of protest for fear of worsening the conditions of a possible detainment.

For years, this situation was a daily reality in the countries that have experienced state terrorism. In the first four months following the 1973 coup d'état in Chile, tens of thousands of citizens were arrested and tortured, and approximately 2,000 were killed. 800 more were declared dead in 1974, and another 467 victims were confirmed in the waves of repression that followed between 1981 and 1990. The DINA, Dirección de Inteligencia Nacional (National Intelligence Directorate), the nucleus of the state's repressive apparatus, was established as a secret society and eventually employed up to 4,000 agents, as well as thousands of informants and collaborators. Centres of detention and torture were opened in different areas of the country, some close to the capital, such as Londres 38, set up in the building that had been the main seat of the Socialist Party; or Villa Grimaldi, an estate confiscated from one of the supporters of President Allende. At least 5,000 kidnapped people are known to have been held there, 240 of whom died as the result of torture. The bodies of the victims were buried in secret (often in mass graves), thrown into rivers, or even dumped from airplanes flying over the open ocean or high above the Andes. In Argentina, the number of the victims of the coup d'état of 1976 was even higher: 14,500 opponents of the regime were jailed in the five main detention centres (one of which, Vesubio, was built inside a summer vacation resort) from which the bodies of 3,800 people were recovered. Overall, the desaparecidos numbered between 13,000 and 30,000, depending on the source; 70 per cent of them were men and 30 per cent were women, among whom 10 per cent are known to have been pregnant (Wright, T. C., 2007: chpts. 3-4). Argentina would go on to distinguish itself through the perverse practice of allowing imprisoned mothers to give birth before killing them in order to offer the children up for adoption by the members of the military regime (Gorini, 2006; Abuelas de Plaza de Mayo, 1997).

The existence of an invisible area of power is not a characteristic unique to autocratic states. Democracies maintain shady areas as well. First of all, there are spaces institutionally defined by the tasks assigned to intelligence agencies, with their public and secret centres, their official sections - those with limited access, and those entirely concealed - and their budget, only partially subject to effective legal scrutiny (Johnson, \& Wirtz, 2008). The legitimate goals of these agencies' interventions are neither always clear, nor definitively determined. Think of the public debate that took place in the USA over the expansion of powers that permitted authorities to investigate and intercept not only telephone conversations, but also email, as provided for by the Patriot Act - approved by President Bush on October 26, 2001, and renewed on several subsequent occasions. The debate pitted those 
who considered the measures fully justified during the GWOT against those who, on the contrary, interpret US citizens' right to privacy as inalienable (Foerstel, 2008). A history rich in covert actions and efforts to deviate the course of investigations or throw them off track entirely - especially during the Cold War, when everything seemed to be allowed - has contributed to blurring the picture even more, offering plenty of 'evidence' to supporters of conspiracy theories.'

These permanent intelligence and secret service agencies occasionally join forces with other, provisional ones, typically during particularly grave emergencies. The most famous example is the Executive Committee of the National Security Council, set up by President Kennedy in utmost secrecy during the Cuban Missile Crisis of 1962. Council members were not allowed to reveal their activities even to family members, and accessed the White House through underground tunnels in order to avoid being seen by the press. In a departure from standard practice, the President named the Attorney General, his brother Robert Kennedy, to the Committee and confided only to him the fact that an audio recording system had been installed in the Oval Office and the Cabinet Room. ${ }^{10}$ In a similar vein, during the kidnapping of Aldo Moro in 1978, the Italian government established an ad hoc Committee for Ministerial Coordination. Among the members of that group, which met regularly during the entire period of the crisis, were senior officials in the Italian police force and secret services, many of whom also belonged to the covert Masonic lodge, P2, a fact that only came to light many decades later (De Lutiis, 2007; Drake, R., 1995).

Like the states, guerrilla movements used invisibility and camouflage extensively after World War II, making them the guiding principles of their strategy (Guevara, 2009; Laqueur, 1998). In many of the European countries under German occupation, the activities of resistance movements had paved the way, often providing the Nazis with a pretext for civilian reprisals. Partisans did not have uniforms, and, often, were not identifiable as combatants; they hid among the population, using the element of surprise to attack enemy forces (Schmitt, 2007). Yet these were relatively small groups of combatants.

In the 1960s and 1970s, on the other hand, some attempts to give rise to true people's wars that united military action and mass political indoctrination were made, mainly in Asia and Latin America. In Vietnam, the concept of concealment and infiltration of enemy lines was embodied in one of the most ambitious architectural projects ever realised: the Ho Chi Minh trail, which ran from North to South Vietnam, and branched out to Cambodia and Laos as well. In many places, the trail ran underground, hiding hospitals, weapons and ammunition depots, and stockpiles

9 For the history of the most well-known of these agencies, the CIA, see Monje (2008). 10 Stern (2005) is dedicated entirely to the reconstruction of the evolution of this crisis, and is based on the analysis of the conversations taped during the secret meetings of the ExComm (Executive Committee of the National Security Council). See also Munton, \& Welch (2007), chpt. 3. 
of fuel. In some ways, it represented a reinterpretation of the trenches of World War I, which crossed the entire territory of Europe like one, long scar; but the trail also imitated the far more ambitious (in scope and purpose) underground bunkers and silos that constituted the new geostrategic map of thermonuclear war, constructed with very different resources and technologies.

In this case as well, the main innovation represented by many of the new VNSAs is their capacity to promote those aspects which were previously circumscribed by the confines of a strategy (albeit one of long-term war), to the level of a system. Guerrillas camouflage themselves simply by continuing to do their daily jobs as peasants; mafia members can spend their entire lives in hiding (perhaps in remote, or relatively inaccessible shelters, at times, even underground, as documented in the press), and terrorists lead clandestine lives, at least in part because very few of them have a job or other lucrative activity to which they could return.

At the end of a war, soldiers come back to their country as veterans weighed down by the experiences and indescribable trauma of the conflict, but also possessing the ambition, and most of the time, the ability, to fully reintegrate themselves into the civilian society to which they belong. By contrast, those who choose to become part of secret organisations decide to exclude themselves from the rest of civil society and to lead, in the best of cases, a double life guaranteed by a double identity. Most mafia organisations do not allow their affiliates to leave, and make clear that such an action represents a betrayal punishable by death. Yet precisely because they are aware of the definitive nature of this choice, mafias guarantee their members forms of welfare that reflect their position or level of rank within the clan: a paid activity, to be carried out in one's free time; payment of legal fees; assistance to wives and children in case of one's imprisonment or death. Many terrorist groups have adopted the same model and, for some time now, have been putting it to work in their own territory - offering, for example, economic incentives to the families of suicide bombers (Palmer Harik, 2005).

One of the few options available to VNSAs is the possibility of institutionalising themselves to the point of becoming a state. This was the experience, at the start of the twentieth century in some American cities, of a few gang members who managed to reinvent themselves as legitimate state administrators of the same territories that, for a long time, they helped plunder. And the same occurs even more frequently with mafia representatives who gain access to the legitimate national or local political arena.

The spaces of invisibility enjoyed by PMCs are different. A first, provisional, dimension corresponds with the places and times of the dirty wars these firms conduct with due discretion in order not to compromise the good name of their public or private clients. The second space, which is for all intents and purposes permanent, is defined by tax havens and numbered bank accounts through which PMCs hide the traces of all transactions with their clients, regardless of the services (from simple consultancy to training, to combat) or goods (arms and security technologies) sold. 
In this case the corporations, together with many other global market actors, both illicit and legitimate, benefit from a structural change originally generated by the decision of international financial authorities, in agreement with the governments of the most important Western states, to abandon the Bretton Woods system in the mid1970s. Fixed exchange rates between currencies were abolished and the circulation of capital was liberalised, which allowed for an unprecedented expansion of private credit (Gilpin, 1987; Strange, 1996).

Such deregulation of financial markets gives a completely new meaning to what we call the 'black market'; that is, the area of exchange that, historically, has always been an essential corollary of every conflict as well as an unlimited source of profits for the organised crime groups which always flourish around its edges. Until then, the black market had essentially existed as a physical place, a centre for the exchange of illegal goods and services. During the 1970s, it went global for the first time, thanks to the worldwide demand for drugs as goods of mass consumption. Today the black market profits from a new, virtual space in which the incomes of individuals and businesses eager to evade tax authorities merge with dirty money generated by illegal trafficking and financing for terrorist groups, contributing to a further reduction of traditional state prerogatives: not only the monopoly of force, but also the power of taxation. Back in the 1960s and the 1970s, 'illegal markets were small and isolated. However large the sums of money derived or however frequent the operations, the black markets and the entrepreneurs who ran them were segregated from the mainstream of economic society and from each other. But what has emerged today is a set of interrelated, mutually supporting black markets [...]. No longer isolated, these black markets are institutionally embedded in the legal economy (Naylor, 2002: 3) but we will draw more on this topic in chapter 6 . 


\section{The Propaganda Machine}

War - we stated at the very opening of the book - is a social construction. We already stressed, in the previous chapters, that this assumption finds confirmation in many different facts. For example, in the need for all societies from different epochs to subject their soldiers to a proper education and training process, so to hone their willingness to obey orders (never turning their arms against the authorities), as well as to overcome their natural inhibition against killing. We also stressed how states, in particular, all along their state- and nation-building process, devoted huge resources to military apparatuses, paying particular attention to the congruence between these same apparatuses and the specific foundations of legitimacy claimed by their sovereign power. A further confirmation of the social and cultural character of war is offered by the fact that, over the centuries, states have invested ever greater resources in the creation and maintenance of propaganda apparatuses aimed at legitimising war. For an eighteenth century monarch, the eloquent output of poets and court historians may have been enough to ennoble his blood-soaked undertakings and satisfy his need for recognition and glory. In a state that still saw itself as patrimonial, and which, therefore, preferred to relegate its security and ambition to armies consisting mainly of mercenary troops, the ability to guarantee continuity of pay constituted a priority far more important than that of providing arguments that justified the cause for which the soldiers were fighting. It was only with the industrialisation of death and the nationalisation of the masses of the twentieth century's two World Wars that the era of the apparatuses of mass persuasion was launched.

The necessities of war force the sovereign power to renounce the privilege of not having to answer for its actions, and instead subjects it to the judgment of those it governs. It is impossible to ask the members of any society or state to fight and die without first persuading them of the inevitability and ethical value of their sacrifice. From that moment on, the act of creating a consensus in favour of the war, justifying the sovereign power's positions and finding fault with those of its opponents, becomes a defining element of the war's eventual success. We will see in the following pages how each phase of the conflict is characterised by its own specific language which draws upon a vast repertoire of tools to reach the target audience in the most effective manner. Before that, however, it seems necessary to outline a definition of the concept of propaganda, based on four elements: the propagandist, the audience, the content, and the media. 


\subsection{The Elements of Propaganda ${ }^{1}$}

Propaganda was originally defined as the use of stories, images and other forms of social communication to control or manipulate public opinion by awakening animosity toward the enemy, and feelings of brotherhood toward allies (Lasswell, 1971; Lasswell, Lerner, \& Speier, 1970-1980). Since then, newer, broader definitions have been proposed, and the use of propaganda has been extended to areas other than war, further blurring its boundaries (Cunningham, S. B., 2002; Jowett, \& O’Donnell, 1986). One way to compensate for what some consider an excessive expansion of the concept is to limit the 'who' and 'how' of propaganda, distinguishing on the one hand between the propagandist and the target audience; and on the other, between the content and the media used to transmit it.

\subsubsection{The Propagandist}

With regard to the agents of information, the most notable trend during the twentieth century was the shift from the volunteer to the professional propagandist. During World War I, governments firstly appealed to churches or intellectuals (at best organised into voluntary patriotic associations). The propaganda in favour of war organised by religious institutions, sometimes also independently from the government, was particularly questionable since it originated forms of clerical nationalism which subjugated the most intimate religious feelings of soldiers to love of the country (Schweitzer, 2003). The more successful this operation was, the more concrete the risk that the political disappointment which often accompanies the experience of combat could also involve the loss of faith and the abandonment of the church (Snape, 2005). This voluntaristic approach quickly ceded ground to a more careful kind of planning entrusted directly to ministries, or at least coordinated by them.

In Great Britain, the Department of Information was in charge of psychological warfare against the enemy, while the National War Aims Committee managed domestic propaganda. In the USA, on the other hand, these tasks were shared by both a civilian (the Committee on Public Information) and a military agency (the Propaganda Section

1 The analysis that follows has no ambition to be exhaustive, but only proposes to provide a 'operational definition' of the concept of propaganda, which might serve as a guide in the rest of the chapter. In the same manner, the bibliography used here cannot be considered exhaustive in the context of the debate and applied research which has produced, especially immediately after World War II, a boundless body of literature. The sources cited are limited to those we considered to be particularly relevant to the topics discussed in this text. 
of the American Expeditionary Forces). ${ }^{2}$ Germany would later attribute its defeat, in part, to the inadequacy and nonprofessional nature of its propaganda apparatus, an error that the next regime was careful not to repeat. The Nazis developed their consensus-building machine to unprecedented levels of efficiency, not only by fully exploiting the potential of new instruments of mass communication (primarily the radio), but also through the rediscovery and amplification of the effects of traditional manifestations such as mass rallies and military parades, which, thanks to the coordinated use of sophisticated choreographies, evoked and embodied the myth of Teutonic power (Herf, 2006; Kallis, 2005; Uziel, 2008; and Welch, 2000). An entirely different propaganda and mobilisation model was proposed by Japan, defined as 'democratic fascism' and considered even more efficient than German and Italian models: 'Japanese propaganda demanded active participants, not dronelike followers'; the propagandists 'came from different backgrounds, liberal and conservatives, and the range of their experiences and attitudes supports the label of "democratic fascism"' (Kushner, B. 2006: 26 and 32).

The Cold War, which by definition was destined to be fought on the virtual level of (false) communication more than on the battlefield, pushed the conflict's protagonists to invest in the professionalisation of state apparatuses and, at the same time, fostered the increased involvement of civilian institutions (one is reminded of the phenomenon of McCarthyism in the USA).

The collapse of the Berlin Wall and the subsequent proliferation of violent nonstate actors (VNSAs), on the one hand brought about the rediscovery of forgotten figures, such as the volunteer: yesterday, a member of a patriotic association; today, a supporter of terrorism or a recruiting member of a gang or a clan. On the other hand, these events also favoured the growing differentiation of professional roles. The traditional propagandist may still be a functionary of the secret services, expert in covert operations and psychological warfare, but today, this figure abounds in other contexts as well: a marketing professional charged with selling the services offered by private military corporations (PMCs) as peacekeeping operations is a propagandist; as is the information systems specialist who manages Internet data distribution for opposition movements or disseminates the video testimony of young people about to sacrifice themselves as martyrs to their cause.

This 'martyrdom mythology', with reference to Iraq, has revealed that 'the dominant narratives in insurgent videos, audio recordings, online magazines, and biographies revolve around three themes that are often presented in a sequence as if to show a play in three acts. Act one depicts the unmerciful humiliation and

2 On the subject of propaganda in Great Britain and the USA, see Buitenhuis (1987) which deals particularly with the involvement of writers and intellectuals. Axelrod (2009) reconstructs the human and political experience of the first US propaganda minister, George Creel. See also Laurie (1996); and, on the peculiar element of the Anglo-American relationship, Cull (1995). 
suffering inflicted on Muslims in Iraq and throughout the world, suggesting that there is a conspiracy by the Western "crusaders" to target Muslims and single them out for punishment. The second act shows the impotence of existing Muslim regimes and their collusion with the West, suggesting that they are not the true leaders of the Muslim world, but servants of their Western "masters". The final act insists on the inevitability of Muslim victory because pious and heroic cadres have stepped forward to redeem the suffering and humiliation of their fellow Muslims through faith in God, sacrifice on the battlefield, and righteousness in their cause. These three narratives are sometimes presented separately, but often they are woven together to suggest a problem, a cause of the problem, and a solution to the problem' (Hafez, 2007: 96).

\subsubsection{The Audience}

In reference to the audience, it is important to note that propaganda always targets a specific public. In general, it may be directed at influencing either domestic or foreign opinion. In the first case, the propaganda must contribute towards maintaining high morale among the troops and the civilian population, while simultaneously combating internal dissent (Thomas, W. H. Jr., 2008). In the second, the goal is to terrorise the enemy population and foment opposition to the enemy regime.

The attacks of September 11, 2001 drove many scholars to assert that, in contrast to traditional warfare, terrorism introduces an element of novelty by making violence itself the main instrument of propaganda. As we already adumbrated in chapter 2, they claim that the victims are not the true objects of the violence; that most of the time, in fact, the victims are irrelevant to the terrorist cause; and that the true goal of the action is to generate a debate among as wide an audience as possible (Tuman, 2010). 'Terrorism, by using violence against one victim, seeks to coerce and persuade others. The immediate victim is merely instrumental, the skin on a drum beaten to achieve a calculated impact on a wider audience. [...] While a political assassination juxtaposes the murderer (or the one who has been ordered to do it) with the victim, the terrorist act is based on an indirect strategy: a randomly chosen or representative victim is killed in public but the ultimate addressees of the victimisation are one or several target audiences: others from the group of the victim, the public at large, or, more narrowly, members of the constituency of the terrorist. In other words, terrorist violence is mainly perpetrated for its effects on others rather than the immediate victims (who might be dead)' (Schmid, 2004: 207).

We may observe, however, that communicative intent is not unique to terrorism: all forms of violence claim a similar function, although it may be expressed in ways that are more or less deliberate or direct. An obvious example is the use that states have made of propaganda to amplify an already explicit message of war. In other words, violence is always the product of a carefully calibrated dose of victims and words, but is actually never aimed at provoking a discussion. If anything, it is designed to produce 
the opposite effect: blocking discussion by emptying the discourse of all meaning in order to reduce it to the rhetorical expressions of a proclamation or invective against the enemy: 'Thought was secondary to speech, but speech and action were considered to be coeval and coequal, of the same rank and the same kind; and this originally meant not only that most political action, in so far as it remains outside the sphere of violence, is indeed transacted in words, but more fundamentally that finding the right words at the right moment, quite apart from the information or communication they may convey, is action. Only sheer violence is mute, and for this reason violence alone can never be great' (Arendt, 1958: 25-26).

With regard to propaganda's audience, what counts most is the complicity and the responsibility of its targets: 'Typically, the propagandee is someone who has little time or opportunity to become well informed about a wide range of social, economic, and political issues; nor can we assume that the average citizen is well enough equipped in intellectual development, memory, and training to become a confidently discerning observer, critic, and discussant. [...] The propagandee, then, both psychologically and behaviourally, is already complicit in this process of being influenced' (Cunningham, 2002: 106). A propaganda machine that is aimed at the masses, and therefore collects (and exalts) only those aspects that each single element shares with the overall group, resonates with the individual who is predisposed to accept its message, either because s/he lacks the time or desire to become better informed, or because s/he lacks autonomy of judgment and simply prefers simple solutions and pre-constituted opinions - because 'of the individual's laziness' (Ellul, 1973: 140). In this sense, propaganda could not exist if there were no one who wished or needed to receive it. The recipient, by inertia or through excessive indulgence, consents to the process of subjugation to 'groupthink' and, as a consequence, shares in its responsibility (Rohatyn, 1988: 79).

\subsubsection{The Content}

Concerning content, propaganda uses symbols that reveal latent responses. The fact that most of the time the text and the images it adopts are fairly coarse should not lead us to believe that propaganda is improvised or superficial and therefore easy to identify and neutralize. On the contrary: propaganda plays on the darkest feelings of the members of a group: inhibitions and fears, as well as aggressiveness and the desire to externalise one's own guilt. ${ }^{3}$ Propaganda does not invent anything, but, rather, simply confirms and validates the prevailing stereotypes within a given community. In

3 The reference made here is to those Freudian studies which consider the invention of enemy to be a self-generated mechanism through which the individual attempts to neutralise strong internal menaces (Fornari, 1974). 
this sense, propaganda is reassuring and comforting even when it predicts a menace to one's own safety. In fact, stereotypes serve a variety of functions: 1) they explain, in the sense that they facilitate the process of categorisation by which the differences (and similarities) between one's own group and those of others are identified; 2) they represent expedients for saving time and energy, because, by linking every individual with a group, they allow us to ignore all the different and detailed pieces of information that concern that individual; 3) they embody shared beliefs, or those which are in line with the prevailing opinions in the group of origin - if everyone developed their own, different stereotypes, no one would pay any attention to them (McGarty, Yzerbyt, \& Spears, 2002).

In the next section we will return to the questions of how stereotypes that are traceable to the context of inter-group conflict are conceived and what elements nourish them. Here it is sufficient to observe that propagandists accomplish their mission the moment they prove themselves capable of convincing the public that the enemy, who- or whatever that may be, is the one responsible for starting the war and thereby ending a peace that was profitable for everyone (Lasswell, 1971: chpt. 4). To reach this goal, the propagandist must compose messages whose content is at once: 1) informative, rich in the kind of detail that will spread easily in an environment already saturated with news (the best audience for propaganda is actually not one that is poorly informed, but, rather, highly exposed to the media blitz); 2) plausible, both 'empirically' (anchored in reality), and 'logically' (conforming to the stereotypes prevalent in the group); 3) immediate, so that it discourages any reflection and subverts the development of critical thinking. In addition, the language of propaganda will be increasingly impoverished and degraded in order to transform it from a vehicle of communication linking thought to the material world into a simple impulse intended to generate reflex responses - to such an extent that it could more precisely be defined as pseudocommunication (Cunningham, 2002: 177). In order to spread hate, in fact, the slogans and epithets must function as Pavlovian stimuli that lead recipients to accept an order to kill the enemy, and reject any element or information that does not fit into the scenario that the propagandist has constructed.

Today's VNSAs are not exempt from these dynamics. On the contrary, the identification of an easily stigmatised enemy in most cases constitutes an indispensable factor of legitimacy, if not a raison d'être. Mafias, gangs, and terrorist groups feed the idea that an omnipresent adversary exists and must be opposed, and that one's own group must be protected from the risks of infiltration by institutional agents (Armao, 2000: chpt. 3). The public enemy may assume the semblances of a political leader, a prosecutor, a policeman (or a soldier), or a journalist, according to the propagandist's needs. The private enemy multiplies itself by the number of groups competing with VNSAs for control of the same territory or illegal markets. Two of the best known stigmatised enemies are the 'rat' or 'snitch' in mafia culture and gangs, and the 'infidel', for terrorist groups. 
PMCs also make extensive use of propaganda to fuel the stereotypes that are essential for the development of their markets. As an example we might cite the endless refrain from advertising for private security and surveillance services for homeowners and the residents of gated communities that plays heavily on the perceived threat of delinquency as personified by the immigrant, the homeless, and any number of marginalised figures that populate the urban landscape.

\subsubsection{The Media}

The fourth and final point concerns the media. In order to convince its audience of the reliability, plausibility, and immediacy of its messages propaganda has always made as much use of words as images. In its mid- to long-range work, aimed at implanting a certain opinion in the target population, it prefers the former, and applies the latter to consolidate those opinions by appealing to a more emotional sphere. In the twentieth century, educational institutions played a decisive role in lending substance and historical weight to the hawkish culture of certain political circles in western democracies, as much as they supported totalitarian regimes in their efforts to indoctrinate the masses and militarise society. ${ }^{4}$ The literature on propaganda, however, has always focused more attention on the instruments of mass media. From this perspective, the most relevant issue today is the decline of traditional print media and the advent of new media, a problem which, with increasing frequency, seems to be resolved through the concentration of newspapers, television networks, and web sites in the same hands.

In reality propaganda specialists have always considered a multi- or pan-media approach as the ideal. During World War I, daily newspapers gave ample space to official rhetoric (Paddock, 2004), as well as the vignettes, caricatures, and political cartoons which, through posters and postcards, reached a much wider audience both among soldiers and the civilians back home behind the lines (Paret, Pe., Lewis, \& Paret, Pa., 1992). World War II witnessed the boom not only in radio broadcasting, as the chief protagonist in the diffusion of information (and counter-information), but cinema as well, which played an important role through newsreels, and above all, films. Movies were especially effective, exploiting the charisma of screen actors to reinforce the credibility of the propagandistic message (and the stereotypes associated with it) (Fyne, 2008; Rollins, \& O’Connor, 2008; Earhart, 2007). The Cold War (at least in the first two decades before détente) prompted further advances in the use of radio

4 It should be mentioned that in the recent years this subject has very much been back in fashion, but almost exclusively when referring to Islamic schools and their supposed role in supporting terrorism. See, among the most recent works, Fair (2008a); Noor, Sikand, \& van Bruinessen (2008); Malik (2008). Fair, \& Ganguly (2008) in a sense reverses this perspective by analysing the dynamics among believers, insurgents, and military forces when a conflict is directly related to holy sites. 
(Parta, 2007) and cinema (Shapiro, 2002) as vehicles for information dispersion; and also saw the advent of television, whose propagandistic possibilities were recognised and exploited, though not, of course, to the utmost of their potential, which at that time was yet to be achieved (Schwoch, 2009).

Today, in the context of the technological divide which still prevents the populations of entire subcontinents from accessing the Internet or even just television, radio - an instrument marginalised elsewhere - has reemerged as a major medium for propaganda. From the mid-1980s onwards, for example, in the Great Lakes region of Eastern-Central Africa, almost every new leader has engaged in some form of radio broadcasting, and in some instances such broadcasts have been central to the leader's very claim to power, and to the engagement of the listeners in extremely violent acts (Vokes, 2007). Some authors considered the radio no less than decisive in propagating the genocidal killings in Rwanda, but this hypothesis has been criticised and accurately tested, bringing to the conclusion that 'the positive evidence of radio media effects is that radio instigated a limited number of acts of violence, catalyzed some key actors, coordinated elites, and bolstered local messages of violence. Based on these findings, it is plausible to hypothesise that radio had conditional and marginal effects. Radio did not cause the genocide or have direct, massive effects. Rather, radio emboldened hard-liners and reinforced face-to-face mobilisation, which helped those who advocated violence assert dominance and carry out the genocide' (Straus, 2007: 631).

This propagandistic eclecticism has acquired new force from the proliferation of VNSAs in the globalised market. Large PMCs, capable of making sizable financial investments into some of the most sophisticated and persuasive forms of commercial advertising, co-exist with terrorist groups that produce low-quality home movies which are then distributed through newspapers or broadcast on semi-clandestine Internet sites. Concerning terrorism, in particular, it has been claimed that the Internet is a 'virtual training camp' for organisations like Al Qaeda. More accurate research, however, also in this case, as before for the role of the radio in Rwanda, demonstrated that 'as of today, the Internet is best viewed as a resource bank for selfradicalised and autonomous cells, which is used alongside more traditional ways of training and preparing. In many cases, jihadi Internet manuals may function as a preparation for real-life training, rather than a substitute for it. This also seems to be a common view among the jihadis themselves. The idea that Internet training material should be used to learn the basics - before moving on to classical jihadi training makes it perhaps more accurate to talk about the Internet as a "pre-school of jihad" rather than a "university"' (Stenersen, 2008: 231). ${ }^{5}$

5 A new debate is developing about the evolving communication strategy of the Islamic State (IS) (Lister, 2015; Zaman, 2015), with particular regard to new social media such as Twitter, and their specific role in facilitating the recruitment of foreign fighters (Klausen, 2015; Carter, Maher, \& Neumann, 2014). 
It is worth noting that another telling debate developed in these last decades, on cyberterrorism: 'When, in the early 1990s, the public at large began to be familiarised with the epitome of all computer networks, namely the Internet, many governments "cried wolf". They considered that its unrestrained diffusion might turn into a threat to national security. For some, it could be seen as a threat - an entry point to the national information infrastructure, which potential adversaries might exploit'. On the contrary, for terrorists and other VNSAs the Internet is still mainly 'a tool to spread their ideas and points of view. The network is excellent for propaganda purposes (whatever that might entail) or to gather information' (Giacomello, 2004: 402). For sure, the web has become one of the most efficient channels for promoting religion; the material ranges from the mere distribution of information ('religion online'), to direct participation in religious practices ('online religion') (Dawson, \& Cowan, 2004).

Finally, gangs have rediscovered and reinterpreted the graphic art of murals (Phillips, 1999) and tattoos (Valentine, 2000) - a kind of self-inflicted graffiti - as a means for communicating challenges and threats to their enemies. And like some other large criminal organisations, such as the Italian Cosa Nostra or the Camorra, urban gangs are now re-appropriating the language of music. Especially Hispanic and Black communities proved to be particularly inclined to use music as a propaganda channel and means of recruitment; so much so to create, starting from prisons, new musical genres - respectively, rap and narcocorridos. Paradoxically, this happened when 'violence in music' had been almost entirely abandoned by the state, which for centuries provided composers with infinite opportunities to celebrate patriotism and militarism (as well as to reap great profits) (Johnson, \& Cloonan 2008).

\subsection{Inventing the Enemy}

The use of propaganda begins long before the start of armed conflict, and concludes long after the end of hostilities. The efficient construction of the enemy's image constitutes an indispensable prerequisite to conflict - the crucial prologue to the 'call to arms' - because it not only permits, but actually justifies, such a radical reversal of values that the act of assassination is transformed from something forbidden and punishable to a necessary, and even inevitable, undertaking, worthy of celebration (Beck, 1997). If, as previously asserted, the propagandistic message presumes the existence of individuals predisposed to receive its content, we must ask ourselves: what are the 'environmental conditions' that facilitate its distribution?

Studies of the dynamics of 'enemy-making' (construction of the enemy) in early childhood development have shown, for example, the extent to which the processes of primary and secondary socialisation influence the propensity for empathy or its opposite (aversion, jealousy and even hatred toward strangers). Empirical research proved that "children who are raised in an authoritarian parental environment will have trouble in assuming responsibility for their own lives and in developing 
separate, independent identities. In the need for guidance and leadership they will escape from freedom by following a leader or group. That is, children raised in authoritarian environments obey, do not protest, and are in need of strict discipline. As a consequence they are more likely to develop prejudiced attitudes. [...] [S]ome parents explicitly teach their children negative characteristics of other individuals or groups and communicate their stereotypes and prejudices. Other children develop stereotypes and prejudices by observation and imitation of their parents. [...] When children pass from infancy and toddlerhood to childhood, the parental roles within the socialisation process gradually diminish and are taken over by a wider social context, including peers' (Oppenheimer, 2006: 274-275). However, unless it provides alternative and more democratic models of co-existence, school only reinforces these attitudes. ${ }^{6}$

Moving from the individual to the collective dimension, the predisposition for accepting the images of the enemy suggested by propaganda has been correlated with the degree of complexity of the society of origin and, particularly, its ability to offer its members multiple and concentric, as opposed to exclusive, loyalties. Open societies - defined as those that are both democratic and borderless (and therefore subject to the material and virtual flows of globalisation) - potentially offer individuals greater possibilities for rejecting propagandistic views of their enemies and instead developing different forms of affiliation and attachment (to the nation and - why not? - to the whole of humanity on the one hand, and to the city, workplace or religious community, on the other). In this way, they reduce the probability of irremediable fractures developing along one of these axes. The multiple or multi-faceted identity entails a relative need to resolve the daily micro conflicts to which this multiplicity gives rise and prevents the individual from cultivating an all-encompassing sense of belonging to only one identity, rendering him or her more tolerant towards strangers.

The preliminary assumption of this theory is that processes of ingroup formation and attachment psychologically prevail over attitudes toward outgroups (Allport, 1954). 'Many discriminatory perceptions and behaviours are motivated primarily by the desire to promote and maintain positive relationships within the ingroup rather than by any direct antagonism toward outgroups. Ingroup love is not a necessary precursor of outgroup hate. However, the very factors that make ingroup attachment and allegiance important to individuals also provide a fertile ground for antagonism and distrust of those outside the ingroup boundaries. The need to justify ingroup values in the form of moral superiority to others, sensitivity to threat, the anticipation of interdependence under conditions of distrust, social comparison processes, and

6 The indispensable work, in which a comprehensive theoretical section is coupled with case studies, such as, above all, the Nazi Holocaust, but also the Armenian genocide in Turkey, the slaughter of the Khmer in Cambodia and mass-killings in Argentina, remains Staub (1989). For an exhaustive introduction into the psychology of ‘enmification' see Rieber, \& Kelly (1991). 
power politics all conspire to connect ingroup identification and loyalty to disdain and overt hostility toward outgroups. [...] [T] hese forces are likely to be particularly powerful in highly segmented, hierarchically organised societies. Societies characterised by multiple cross-cutting group divisions are more likely to provide a context in which ingroup attachments and loyalties are not necessarily associated with outgroup antagonisms' (Brewer, M. B., 1999: 441-442).

The soundness of this theory is further demonstrated by the fact that, in order to sell the image of the enemy to the public, democratic governments must 'close' themselves off preventively, emulating authoritarian systems by proposing a single (or at least prevalent) loyalty that is incompatible with that of the antagonist (Sproule, 1997). The lack of hesitation on the part of the citizenry in accepting this message, and their willingness to maintain a high degree of mobilisation, and, in the case of new elections, reelect the sameleadership, are, at once, indicators of the strategy's success, and also symptoms of the weaknesses present in the democracy itself. This helps to explain, for example, the decision by the George W. Bush administration - obvious especially just after the attacks of September 11, 2001 - to adopt a communicative strategy entirely symmetrical to that of the terrorists, reclaiming the priority of the (presumed) religious identity over the political identity of the American people, only to affirm later the absolute irreconcilability of its own credo with that of the enemy (Brewer, S. A., 2009: chpt. 6; Secunda, \& Moran, 2007: chpt. 7).

That which truly threatens a democratic state's basic stability, propelling it gradually towards the conflictual models typical of so-called failed states, is once again the proliferation of VNSAs within these states. The salient point in this case is that the more the government devolves its legitimate monopoly of physical force, the more it also abdicates its exclusive right to define the enemy, and why it should be fought. In the best possible case - with PMCs, for example - the multifaceted identity of the citizen and of the soldier (who is no longer a citizen-soldier) produces a conflict of loyalties: the contractor answers first to his corporation even while fighting on behalf of his own government. In the worst case scenario - one in which an individual becomes a member of a gang, mafia or terrorist group - every other identity (that of citizen, father, believer, etc.) succumbs to the demands of his 'primary group' to preserve the interests and the unity of the organisation by adopting a model of affiliation whose main source of internal cohesion is nourished by hostility towards outsiders. ${ }^{7}$

But let us return to the process of composing a text designed to convince its readers of the expedience, or indeed the necessity, of killing. The process of inventing the

7 The concept of 'primary group' recalls behaviourist research, particularly that related to military institutions and to electoral behaviour of citizenry developed in the immediate post-World War II period, especially in the USA (Heims, 1993). 
enemy is never unilateral, but rather feeds on the reciprocal perceptions of the groups involved in the conflict, and is distinguished by three main, progressive phases:

1. spreading rumors: rumor is a 'form of communication through which men caught together in an ambiguous situation attempt to construct a meaningful interpretation of it by pooling their intellectual resources. It might be regarded as a form of collective problem-solving' (Shibutani, 1966: 17). Propagandists use the environmental conditions of uncertainty and ambiguity to their advantage and even feed into them, so that the flow of data and news from institutional channels never fully satisfies the public's need for confirmed information. This leaves ample margin for the development of informal modes of collective communication, inevitably based on rumors, stereotypes, and prejudice;

2. forming the stereotype: rumors tend to form into stereotypes related to the traits and attributes which supposedly characterise members of the adversarial group, as well as judgements about their intentions and the motives for their behaviour. In this phase, the components that contribute to the formation of a definitive image of the enemy begin to take shape: 'the structure of intergroup relationships (cooperation-competition, relative strength, and relative status) gives rise to sentiments and behavioural inclinations that must be balanced with the in-group's positive and moral self-image. Any tension between the behavioural inclination and the restraints of a moral self-image elicits a balancing process that results in a construction of the situation in which the tension is resolved by the in-group providing a morally acceptable account for acting in line with the behavioural inclination. Stereotypes or images of the out-group are constructed to serve this balancing function' (Alexander, Brewer, \& Herrmann 1999: 79; see also Alexander, Brewer, \& Livingston, 2005; Fiske, Cuddy, Glick, \& Xu, 2002).

3. strategic definition of the image: through an increasingly direct involvement of the propaganda machine, a set of public perceptions gradually becomes structured into a real strategic image aimed at legitimating 'a construction in which attacking the enemy is the instrumentally reasonable course of action and a moral duty' (Alexander, Brewer, \& Herrmann 1999: 79). This image will accompany participants into the conflict, at least until the reality of combat intervenes and modifies their attitudes and beliefs.

After this process has been completed, the image of the enemy is reassembled according to three main variables: ${ }^{8}$

1. The degree of incompatibility (individual/collective): hostility can extend to specific persons, the leadership of a group, indiscriminately to all of its members,

8 Such variables draw on, and further develop, the discourse on the enemy images outlined above all in Herrmann, \& Fischerkeller (1995). For an initial reconstruction of the idea of enemy, see Armao (2009). 
or even to more abstract and anonymous entities (Beck, 1997). As an example, we might compare the eighteenth century wars between absolute monarchs, whose conflicts did not directly involve their respective subjects, to the many inter-state wars of the twentieth century, whose motives, whether political, economic or religious, led to the planning and execution of mass exterminations of civilians. Incompatibility can also reach high levels in conflicts between gangs, which can be exacerbated by ethnic affiliations. On the other hand, a more pragmatic and profit-driven approach to conflict leads some private actors to sketch the profile of their adversary with greater precision. Finally, terrorists alternate between precise and indiscriminate uses of violence, depending on their objectives. At times, they identify a single representative of the enemy camp as their target; at others, they extend the hostilities to the entire group (whether a people, economic or social class, or faith community). In the first case, they tend to make selective use of violence, hoping perhaps to grow consensus around their group and favour efforts at proselytisation. In the second case, however, they tend to prefer the slaughter, the indiscriminate use of violence.

2. The difference in status (foreign/barbarian): the enemy may be perceived as foreign from a purely political (xenos) or from a cultural point of view (bàrbaros), in which case the image is furnished with the ignominious traits of brutality, irrationality, and mercilessness (Moggi, 1992). For centuries, the exercise of violence was regulated by a code of chivalry which, regardless of the rhetoric, assumed that the contenders were members of the same elite and, despite being destined to confront each other in a duel to the end, recognised each other as such (Kiernan, 1988). Eventually, states consecrated the status of the combatant in the laws of war, according special privileges to the wounded or captured. These principles survived the two World Wars, as well as the radical delegitimisation of the enemy promulgated by the propaganda machines.

Ironically, the image of the barbarian fully re-entered the public discourse only following the definitive triumph of democracy over communism. Even more recently, this image was institutionalised by the American administration, preoccupied with fighting a GWOT, as embodied by the figure of the 'enemy combatant' (Greenberg, \& Dratel, 2008). Such an individual is considered unworthy of the rights guaranteed both the common soldier (the protection of the Geneva Conventions, or, if accused of war crimes, a trial before an international criminal court), and the common criminal (entitled to a hearing before a civil court). Indeed, it has been asserted that this new type of (presumed) enemy - presumably Islamic (Gottshalk, \& Greenberg, 2008) - may be subjected to indefinite detention or targeted killing - for example, by drones.

At the opposite end of the spectrum, many VNSAs seem to share - as seen in chapter 3 - the desire to reclaim the existence of an 'honour code' as a way of safeguarding the security and integrity of the group. Unlike the judicial norms of which they are often little more than a parody, these codes have no universalist 
ambitions: they are applied exclusively to members of the group. On the one hand, they reinforce the contractual link among associates, adding credibility to the organisation's threat of punishing betrayal with death. On the other hand, these 'honour codes' have the effect of reinforcing the stigma of the barbarian attached to anyone who is not a member of the group and therefore cannot share in its particular brand of 'rectitude'.

3. The difference in power (low/high): the enemy is evaluated on the basis of the political, economic, and military resources at his disposal. The resulting image is that of an adversary who can either be confronted at a level of substantial parity, or with a dramatic imbalance of power. In the case of parity, the conflict is represented as a battle to determine the reciprocal positions in the hierarchy of authority, whether it is a case of hegemonic war for the conquest of leadership of the international system, or a dispute between clans for the control of a territory or a drug market. In other words, the adversary is only a competitor for the acquisition of resources considered to be scarce or, in any case, limited. The enemy represents an impediment to one's own expansion in a highly competitive market.

The involvement of ideology, understood as something that also highlights differences in status, is a possibility, but not a necessity. It was used in the propaganda of World War II and the Cold War to emphasise the irreconcilable differences between democracy and forms of totalitarianism. But in prior centuries, dominated by the constantly shifting order among European states, ideology was never evoked. Instead, ample room was given to the complex practice of forming alliances - a practice intended to produce another image, precisely that of the ally (Herrmann, \& Fischerkeller, 1995). Alliances still matter, even on many private-war fronts, because they can have the effect of subverting an expected outcome by altering the relationship of strength (and force) between (or among) the contenders. It is worth noting that in recent years, the scholarly debate on alliances has been replaced by a much more current one, on unilateralism and multilateralism, with a particular focus on different strategies adopted by US presidents (Schlesinger, 2005).

By contrast, in the case of an imbalance or significant difference in power among rivals, the battle cannot avoid taking on the antithetical connotations of conquest or liberation. In the case of conquest, since there can be neither honour nor glory in subduing a defenceless enemy, the conquering power must endow the image of the victim-enemy with every possible attribute of barbarism in order to justify its annihilation or conversion (the colonial paradigm). In the case of liberation, the victims who survive the violence must first find a way to undermine the aura of invincibility with which the conquerors surround themselves, and then construct a new image of the enemy, starting with the atrocities that they have committed. In this way, it becomes possible to legitimise the claims of the elites leading independence movements - mainly, that one should not negotiate with 
the enemy but instead should defeat and expel it from the country - offering at the same time both the meaning and the measure of their victory (the antiimperialist paradigm).

\subsection{News Management}

When the shift from the virtual dimension of an imagined enemy to the reality of combat is complete, propaganda enters into its second phase. The explosion of war marks a point of no return, a fundamental turning point in the course of events. The background, language, and rhythm of the texts that the propagandists must prepare suddenly change, and authors are faced with an entirely new set of problems. The first issue is establishing how far the display of naked violence can be pushed without provoking undesirable reactions from the audience - such as the temptation to turn away from the sight of blood and lose interest in the events, or to actively oppose the carnage. The dilemma, in other words, is how to provide as much news on the events as possible, without allowing this to degenerate at the same time into pornography of violence (Seaton, 2005).

The contrast between a crowd of 'friends' and the crowd of 'enemies' that characterised the narrative during the preliminary phase of the conflict, is now replaced by an opposition of a different sort: the living versus the dead: 'War has to do with killing. The enemy ranks are "thinned". It is killing wholesale; as many of the enemy as possible are cut down. The aim is to transform a dangerous crowd of live adversaries into a heap of dead. The victor is the one who kills the largest number. [...] Each side wants to constitute the larger crowd of living fighters and it wants the opposing side to constitute the larger heap of dead' (Canetti, 1973: 67-68). Here, the communication of violence emulates ancestral rites of end of life passage, universalising them (van Gennep, 1960). The representation of death is neither individual nor accidental, but, rather, collective and intentionally sought by the society itself. In addition to helping witnesses exorcise the fear of their own death, these new rites serve a further purpose: political legitimisation and, wherever possible, the ethical justification of one's own government's actions. ${ }^{9}$

\footnotetext{
9 From this point of view, the recent proliferation, especially in the US market, of television movies inspired by the judicial system, which linger on necroscopic examinations of cadavers, has represented a real means of mass distraction, by its shifting of the attention from the collective, systemic violence to the individual, pathologic kind, and at the same time paradoxically objectivising the victim in the double sense of making her anonymous and reduced to a thing. The dissected body, deprived of any residue of humanity and personality, and transformed into a factor of truth and justice, exorcises life rather than death, absolving the society of all guilt. The popular success of such serials is matched by the scholarly attention given to them. See Allen, M. (2007); Byers, \& Johnson (2009); and Ruble (2009).
} 
The victimised body constitutes the physical and symbolic centre of the stage: the most effective representation of violence in action. ${ }^{10}$ The sight of the bodies of fallen companions (and enemies) is consistently the most harrowing memory survivors report in their accounts of conflict. Indeed, some of the most influential pages of war narratives recount the sufferings of the wounded. In art, the body of a dead soldier is always at the centre of the frescoes which, for centuries, have performed the function of depicting the horrors of battle. Starting with the Crimean War, this task was entrusted to photography (and eventually, as has been observed, to cinema and television cameras), and ever since, the emphasis has been on the images, with words assuming the role of mere commentary. ${ }^{11}$

If the first cameras allowed only individual shots of an immobile subject, the development of lighter equipment capable of modulating timing and aperture made it possible for photojournalists to immortalise scenes that have become icons of the conflicts they record. The increased chromatic variety that became available with the advent of color photography affected the portrayal of blood in photographs (Zelizer, 2004). This, along with the fact that violence demands representation in all possible media, helps explain why photography survived the rise of film and video cameras capable of capturing entire sequences.

The evolution of technology, however, is not limited to the aesthetics of violence. It also affects perception, and influences the formation of individual and social memory (Hoskins, 2004). In fact, overexposure to images can provoke a saturation effect on viewers that actually limits their ability to process and remember them. Even more relevant is the fact that, while a photograph is perceived in a far more direct and immediate manner than a written text, at the same time it cannot assure the same level of understanding of the events it depicts. The risk is that the image becomes a substitute for the story, and that the photographic record of events prevails over all other forms of comprehension, interpretation, and memory: 'Awareness of the suffering that accumulates in a select number of wars happening elsewhere is something constructed. Principally in the form that is registered by cameras, it flares up, is shared by many people, and fades from view. In contrast to a written account which, depending on its complexity of thought, reference, and vocabulary, is pitched at a larger or smaller readership - a photograph has only one language and is destined potentially for all. [...] Nonstop imagery (television, streaming video, movies) is our surround, but when it comes to remembering, the photograph has the deeper bite.

10 We here draw on a piece of research dedicated entirely to the analysis of how the media in the ex-Yugoslavia used the body - in the three examples of the maternal body, the victimised body and the armed body - to give credence to the idea of the ethnic nature of the conflict. See Žarkov (2007). 11 On the subject of war reporting see, most recently, Moorcraft, \& Taylor (2008). See also the now classic work of Knightley (2004), the first edition going back to 1975; and, for a detailed analysis of the photographic medium, Moeller (1989). 
Memory freeze-frames; its basic unit is the single image. In an era of information overload, the photograph provides a quick way of apprehending something and a compact form for memorising it. The photograph is like a quotation, or a maxim or proverb' (Sontag, 2003: 20 and 22; and 1977). Furthermore, the fact that the 'artificial' memory of media archives is incomparably superior to that of 'natural' human memory places the people who control those means of information in the position of deciding which historical events are worth evoking, and which, instead, will be consigned to oblivion. This grants them the ability, if only theoretical, to manipulate the contents of media archives, and, consequently, of collective memory.

So far, we have examined the effects of war on the content of propaganda. Now, another issue must be addressed: the relationship between governments and media outlets destined to collect and distribute this 'news' to its intended audiences (Carruthers, 2000; Cumings, 1992; Starr, 2004). Well-recognised since the earliest days of modern propaganda, this question has assumed fresh relevance in the postbipolar period as 'information warfare'. From the point of view of the institutions that propose its use, this new kind of intelligence campaign consists of an increasingly systematic and global control of the flow of information issuing from the theatres of war. To this end, first of all, the old practice of attaching reporters to military divisions ('embedded journalists'), with the goal of actually limiting their access to the sources, has been resurrected. In fact, there are precedents going back as far as the 1846-1848 war between Mexico and the USA, and the American Civil War, but also World War II, all of which makes it possible to conclude that Pentagon's decision during the Bosnian War and the wars in the Persian Gulf to 'draft' journalists, giving as the need to guarantee their safety, is not at all new (Sweeney, 2006).

Secondly, the management of this information has been entrusted to a new category of 'news management' professionals capable of handling the entire process: from the packaging of the news item, to its airing at press conferences in which journalists become yet another mouthpiece for the administration's message. And none of this excludes the simple exercise of censorship of texts and images that might have escaped previous controls, or the expulsion of reporters from combat zones (Paxton, 2008: chpt. 2). Finally, governments have also developed a strategic definition of 'information warfare' as a kind of ancillary technique for the management of the conflict consisting of the planning of cyber attacks on the enemy's electronic networks, in order to block, for example, the lines of communication between officers and troops. In this sense, the concept of 'information warfare' tends to spill into that of the 'cyberwar' (Rattray, 2001).

There is, nevertheless, an opposite perspective from which to observe the phenomenon of 'information warfare': one that highlights the true revolution in journalism which took place between 1980, the year of the birth of CNN (Cable News Network, the first television channel in the world dedicated exclusively and uninterruptedly to news) (Robinson, 2002), and 1996, the date that marked the inauguration of an Arab-language news and current affairs satellite channel by the 
Qatari broadcaster, Al Jazeera - whose English channel was inaugurated only on November 2006 (Seib, 2007 and 2008). These two events contributed to changing the context in which journalists work, compounding the devastating consequences that the processes of the privatisation of violence have already had on their activity. On one hand, and just to give an example, the success of Al Jazeera has generated an unstoppable chain-reaction, to the point where only in the Middle East there are now 450 satellite channels, most of them private, which has put an end to the public monopoly of information (Seib, 2008). On the other hand, this same proliferation creates the problem of different journalistic cultures facing the new global information market and war events, in particular (Thussu, \& Freedman, 2003).

Statistically speaking, the ratio between journalists and combatants has changed. Back when mass armies were involved in conflicts, news coverage was guaranteed by a few dozen correspondents from a handful of prestigious newspapers and press agencies (Reuter, Associated Press). Today, small irregular units engaged in their many clan-like conflicts face entire armies of journalists, reporters, and video operators, associated with thousands of information brands forced by the market to guarantee news coverage twenty-four hours a day, seven days a week.

The effects of the dual expansion of privatisation - of both violence and information - are inextricably linked and more complex than might be imagined. The most obvious and alarming fact is that journalists (and the same might be observed of humanitarian aid workers and other categories of private actors increasingly present in conflict zones) are viewed less and less as simple witnesses, and defined more and more as 'diversely armed combatants' - rather than 'disarmed' (Foerstel, 2006; see also Tumber, \& Webster, 2006). In the contexts which presently are beyond state control, unscrupulous groups locked in fierce competition with each other find it easy to transform the lives of reporters into a commodity to be exchanged for cash or even media coverage, and their expensive equipment into plunder to be resold on the black market. ${ }^{12}$ At the same time, competition in the information market itself, where the news becomes an asset to be sold in exchange for advertising revenue, also contributes to inflating the value of a journalist's death.

Elevating the degree of cruelty may therefore serve as a useful instrument for guaranteeing the networks a wider audience in one particular field: that of violence, where even patriotism is no longer considered sufficient to raise prime-time ratings. This has been demonstrated by the frequent accusations made by the veterans associations and the families of the fallen, which state that the networks do not dedicate sufficient space to wars in Iraq and Afghanistan. This fact has also been confirmed by periodical surveys of sources, for example in the Tyndall Report, which

12 It is, then, not coincidental that the first research on the post-traumatic stress disorder (PTSD) among journalists has been published only recently. See Feinstein (2006). 
monitors some of the most popular daily news programs of the USA networks: ABC, CBS and NBC. ${ }^{13}$

In other words, today, a journalist who dies in a war can no longer be assumed to be the victim of an accident, like Robert Capa, one of the most famous photoreporters of the twentieth century, who in 1954 stepped on a mine in Indochina. As the representative of a profession that is de facto involved in the conflict, today's journalist is now forced to accept the role of 'legitimate' target. In the many peripheral areas of the world where, from the standpoint of the media, even less noble battles are fought, mafia and political bosses, gangs, drug traffickers, and death squads treat the reporter as a personal enemy to be eliminated because of what $\mathrm{s} /$ he represents as an individual, or because of the contents of a particular investigation, or even simply because s/he incarnates an example of civic virtue. Three recent examples come to mind here: the journalist Anna Politkovskaya, assassinated in Moscow in October 2006, or the French documentarist Christian Poveda, killed in September 2009 near San Salvador for having denounced, in a documentary (La vida loca) released in France shortly before, the violence of the Mara 18, one of the most well-known gangs in Latin America; and, more recently, the terrorist attack on the French satirical newspaper Charlie Hebdo in Paris, on January 7, 2015, killing 12 people.

The widespread idea that the proliferation of new outlets represents per se a guarantee of pluralism, and the diffusion of accurate information, seems optimistic and reductive. In the first place, the sometimes hasty shift from a public monopoly to the free market does not resolve the problem of the concentration of media power which, put simply, clearly benefits large corporations over state governments. And neither is it credible to assert that political considerations do not influence the priorities of television executives and do not therefore affect or determine which conflicts are presented in prime time. Secondly, the market itself is not perfect, and presents significant structural distortions which prevent any type of equilibrium: 1) barriers to media access, either of an economic (cost of devices, taxes, fees) or technological nature (lack of area coverage), limit the free circulation of news; 2) the dynamics of supply and demand of the news still reflect the imperialistic, as opposed to competitive, nature of the relationship between the centre and the periphery of the media system. In this sense, the news tend to lose their value as a 'public good' - characterised, by definition, by the absence of rivalry and non-exclusive

13 See http://tyndallreport.com (03/06/2015). Numerous case-studies have been done, which empirically analyse the media coverage of the post-1989 wars, and also offer an in-depth look into the impact the new menace of international terrorism has had on the media since the attacks of 2001. For a broad introductory study going from the Arab-Israeli wars, to terrorism in the Northern Ireland, and to September 11, see Norris, Kern, \& Just (2003). See also Hammond (2007), which analyses the coverage guaranteed by the British media through six conflicts, and the international response they have generated: Somalia, Bosnia, Rwanda, Kosovo, Afghanistan and Iraq. See, finally, van der Veer, \& Munshi (2004); and Simons (2009). 
access - which should, in fact, be their core (Baker, C. E., 2002 and 2007); 3) with the proliferation of private media, a third interlocutor has been inserted into the traditionally dyadic relationship between those who produce information and those who receive it: a media enterprise (whether newspapers, television or radio channels) sells news to its audience, and sells its audience to its advertisers.

This, too, represents a disruptive element in the free circulation of news; one that undermines the already challenging task of providing equal space to all victims of conflict. In this complex interplay of roles, in fact, the need to please (or at least avoid displeasing) advertisers (as well as the government) can accentuate the propensity for self-censorship which typically manifests itself in a reluctance to show images of the dead bodies of fellow countrymen, while making ample display of those of the enemy. The gallery of dead enemy leaders is amply publicised: from Mussolini and Che Guevara, to Saddam Hussein and his sons, to Muammar Gaddafi. On the other hand, only a few photos of the caskets of American soldiers dead in Iraq, which escaped the net of the censorship, have sufficed to start a wide debate on the lack of patriotisim in some of the US media (De Luna, 2006).

There are those who believe that the latest technologies - from cellular phones with video cameras to information superhighways - can overturn this situation and attribute a new meaning to the term 'war coverage'. In 2009, for example, the footage of anti-regime demonstrations in Iran contributed to nurturing this enthusiasm, and the same happened with the Arab spring, the wave of protests and riots which lasted from 2010 to 2012. This also prompted many television networks, starting with CNN, to regularly invite their audiences to send in videos and testimonies they might have gathered during these events (Matheson, \& Allan, 2009; Seib, 2004: chpt. 5). In a kind of historical irony, the citizen-soldiers of the World Wars now seem to be passing the torch to the citizen-journalist of the new millennium. In addition to all the possible positive effects, an evolution of this kind (if it were indeed to come into being) would further dramatise the problem of verifying sources which is already aggravated by the rhythms imposed by the proliferation of the 24/7 news cycle. Moreover, it would exacerbate beyond measure the previously discussed risk that images will supplant the story and prevail over all other forms of understanding and interpretation of events. Finally, the sheer accumulation of these images could obscure the fact that any framing of events implies some kind of editing which necessarily entails ethical choices made all the more excruciating when the subjects of portrayal are suffering and death. ${ }^{14}$

14 Robert Capa was well aware of it when he said that he often felt like a hyena, and that he was afraid that the people he photographed might consider him as a spy or a person eager to make money through someone else's death (Moeller, 1989: 12). The ethical component implicit in transmitting dramatic events is the subject of Simpson, \& Coté (2006); at the end of this text the authors propose a true Decalogue of behaviour for journalists involved in gathering this kind of news. 


\subsection{Heroes and Survivors}

The story of the war does not simply end when the protagonists achieve or are thwarted from achieving their goals, but rather must go on to describe the new life that awaits the victors, and the defeated. From an institutional perspective, this means making renewed use of propaganda to construct the myth of the hero. Found in all cultures, the figure of the hero, more than any other, fully satisfies the 'aesthetic' ideal of sacrifice: dedication to a cause, exemplary conduct, the drama of fate (Calder, 2004). The more spectacular the victory, the more exquisite his gesture, the greater the obstacles and adversities he faced, the greater the hero's glory. The numerous portrait galleries that once adorned the residences of European monarchs testify to the importance of heroes, no less than the filmed testimonies of today's martyrs of jihad, shown in the virtual rooms of the Internet (Kirchner, 2007).

Over the centuries, and in Western culture in particular, the state and the church have traditionally celebrated the rites with which the myth of the hero are commemorated together, enhancing the legitimacy of their own powers and causes it is worth remembering, as far as the church is concerned, the role played by the military chaplains in modern mass-armies (Bourke, 1999: chpt. 9). For centuries (with the only exception of the wars that followed the French Revolution in the early nineteenth century), even the simple privilege of an individual burial was reserved exclusively for officers, while soldiers were buried on site, in common graves, and immediately forgotten. In World War I, on the contrary, the 'democratisation of memory' was definitively affirmed through the construction of the universalist myth of the fallen, and in particular, the iconography of the nameless soldier. Since mass death could no longer be concealed, it might as well be evoked, neutralised, and exorcised through monumental celebrations which vindicate the collective, egalitarian (and therefore, essentially anonymous) nature of any belligerent enterprise (Mosse, 1990: chpt. 3; Vovelle, 1983). Having finally realised, in death, the ideal of the French Revolution (equality), the fallen were buried in military cemeteries without rank distinctions, officers together with troops. The statue of the 'military genius' was replaced by the tomb of the Unknown Soldier (Ehrenreich, 1997). ${ }^{15}$

The ritualisation of burial represents only the first act in a complex process of constructing a panorama of collective memory, or memoryscape, in which cemeteries, monuments to the fallen, and even battlefields, help define itineraries that are intended (at least by those who design them) to root shared historical experiences and a consciousness of a common past in the community, almost as if the production

15 An officer in charge of identifying bodies in the plane of Verdun, after the end of the war, is given the difficult task of finding a body to be buried as the Unknown Soldier in the Triumphal Arch in Paris. This is the plot of Bernard Tavernier's film Life and Nothing Else (1989). 
of dead bodies were a conditio sine qua non for the formation of the political sphere. ${ }^{16}$ In effect, the success of so-called war tourism - especially in the period between the two World Wars - seems to be an obvious demonstration of the usefulness and the plausibility of such itineraries, and more generally, testifies to the pervasiveness of war, in the life of civilians, as well as ex-combatants (Lloyd, 1998). In the USA, for example, the valorisation of war sites is a tradition that goes back to the period immediately following the Civil War (Smith, T. B., 2008). It is significant that recently there has been a revival of interest in this kind of tourism, albeit consistent with a kind of globalisation that tends to substitute the direct transmission of events for depth of memory. The unsavory case of guided visits to a besieged Sarajevo (1992-1996) by unscrupulous tour operators during the Bosnian War, were reproduced in January 2009, when groups of Israelis onlookers crowded together to watch the bombing of the Gaza strip.

Yet we should not assume that the politics of memory mark the definitive end of hostilities, leaving space only for an unanimous expression of shared grief. On the contrary: it can create or reinforce completely disparate visions of the world. Battles and the fallen can be used to feed into the sense of national unity, just as they can be used to fuel autonomist claims made by separatist movements (Lebow, Kansteiner, \& Fogu 2006). In other words, state institutions' attempt to use postwar commemorations to convince their citizens that human sacrifice is the tragic, but necessary, price for being part of a community may be contested by a counterelite convinced that a different reading of the same events holds the key to their own (alternative) claim to legitimacy. Moreover, the agonising experience of personal grief can motivate these same citizens, or at least some of them, to contest the rhetorical, consensus-building use of their family members' death. ${ }^{17}$

The best-known example of 'contested memory' from this point of view is certainly the US war in Vietnam, where the discourse on commemoration exceeded the limits of the debate between the opposing factions, and began to resemble a kind of collective self-analysis on the very meaning of war and the democratic value of reconciliation. The contrast between the intimate, private nature of grief - which is still, however,

16 This is the opinion of Zertal, \& Eldar (2007), who speak without euphemisms of setting up a catalogue of martyrs specific to the community. Sledge (2005) is, on the other hand, a study dedicated entirely to the analysis of rituals and techniques of burial of the US soldiers since World War I. On the discovery of the political function of commemorating the fallen in the USA in World War I, see Budreau (2009). Finally, on constructing the 'memoryscape' as a particular spatio-temporal matrix see Foote, \& Azaryahu (2007).

17 A volume that closely examines the political uses of post-war commemoration is Ashplant, Dawson, \& Roper (2000). For a very different perspective, whose focus is the analysis of the experience of loss by millions of men and women at the end of World War I, see Winter (2006 and 1995). Finally, Acton (2007), takes a look at the private narratives of loss and mourning at wartime, and public and accepted forms of commemoration, from the Great War to the wars in Vietnam and Iraq. 
able to acknowledge the enemy in its memory - and the public, utilitarian concept of commemoration, is reflected in the story of two different monuments.

The first is the Vietnam Veterans Peace and Brotherhood Chapel erected by Victor Westphall in Angel Fire, New Mexico, in memory of his son, a US Marine, and fifteen other soldiers who all died near Con Thien in South Vietnam on May 22, 1968. ${ }^{18}$ Within a very short time, the chapel - two wings of white stucco surrounding an eternal flame and a collection of photographs of the fallen - became a reference point for all veterans. But Westphall's intention was for it to become a universal symbol of peace, and, therefore, wished for it to include photographs of the Vietnamese soldiers who died in the same battle. In an attempt to achieve this goal, which was shared by other family members of the dead American soldiers, Westphall contacted the Vietnamese president Ho Chi Minh, though to no avail. The pacifist undercurrent of the monument explains Westphall's uneasy relationship with state institutions and with some veterans associations, as well as the subsequent long-term difficulties he experienced in collecting the funds necessary to keep the site open. It also explains the delay with which the US Congress sanctioned the monument, which was officially recognised only in 1987.

The second, far more famous, monument, is the Vietnam Veterans Memorial in Washington DC, the most imposing part of which is a black granite wall engraved with the names of more than 58,000 fallen Americans. Its inauguration in 1982 marked the end of a long process which witnessed, at first, the collective repression of an unprecedented military defeat, and then the failed attempt by the new Reagan administration to suggest, again, that the war had been fought for a noble cause. The law adopted by Congress in 1980 to provide the considerable financing for the project intentionally avoided expressing any political judgment on the conflict. It was only in this way that it succeeded in overcoming divisions and reconciling the will of a substantial part of the American public opinion, who were opposed to the commemoration of a war they considered to have been unjust, with the desire of its survivors, who asked not to be forgotten, or even criminalised, for their (often unwilling) participation in the conflict. For the same reason, this memorial is named for the veterans, and not the war (as had been the tradition), and thus resembles (although, all things considered, for more prosaic reasons) Westphall's choice (Hagopian, 2009).

On the opposite frontline, in particular the My Lai massacre - where hundreds of defenceless civilians were killed, on March 16, 1968, by a US infantry division (Oliver, 2006; Nelson, 2008) - seems to have left a strong legacy of ritual practices through which the surviving Vietnamese daily interact with their deities, ancestors, and souls of the dead. This is a peculiar example of how the ritual domestic space can become

18 See http://www.emnrd.state.nm.us/SPD/vietnamveteransmemorialstatepark.html (accessed 04/10/2015). 
relevant to the goal of constructing a public, secular, dimension which refuses to ignore the traumas of collective memory (Kwon, 2006).

The hero is the undisputed protagonist of post-war narratives. He is idolised by institutions even more than by the masses precisely because his existence reassures them, and confirms their convictions about the necessity of war. The soldier who falls in battle, especially the citizen-soldier, represents the most effective proof of the institutions' own legitimacy and power. But the masses of survivors, unlike the martyred soldiers immortalised by the memorials, can, on the contrary, disrupt the process of a swift return to normality. Surviving veterans disturb this transition with the terrible reality of their physical and mental handicaps, and their tragic need to communicate what cannot be communicated: war's disdain for everyday life, the harrowing reality of the battlefields and the deafening noise of weapons and bombs, the fear of death or, worse, of being wounded, and the trauma of the memory of their dead companions. The trenches of the World War I, with their frightening mixing of body and matter, the contamination of biological material (excrement, blood, brains) with earth and mud, still remains, a century later, the most realistic representation of the hell of war (Gibelli, 1991: 188). The mass-killings of that war had dramatic effects on the bodies and minds both of soldiers and non-combatants, including women and children (Kramer, 2007).

Missing in action and prisoners of war too disturb the transition to normality. Once again we are reminded, above all, of the Great War (Hanson, 2006). The topic of the prisoners of war and the missing-in-action, however, has for years monopolised the debate on the Vietnam War, in spite of the fact that their numbers were much lower than in the preceding conflicts (Allen, M. J., 2009). For all of these protagonists, mutilated in body or spirit, reintegration into civil society can be long, painful, and incredibly costly. ${ }^{19}$ Their experiences add depth to the war narrative through texts and literary genres which often contradict official propaganda. Primary sources, such as letters and memoirs, are supplemented by secondary sources that organise and interpret these documents. The literature 'from the bottom', written by simple soldiers, stands alongside the official interpretations authored by military officers or political leaders. $^{20}$

19 This question of the reintegration of disabled veterans, too often has been neglected even by the scholars (Gerber, 2000; Cohen, D., 2001). And yet in the USA, several recent scandals have shed light on the culprit: the gaps in the support system for the handicapped in the Iraq and Afghanistan Wars (Glantz, 2009). These scandals also reignited the interest for the study of laws created in the USA to support veterans, adopted already at the end of the World War II (Altschuler, \& Blumin, 2009; Mettler, 2005).

20 It would be impossible, in this context, to do justice to the vast body of literature in this field. We are, therefore, limiting ourselves to highlighting three texts which, through different perspectives and analysis of three main twentieeth century conflicts, offer a sufficiently clear picture of the kind of studies done in this field: Fussell (1975); Cappelletto (2005); and Peters, \& Li (2004). 
With the end of the Cold War, one might have expected a gradual diminishing of this narrative vein, if only because of the trimming down of the state's role in the management of collective violence, and the consequent disappearance of the traditional protagonists of war. Instead, the opposite occurred: new narratives have proliferated along with new forms of violence. Mafia members, like contractors or terrorists, seem pleased to indulge in self-representation and propaganda, especially if someone (a journalist or an academic) offers to give shape and written form to their thoughts. ${ }^{21}$ The tragedy of child soldiers, to cite another example, has generated its own publishing field, which ranges from journalistic investigations to academic and scientific studies (Honwana, 2006; Singer, 2005a), and even novels based on autobiographical experiences (Beah, 2007). The privatisation of violence is destined to change the ways in which collective memory develops and is processed, as well as the politics that feed it, since, by definition, 'private' actors cannot avoid providing partisan accounts that support their own interests and objectives. What state governments seem to miss entirely, however, is the fact that their decision to subcontract the physical exercise of violence to new actors present on the market regardless of whether these are military corporations or organisations of a criminal nature - necessarily requires the abandonment of their 'copyright' on the very concept of sovereignty: the inadvertent selling off of a cultural patrimony of ideas and values which, after five centuries of evolution and editing, had come to represent the shared history of their people.

21 See, as an example, the two-part biography of Tommaso Buscetta, edited by Arlacchi (1994) and by Lodato (2007). But see also Spicer (1999), the autobiography of one of the most famous mercenaries of the post-Cold War period. The attacks of September 11 have also created the icon of terrorism, Osama bin Laden; the catalogue of the online bookstore Amazon.com contains 15,793 titles related to him, and the library catalogue used in US universities (www.worldcat.org) 5,538. The more recently coined brand of the IS, generated respectively 331 and 1,024 titles (accessed 01/27/2015). 


\section{War Political Economy}

After having addressed in the previous chapters the role of the human factor, the military institutions, the spaces where violence is carried out, and the propaganda machine, the last factor to consider in the analysis of war as a social construction is the concurring role of politics and market forces in the war making process, highlighting how the growing privatisation of violence in the post-Cold War era is favouring violent non-state actors (VNSAs) in their competition with the state. This also means, preliminarily, to deal with the historical longue durée or, as we defined it in the first chapter, the spiral - the phases of slowing down, stalling, and actually going backwards - reproducing the evolution of the interplay between the public and private domains with regard to organised violence.

The transition from the ancient to the modern world was marked by the expulsion of violence from the private sphere and subsequent entrance into the public sphere: the power of the pater familias over his slaves (as well as over the members of his own family) made way, first, for the sovereign's dominion over his subjects; and then, for the government's authority over its citizens: 'What all Greek philosophers [...] took for granted is that freedom is exclusively located in the political realm, that necessity is primarily a prepolitical phenomenon, characteristic of the private household organisation, and that force and violence are justified in this sphere because they are the only means to master necessity - for instance, by ruling over slaves - and to become free. Because all human beings are subject to necessity, they are entitled to violence toward others; violence is the prepolitical act of liberating oneself from the necessity of life for the freedom of world' (Arendt, 1958: 31).

But passage from private to public violence took centuries and was a process distinguished by two main phases: first, the formation of monopolies, characterised by the accumulation of resources in the hands of a few and, eventually, of a single authority; second, the actual transformation of power from private to public, in which the sovereign assumed the task of redistributing opportunities, rights, and obligations among increasingly extended social groups, without ever renouncing the monopoly of the legitimate use of physical force (Elias, 1993). The accumulation of resources was initially undertaken by groups that, in reality, were scarcely better than bandits. At its origins, the state was characterised by a kind of competition in which those groups or peoples who were the first to abandon nomadism and establish themselves in a given territory prevailed: 'If the leader of a roving bandit gang who finds only slim pickings is strong enough to take hold of a given territory and to keep other bandits out, he can monopolise crime in that area - he becomes a stationary bandit. The advantage of this monopoly over crime is not mainly that he can take what others might have stolen: it is rather that it gives him an encompassing interest in the territory' (Olson, 2000: 7).

This monopolisation process, triggers a further competition, that of legitimacy: 'What distinguished the violence produced by states from the violence delivered by 
anyone else? In the long run, enough to make the division between "legitimate" and "illegitimate" force credible. Eventually, the personnel of states purveyed violence on a larger scale, more effectively, more efficiently, with wider assent from their subject populations, and with readier collaboration from neighbouring authorities than did the personnel of other organisations. But it took a long time for that series of distinctions to become established. Early in the state-making process, many parties shared the right to use violence, the practice of using it routinely to accomplish their ends, or both at once. The continuum ran from bandits and pirates to kings via tax collectors, regional power holders, and professional soldiers' (Tilly, 1985: 172-173). From that moment, the management of collective violence produced an increasing separation of roles between the political entrepreneur who represented and mediated on behalf of various social elements, and those groups or individuals who were specialists in the use of violence (Tilly, 2003).

\subsection{State, Capitalism, and War}

In the arena of war, the public-private dichotomy represents one of the most basic interpretations of the evolution of armies with regard both to rank and file and the officer corps. After the feudal period, when the knight - a specialist trained since childhood in the use of arms and compensated for his service by the grant of a feud or fief - was basically his own officer, mercenaries established themselves as the main protagonists of the battlefield. The private management of armies, at times of considerable dimensions, became an activity that not only guaranteed many arms specialists paid work, but also contributed significantly to the distribution of resources at the collective level (Lane, 1979). One is reminded of Wallenstein, the much-soughtafter, but also much-feared, colonel of the seventeenth century.

A further indication of the privatistic nature of this practice is the fact that the hiring of mercenaries was not governed by laws, but, rather, by contracts, which specified, case by case, the number of soldiers needed, the agreed-upon pay and length of duty, and other relevant details such as, for example, clauses relative to the extension of service. The condotta was a typical contract found in Renaissance Italy, on the basis of which, in addition to his other responsibilities, the recruiter (the condottiere) also committed to leading his troops into battle. In Germany, on the other hand, recruiter-entrepreneurs - in effect, capitalists - were already beginning to delegate command of the company to others (Mallett, 1974: chpt. 4; Maire Vigueur, 2003). This differentiation of roles was likely favoured by the fact that, often, those responsible for recruiting the men were also charged with advancing the capital necessary to clothe and arm them.

Flush with the funds made available by the creation of a central treasury, monarchs now transformed war from a mainly domestic event (a battle for supremacy among the local magnates) to an international one. The invasion of Italy by the French 
king Charles VIII in 1494 is usually seen as the enterprise that marks the beginning of this qualitative change. Afterwards, the question of how to compensate for some of the biggest disadvantages of these mercenary formations (such as their lack of loyalty in battle and their propensity for pillaging the local territory once they had exhausted their salaries ${ }^{1}$ ) became a major priority; and, gradually, the mercenaries were transformed into permanent armies. Charles V of Spain was the first to create, in the provinces of his great empire, the garrisons that became military schools for his soldiers. Around the same time, the first forms of long-term conscription were introduced (with more or less efficacy, according to the country in question), which also allowed for the establishment of territorial militias.

But training and maintaining permanent armies is a costly enterprise, so this era also (and often) witnessed a return to the recruitment of mercenaries: a necessity dictated by central governments' frequent bankruptcies. In the seventeenth century, the regiments of the Sun King, Louis XIV of France, were still made up mainly of volunteers whose recruitment fed corruption and speculation: colonels, for example, regularly included in their muster rolls the names of soldiers who never actually appeared on the battlefield. And in the eighteenth century, even the famous armies of Frederick the Great of Prussia, which were founded on a system of obligatory military service for peasants and artisans (but which included a complex system of exemptions, as well as the possibility of procuring a paid substitute for conscripted soldiers), over time became increasingly dependent on foreign mercenaries. ${ }^{2}$

The consolidation of this first stage of troop development - that is, the constitution of a real national army - was finally achieved with the mass conscription at Valmy in 1792. Fighting for one's own country became a universal obligation, but only because people had finally acquired the political and social rights previously denied them. The obligatory presence of the armed citizen offered war the kind of public character that it had previously been denied, but that now endowed it with a degree of political legitimacy both superior to that of any previous conflict among mercenaries, and (as evidenced by modern democratic systems) directly proportionate to citizens' ability to freely concede or withhold their support for their rulers.

Members of the officer corps experienced an entirely analogous evolution: the gradual shift from the private sphere of the contract, to the public domain, controlled by law. In the Middle Ages, the head warrior was identified tout court with the political authority; while during the state-making process, these two roles

\footnotetext{
1 'Mercenaries and auxiliaries - Machiavelli wrote in 1515 - are useless and dangerous; and if one holds his state based on these arms, he will stand neither firm nor safe; for they are disunited, ambitious and without discipline, unfaithful, valiant before friends, cowardly before enemies; they have neither the fear of God nor fidelity to men, and destruction is deferred only so long as the attack is; for in peace one is robbed by them, and in war by the enemy' (Machiavelli, 2007: 55-56).

2 In the end, this would render useless the sophisticated tactics that ensured the success of Frederick the Great by finally forcing Prussia to settle for waging limited wars in defence of its borders.
} 
became increasingly distinct from one another, passing from loyalty to the person of the sovereign, to loyalty to the institutions of government. Two aspects of this evolution are particularly significant. The first consists of the gradual enlargement of the recruiting base. In fact, the art of command originally resided exclusively in the domain of feudal nobility. Soon afterwards, sovereign leaders began to make ample use of the system of the so-called sale of officers' licences (in addition to noble titles). This allowed them to fill drained state coffers, while at the same time offering wealthy members of the emergent bourgeoisie access to reliable mechanism of social promotion as a means of securing their future, and that of their descendants.

The second aspect is what military sociologists define as the professional revolution' (Huntington, 1957). The growing pace of technological innovation - in fields ranging from the science of building fortifications to artillery and ballistics imposed the shift from a model based on the idea that the art of command is an inborn or inherent human quality (as claimed by the old, faded nobility), to one based on the concept that command and leadership are instead the result of rigorous training. The birth of formal military academies entailed the gradual transformation of the officer corps into an organisation that to a great extent imitated the values of modern civilian bureaucracies: esprit-de-corps and competitiveness within the group; competence as the criterion for selection and advancement; and adherence to the government's values and ideology (Perlmutter, 1977).

What we have covered so far, however, does not exhaust the list of possible forms of military institutions. In fact, to the 'authorised' history of the process of the monopolisation of force in the state, we must add another, less well-known account concerning the field of violence management. The same states that undertook the development of public professional armies continued to subcontract the management of certain types of violence out to private actors: 'Rulers began authorising non-state violence as early as the thirteenth century, when privateering was invented. Largescale private armies dominated Europe during the fourteenth and fifteenth centuries. Mercenary armies were the norm for eighteenth-century European states; naval mercenaries were common through the eighteenth century. Mercantile companies flourished from the sixteenth to the nineteenth century. All of these practices reflected the marketisation and internationalisation of violence that began with the Hundred Years' War' (Thomson, 1994: 21).

European states sought to derive the maximum possible advantage from the inevitable ambiguity of this arrangement: were these private players acting on their own, and therefore, illegally; or, on the contrary, were they following the orders of the sovereign power? 'Privateering', strictly speaking, was the practice by which, in times of war, a sovereign could authorise private armed vessels (corsair ships) to attack an enemy ship and keep part of the booty for themselves. The line between privateering and piracy was rather indistinct, both because a privateer might occasionally decide (independent of any form of consent or approval from the sovereign) to broaden the terms of his mandate; and because the state might suddenly find it useful to withdraw 
its delegating power in an effort to conceal its responsibility from the enemy. On close examination, this irregular form of warfare appears little different from the more traditional work of mercenaries; if anything, it further enriched an already dynamic sector with new and imaginative characters who made their (and others') fortune thanks to their ability to use violence as a means for determining the distribution of scarce resources (Lane, 1979).

On a far more advanced level, both with regard to organisation and capitalisation, we find chartered companies, the privileged commercial enterprises which, to this day, remain history's purest examples of private violence in public service. For the market, these organisations represented an ideal of self-managed power; for the state, they were a partner to be legitimised, tolerated, or opposed, depending on the situation. Reserved for professional merchants, who, as with the old trade guilds, agreed to pay a fee and submit themselves to rigid regulation, chartered companies did not cover individual risk, but still guaranteed unprecedented privileges. Although they were usually divided into business ventures of a decidedly private nature (as was the case with the Dutch companies) and state enterprises (as was true of the French and the Portuguese companies), the chartered companies all possessed the typical attributes of sovereignty. 'A state independent from the state' (staat buiten die staat), as they were defined, these concerns recruited armies and armed fleets; created settlements in those places where they had been granted powers of governance over their compatriots; minted currency; and had the ability to declare wars and sign treaties (Thomson, 1994: 32-40). This peculiar 'constitution' allowed them to operate under the conditions of quasi-monopoly; exercise strong influence over the crown; and apply their great capacity for influencing (when not actually corrupting) the parliament.

Chartered companies' greatest advantage, however, resided in their management of violence, which was used to defend their own trade and interests, and implement their policies. These companies financed and recruited their own troops, furnished them with weapons, and deployed them without regard for the normal rites and restraints of politics, or the delays inevitably imposed by the mobilisation of large contingents (Steensgaard, 1975 and 1981). In other terms, chartered companies could count on a much better 'protection rent', compared both to states and other privateers (not to talk of individual entrepreneurs). In fact, 'an essential charge on any economic enterprise is the cost of its protection, its protection from disruption by violence. Different enterprises competing in the same market often pay different costs of protection, perhaps as tariffs, or bribes, perhaps in some other form. The difference between the protection costs form one element in the income of the enterprise enjoying the lower protection cost' (Lane, 1979: 12-13). This element, or protection rent, was higher for chartered companies just because they were more easily and efficiently protected, assuming protection as a normal and calculable item in the product cost management. 
Occasionally the companies competed for control of specific markets: like the English and Dutch East India Companies' struggling for supremacy in the Indian Ocean between 1618 and 1620. However, the companies rarely (if ever) replicated the wars fought in Europe by their respective sovereigns in the colonies. In the international system of that era, the anomaly of the chartered companies consisted precisely in the fact that they would not allow themselves to be conditioned by the immediate interests of the defence and territorial expansion prevalent at home, preferring to pursue their own overriding statutory interest instead: the protection and growth of their capital. In the case of the English East India Company, independence from the crown would be pushed to the point where it aroused a violent parliamentary protest that concluded in 1794 with the passing of the India Bill - an attempt, destined to failure, to bring at least the company's foreign policy back under state control. Until 1857, the year the Great Mutiny erupted in India, England actually possessed two armies: one in the service of the state and the other assembled by the Company. In the end, however, the Indian Army emancipated itself from both: determined not only to gain independence from the British military apparatus, but also to reaffirm its supremacy over the civil administration of the Company, the Indian Army irremediably damaged the Company's economic interests thereby precipitating its inevitable demise (Lawson, 1993).

The failure of other chartered companies was caused, variously, by bankruptcy, merger with other groups, or through the simple revocation of the concession granted by the government, among other things as a response to new economic actors' growing calls for market liberalisation. Yet generally speaking, the renunciation of private violence was imposed more by the international system than the demands of domestic politics. Problems with privateering had become evident early on, but only in the nineteenth century European powers began to negotiate an end to its practice. The activity of mercenaries and pirates, in fact, contradicted any eventual claims of neutrality by their countries of origin and, above all, risked provoking an uncontrolled escalation of the conflicts among states. Beside that, the proliferation of privateers provoked also the protest of insurance companies, whose losses mounted because of their activities. And yet, 'while friendly states, neutrals, and insurance companies periodically defined privateering as a problem, their protests only resulted in the imposition of tighter controls of privateering. It was only when the greatest commercial and military naval power - Great Britain - defined privateering as a problem that is was permanently abolished' (Thomson, 1994: 70). On 1856, the Declaration of Paris was signed by the era's major powers: France, Great Britain, Russia, Austria, Prussia, Sardinia, and Turkey, all of whom would go one to respect and uphold its application.

The history of states reasserting 'public' control over their monopoly of the legitimate use of physical force does not end here, however. The significant step backwards that private actors suffered at the end of the nineteenth century with regard to the exercise of violence, actually coincides with their triumphal entrance 
into the sector of weapons manufacturing. Starting with the naval arms race between Germany and Great Britain in the 1880s, private armament industries gained a strong competitive advantage over the old military arsenals owned by the state; a disparity from which the state would never fully recover. This was an era of technological revolution in the field of weaponry: the invention of breech-loading rifles in the mid-1800s, for example, which represents the single most significant innovation in small arms; or the evolution of sea vessels (from sail to steam, and from wooden to steel ships) which between 1830 and the end of the century proceeded at such a quick pace that often newly built crafts became obsolete even before they were launched. In these same years, 'railway mania' and the discovery of the telegraph unsettled the very concept of logistics, while discoveries in the medical field, such as quinine, dramatically cut the mortality rate of troops involved in colonial wars. These developments help explain the striking progress of European global expansion far better than any ideology can: 'In the year 1800 Europeans occupied or controlled thirty-five per cent of the land surface of the world; by 1878, this figure had risen to sixty-seven per cent, and by 1914 over eighty-four per cent of the world's land area was European-dominated. The British Empire alone, already formidable in 1800 with a land area of 1.5 million square miles and a population of twenty million, increased its land area sevenfold and its population twentyfold in the following hundred years' (Headrick, 1981: 3).

All this would have been unimaginable without careful research and development planning which in the years between the two World Wars produced many other important innovations: from trucks and tanks, to planes, radar systems and the atomic bomb. And none of it would have been feasible without the standardisation of the manufacturing and production of everything from ammunition to packing materials, and the adoption of massive economies of scale. The period witnessed national governments' loss of control over the production of weapons, as well as the birth of a transnational economy destined to have two major effects: the first was the propensity of the principle manufacturers (Armstrong and Vickers in Great Britain, Krupp in Germany, and Schneider-Creusot in France) to respond to increases in the cost of production with mergers; and the second was the unceasing search for new commercial outlets outside of Europe. Among the various consequences of this evolution, we might cite collusive agreements between businesses from different countries (some of which were actually at war with each other at the time), the systematic lobbying of military officers and politicians (which occasionally degenerated into open corruption), and the willingness of parliaments to cover the budget deficits created by military expenses that had spun out of control (McNeill, 1982: chpt. 9). In short, the birth of what is now defined as the military-industrial complex (but what should more correctly be called 'the industrial-military complex').

A simple comparison suffices to clarify the extent of this revolution: it has been calculated that in the seventeenth century - a time when the state did not yet possess the means to conduct wars of extermination, but was certainly able to fight 
for many years and on multiple fronts - between ten and twelve million Europeans were employed as soldiers, many of them deployed in theatres on other continents. The soldier-nomad was pre-industrial Europe's main export commodity to the rest of the world (Parker, G. 1988). At the beginning of the twentieth century, on the other hand, the number of soldiers mobilised in the two World Wars was 65 and 80 million, respectively. ${ }^{3}$ This increase in the size of armies offers an idea of the level of productivity reached by the industrial complexes of the great powers. Soldiers must be clothed, armed, transported to the front lines, and sustained with provisions and ammunition for the entire duration of the conflict. And when they die, soldiers must be buried. The 8.5 million victims of World War I and the 50 million killed during World War II (of whom 30 million were civilians) not only provide a picture of the extent of devastation achieved by modern weaponry, but also offer a glimpse of the organisational, sanitary, and even ethical issues that governments prefer not to make public.

Throughout the conflict, the transnational economy of arms production and trade necessarily requires the direct involvement of governments, which provide a technocratic elite capable of directing and coordinating the work of millions of workers and the military activity of millions of soldiers. During World War I, international administrative agencies tasked with managing the division of labor and the distribution of provisions in the allied countries were constituted; and when World War II broke out, a centralised economy once again became a necessity for all warring parties. In fact, final victory ultimately depended on the results obtained in that sector. As early as 1943, Japan was no longer capable of regularly providing for the garrisons dispersed along the immense Pacific frontline, in spite of the significant contributions of the countries allied in the Japanese Co-Prosperity Sphere. The USA, on the other hand, obtained spectacular results by applying Taylor principles for running a large factory to the entire national economy. The Manhattan Project represents perhaps the most successful example of this policy in practice: in only three years, a two-billion dollar investment and the coordinated activity of 120,000 scientists brought about the creation of the first atomic bomb (McNeill, 1982: 359).

\subsection{The Global Market of Violence}

The end of the Cold War and the proliferation of VNSAs has generated a market of violence that is ever more competitive, and capable of adapting to a demand that is in constant evolution. On the one hand, the state is not totally renouncing its traditional apparatus of coercion, the army and the police; nor it is abandoning the

3 The calculation relative to the World War II is far more vague, as it does not include all irregular forces operating on different fronts. 
possibility of employing those instruments wherever they may be useful in pursuing its internal or international political strategies. On the other hand, however, the proliferation of VNSAs produces an unprecedented increase in the ambits of coercion, and a corresponding reduction in the social and political rights available to the individual. In other words, the post-bipolar world seems to imply the rediscovery of the 'advantages' of self-governance by small groups of individuals (as opposed to delegating the monopoly of force to the state), made possible by innovations in market dynamics and applied technologies - in particular, by the decreased cost and greater destructiveness of new small arms and light weaponry systems.

The deliberate choice of some governments, even in Western democracies, to re-arm their citizens, suddenly removing the barrier that they themselves had erected between civilians and the military, reinforces this fragmentation process in the monopoly of violence. The diffusion of vigilantism as an organised form of civil defence, as well as that of private military corporations (PMCs) or warlords, fits the neoliberal strategy which requires the state to externalise the costs of security, allowing the citizens who can afford it to pay a private agency to guarantee their own protection; and those who cannot, to defend themselves by themselves. 'From a global perspective the relationship between vigilantism and globalisation would appear almost self-evident. Seen on a macro scale the global political order wrought by neoliberalism has created unparalleled opportunities and motives for citizens to take the law into their own hands. If the politics of deregulation, the franchising of sovereignty, and the "privatisation of indirect government" are the signature features of the current international economic regime, then vigilantism is both a logical response and an integral aspect' (Sen, \& Pratten, 2008: 2). It is worth noting that all these brands in the global market of private violence avoid the political and social submission that was typical of the feudal relationship between the lord and his tributaries.

This 'back to the future' scenario marks the opening of a new era of endemic violence in which the conventions that had been taken for granted tend to lose their meaning. One has only to think of the complete abandonment of the state practices of issuing a declaration of war or signing a peace treaty - legal processes that once marked the official beginning and end of a conflict; or, in even more concrete terms, the continuous violation of the rules of war, and the perpetration of crimes against humanity. ${ }^{4}$ But by far the most relevant consequences, at least from the point of view of the material forces involved, pertain to the economic sphere. On the one hand,

4 The obsolescence, in particular of the declaration of war, even among the democratic countries, goes back to the end of the World War II. One of its causes is certainly the fact that such a declaration marks the opening of a 'state of exception' which has relevant political and legal consequences. For an empirical analysis on observing the rules of war by the states, see Morrow (2007); and Morrow, \& Jo (2006). 
since there no longer exists a time period explicitly dedicated to war, it has become impossible even to imagine that all the productive resources of a nation could be applied to the single purpose of defeating an enemy. ${ }^{5}$ On the other, the peacetime economy is increasingly dependent on the dynamics of a privatised market of violence; one that is free from the obligation to protect the national interests of a specific customer and in which the most competitive VNSAs influence the demand as well as the supply side by generating and amplifying the collective insecurity that feeds the requests for protection.

The capitalist system is involved in this process both on the global level of the strategies of middle- and long-term investment, budget politics, and the uninterrupted virtual circulation of currencies; as well as on the concrete and local level of exchange (of work, goods, or money) among individuals. To give only one example, the criminal group which produces drugs and reinvests the profits obtained from their sale into the legal economy travels continuously from one dimension of the capitalist system to another, and operates in the speculative sphere of high finance no less than in the daily sphere of the relationships of trade and exploitation. The problem becomes one of understanding what has changed in the market of violence since the end of the Cold War - that had been prolonged well beyond the real defeat of the USSR, in order to allow the US military-industrial complex to survive until a new credible enemy appeared (Craig, \& Logevall, 2009); and, in particular, which provoked the appearance, alongside the state, of the multitude of new VNSAs.

Over the last few years, we have witnessed a rebirth of interest in the role played by war in promoting international trade (Findlay, \& O'Rourke, 2007), as well as in the relationship between the economy and military history (Brauer, \& van Tuyll, 2008). There has been a return to the study of 'economic wars' - naval blockades, embargoes, sanctions - from a historical perspective, and/or with regard to their economic and social consequences (Davis, \& Engerman, 2006; Naylor, 2001). Finally, we have seen a growing interest in the economies of civil wars (Ballentine, \& Sherman, 2003; Ballentine \& Nitzschke, 2005; Jung, 2003; Pugh, \& Cooper, 2004). At the same time, far less attention has been dedicated to the market of violence as such, which is what we propose to examine here, starting with a list of the characteristics that explain its competitive nature and its success: ${ }^{6}$

1. invisibility: the market of violence is conceived in such a way to avoid, to the greatest possible extent, any form of control by public opinion. Individuals and corporations operating in other sectors may have an interest in hiding at least a part of their profits in offshore fiscal havens; but for those who are busy

5 This is precisely the definition of the 'war economy' reported, for example, in the opening of Neal (1942).

6 For the few exceptions, see Ruggiero (2009), which has specifically inspired our forthcoming observations. 
trading arms, hiding their movements becomes a systemic priority. Weapons producers have an interest in concealing the names of their clients from their own governments, especially if those clients happen to be militants active on the enemy side. Governments themselves often prefer to keep their citizens in the dark about foreign policy strategies, entrusting the task of financing and supplying the allied war factions of conflicts in which they do not wish to become directly involved to the secret services and covert operatives. For terrorist and mafia groups, finally, the elimination of any traces of evidence that could lead to the identification of their members represents a question of survival: banking secrecy is the indispensable corollary of their clandestinity, and the black market a natural complement to the secretive nature of their organisation;

2. dynamism: privatisation has made it possible for the market of violence to take advantage of the existence of a growing number of brands. During the Cold War, the only protagonists were, on one side, large armament industries, and on the other, states; in particular the two superpowers and a few European countries who played a double role of direct purchasers and mediators with governmentclients in the developing countries. Today PMCs are also part of the game. The most important players among them tend to operate as oligopolies and develop cartel-like strategies. And then, of course, there are all the other VNSAs already discussed - with mafias especially well-placed to offer a wide range of goods and services beyond violence in the strict sense. The number and variety of these actors guarantees an unprecedented level of dynamism in the market of violence: the simultaneous presence of traditional wars where regular state armed forces are used, low-intensity ethnic conflicts, and social violence of an epidemic nature, provides a balance of supply and demand that avoids any risk of stagnation or recession;

3. profitability: unlike in other markets, the high profitability of investments in the field of violence is not limited to specific productive sectors (such as those with high technological content), nor to reaching fixed economies of scale: even a small shop capable of producing light machine guns or antipersonnel mines, and not subject to the burden of paying patent rights, proves itself amply capable of covering its startup costs. Furthermore, the constant rise in demand due to the exponential growth of VNSAs also makes the collateral second-hand market particularly profitable. The long life of certain firearms, for example, allows for their reuse in different conflicts, thus increasing - almost adinfinitum - the rate of profit. In more general terms, the market of violence proves capable of integrating production and distribution in the most effective way, thanks essentially to the fact that it tends to follow a pyramidal scheme, where the individual consumer also acts as a sales promoter: from the government of a superpower to the 
smallest warlord, all the actors foment the race for rearmament which hardly seems destined to slow, let alone cease; ${ }^{7}$

4. social irresponsibility: in the market of violence, companies are not required to answer for the consequences of their activities: the only real moral imperative consists in guaranteeing the maximum possible profit to their shareholders. If we assume that the accumulation of profits of any entrepreneur of violence necessarily may imply the death of the final user, we see that, in this specific market, the rate of marginal return tends to rise with the increase in the death toll. In this sense, social irresponsibility is pushed to its theoretical (and sometimes also, empirical) extreme by prefiguring the end of the society itself. The sole remnant of responsibility that survives, essentially, is the joint liability of the individuals who happen to be managing the material or financial resources of a given group: any misappropriation, or even simply a poor investment, can determine their own extermination in a kind of twist of fate that sees the merchants of death swallowed up by the same system they helped create. ${ }^{8}$

These characteristics tend to reinforce one another, to the extent that today's violence is self-fed, pushing the immediate or historical causes of a conflict into the background, and, at times, actually making it more profitable to continue fighting than to win. The siege of Sarajevo, for example, was protracted from 1992 to 1996 thanks also to the flourishing black market generated by the influx of humanitarian aid, and in which United Nations peacekeepers were also involved (Andreas, 2008; Strazzari, 2008). Further, in its process of expansion, today's market of violence has involved a growing number of freelance professionals, indispensable to the survival of the market itself: from the accountants and bankers in charge of collecting and laundering the money derived from sales, to the financial experts whose task is to reinvest profits, and the lawyers commissioned to protect the legal interests of the parties involved. The fact that these professionals place their competencies indiscriminately at the disposal of both legal and criminal actors, claiming it impossible to tell the difference between them, and denying that they themselves have been asked to bend (if not actually to violate) current regulations, contributes to the increasingly open-ended nature of the border between the legitimate and the illegal economy. Finally, the objective difficulty

7 Such a model, generally considered unsustainable for the simple reason that profit margins tend to decrease going down the steps of the pyramid, has revealed itself to be entirely functional in guaranteeing a more ample diffusion of numerous products available in the market of violence. The theme of the Ponzi scheme has recently been revisited in the USA as a consequence of the numerous scandals related to the financial crisis and, in particular, to the Madoff case. See Kirtzman (2009).

8 It is worth remembering the Italian cases of Sindona (Stajano, 1991) and Calvi (Almerighi, 2002), the bankers who paid for their inability to manage with due discretion the illegally originating capital which certain representatives of Cosa Nostra (among others) had entrusted to their care, with their lives. 
of sanctioning their behaviour not only feeds into the sense of impunity of those who are already used to crossing this boundary every day, and by now see it as only an imaginary line; but also risks tearing down any residual resistance in those who, by respecting the regulations, find themselves penalised by the market.

Inshort, the privatisation of the market of violence gives rise to three consequences: 1) the substitution of (universal) laws with contracts (valid only for the actual contracting parties) as the main legal instrument regulating relationships between the actors; 2) the growing indeterminacy of the spaces of legality, a consequence both of the deregulation associated with liberalisation - i.e. the lack of political will to give at least some coherent normative structure to the market - as well as of the fact that anyone who holds sufficient resources of violence can either defy the law or demand that it be rewritten; 3) the extraordinary diversification in the offer of goods as well as services, in reply both to stimuli coming from the competition and to continuous requests from the demand side. A market of this nature does not respond to the law, which presumes a marginal utility tending towards zero because of the gradual saturation of consumption. As a consequence, it is not destined to succumb to periodic contractions in the production cycle, nor likely to undergo significant and generalised price increases. But these are not the only apparent anomalies.

Arms production, certainly the key product in the market of violence, is an example of the paradox of a Western (developed) world which, despite feeling constantly threatened at its borders, controls the production and sale of the most sophisticated technologies and means of mass destruction. In 2009, 44 of the 100 most profitable military corporations on the planet were located in the USA; and 32 in Western Europe. Together, they accounted for 92 per cent of global sales (61 and 31 per cent, respectively), having grown by 37 per cent in real terms between 2002 and 2007, for a total that increased from 252 to 347 billion US dollars. The USA and Russia, (followed only distantly by Germany, France, and Great Britain) were the largest exporters: together they represented 79 per cent of the total volume of global exports between 2004 and 2008. The largest importers were China - which is not listed among the producers because of the lack of any information from the government which purchased mostly from Russia, followed by India, the United Arab Emirates, South Korea, and Greece (Sipri, 2009: chpts. 5, 6 and 7).

In 2013, 'the sales of arms and military services by the Sipri Top 100 - the world's 100 largest arms-producing and military services companies (excluding China), ranked by their arms sales - totalled $\$ 402$ billion [...]. This is a decrease of 2.0 per cent in real terms compared to Top 100 revenues in 2012, continuing the decline that started in 2011, but at a slower rate. Despite three consecutive years of decreasing sales for the Top 100, total revenues remain 45.5 per cent higher in real terms than for the Top 100 in 2002'. Beside that, 'companies headquartered in North America and Western Europe continue to dominate the global arms industry and comprised 69 of the Top 100 companies for 2013. They accounted for 84.2 per cent of the total arms sales of the Top 100 - a slight drop from 85.3 per cent in 2012. The total arms sales of 
the 39 ranked North American companies ( 38 from the USA and 1 from Canada) fell by 4.5 per cent in real terms in 2013. The decrease for West European companies (30 in the Top 100) was a modest 2 per cent in real terms' (Fleurant, \& Perlo-Freeman, 2014: 1 and 2).

These numbers - with all their implication in terms of capital investment as well as research and innovation - show how the 'old' military-industrial complex has not only survived the end of the Cold War, but also succeeded (rather well) in consolidating its position in the market, all at a time when interstate warfare has been clearly declining. ${ }^{9}$ The drastic downturn in orders at the beginning of the 1990s, inevitable as always during the period of demobilisation that follows a long war, was faced and resolved in the usual terms of economic rationalisation: by resorting to the strategy of mergers, that had already characterised the arms race of the early twentieth century (McNeill, 1982), and the consequent decrease of the workforce. This happened in both the USA and Europe, further reducing the already weak competitiveness of the arms market (Krishnan, 2008).

Yet the present phase in the growth of the industrial-military complex allows us to shed light on another paradox: with all the increase of expenses in the heavy armaments sector, the weapon that in fact kills most victims today is the AK-47 (Kahaner, 2007). With the proliferation of VNSAs, the market of small arms made for individual use (revolvers, automatic pistols, rifles and carbines, light machine guns, etc.), and light weapons adopted by small units (heavy machine guns, fixed grenade launchers, anti-aircraft missile launchers and hand-held anti-tank weapons) has seen an unprecedented, basically uncontrollable, expansion since the end of the Cold War. In fact, it is almost impossible to gather reliable data about their production. The United Nations Register of Conventional Arms, for example, is based on a kind of selfcertification undertaken by governments that agree to make public the information available to them. In 2013, these governments numbered 47, most great and regional powers were missing, and the data were fairly incomplete (www.un-register.org, accessed 01/31/2015).

Even more ambitious projects may only collect information drawn from the official reports made by governments, and estimates derived from investigations and polls; or, alternatively, they may focus on research related to specific areas or conflicts. Small Arms Survey, which also publishes a yearbook on specific topics, states in its website: 'There are an estimated 875 million small arms in circulation worldwide, produced by more than 1,000 companies from nearly 100 countries. All countries - and numerous non-state armed groups - procure small arms; the Small Arms Survey estimates that their annual authorised trade exceeds 8.5 billion US\$. Accurate assessments are

9 In recent decades analysis of the military-industrial complex has disappeared almost entirely from the agenda of social scientists. Among the few significant exceptions, see Hossein-zadeh (2006); and Roland (2001). 
difficult, complicated by the reluctance of many states to report publicly on their legal production, exports, and imports of small arms. Analysis of their illegal activities is even more difficult. Significantly, many important exporters are not major producers of small arms, with substantial numbers of legally acquired small arms entering illicit markets through corruption, seizure, and loss (www.smallarmssurvey.org, accessed 01/31/2015). These small arms, quite easy to use, are employed daily by military divisions in war zones, as well as by terrorists and common criminals in every country of the world (Jojarth, 2009: chpt. 7).

Weapons are not the only product for sale. Indeed, they alone do not explain the raison d'etre of the market of violence. They find their natural use inside a more or less sophisticated context of relationships of physical domination and the extraction and redistribution of resources. In this sense, they require not only a territory where their firepower can be discharged, but also set of individuals upon whom they can wreak their violence. The weapons need the 'soldiers' capable of using them (and determined to do so), and the institutions capable of organising these soldiers. The promise of profits made from violence has therefore increasingly come to depend on the tertiary service sector more than on the secondary industrial sector, and furthermore on the efficiency with which it succeeds in combining traditional organisations active in the private exercise of violence like mafias, gangs, and terrorist groups, with more advanced organisations like military corporations and other private security firms. Depending on the context, the political or the economic component of the service will prevail. The affiliates of a mafia clan, or a narco-trafficking gang can defend the illegal trafficking of their organisation from assault by the enemy; dedicate themselves to the practice of extortion/protection of the commercial entities and businesses present in their territory of entrenchment; or be involved in any number of subversive plans that their boss decides to execute against the state. These may include even his eventual aspiration to construct a legitimate political career. In West Africa, for example, several warlords have used the riches illegally accumulated during the conflict to reinvent themselves as political leaders, and participate in the electoral campaigns, with their demobilised ex-combatants providing the support they need to collect votes (Reno, 2009b). Many Islamic fundamentalist groups, vice versa, it seems reversed this process beginning to sell their followers the brand of an unitary Islamic State (IS) long before its (still to come) realisation; and cashing on extortion and illicit traffickings (arms, drugs, oil, and cultural properties) to finance their political project (Weiss, \& Hassan, 2015).

A contractor may rather be hired by his own government to combat terrorism; employed by a regime that is unable to train its own troops or faces a rival faction; or may simply be engaged to provide the security for the plants of a multinational company located in dangerous countries. PMCs can provide a vast array of services: research and analysis, technical services (information technology services, system support), operational support (logistics, training, intelligence services), and combatants (Perlo-Freeman, \& Sköns, 2008: 6). 
As is the case with all complex settings for trade and commerce, the market of violence generates related goods and services industries which, at times, can even surpass the 'parent industry' both in terms of profit and the employment of skilled labor. On the legal side, these satellite industries include, for example, companies that produce video-surveillance systems and electronic and biometric machinery for access control, as well as agencies offering investigation services. Nourished by an increasing societal alarm over the growing threat (sometime more propagandised than real) of crime and terrorism, this economy, in parallel with the economy of violence (in a narrow sense), is estimated to produce a turnover of 100-120 billion US\$ a year, with an annual growth rate of 7 to 8 per cent (OECD, 2004).

On the illegal side, we must consider satellite industries such as drugs, counterfeited or smuggled goods, and forced slave labor; as well as services directed at the systematic pillage of natural resources and the environment, or the recycling of toxic waste (Clapp, 2001; Le Billon, 2005; Peluso, \& Watts, 2001). These are, in fact, the activities that allow a group entrenched in a given area to reap the profits of the powers of intimidation and control that derive from the direct exercise of violence; and to evolve from the level of a mere criminal organisation to the more advanced stage of a mafia system. But in this case, what should be highlighted (but which is more often obscured) is the function of demand: the tastes and needs of the consumer, which are almost entirely external to the criminal environment, determine the quality and the nature of the offer (Gottshalk, 2009).

\subsection{Shadow Economy and Finance}

Analysing the evolution of the market of violence from the perspective of international trade means going beyond the traditional, circumscribed perspective of weapons transfers, and adopting a much more complex and fleeting model of analysis linked to the much discussed and contested concept of shadow economy. Even though it is very difficult to get accurate information about shadow economy activities on the goods and labor market, because all individuals engaged in these activities do not wish to be identified' (Buehn, \& Schneider, 2012: 2), nevertheless the phenomenon it sets out to define is so vast that it is impossible to continue to ignore it.

According to recent research conducted in 162 countries, in fact, the weighted average size of shadow economy amounts to 17.1 per cent of official gross domestic product over the period 1999 to 2006/2007. In Sub-Saharan Africa, this average rises to 38.4; in transition countries in Europe and Central Asia, to 36.5 per cent; in high-income OECD (Organisation for Economic Cooperation and Development) countries, the average decreases to 13.5 per cent. Such estimates exclude proceeds from illegal economies, and consider only the legal production of goods and services intentionally hidden from the authorities in an attempt to avoid payment of taxes and social contributions, avoid the adjustment of standards imposed in the official 
labor market (maximum working hours, minimum wages, safety standard, etc.), and reduce the burden of administrative procedures (completing statistical questionnaires or other administrative forms). In this perspective, the shadow economy is considered essentially to be a reaction to normative excesses by the state; in particular, to tax and social security contribution burdens, and to increased intensity of regulations in the labor market, trade barriers, etc. The very existence of shadow economy, however, further reduces state revenues, which in turn reduce the quality and quantity of public goods and services (Buehn, \& Schneider, 2012; Schneider, \& Enste, 2007).

In the case of the market of violence, however, excluding illegal trafficking would be empirically impossible, since all too often the same actors operate in both dimensions: legal and criminal. The shadow economy, therefore, should in this case be defined in its wider sense as the area in which the grey market, represented by war industries and PMCs, meets the black market, which typically attracts activities of transnational organised crime, be it in the form of monetary transactions or barter (trading drugs for arms is the most frequent case here). For the actors operating on the grey market, the decision to conceal themselves can be explained by the reasons listed above, to which, however, we should also add the demand (and sometimes need) that their clients remain anonymous. On the other hand, given their nature, for those who participate in the black market, invisibility constitutes an essential prerequisite. In the particular case of terrorists and guerrilla movements, that is, of VNSAs of a more political orientation, the inscrutability of the market offers the possibility of concealing behaviours that could undermine the basis of their consensus - such as the decision to seek financing through narco-trafficking.

The end of the Cold War represented the moment in which two different processes of development met and merged into a new kind of global shadow economy of violence. The first regards arms trafficking. The mergers imposed by the downsizing of the military-industrial complex eroded the national identities of the defence industries, an experience that was actually common to all sectors involved in the processes of globalisation. In this case, the de-localisation mainly took the form of the concession of production licences and technology transfers granted to subsidiary companies and foreign commercial partners. As a consequence, the state not only lost any residual possibility of appealing to the national interest, but is also no longer capable of imposing (if it wished to do so) respect for domestic and international norms related to arms transfer. A further problem 'is presented by the growing employment of dual-use technology in defence equipment, thus permitting suppliers to source controversial equipment in components that are treated as far more innocuous'. If clients have the possibility of acquiring components to be assembled in their own plants at a later time, the producers can easily deny the military nature of the order; and 'indeed, current policy seems designed to facilitate this process rather than actually address it' (Cooper, 2006: 123). Finally, the proliferation of light weapons, impossible to trace and easy to market, even in a barter economy, should not be forgotten. 
The second process regards narco-trafficking, inasmuch as drugs represent the main commodity and source of income for criminal organisations (Courtwright, 2001; Gootenberg, 2008; Thoumi, 2003). As is true of weapons, drugs are certainly not a new product; and their relationship to war in particular has been broadly documented. The modern history of drug trafficking is marked by a strange but significant trajectory that begins with the successive wars with which the British imposed the total legalisation of opium traffic on the Chinese (between 1839-1842, and 1856-1858, respectively), and concludes with the many pointless wars fought today by the Americans, mostly in Latin America, in an effort to eradicate the production of drugs (Youngers, \& Rosin, 2005). Over this time span, the war-drugs connection has been confirmed by at least two remarkable events: just as the birth and the development of the heroin market in the Golden Triangle was linked to the Chinese Revolution and the Vietnam War that followed (Chin, 2009), the thriving Golden Crescent essentially owes its success to the wars in Afghanistan, beginning with that fought against the Soviets in the 1980s (Unodc, 2009). The end of the Cold War, in this case, created an extraordinary qualitative jump.

The fall of the Russian and Chinese borders, which essentially broke down the doors to an entire continent, offers criminal groups the unforeseen and unprecedented perspectives of growth in drug consumption on the one hand; while on the other, it also presents them with new, unlimited resources and extraordinary opportunities for investment. ${ }^{10}$ Narco-trafficking routes multiply and trace increasingly bold perimeters around world-economies that enrich the large and small organisations which find themselves involved in the construction of what has become a real sphere of 'criminal prosperity' (Fabre, 2003) as the links of a long chain of commerce along which any illegal goods - even weapons and slaves - can travel.

Yet the integration of these two developmental processes into a global shadow economy of violence cannot simply be reduced to the possible confluence of drugs and arms in the same trade networks, nor to the fact that the same criminal actors are likely to manage their distribution. Neither can it be explained by the common interest of its protagonists to marginalise the state - itself increasingly at ease with the various roles it is being asked to play each time: from the laissez-faire theoretician, to the generous financier of war enterprises and the direct beneficiary of corrupt practices that regularly accompany the development of a black market. ${ }^{11}$ The most

10 The Russian and Chinese cases are certainly among the most interesting and most relevant, both with regard to the dimensions that the criminal phenomenon has assumed, and the sudden shift in two of the greatest world powers from a state-run economy to a market economy (although with somewhat different modalities). On Russia, see Galeotti (2004); Volkov (2002 and 2004). On China, see Chin, \& Godson (2006); and Shiu-Hing Lo (2009).

11 Cox, M. D. (2008). Its first part is dedicated to the general analysis of the problem of political corruption in its relation to drugs and weapon trafficking; the second is a closer look at individual cases related to several countries on different continents. See also Beare (2003); and Holmes, L. (2007). 
relevant aspect is the fact that both processes - the arms trade and narco-trafficking - can only maintain their strength by generating new violence. This implies the militarisation of every single zone of territory through a process of subcontracting to private legal and illegal actors, as well as an extension of the range and the intensity of coercion - making violence available to a growing number of individuals for governing their social and work relations. ${ }^{12}$

The shadow economy could not exist without shadow finance. Any type of grey or black activity that necessitates the virtual displacement of capital, or direct transfer of cash - as still happens in almost all retail sales of illegal goods and in the daily practice of corruption - requires, sooner or later, some form of the camouflage known as 'recycling' or 'laundering'. This final and decisive phase of concealment takes place in the global and abstract sphere of financial capitalism, but has at least two physical points of contact with reality (even though they are difficult to locate): the bank where the money was initially handled or deposited, and the financial haven in which the sum is destined to 'disappear' (Masciandaro, Takáts, \& Unger, 2007; Unger, 2007).

The liberalisation of financial markets that began in the 1970s, with the hasty dismantling of the system of checks and balances conceived at Bretton Woods following the end of World War II, is undoubtedly the event that, more than any other, created ideal conditions for those who wish to conceal their profits without encountering excessive obstacles. 'The Western financial system - wrote Susan Strange, with extraordinary awareness, if not precognition of the oncoming global financial crises - is rapidly coming to resemble nothing as much as a vast casino. Every day games are played in this casino that involve sums of money so large that they cannot be imagined'. Crowds of young men 'in the towering office blocks [...] play by intercontinental telephone or by tapping electronic machines. They are just like gamblers in casinos watching the clicking spin of a silver ball on a roulette wheel and putting their chips on red or black, odd numbers or even ones' (Strange, 1986: 1).

The VNSAs that emerged at the end of the Cold War have not only succeeded in affirming themselves as protagonists in both the territorial processes of authoritative reallocation of resources, and the sphere of transnational trade in illegal goods; but, thanks to their almost unlimited ability to produce profits, have also become the preferred interlocutors of the representatives of speculative interests present in the financial market. In this sense, history reminds us once again of the pre-state era, when armies were a private resource offered up for sale to any sovereign who was able to pay for their services (Lane, 1979), but re-interpreted in ways that allow the new VNSAs to respond to the demands of the market.

12 Or even for guaranteeing the body parts that are vital for their survival or that of their clients. Given its structure, this market could not exist without a consolidated network of physicians and health-care structures available to collaborate with elements of the organised crime (Goodwin, M., 2006). 
From the moment in which monarchies began to effectively implement tax collection policies and thereby guarantee the central treasury a constant flow of revenue to be invested in strengthening the military apparatus, the market ends up assuming a subsidiary role. That role becomes truly critical in a time of war when the government cannot continue to rely only on the current budget to face the many expenses that, because of the need to arm, clothe and feed its soldiers, it cannot postpone to a later date. In similar situations, the duality of coercion-taxation must rely on a third element: credit (Tilly, 1990: chpt. 3). The market again enters into play, advancing the necessary sums through loans granted by the banks and by the states' issuing bonds to raise new money.

In most cases, the discharge of public debt generated in this manner is achieved by raising taxes and printing money in order to fuel inflation - to which governments attribute the double advantage of reducing workers' consumption by directing the saved resources towards war production or the soldiers on the front lines, and increasing fiscal revenues thanks to rises in the price of goods. It is worth noting that this inflationary strategy was bitterly contested at the beginning of World War II by Keynes, who affirmed that, apart from being a waste of resources, it also damaged workers and risked provoking social disorder. Instead, he proposed a plan for a mandatory fund to be deducted from workers' salaries, which would allow the government to limit consumption, and make it possible for workers to have access to their earnings at the end of the war. This strategy was based on the assumption that 'for each individual it is a great advantage to retain the rights over the fruits of his labour even though he must put off the enjoyment of them. His personal wealth is thus increased. For that is what wealth is, - command of the right to post-poned consumption' (Keynes, 1940: 30; see also de Carvalho, 2008). ${ }^{13}$

The prolonged reliance on mercenaries and other actors, such as the chartered companies, should be interpreted through this same lens of the subsidiary role of the market with regard to the state. Mercenarism allows sovereigns to compensate for the lack of political legitimacy that prevents them from instituting a mandatory draft. Chartered companies play a more articulated role. First of all, they help the state to reduce the otherwise unbearable costs of colonial conquest by assuming all the risk of the enterprise while sharing the profits with their governments. Besides that, thanks to their ability to circulate goods and money, and to feed consumption, they contributed to creating the right conditions for the birth of Industrial Revolution. British government, in particular, took all the possible advantage of the East India Company valuable entrepreneurship; but it also did not hesitate to dissolve that same company - as we have seen - as soon as its claims to independence transformed it

13 Much more recently, it has been sustained that the inflationary effects of wars, and the consequent risks of market instability are among the main causes of the profound aversion towards war always shown by the financial communities of different countries (Kirshner, 2007). 
into a political menace (Lawson, 1993). It is therefore not by chance that with the entry into the century of mass conscription and the industrialisation of death, both of these actors tended to disappear, or, at best (as far as the mercenaries were concerned, in any case), survived only in their residual form as extras in dirty wars.

On the contrary, today the state increasingly assumes the subsidiary role with regard to the market of violence, which asks it to limit itself to providing investment opportunities (i.e. wars), and, even more directly, sub-contracts. The inversion in the direction of the relationship emerges, for example, from the statistics related to the role of private contractors employed by the USA in the wars of Iraq and Afghanistan. Employees of private corporations constituted approximately 50 per cent of the forces deployed in the field, confirming the tendency which had already been evident during the conflicts in Yugoslavia, and which analysts justified through drastic cuts in the logistics and support personnel in the US Department of Defense soon after the end of the Cold War. The contracts awarded by the DOD in the fiscal year 2007 and first semester of the year 2008 numbered 55,603, for a total cost of 30.3 billion dollars. This money covered services ranging from the maintenance of installations to their security, from supplies to reconstruction (Gao, 2008). ${ }^{14}$

Yet, what the numbers alone do not reveal is the structural nature of this reversal in power relations. Today, the DOD is no longer capable of mounting a military operation without relying on private corporations; and, in the near future, making up for the loss of competencies and know-how caused by this massive reliance on outsourcing could become untenable. Even if it is true - as most scholars in the field doubt - that this kind of practice has so far helped reduce the overall cost of war, the growing dependency of the government on a market that is highly imperfect and uncompetitive in its very origins, seems destined to give rise to practices such as cartel strategies, embezzlement, and corruption (which have already been amply documented), that are facilitated by the lack of controls: in 1998, the Pentagon employed one auditor for every 642 million dollars' worth of contracts; in 2008 it had one auditor for every 2.03 billion dollars (Singer, 2008).

Compared to the era of mercenaries and chartered companies, this change could not be more radical: the state assumes all of the economic burdens of the conflict while private actors reap all the profits. For the companies involved, in contrast to what happened with the old chartered companies, the risk of the enterprise tends toward zero: they do not need to advance the capital, which are provided at the time of the contract by the US government and other eventual clients (upon whom the

14 With the data available, it is impossible to calculate the per cent value of this budget item over the total cost of the two wars. However, several projections referring to the fiscal year 2006 are available in Perlo-Freeman, \& Sköns (2008: chpt. 4). For a much more comprehensive analysis of the real cost of the war in Iraq, see Bilmes, \& Stiglitz (2008). The US government is not capable of providing any information on the widespread practice of subcontracting and its effects on contract costs. 
additional burden of the frequent cost increases in the course of the action are destined to fall); neither do they need to conquer a market and compete for the acquisition of resources, given that their presence is favoured (or imposed) by the US administration itself. Between the years 2000 and 2006 of the Bush Administration, the DOD alone increased its contract expenses by 123 per cent; and yet 'while the amount, nature, and complexity of DOD contract activity have increased, its acquisition workforce has not adjusted accordingly, remaining relatively unchanged in size. Consequently, the incredible flurry of contracting means that the Pentagon's capacity to monitor the activities it outsources has never been lower' (Stanger, 2009: 89) - and we should add that this privatisation process in the USA has been pushed well beyond the war per se, and entered the entire governing apparatus which oversees foreign policy (Dickinson, 2011; Freeman, \& Minow, 2009).

In awarding such contracts, US companies were predictably favoured, creating what has come to be defined as a 'revolving door effect' between the government and industry - carrying the traditional lobbying activities associated with the 'old' military-industrial complex to their highest level of perfection - which has facilitated the spread of practices in defiance of all criteria for transparency and economic prudence. In 2005, a Congressional report showed how one PMC, Halliburton, was awarded the privilege of signing flexible contracts that allowed it to charge the government 1.2 billion dollars in undocumented (and highly questionable) expenses (Perlo-Freeman, \& Sköns, 2008: chpt. 5). It is worth remembering that Halliburton's rise had begun during President Clinton's second term, when the chair of the company was Dick Cheney who, thanks to the 'revolving door' was later named Vice-President in the Bush administration. In those years, in fact, the total amount of private contracts with the federal government was doubled, going from 1.2 to 2.3 billion dollars. This demonstrates that 'while reliance on contractors has been especially prominent in the Iraq and Afghanistan interventions, Republicans and Democrats alike have contributed to turning outsourcing into business as usual; what started as a Republican ideal has since been embraced by Democrats' (Stanger, 2009: 162).

It should be added that the practice of awarding external contracts is now part of every stage of war: from the training of troops to post-war reconstruction. As far as the first is concerned, from a strictly financial standpoint, PMCs are put in the position, at least potentially, to make a double return on a single soldier. Their employees have been recruited from the elite corps of the best armies, in particular the US and UK military, which bore the cost of their training within the old state apparatus. This competitive advantage - the fact of hiring trained personnel - was one of the conditions that allowed them to offer better compensation, forcing the state to undergo a substantial reduction in staff precisely in the most highly qualified military corps. Now the same soldier, first in the incarnation of recruit-client, and then in the role of professionalemployee, doubles his value, above all granting the private company the ability to select, from the earliest stages of the training process, those individuals best suited to 
pass into their ranks at the end of their service, and to convince them of the idea that loyalty to a brand is worth more than loyalty to their nation.

As far as the second case is concerned, post-war reconstruction, there is no doubt that the short-term economic advantage related to a single contract should be added the long-term one, related to the possibility of imposing one's own model of development on the defeated country. The reconstruction in Iraq, for example, not only ended up mainly benefiting US companies, but it also allowed them to mortgage the future of that country by destroying the economic and social capital available in its territory while at the same time reaffirming the superiority of the "military neoliberalism' of which they believe they are the diligent interpreters (Ruggiero, 2007; Schwartz, Mi., 2007).

This true surrender of power by the government, which relegates the state to a purely ancillary role when compared to that of the market, has found another, final proof in the evolution of the strategy for financing war. The Bush administration, in fact, not only reduced taxes instead of raising them from 2001 onwards - sacrificing any real possibility for the redistribution of income and hence acting to the exclusive advantage of the very richest (individuals and corporations) - but also obtained the necessary resources by cutting social spending and relying, in an unusual fashion, on extraordinary financing, allocated directly to different departments, outside of any real fiscal supervision. ${ }^{15}$

The choices made by the most powerful political regime in the world represent $d e$ facto an unprecedented legitimisation of the economic actors' demand to do without the state. The CEOs of a PMC today can concentrate in their own hands the powers that even totalitarian regimes were forced to share - with the indoctrinated masses on one side and with the economic and industrial apparatuses on the other. They can recruit soldiers, provide them with weapons, and finance their employment with the profits accumulated in the stock market - all thanks to the fact that violence is their chief source of income. Through this kind of activity, they end up becoming allies of their enemies: the justification of their very existence derives from the plausibility of the terrorist menace; from the entrepreneurship of narco-traffickers; from the ability of mafias, gangs and warlords to create a climate of emergency and social alarm.

All these other VNSAs, moreover, live symbiotically in the same market: they receive weapons and other resources necessary for the survival of their organisations from it, and they offer the profits from their activities to it in a circuit that feeds upon itself and whose development, therefore, does not seem destined to encounter major obstacles. Among these activities, the one which today seems best able to propose the most original financial model, and which presents the added advantage of profitable

15 The reduction in social spending has had dramatic effects on the public infrastructure whose task it is to resist natural catastrophes. These added costs then fall on the shoulders of the less affluent and less protected strata of the society. See Hossein-zadeh (2008). 
marketing, is narco-terrorism. Not only has this species of VNSAs succeeded in imposing itself as the point of natural convergence between two of the most profitable markets - drugs and light weapons - but it has also proven itself capable of innovation along the traditional lines: linking the resources coming from sponsor-states (Byman, 2005 and 2008) with the conspicuous capital raised among members of the diaspora, through the sometimes capillary system of charitable organisations (Acharya, 2009a and 2009b; Biersteker, \& Eckert, 2008; Costigan, \& Gold, 2007). 

Part III 


\section{Perspectives on the Coming World}

Exactly one hundred years ago, between February and December 1916, over 162,000 French and 143,000 Germans were killed (the total number of wounded was about 400,000 ) in Verdun - by many accounts the bloodiest campaign of the Great War: almost one casualty per minute, day and night, throughout the ten months of battle (Ousby, 2002). Located in the heart of the continent, Verdun marked the epicenter of the last truly European hegemonic conflict. It represents the industrialisation of indiscriminate massacre and, as a consequence, symbolises the apotheosis of the modern state before the era of totalitarianism - indelibly marked by the invention of extermination camps and weapons of Armageddon; as well as the triumph of mass ideologies and partisan warfare.

Verdun is paradigmatic of the shift from the nineteenth to the twentieth century, an event that summarises the past - in its naked essence - and foreshadows the future. The armies lined up on the battlefield still duplicated the organisational models of the previous century, especially in the hierarchical relations between the officers who, determined to defend their status and prerogatives, essentially placed their trust in discipline; and the troops, who were still far from offering a conscious and unconditional support of the war (Vagts, 1967). Even the strategic planning followed a nineteenth-century - or perhaps even an eighteenth-century - model (Liddell Hart, 1963). Yet the logistics of mobilising soldiers on the front and the level of production achieved by industrial planning already bear the clear mark of the twentieth century (McNeill, 1982: chpt. 9). The primitive technological nature of the period's air power make Verdun an epilogue to the previous century. And yet the merciless and obsessive repetition of attacks and retreats, the endless columns of men and arms that form the transmission belt feeding the engine of destruction, the moon-like landscape of craters and heaped remains (bodies, human and animal; the carcasses of vehicles; skeletons of houses and trees; and the lurking hulks of unexploded munitions) all seem to create what Clausewitz would have considered a 'perfect battle': one in which the reality of combat replaces an abstraction and serves the tendency to go to the extreme instead of moderating it. At Verdun, all the difficulties that usually diminish 'war performance' - what Clausewitz called the 'friction' of war (Clausewitz, 1976: Book 1, chpt. 7) - are transformed into a terrible propellent capable of repeatedly unleashing new energies.

The Battle of Verdun institutionalises the revolutionary principle of the universal draft, the substitution of professional soldiers with conscripts who have not been truly acclimatised to violence beyond a brief period of training; and yet also preserves the distinction between combatants and non-combatants, with only the former being recognised as legitimate targets. In this sense, it evinces a sense of clarity that is to be irretrievably lost in the future; and in particular after World War II, when the boundaries between the spaces devoted to war and those of peace, and between the military and civilians, become increasingly blurred. Finally, Verdun testifies to the 
impossibility of conveying the experience of war to those who have not lived it, be they relatives or friends. The daily cohabitation with death and suffering - which fosters uncommon feelings of brotherhood amongst comrades in arms, and at times even with the invisible enemy beyond the no-man's land (Fussell, 1975) - foreshadows the traumas suffered by a growing number of soldiers in later twentieth-century wars, as well as by millions of civilians who witness the destruction of their cities, and the even fewer who survive extermination camps.

In sum, the Battle of Verdun is the most complete expression of its time; it marks the end of the nineteenth century liberal state and a dramatic break of a gradual, if discontinuous, process of the growing inclusion of the masses in economics and politics by means of improved mechanisms of income redistribution and the birth of new forms of representation. Furthermore, this break in the slow and unfinished process of democratisation will be 'healed' by the rise of totalitarianism - with dire consequences for the processes of both war and peace.

The beginning of the twenty-first century was marked by the terrorist attacks of September 11, 2001 on Washington DC and New York. The collapse of the Twin Towers is as much an iconic and paradigmatic image as the carnage of Verdun. And that image as well seems destined to symbolise the turn of the new century with regard to warfare, summarising the past and foreshadowing the future. Many authors, as well as ordinary American citizens and their President, George W. Bush, compared the events of September 11 to Pearl Harbor; 'and one can see the similarities: surprise; planes; many dead. The differences [however] are more telling: Pearl Harbor was a military target; the attack came as the culmination of long-standing tension between the USA and another nation-state; there was a formal declaration of war' (Dudziak, 2003: 14). The attack on the World Trade Center, conversely, evokes the World War II aerial bombings of cities, which - like September 11 - intentionally targeted civilians with the express (yet failed) aim of breaking the nation's spirit. At the same time, September 11 foreshadows a future dominated by private violent non-state actors (VNSAs), considering that a small group of practically unarmed terrorists crashed two passenger airliners into the symbolic heart of global financial capitalism.

\subsection{A New Geography of Cities and States}

September 11, 2001 epitomises the main results of the analysis conducted in the previous chapters. It is worth reviewing some of these findings with the aim of prefiguring their possible outcomes in the ensuing years.

Our preliminary assumptions are the following:

1. at present the state is going through a process of increasing dispersion of its prerogatives, induced by globalisation and by the state itself, which inverts the traditional sequence of modern state formation, favouring the de-construction of 
state apparatuses on the one hand, and offering unprecedented opportunities for VNSAs on the other;

2. the end of the Cold War produced a similar inversion in the historical relationship between the centre and the periphery; and, as a consequence, a growing number of centres - states traditionally positioned at the highest ranks of the international hierarchy - are now dependent on (insomuch that they feel menaced by) one or more peripheries; which, in turn, vindicate a higher level of protagonism on the global scene, and seek payback (often legitimately) for wrongdoings they have suffered;

3. this evolving scenario gives rise to new cleavage structures, or prolonged and systemic conflicts, in both functional and territorial dimensions. For example, contention between the unemployed and immigrant communities; or between the global culture (which is chiefly perceived as American) and local traditions; or even between a secular interpretation of the role of the state and a religious one which requires the submission of the citizen to the Law of God.

In such a context, it is not at all surprising that war - as continuation of politics by other means, and as one of the historically-preferred instruments for the authoritative allocation of resources - is going to change. The true question, however, is not what is new in the new wars; nor whether it is worth trying to trace the 'proper' limits of warfare, which would exclude any kind of organised violence that does not perfectly fit those parameters from our analysis. On the contrary, we must abandon any ideological or academic preconception and look to the actors of violence, the means by which they practice it, and to what ends.

In its analysis, this book included, and even focused on, VNSAs, never attributing a peculiar and superior role to the state, nor prefiguring the capacity of any specific discipline to guarantee a better knowledge of war. We further assumed that war must be studied within the confines of the scenario in which it is waged, more or less effectively, whether according to the laws of war or in an openly criminal manner. The main corollary of this assumption is that, from time to time, and from place to place, war will be the result of a peculiar combination of traditional interstate conflict managed by the military-industrial complex, asymmetric and guerrilla warfare, terrorist attacks, as well as telluric and routine organised violence meted out by warlords, mafias, or gangs.

The following are our main findings concerning VNSAs as examined in each of the previous chapters:

1. VNSAs do not show any particular respect for the state; rather, they compete against, or more frequently, collude with the state. VNSAs are capable of offering their members what they need to become 'good soldiers': charismatic leadership, a code of honour to reinforce group cohesion, effective training, and the right social setting to transform the act of killing into an entirely legitimate act of duty. Terrorists, mafia members, and contractors do not hesitate to inflict violence 
upon their targeted victims - or even upon themselves, in some cases going so far as to transform their own bodies into improvised explosive devices;

2. we offered a classification of all the military professions available in the postCold War global market of violence. Further on, we claimed that VNSAs are better placed than state armed forces (and in particular, those of democratic regimes) to inculcate a lack of inhibition to kill in their affiliates because they can reduce the physical and mental spaces of engagement with the enemy to a minimum: the territory to be conquered or controlled may be a single street, and the logic of war may be reduced to that of a feud. Depending on their nature - non-profit, commercial, or fringe - VNSAs may adopt varying combinations of indoctrination, training, and coercion to meet their institutional aims. And by mimicking the rites and codes of secret societies, VNSAs have the further advantage, as compared to state armed forces, of extending the promise of being members of an elite to all their members (instead of restricting it to an officer corps). Moreover, the unparalleled proliferation of different brands in the private market of violence is the result of the extraordinary capacity of these different organisations to offer their soldiers that specific mixture of ideals, motivation, and economic incentives needed to gain their obedience - to compel them to kill and, if necessary, to risk their own lives. Finally, VNSAs adopt exclusion as the main means of reinforcing intra-group cohesion and esprit-de-corps: claiming loyalty to a faction, religious or ethnic group; and/or vindicating their professionalism in killing;

3. VNSAs take advantage of the processes of re-localisation and neoinstitutionalisation induced by the 1989 cleavages, gaining effective control of the neighbourhoods they occupy, and imposing updated versions of authoritarian or even totalitarian models of dominance. VNSAs perform well in both urban and rural spaces: in the former, conquering ghettos and the informal urban settlements at the outskirts of megacities, and using prisons as a reservoir for recruitment and legitimisation; in the latter, capitalising on central governments' inability to truly monopolise the use of force in the whole state territory in order to exploit natural resources, or establish narco-dictatorships to fuel the ever growing global demand for drugs consumption. In their confrontation with the state (above all with democratic regimes), VNSAs exploit the further advantages offered by their predilection for 'the spaces of concealment' and their ability to practice all the known forms of dissimulation;

4. VNSAs may develop their propaganda machines, recruiting professional or volunteer propagandists for spreading their messages, targeting a specific audience, profiling their stigmatised enemies, and revealing - as is the case with some terrorist groups - an extraordinary propagandistic eclecticism: using radio, video, and the Internet as both a 'pre-school of training camp' and a recruitment office. Moreover, terrorist groups can fully exploit the massive exposure offered by $24 / 7$ television news networks which reach a global audience, a target that may be of considerably less interest to mafias and contractors. Finally, while 
other brands in the private market of violence may limit themselves to indulge in self-representation, terrorists prefer to invest their resources also in developing their new narratives of heroism and martyrdom;

5. different types of VNSAs - mercenaries, pirates, chartered companies accompanied European states in their monopolisation process for centuries; finally to be discharged by those same states, mainly because of the risks these extra-governmental groups posed to the international order. The reasons for the sudden and relentless recovery of VNSAs at the end of the Cold War must be sought in the privatisation of internal and external security imposed both by the state de-construction and the globalisation process. The influence of market rules on the laws of politics generates a vicious circle of growing insecurity and parallel demand for more protection. The final result is an unprecedented increase in the ambits of coercion, and the downgrading of security from a social and political right associated with citizenship, to a mere service available only to those who can afford it (and the quality of which is proportionate to the amount of money each individual can invest in it). In addition, the proliferation of VNSAs feeds the production and commerce of arms and, with the corresponding market of illicit products, generates limitless profits to be reinvested in the legal economy and recycled in the international financial market.

This post-Cold War scenario is set to subvert the traditional dynamics between coercion and capital and, as a consequence, the relationship between the state and the city. As has been observed, in fact, 'behind the changing geography of cities and states operated the dynamics of capital (whose preferred sphere was cities) and of coercion (which crystallised especially in states). Inquiries into the interplay between cities and states rapidly become investigations of capital and coercion. A surprising range of combinations between coercion and capital appeared at one point or another in European history' (Tilly, 1990: 5). Since the end of the Cold War, a new combination of coercion and capital has appeared which seems to be crystallising especially in cities, almost bypassing the state. This specific new combination is producing two main consequences - the redefinition of the very concept of sovereignty, and the revival of the clan as a form of social organisation - which prefigure the advent of a condition of 'permanent global civil war', and the need to finally recognise a new way of conceiving security.

\subsection{Clusters of Sovereignty}

The state-centric perspective has made it almost impossible for scholars fully to grasp the meaning of the transformations that occurred after the Cold War, especially with regard to the organisation of violence (Davis, D. E., 2003). In the contemporary context - as we have argued throughout this book - the state is no longer the sole political 
and social actor. In addition to the head of a government, the leader of a rebel group or gang, and the boss of a mafia clan or narco-trafficking cartel all seek the loyalty (or at least the acquiescence) of individuals present in a given territory. These VNSAs create new political spheres of reciprocity, 'new imagined communities', each of which is capable of offering its members different identities, and employs different models for their coercion and welfare: 'in a globalising world where neoliberal political and economic policies are ascendant, citizens become less connected to national states as a source of political support or social and economic claim-making, and more tied to alternative "imagined communities" of loyalties built either on essentialist identities like ethnicity, race or religion or on spatially-circumscribed allegiances and networks of social and economic production and reproduction. [...] When these new imagined communities exist apart from (if not in opposition to) traditional nation-state, they often choose (or are forced) to rely on their own armed actors to sustain, nurture, or protect their activities and dominion, especially when they conflict with national state priorities' (Davis, D. E., 2009: 226).

Between the nineteenth and the twentieth centuries, in a world composed of sovereign states, the idea of the nation revealed itself to be the most effective agent for reinforcing individuals' sense of belonging to a community. The concept of 'nation' makes it possible clearly to delineate the border between the internal space of the legitimacy of the sovereign power, and the external space occupied by other political entities. War represents the moment at which these borders are crossed; while peace intervenes to reestablish order, by redrawing the geographies of power or restoring the status quo ante. The privatisation of violence generates a far more fluid form of territoriality, and with it, an unstoppable proliferation of contested spaces and no man's lands, both between the states and, above all, within them. Sovereignty ceases to be an absolute and indivisible prerogative of the state and instead becomes a resource to be apportioned, and occasionally divided, within specific (conceivably even cross-border) regions or in the suburban peripheries: 'effective sovereignty is not necessarily predicated on and defined by the strict and fixed territorial boundaries of individual states' (Agnew, 2009: 438; see also Brown, 2010). ${ }^{1}$

Within urban perimeters, and not only in developing countries, mafias and gangs transform some neighbourhoods into junctures of strategic importance, as much from the political perspective of effective exercise of coercive power and the maintenance of a certain degree of social cohesion, as from the economic point of view of the management of traffic of illegal goods. Even more than the state-level dimension, the urban sphere also highlights a second aspect of these new imagined communities: their transnational character. Terrorists, mafia, and gang members

1 And, as a consequence, nationalism 'is simply no longer the historical force it was in the era between the French Revolution and the end of imperialist colonialism after World War II' (Hobsbawm, 1992: 169). 
follow the migratory flows created by globalisation, projecting themselves from the peripheries (developing countries) toward the centres of the world capitalist economy (developed countries) while maintaining their identity and sense of belonging to the group. Their first task is to subjugate the members of their own community of origin, and shape the new environment to serve their own needs (Armao, 2000).

This is not unlike the behaviour of the contractors of modern private military corporations (PMCs), whether hired by the governments of developing countries in an attempt to manage conflicts with internal enemies, or engaged by transnational enterprises seeking to protect their investments in unsafe areas; but in these cases, this new mercenary class runs the more traditional route from the centre of the worldsystem to its many peripheries.

Each of these groups - whether mafia, gang, or terrorist - may be defined as 'political' only if it is capable of effectively competing for the monopoly of force in a certain territory, however limited. Yet the peculiarly private nature of VNSAs cause them to operate like a 'company' within a cluster, developing systemic relationships with other 'companies' operating in its area of settlement. ${ }^{2}$ Just as some industrial clusters branch out well beyond national borders, some of these new political clusters - as just explained - travel abroad and create settlements in regions far from their country of origin, thereby demonstrating not only their ability to cooperate and compete at the global level, but also to pose a new challenge to the traditional prerogatives of the state. ${ }^{3}$ In this way, different clusters of sovereignty may become concentrated, and are therefore destined to co-exist - and sometimes conflict - within a specific geographical space. In terms of physical, military, control of a particular territory, the traditional state often tends to become just one among many clusters laying claim to a portion of the coercive power exercised by all the violent actors present in a given area (and the state may not even represent the most successful of these contenders). This is true of so-called failed states, in which the government in charge in the capital competes with ethnic clans, liberation movements, warlords, or simple criminals in a daily struggle for the control of territory. And yet, also democratic regimes take the same risk when, for example, are incapable of guaranteeing the full complement of citizenship in the various zones (both large and small) of their own national territory controlled by mafia.

A fragmented political universe characterised by a plurality of sovereignty clusters may be even less appealing than the world of states that prevailed throughout the

2 Following the pioneering studies of Porter, a cluster is usually understood as an integrated, geographically proximate group of companies, suppliers, service agencies, and other institutions in a specific sector, linked by externalities of different kinds (Porter, 1990 and 2003). For an analysis that foregrounds the different territorial dimensions involved, see also Fujita, Krugman, \& Venables (1999). 3 On the apparent paradox of the simultaneously local and global character of industrial clusters, see Wixted (2009); and Pitelis, Sugden, \& Wilson (2006). 
twentieth century. Certainly, even the possibility of simply reconstructing its contours or predicting its developments becomes almost impossible, and, in many ways, may cause us to become nostalgic for the admittedly meagre heuristic capacities of the old paradigms such as the balance of power or international anarchy. In any case, in an effort to further the analogy with industrial clusters, it is possible to identify at least two variables which allow us to recognise and classify political clusters:

1. life cycles: sovereignty clusters follow a four-phase model of development (Wolfe, \& Lucas, 2005: 6-8). The first, latency, witnesses the presence in a given territory of conditions that are favourable to the birth of a particular kind of violent organisation: an adequate military recruitment pool; forms of social aggregation capable of supplying the required basis for consensus among the local population; the presence of political and economic actors ready and able to exploit the opportunities created by the new cluster. The second phase, development, represents the moment in which a given group asserts itself through its own initiative and the boldness of its actions; at this juncture, recourse to direct violence is the action which best legitimates its claims to governance over the area of settlement. The third phase, institutionalisation, entails a gradual reduction of the conflict made possible by the consolidation of relations with other political and economic actors in the area, as well as the accumulation of enough financial resources to ensure the survival of the organisation. Finally, the fourth phase, transformation, highlights the cluster's ability to adapt itself to the needs of the wider market of violence (for example, modifying its organisation and adjusting the strategies it employs to govern its own territory); or, vice versa, its tendency towards paralysis and decay. Many criminal organisations of a mafia-like nature, like some noted terrorist groups, have demonstrated a strong predilection for institutionalisation; and, in some cases, for the process of marginalisation which, at times, is accelerated by the appearance of new, more dynamic, and aggressive actors; ${ }^{4}$

2. the degree of structuralisation: sovereignty clusters are characterised by the degree of access to the organisation, by the level of rigidity of its internal hierarchies, and by the extent to which its values and rules are shared by its members. On the basis of these criteria it is possible to label the clusters as pure agglomerations, social networks, and political complexes. ${ }^{5}$ The state remains the group which best embodies the prototype of the political complex: with the concept of citizenship

\footnotetext{
4 Numerous examples could be listed here; on the one hand, we might cite the evolution of the dynamics between different criminal organisations in a country like Italy, and the effects on their international standing created by the appearance of new actors such as the Russian mafiya; on the other, the transformation of terrorist groups like Hamas into real political parties. See, respectively, Armao (2000: chpt.); Mishal, \& Sela (2006).

5 This classification is inspired by Gordon, \& McCann (2000). See also Blien, \& Maier (2008).
} 
effectively setting the boundaries of individual and collective identity; the police and military forces safeguarding the territory; the judiciary and laws setting the limits of the power of sanction. But in urban peripheries, where the government's authority may be weak or lacking in some ways, the mafia can represent the most effective political complex; and in slums or refugee camps where the state is completely absent, social networks of a criminal nature may substitute it in the daily exercise of violence. Finally, in the far-flung zones of the production of such 'luxury goods' as opium, cocaine, diamonds, and coltan, even simple agglomerates of narco-traffickers, contractors or guerrillas can be enough to ensure the coordination that is a prerequisite for the violent expropriation of the territory's resources. In fact, in that context, the model of sovereignty associated with the pure agglomerate may reveal itself to be far more effective than others, thanks precisely to its low degree of institutionalisation and substantive lack of prescriptive ties. In fact, the view of politics as the daily practice of domination obliges us to consider the state as just one possible cluster among many others and confirms that there is no cluster type intrinsically superior to others. Political complexes are not necessarily more efficient at exercising control over a given territory simply because they possess a more sophisticated level of organisation (Armao, 2014).

The strategies of coercion pursued by groups that claim some form of authority over the processes of extraction and redistribution of resources emerge from their continuous interaction with the local environment in a game of reciprocal conditioning. Every sovereignty cluster expresses a unique strategy for the use of violence that changes according to the life cycle phase in which it finds itself at any given historical moment. In particular, their power of coercion may be used for internal or external ends. The state experience shows that the monopoly of the legitimate use of physical force rests in the hands of the police as well as the military; and that it is the governments which determine, depending on the circumstances, its use against their own citizens or foreign enemies. In the same way, mafia and terrorist organisations use violence not only to oppose their adversaries, but also to ensure group cohesion (that is, to maintain order and repress any attempt at sedition) as well. The most authoritarian of these groups attack even their own members (adopting the strategy of next-to-kin revenge, as we said in chapter 3) if they believe that these individuals are capable of dissociating themselves from the aims of the group, thereby betraying it. Also, we should mention that, because each of these groups has access to economic as well as violent resources (instruments for exercising violence), they can adopt a peculiar combination of coercion and capital in exercising their own supremacy.

In the European experience, the prevalence of coercion or capital, respectively, has historically defined competing developmental models of states and independent cities, determining the success of the former, and the substantial disappearance of the latter as autonomous political subjects (Tilly, 1990: chpt. 1). Today, different 
percentages of these two components - coercion and capital - make it possible for us to distinguish, for example, terrorists from members of the mafia, and both of these from contractors (as we have seen in more detail in chapter 3); while cities acquire an unprecedented role as protagonists in the daily application of coercive power.

Democratic governments are not passive spectators in these processes of clustering. On the contrary, at times they support the development of sovereignty clusters; or, rather, in an attempt to keep down the costs of maintaining their own monopoly of force, in fact promote them as new protagonists. In some cases, in addition to the widespread and differentiated practices of subcontracting to private actors on a domestic level, governments re-appropriate the old method of co-opting local magnates, even on an international level. Such a strategy is not, in fact, entirely new. In Europe, in particular, the state-making process 'became a game of shifting coalitions: Kings rallying popular support by offering guarantees against cruel and arbitrary local magnates or by challenging their claims to goods, money or services, but not hesitating to crush rebellion when the people were divided or a sufficient military force was at hand; magnates parading as defenders of local liberties against royal oppression, but not hesitating to bargain with the crown when it appeared advantageous. Ultimately, the people paid' (Tilly, 1975a: 24). Both the strategies of co-opting local magnates and sub-contracting to private actors have characterised, although to different degrees, the processes of formation of almost all European states. These later availed themselves of the same strategy to lower the costs of governing the colonies (Thomson, 1994).

The example of the USA is particularly relevant, if one considers the country's double status as a superpower and a model for democracy. In the USA, in fact, the privatisation of security - as previously repeatedly asserted - has been a fundamental element of government for some time now, among both Democratic and Republican administrations at the federal and state level. Heavy reliance on outsourcing was first extensively experimented with in the domestic sphere (particularly in the prison sector) before being extended to the entire defence sector, and finally to the management of war itself. ${ }^{6}$ Furthermore, co-opting local magnates has been one of the most widely-used instruments for limiting the state's direct involvement in those conflicts on the periphery of the international system whose geopolitical imperatives nevertheless make them impossible to ignore. One is reminded of the case of Afghan mujahideen, who were armed and financed by the Americans to fight against the

\footnotetext{
6 As far as the privatisation of the prison sector is concerned, some recent studies have shown how it has introduced a peculiar element of economic profitability to the exercise of repression by forming a 'correctional-commercial complex' beyond any real public control, in which legislators, lobbyists, private industries, and correctional system professionals collaborate to their own advantage, entirely abandoning any plans for the rehabilitation of prisoners and wreaking devastating effects on the quality of other services (Blomberg, \& Lucken, 2000).
} 
Soviets, and who subsequently transformed themselves into the Taliban, becoming one of the most ferocious enemies of the USA (Cooley, J. K., 2000).

The main consequence of these peculiar clusterings of sovereignty has been the gradual but unrelenting evolution of the USA from a 'social state' to a 'penal state' (Simon, J., 2007), as witnessed by the hijacking of increasingly large portions of the national budget from the traditional sectors of public welfare (health, education, unemployment benefits) to the criminal justice system and defence (military). All this has made the USA not only the country with the highest rate of imprisonment in the world, but has also produced the excesses of Guantánamo and Abu Ghraib, which have jeopardised the country's status as a global leader and democratic role model (Evangelista, 2008). In addition, the USA has sought to export this model, by for example imposing the militarisation of the drug war on its Latin American allies, a strategy that revealed itself to be a failure (Youngers, \& Rosin, 2005); or by involving several European governments in the illegal practice of extraordinary rendition (Paglen, \& Thompson, 2006).

\subsection{The Rule of the Clan}

This new way of conceiving (and practising) sovereignty parallels the resurgence of the clan - a type of organisation far older than the state and one which has never completely disappeared - as the preferred imagined community. The term clan currently carries a wealth of meanings. At one extreme, it may indicate the unilineal male descent from a single progenitor. At the opposite extreme, it may be understood as a simple synonym for an exclusive group of people who share common interests, of whatever nature those may be. And equally ample is the variety of meanings that accompany the use of the word according to whether it associates the idea of the clan with, for example, a glorious past marked by notions of fraternity and honour; or, vice versa, with the underworld of organised crime.

For our purposes, clan is defined as an organisation aimed at uniting and safeguarding the interests and security of its members, based on a subjective notion of identity and belonging, far more than on the objective reality of kinship understood as the existence of family or blood connections. More precisely, 'a clan is an informal organisation comprising a network of individuals linked by kin and fictive kin identities. [...] Clan ties are neither exotic and primordial, nor inherently negative or undemocratic: they are networks based on the rational calculations of individuals [...]; more important than the objective reality of kinship is the subjective sense of identity and the use of the norms of kinship - such as in-group reciprocity and loyalty - to bind the group and protect its members' (Collins, 2006: 17).

This also means that the limits of a clan are defined by their own claims of identity, which, nevertheless, must be confirmed within the social context of reference through a process of affirmation and verification of its own legitimacy; and, 
in the final analysis, by the capacity to obtain the obedience of its own members. Territory is the main factor in clan coalescence, and depends in no small part on shared living conditions and the creation of a collective memory. No less than the state, the clan is a social construction: 'A catalogue of commonplace postnatal means of kinship formation would thus include commensality, sharing food, reincarnation, co-residence, shared memories, working together, blood brotherhood, adoption, friendship, shared suffering, and so on' (Sahlins, 2013: 8). And 'if a relationship does not exist, then one can be created' (Nuttal, 2000: 34).

According to this definition, the clan may represent both the ethnic group and the electoral base or clientele of a political boss (Collins, 2006), as well as the modalities of socialisation within large industrial organisations: 'any occupational group which has organic solidarity may be considered a clan. Thus, a profession, a labor union, or a corporation may be a clan [..]. In these organizations, a variety of social mechanisms reduces differences between individual and organizational goals and produces a strong sense of community' (Ouchi, 1980: 24-25).

There are three main, correlated characteristics which contribute to better defining the clan: imagined family, social control (and informal justice), and neopatrimonialism.

\subsubsection{Imagined Family}

The social construction of the clan originates, first of all, with the rediscovery of the family as the basic factor of aggregation; but, significantly, here we reference the extended family, and not the nuclear family which, precisely by prefiguring the death of the clan, constituted the social basis of modern capitalism: 'Until the modern period, corporations and nuclear families constituted a distinguishing feature of the particularly European institutional foundations of markets, polities, and knowledge. [...] Successful economic and political corporations undermined large kinship groups' (Greif, 2006: 310-311).

After all, the concept of family evokes links which are so strong that even the thought of any violation of them is taboo. The ties of blood (family and blood relationships), together with the ties of place (neighbourhood; region; area) and spirit (friendship) envisage the community as an organic, rather than artificial, complex in which relationships are not partitioned on the basis of specialised roles, but rather require that members of the community commit and are present in the totality of their being. Since antiquity, family has been recognised as the primary form of (social) organisation, to the point of configuring paternal power as a category in and of itself (Bobbio, 1985). The family is responsible for the primary socialisation of children; and defines the basic unit of the local community (Weber, 1978), as well as the friend-foe dichotomy that is epitomised by the blood feud (Grutzpalk, 2002). Therefore, evoking a return to pre-state origins through the image of the family, above all during a phase 
in which the collective identities that accompanied the state- and nation-building process are now in crisis - from the imperialistic forms of nationalism of European powers to the emancipative forms of nationalism of developing countries, which elicit an additional, larger identity, that of the international proletariat - shows itself to be a winning choice. And not only in cultural terms.

As a wholly imagined family (in which it is neither possible nor useful to make a claim for true blood communality), the clan shows itself to be useful to both politics and the market. On the one hand, it is better adapted to the growing privatisation of politics generated by the end of ideologies and of mass political parties; on the other, it responds more efficiently to the needs of a capitalism that is increasingly more dependent on the accumulation and circulation of money for speculative ends than on production and the sale of consumer goods. Precisely because it is better rooted in the territory and because of the nature of the ties it is able to develop within the organisation itself, the clan proves to be the best partner for the construction of those networks of patron-client relationships that are useful for the reproduction of new political and economic elites and that act as a flywheel for the corruptive phenomena associated with clientelism (Kawata, 2006).

\subsubsection{Social Control and Informal Justice}

The second characteristic, which depends on the clan's ability to appeal to familial ties, is represented by the possibility of guaranteeing a type of social control that is more effective and above all, less costly, than that of the state - without the involvement of the kinds of apparatuses of repression associated with the history of the state in its authoritarian and totalitarian manifestations. In fact, clan identity is as effective on the local level of the territory of origin as it is in the new settlements created by diasporas, basically rendering the state dimension superfluous. The main issue in this context is maintaining the social order, those mechanisms by which society exerts its authority over the individuals which comprise it and imposes respect for the compliance of its norms, punishing deviant behaviour if and where necessary. Put very succinctly, there are two feasible perspectives: social integration, or inclusion pursued through the adoption of adequate processes of socialisation; and social control. It is worth remembering that 'the core element in social control is the idea of self-regulation of the group - whether the group be a face-to-face primary group or the nation-state', and that social control is the opposite of 'coercive control, that is, the social organisation of a society which rests predominantly and essentially on force - the threat and the use of force' (Janowitz, 1975: 105-106 and 84).

At one extreme, we have liberal democracy, which, thanks to the procedures and institutions developed over the course of the twentieth century, has shown itself to be the state model best suited to promoting social integration. At the opposite end of the spectrum, today, the clan guarantees greater social order through direct control of its 
members, thanks precisely to the poorly differentiated nature of its community, and to the fact that within the group the pressure to conform is extremely elevated (LévyStrauss, 1963 and 1969).

In order to ensure this level of control, the clan relies on an informal, though not ineffectual, system for conflict management (both within the single clan, and among different clans) and the administration of 'justice'. The 'law of the clan' is based on codes of honour which, although quite familiar for the most part, are at times relatively sophisticated means for handling conflict through the use of force, if required (Weiner, 2013). Anthropological literature in particular highlights a wide range of 'informal' (that is, non-state) mechanisms for social control, some of which even envisage the creation of assemblies of varying scopes delegated with the task of mediating disputes, as well as ensuring that the rules of the feud are respected - with respect to both the nature and level of the violence undertaken in response to the injury or injustice suffered. Most significantly, the size of the group in question, and the relative impossibility of escaping the scrutiny of other members of the clan, make moral condemnation of the wrongdoer (social shame) the most effective method for guaranteeing respect of group rules, far more efficient than the fear of other sanctions. This kind of moral condemnation also represents the most important factor in the processes of socialisation and integration of younger generations to the values of the group (Caffrey, \& Mundy, 2001).

The state-making process intervened in these dynamics by removing every power of self-administration from the clan, assigning its rule to a higher authority with the aim of reducing, and eventually eliminating, the private exercise of violence within the state's borders; and eventually introducing the principle of the universality of the judicial system and equal treatment for all citizens under the law. However, the end of the state's monopoly of the legitimate use of physical force effectively restores ample margins of manoeuvre for the law of the clan: whether manifested as the outsourcing of the functions for maintaining public order to private security agencies, or the abandonment of parts of state territory to the control of organisations of a terrorist or mafia nature.

\subsubsection{Neopatrimonialism}

The third characteristic of the clan is the neopatrimonialist nature of its organisation. In this setting, it is neither possible nor appropriate to enter into the merits of a debate such as that on patrimonialism, which remains unresolved, and which since Weber has been interwoven with equally complex themes such as patriarchalism, feudalism, personalism, and clientelism (Roth, 1987; Weber, 1978). What is of relevance here, however, is the fact that the return (and the success) of the clan in the years following the end of the Cold War can be explained by the ability of this form of 
social organisation to successfully reinterpret patrimonialism, rendering it functional for the prevailing ways of understanding both politics and the market.

The neopatrimonialism of the clan refocuses attention on power structures and other forms of organisation that were typical in the feudal era: those based on personalistic ties, legitimised by peculiar mixtures of tradition and charisma. The clan develops collective identities, but of a particularistic - and not a universalist nature, starting with the creation of relationships of fealty between the leader and his followers based on both abstract and material interests (Roth, 1987). From this point of view, the clan exploits the alienating effects generated by distance and by the absence or corruption of traditional bureaucratic state apparatuses, offering individuals alternative motivations and justifications; the illusion of participation; and even that sense of identity and belonging which the state often no longer appears capable of supplying. More importantly, the neopatrimonialism of the clan contributes to the institutionalisation of a new parasitic elite of prominent individuals who actively seek or at least are inclined to accept a lasting and, if possible, hereditary appropriation of acquired benefits and advantages. The clan is the sole element capable of attributing structure and permanence to the networks of clientelism that claim to substitute the state in essential functions of the redistribution of resources and the tutelage of rights, thereby definitively subtracting these reserves and systems from any possibility of control or supervision on the part of public opinion. When the time comes for the clan to deploy the coercive means at its disposal, including combatants and weapons, the clan will be in a position to impose its will and defend its interests against anyone who manifests the least bit of opposition. 


\section{Conclusion. Urban Resistance to Violence}

Writing in the early 1940s about the social structure of totalitarian rule, Sigmund Neumann asserted that 'the first aim of totalitarianism is to perpetuate and to institutionalise revolution'; and, further on, restated that: 'belligerence in world politics denotes a major element in the definition of modern totalitarianism. War is its beginning, its demand, its test. It is in the twilight of a world at war that the flames of revolution break through. A constant state of war is the natural climate of totalitarian dictatorship' (Neumann, S., 1965: XII and XV). Since the dawn of this millennium, and as a consequence of the mutations imposed to world politics by the 1989 cleavages, we have entered a new era of 'permanent revolution', whose characteristics of course are quite different than those of the twentieth century, and that rather prefigure the entry into a new era of 'inverted totalitarianism' - 'the political coming of age of corporate power and the political demobilisation of the citizenry' (Wolin, 2010: XVIII).

Based on the analysis conducted in this book, the incoming new era could be defined as an era of 'permanent global civil war'. 'Permanent', because unfortunately war - in the broader meaning developed in these pages - is a daily, almost ordinary, situation for billions of men and women; and as we have seen, it now nurtures both politics and economics. 'Global', as opposed to 'world', because it is not intended as a war involving all the major powers in the same event at the same time. Unless in the coming years Western democracies officially undertake the dramatic clash of civilisations (typically seen as that between the Judeo-Christian and the Islamic world) rather too frequently predicted in many circles, we will experience a continuous, slow loss of blood and lives on the streets worldwide. It seems unlikely that this sort of 'normalised' organised violence will hit the most developed countries directly - if not just occasionally, as in New York (September 11, 2001), Madrid (March 11, 2004), London (July 7, 2005), and Paris (January 7, 2015). And yet it will inevitably and inexorably affect our way of living, for two main reasons.

The first is that the assertion that we all live in the same world is not pure rhetoric. The so-called process of globalisation truly produces 'the intensification of worldwide social relations and interactions such that distant events acquire very localised impacts and vice versa. It involves a rescaling of social relations, from the economic sphere to the security sphere, beyond the national to the transnational, transcontinental and transworld'; and, above all, globalisation is characterised by 'the deepening enmeshment of the local and global in so far as local events may come to have profound global consequences and global events can have serious local consequences' (Held, \& McGrew, 2007: 2 and 3). The second reason is that the spread of VNSAs, their frequent (even obsessive) recourse to violence in their everyday activities, as well as their way of conceiving politics and managing the market inevitably produce 'un-sustainable development', in terms of human ecology - the natural, social and built environment in which we all live. 
Finally, 'civil' means, first of all, that war is increasingly undertaken by actors of civil society, defined as the private sphere of economic relationships. Secondly, 'civil' explicitly refers to the city as the preferred sphere for the dynamics of capital - as mentioned in the previous chapter - and for coercion. We should never forget that we moved 'into what has been called the "urban century"', and that 'there appears to be no end to this headlong urbanization of our world. In 2007, 1.2 million people were added to the world's urban population each week. By 2025, according to current estimates, there could easily be five billion urbanites, two-third of whom will live in “developing” nations. By 2030, Asia alone will have 2.7 billion; the Earth's cities will be packed with 2 billion more people than they accommodate today. Twenty years further on, by 2050, fully 75 per cent of the world's estimated 9.2 billion people will most likely be living in cities' - and, at the end of our research, we could also easily agree that "new military ideologies of permanent and boundless war are radically intensifying the militarisation of urban life' (Graham, 2010: 2 and 60). The following final considerations offer a theoretical way out of the current debate on war from which we started.

The processes induced by the cleavage of 1989, which involve the political as well as the economic dimension, have contributed to generating new territorialities. We propose the following assumptions: a) societies are forced to maintain relations with space, their given 'original prison'; b) space is a mental construction, a concept that cannot be defined absolutely or permanently and is constantly questioned, evolving and changing over time; c) this construction is the result of a complex interplay between the actors in the given territory (Raffestin, 2012: 122). Human territoriality is 'the ensemble of relations that societies, and consequently the humans that belong to them, maintain, with the assistance of mediators, with the physical and human environment for the satisfaction of their needs toward the end of attaining the greatest possible autonomy allowed by the resources of the system. Territoriality is in some sense the "skeleton" of everyday life' (Raffestin, 2012: 129).

Cities, in particular, become the privileged spaces of mediation between actors that are main players both at the local level and in the globalisation processes "Urban territory is indeed that in which monetary fluxes are "rivers" of a sort, to which we tie in so as to derive a fraction, in whatever way, so as to have a "life", if we can call it that' (Raffestin, 2012: 139). But, beside that, violence together with (and frequently, more than) money turns out to be one of the main instruments for mediation in the urban context. More precisely, violence works both as a direct mediator, conforming the territory and tracing new borders, and an indirect mediator, contributing to the creation of jobs (the many professionals of violence) and additional money (for example, through extortion and illegal trafficking). 
The picture drawn so far finds an interesting corroboration in the so-called foam theory. ${ }^{1}$ Adopting the perspective of urban environment development, foam theory describes a process of growing fragmentation of the urban territory into cellular clusters: 'packaged landscapes made up of customised and carefully protected corporate, consumption, research, transit, exchange, domestic and even health care spaces' (Graham, \& Marvin, 2001: 5). In other terms, landscapes characterised by the proliferation of 'privatised spatial entities' that are ruled by surveillance and security strategies, thanks to the contribution of modern video-surveillance technologies (Klauser, 2010: 328). The most important assumptions of this theory are: a) the need to place spatiality at the top of the theoretical agenda; b) the idea that being-in-spheres constitutes the basic condition of human existence - spheres provide meaning (shared ideas and values) and protection (a sort of immunity to the extra-spherical world) to the people who live in them, though they can still be endangered by external factors; c) the fact that, in our current age, the globe has undergone an implosion producing a plurality of minor spherical worlds, or 'foam'. The foam is a 'co-isolated association' of bubbles, singular cells separated by thin walls and, therefore, subject to a state of co-fragility. Foam is characterised by spontaneous generation, disorder, and the lack of a centre (Borch, 2008: 549-552).

In the eyes of a political scientist, foam theory recalls (and in some ways, exacerbates) some organicistic elements that were also peculiar to the system theory (Easton, 1965; Luhmann, 1995). The idea that the cell produces immunity for its interior life from the risks of poisoning from the surrounding air could also cast some doubt. ${ }^{2}$ The fact is, however, that this assumption finds daily confirmation in the conception of architectural space, with the apartment, the shopping mall or the gated community aimed at shaping these cells (as well as the fears that inhabit them). In other words, foam theory conveys an explicit architectural dimension and prefigures an urban environment of more or less purified interiors and more or less dangerous exteriors (Klauser, 2010: 332).

Until now, the main limit of the foam theory has been this concept of the exclusively external nature of threats. It has been observed, for example, that the analysis should be broadened through investigation of the complex relationships between the 'spheres of protection' and the 'spheres of insecurity': 'A more detailed account of the functioning and experiences of the urban "spheres of insecurity" often termed as problem zones or no-go areas - could also provide greater insight into the spatial struggles between opposing interests and actors whose spheres of influence deform, restrict, and fight against one another (as with police and criminal

1 These theory draws direct inspiration from the grand trilogy on spheres by the German philosopher Peter Sloterdijk (1998, 1999 and 2004).

2 Sloterdijk proposes a transformation of Sociology in a general theory of 'air conditioning' or atmospheres (Borch, 2008: 552). 
gangs, for instance)' (Klauser, 2010: 338). Similarly, we should pay more attention to the phenomenon of the deliberate destruction of the spheres of protection of those who are identified as enemies - 'consider, for example, the corresponding logics of "infrastructure warfare" and "sphere annihilation" in the Rapid Dominance strategy of the US military's Shock and Awe doctrine' (Klauser, 2010: 338). Above all, however, we might question how foam theory might confront the danger of internal impurities, and how cells maintain immunity to self-generated dangers (Borch, 2008: 567).

This is exactly the case of cities dominated by mafia groups or gangs - as well as the case of terrorist attacks undertaken by individuals living in the targeted cities. Organised crime groups, in fact, act like parasites inside the urban space, extorting money, and growing rich through illegal trafficking. At the same time, however, they build up symbiotic relationships with the surrounding environment, irreparably polluting its atmosphere. As we have seen, thanks to the huge resources of money and violence at their disposal, organised crime groups successfully step forward as social mediators: dissuading or killing whoever interferes with their business, or corrupting those politicians and entrepreneurs willing to compromise. Most of these criminal groups, moreover, are capable of fostering a basis of consent by offering, for example, welfare payments to their members and their families, or financial and other forms of support to the population in their sphere.

The peculiar nature of organised crime groups renders any military strategy employed against them particularly ineffective. This is demonstrated by the repeated failures of the war on drugs and organised crime periodically launched by national governments and international institutions. These wars, which typically involve extremely high economic costs, always produce a dramatic increase in the death toll (especially of defenceless victims), and a re-localisation of these same organised crime groups to new areas which hitherto had remained uncontaminated. As discussed in chapter 4 - the analysis of the war on drugs must also consider environmental costs, such as the very real pollution suffered by territories flooded with chemical defoliants in order to destroy coca leaf or opium poppy plantations. As a consequence, we must add a corollary to the foam theory, asserting that the 'co-isolated associations' which make up the foam may respond to criminal logic; and as a result of this (alarming) fact, we must begin to rethink our strategies of urban planning. Just as an example, the urban plan of Palermo, the capital city of the Sicilian mafia - where the main streets of the high bourgeoisie intersect with a tangled web of degraded alleyways - may appear to most as incomprehensible and ungovernable. On the contrary, if we read it in terms of 'spheres of mafia protection', it suddenly assumes a striking coherence. It is not by chance, therefore, that, from the very beginning of its existence, the Sicilian mafia has been organised by 'districts'. Mafia bosses demonstrate a much better knowledge of, and higher interest in, the territory than urban planners - who, if anything, should be held responsible for having supported or at least silently complied with the partition of Palermo among the boundary lines of the various clans. 
However, we can also add a second corollary to the foam theory by asserting that those same spheres may develop forms of resilience against internal 'impurities' and even prefigure a genuine immunisation strategy. The concept of resilience refers to the struggle to adapt within complex systems in order to survive or thrive. 'Resilience is a process rather than a subjective or objective "thing”. As such, the study of resilience in the urban is the study of interplay between different forms of thinking, doing and acting to understand the process of change in space and place over time' (Rogers, 2012: 5). A resilient community is, by definition, a community that is able to resist, absorb, adapt to, and recover promptly and efficiently from the effects of a hazard, retaining the same basic structures and providing the same services (World Bank, 2013: 10).

Until now, such a concept was mainly applied to the prevention of natural disasters or terrorism (Coaffee, 2009; Coaffee, Murakami Wood, \& Rogers, 2009). However, the most interesting and compelling challenge today consists in elaborating strategies of urban proactive resilience, or resistance, to the chronic violence produced by VNSAs. This is a topic that goes well beyond the aims of this Conclusion, yet we wish to offer at least two suggestions, derived from two of the authors who inspired this book.

The first suggestion is to foster new research focused more on the areas in which violence flourishes 'turning attention to transforming spaces as the starting point for nurturing resilience. To the extent that territorial control - be it armed, political, social or economic - has been shown to be central to violence, re-ordering space can be a first step in countering the power of violent actors' (Davis, D. E., 2012: 98). This main idea that violence is tied to the nature of urban form, and that by changing the urban form it may be possible even to reduce violence is not new.

The planning of urban spaces that can be defended against crime, for instance in a country like the USA, dates back to the beginning of the 1970s (Paulsen, 2013). The 'Defensible Space Programs' which were elaborated from that time are based on two closely linked principles. The first is that of self-help, or rather the idea that the direct involvement of residents can contribute to the reduction of crime more than any intervention by the government - also depending on the political priorities and the available resources. The second principle is that the physical layout of residential environment should allow residents easier control of the areas surrounding their homes (Newman, 1996: 9). ${ }^{3}$ Both these principles nourished the already mentioned

3 The research on public housing, in particular, revealed that two physical variables influence crime. The first is the project size: the larger the concentration of low-income families, the more residents feel isolated from and stigmatised by the rest of society. Stigmatisation feeds the apathy of the residents, and the neglect by housing management and by municipal agencies. This offers organised crime groups (both gangs and mafia clans) the opportunity to contaminate public spaces with their illegal trafficking activities. The second variable is the number of apartments sharing common entries: the larger is the number of the units, the more difficult is to distinguish other residents from intruders, and to agree with the other residents on the methods to care and control common areas (Newman, 1996: 28). 
phenomenon of gated communities - ever more relevant both in terms of urban planning and for its speculative-real estate implications. However, these controlledaccess residential areas are necessarily reserved for a high-income population (Atkinson, \& Blandy, 2006; Bagaeen, \& Uduku, 2010); as well as those even more ambitious urban projects - such as Masdar City in the United Arab Emirates and Song Do in South Korea - which unite with the benefit of physical security the environmental security guaranteed by their complete eco-sustainability. ${ }^{4}$

Two further and relevant corollaries to this way of conceiving defensible spaces are that prosecuting even the most common offenses discourages new crimes being committed (broken window theory); and that the best method to confront with the problem of urban security is that of investing in strategies of urban policing, in particular exploiting the immense new opportunities created by the development of Information and Communication Technologies (ICTs). Generally speaking, a greater capability in monitoring the territory thanks also to the capillary distribution of video-surveillance systems, together with the availability of data gathering software has engendered a new 'geography of crime', devoted to the spatial and scalar analysis of crimes (Leitner, 2013; Lippert, \& Walby, 2013; Manning, 2008). Unfortunately, this 'order-maintenance approach' has received remarkably favourable attention by media and institutions, mostly due to the dramatic rise in incarceration; but we still not have any other empirical evidence of its success (Harcourt, 2001).

And yet, any strategy aimed at securing a certain territory is still based on the preliminary but not declared assumption that the criminal is an agent from the external world (from the dangerous outsides of our spheres of cohabitation, to go back to foam theory) and that, consequently, it may be sufficient to keep him at a distance or close him in that other particular securitised space which is prison. On the contrary, building resilient urban spaces means to foster inclusion, and to reject conventional approaches based on reciprocal isolation of the well-off and the disadvantaged people: 'building capacities for resilience means promoting and investing in mixed commercial and residential land use, particularly in areas of the city at risk for crime; building infrastructure that enables free movement of people within and between all neighbourhoods (via pedestrian corridors, parks, public transport), and prioritising strategic urban investments that will help establish selfsustaining or self-reinforcing government-community reciprocities for guaranteeing such activities in every neighbourhood' (Davis, D. E., 2012: 99).

The second suggestion consists in reinforcing proactive resilience by means of trust networks capable of opposing VNSAs' offer of social mediation (money and

4 But the most radical urban project so far is that of charter cities, proposed in the 'turnkey' formula to developing countries: cities that are entirely to be planned and built in virgin areas, characterised by a wide autonomy of government and privileged also by the fact of having been conceived as special reform areas, free trade zones not subject to any taxation (Fuller, \& Romer, 2012). 
violence). If over the long run - as we noticed in the previous chapter - cities were the preferred spheres of capital, while coercion crystallised especially in states, the role of the trust networks is to accumulate and coordinate commitment: 'Capital, coercion, and commitment reproduce themselves according to different logics. Capital renews itself through production of goods and services in sufficient abundance to provide for the next round of production. [...] Reproduction of coercion occurs through an openly competitive process in which wielders of coercive means use those means to deprive rivals and potential rebels of their own access to coercion. [...] Reproduction of commitment proceeds in quite a different manner: via recruitment and birth. New members of trust networks arrive through person-by-person enlistment or through birth within households already belong to the network' (Tilly, 2010: 274).

Throughout history, encounters between these three entities - capital, coercion, and commitment - have implied conflicts which the members of the trust networks faced by adopting, at various times, four different strategies: evasion (hiding or dissimulation), integration (by acquiring power or accepting makeshift, secondrate positions), patronage (being protected by a sufficiently powerful intermediary), or resistance (direct confrontation; the riskiest of choices) (Tilly, 2010: 272). The appearance and proliferation of VNSAs as direct competitors for the accumulation and coordination of capital and coercive powers dramatically alters the already complex dynamics between the city and the state. For those subjected to their power, evasion is a precluded strategy - except in the forms of individual migration or of collective forced displacement into refugee camps. Integration and patronage may be an opportunity, depending on the subjects' capabilities (both in terms of power and money as exchange currencies), and on their willingness to introject the rules and values embodied by VNSAs. Resistance is certainly the only real solution; even if, too often, the most uncertain and, for sure, the most hazardous. 


\section{Bibliography}

Aase, T. (2002). Tournaments of Power: Honor and Revenge in the Contemporary World. Aldershot: Ashgate.

Abrahams, R. (1998). Vigilant Citizens: Vigilantism and the State. Cambridge: Polity Press.

Abuelas de Plaza de Mayo. (1997). Restitución de niños. Buenos Aires: Editorial Universitaria de Buenos Aires.

Acharya, A. (2009a). Small Amounts for Big Bangs? Rethinking Responses to 'Low Cost' Terrorism. Journal of Money Laundering Control, 12 (3), 285-298.

Acharya, A. (2009b). Targeting Terrorist Financing: International Cooperation and New Regimes. New York, NY: Routledge.

Acton, C. (2007). Grief in Wartime: Private Pain, Public Discourse. New York, NY: Palgrave Macmillan.

Afflerbach, H., \& Strachan, H. (Eds.) (2012). How Fighting Ends: A History of Surrender. Oxford: Oxford University Press.

Agnew, J. (2009). Globalization \& Sovereignty. Lanham, MD: Rowman \& Littlefield.

Alexander, M. G., Brewer, M. B., \& Herrmann, R. K. (1999). Images and Affect: A Functional Analysis of Out-Group Stereotypes. Journal of Personality and Social Psychology, 77 (1), 78-93.

Alexander, M. G., Brewer, M. B., \& Livingston, R. W. (2005). Putting Stereotype Content in Context: Image Theory and Interethnic Stereotypes. Personality and Social Psychology Bullettin, 31 (6), 781-794.

Allen, M. (Ed.) (2007). Reading Csi: Crime Tv Under the Microscope. New York, NY: I. B. Tauris.

Allen, M. J. (2009). Until the Last Man Comes Home: Pows, Mias, and the Unending Vietnam War. Chapel Hill, NC: The University of North Carolina Press.

Allison, W. T. (2003). War for Sale: The Black Market, Currency Manipulation and Corruption in the American War in Vietnam. War \& Society, 21 (2), 135-164.

Allison, W. T. (2008). The Tet Offensive: A Brief History with Documents. New York, NY: Routledge.

Allport, G. W. (1954). The Nature of Prejudice. Cambridge, MA: Addison-Wesley.

Almerighi, M. (Ed.) (2002). I banchieri di Dio. Il caso Calvi. Rome: Editori Riuniti.

Altschuler, G. C., \& Blumin, S. M. (2009). The G. I. Bill: A New Deal for Veterans. Oxford: Oxford University Press.

Amnesty International. (2004). Colombia: 'Scarred Bodies, Hidden Crimes': Sexual Violence Against Women in the Armed Conflict. http://www.amnesty.org/en/library/info/AMR23/040/2004 $(02 / 16 / 2015)$.

Anders, G. (1961). Burning Conscience: The Case of the Hiroshima Pilot Claude Eatherly, Told in His Letters to Günther Anders. London: Weidenfeld and Nicolson.

Anderson, B. (1983). Imagined Communities. Reflections on the Origins and Spread of Nationalism. London: Verso.

Anderson, D. L. (2005). The Vietnam War. New York, NY: Palgrave Macmillan.

Anderson, D. L., \& Ernst, J. (Eds.) (2007). The War that Never Ends: New Perspectives on the Vietnam War. Lexington, KY: The University Press of Kentucky.

Andersson, R. (2014). Illegality, Inc. Clandestine Migration and the Business of Bordering Europe. Oakland, CA: University of California Press.

Andreas, P. (2008). Blue Helmets and Black Markets: The Business of Survival in the Siege of Sarajevo. Ithaca, NY: Cornell University Press.

Andreas, P., \& Nadelmann, E. A. (2006). Policing the Globe: Criminalization and Crime Control in International Relations. Oxford: Oxford University Press.

Angell, N. (1913). The Great Illusion. London: Heinemann.

Appadurai, A. (1998). Dead Certainty: Ethnic Violence in the Era of Globalization. Development and Change, 29 (4), 905-925. 
Archibold, R. C. (2010). Budget Cut for Fence on U.S.-Mexico Border. New York Times, March 16.

Ardrey, R. (1966). The Territorial Imperative. New York, NY: Atheneum.

Arendt, H. (1958). The Human Condition. Chicago, IL: University of Chicago Press.

Arendt, H. (1963). Eichmann in Jerusalem: A Report on the Banality of Evil. New York, NY: The Viking Press.

Arendt, H. (1966). The Origins of Totalitarianism. New York, NY: Harcourt, Brace \& World.

Arendt, H. (1970). On Violence. New York, NY: Harcourt Brace \& Company.

Arendt, H. (1972). Lying in Politics: Reflections on the Pentagon Papers. In H. Arendt, Crises of the Republic (pp. 1-48). New York, NY: Harcourt Brace \& Company.

Arias, E. D., \& Goldstein, D. M. (Eds.) (2010). Violent Democracies in Latin America. Durham, NC: Duke University Press.

Arlacchi, P. (1994). Addio Cosa Nostra. La vita di Tommaso Buscetta. Milan: Rizzoli.

Armao, F. (1994). Capire la guerra. Milan: Franco Angeli.

Armao, F. (2000). Il sistema mafia. Dall'economia-mondo al dominio locale. Turin: Bollati Boringhieri.

Armao, F. (2003). Why Is Organised Crime so Successful? In F. Allum \& R. Siebert (Eds.), Organised Crime and the Challenge to Democracy (pp. 27-38). London: Routledge.

Armao, F. (2005). Who Is the Enemy? Scenarios of War in Times of Globalization. In M. Evangelista (Ed.), Peace Studies: Critical Concepts in Political Science, vol. 3 (pp. 279-305). New York, NY: Routledge.

Armao, F. (2009). The Market of Violence: From Monopoly to Free Competition. In G. Giacomello \& R. Craig Nation (Eds.), Security in the West. Evolution of a Concept (pp. 101-133). Milan: Vita e Pensiero.

Armao, F. (2014). Criminal Clusters: State and Organised Crime in a Globalised World. The European Review of Organised Crime, 1 (1), 122-136.

Aron, R. (1966). Peace and War. A Theory of International Relations. Garden City, NY: Doubleday.

Arriagada, G. (1991). Pinochet: The Politics of Power. Boulder, CO: Westview Press.

Asad, T. (2007). On Suicide Bombings. New York, NY: Columbia University Press.

Ashplant, T. G., Dawson, G., \& Roper, M. (Eds.) (2000). The Politics of War Memory and Commemoration. New York, NY: Routledge.

Atkinson, R., \& Blandy, S. (Eds.) (2006). Gated Communities. New York, NY: Routledge.

Austin, J. E., \& Bruch, C. E. (Eds.) (2000). The Environmental Consequences of War: Legal, Economic, and Scientific Perspectives. Cambridge: Cambridge University Press.

Avant, D. D. (1994). Political Institutions and Military Change: Lessons from Peripheral Wars. Ithaca, NY: Cornell University Press.

Avant, D. D. (2000). From Mercenary to Citizen Armies: Explaining Change in the Practice of War. International Organization, 54 (1), 41-72.

Avant, D. D. (2005). The Market for Force: The Consequences of Privatizing Security. Cambridge: Cambridge University Press.

Avant, D. D. (2007). Contracting for Services in U.S. Military Operations. PS: Political Science and Politics, 40 (3), 457-460.

Avant, D. D., Finnemore, M., \& Sell, S. K. (Eds.) (2010). Who Governs the Globe? Cambridge: Cambridge University Press.

Axelrod, A. (2009). Selling the Great War: The Making of American Propaganda. New York, NY: Palgrave Macmillan.

Bacevich, A. J. (2005). The New American Militarism: How Americans Are Seduced by War. Oxford: Oxford University Press.

Bagaeen, S., \& Uduku, O. (Eds.) (2010). Gated Communities. Social Sustainability in Contemporary and Historical Gated Developments. London: Earthscan. 
Bailey, J., \& Godson, R. (Eds.) (2000). Organized Crime \& Democratic Governability: Mexico and the U.S.-Mexican Borderlands. Pittsburgh: University of Pittsburgh Press.

Baker, A. P. (2008). Life in the U.S. Armed Forces: (Not) Just Another Job. Westport, CT: Praeger Security International.

Baker, C. E. (2002). Media, Markets, and Democracy. Cambridge: Cambridge University Press.

Baker, C. E. (2007). Media Concentration and Democracy: Why Ownership Matters. Cambridge: Cambridge University Press.

Ballentine, K., \& Nitzschke, H. (Eds.) (2005). Profiting from Peace: Managing the Resource Dimensions of Civil War. Boulder, CO: Lynne Rienner.

Ballentine, K., \& Sherman, J. (Eds.) (2003). The Political Economy of Armed Conflict: Beyond Greed \& Grievance. Boulder, CO: Lynne Rienner.

Barbier, M. K. (2007). D-Day Deception: Operation Fortitude and the Normandy Invasion. Westport, CT: Praeger Security International.

Barkawi, T., \& Brighton, S. (2011). Conclusion. Absent War Studies? War, Knowledge, and Critique. In H. Strachan \& S. Scheipers (Eds.), The Changing Character of War (pp. 524-541). Oxford: Oxford University Press.

Barkun, M. (2007). Appropriated Martyrs: The Branch Davidians and the Radical Right. Terrorism and Political Violence, 19 (1), 117-124.

Bartle, R., \& Heinecken, L. (Eds.) (2006). Military Unionism in the Post-Cold War Era: A Future Reality? New York, NY: Routledge.

Baum, D. (2004). The Price of Valor: We Train Our Soldiers to Kill for Us. Afterward, They're on Their Own. New Yorker, July 12 and 19, 44-52.

Baumler, A. (2007). The Chinese and Opium Under the Republic: Worse Than Floods and Wild Beasts. Albany: State University of New York Press.

Bayart, J.-F., Ellis, S., \& Hibou, B. (1997). La criminalisation de l'état en Afrique. Paris: Editions Complexe.

Baylis, J., Wirtz, J. J., \& Gray, C. S. (Eds.) (2013). Strategy in the Contemporary World. An Introduction to Strategic Studies. Oxford: Oxford University Press.

Beah, I. (2007). A Long Way Gone: Memoirs of a Boy Soldier. New York, NY: Farrar, Straus and Giroux.

Beare, M. E. (Ed.) (2003). Critical Reflections on Transnational Organized Crime, Money Laundering, and Corruption. Toronto: University of Toronto Press.

Beck, U. (1997). The Sociological Anatomy of Enemy Images: The Military and Democracy after the End of the Cold War. In R. Fiebig-von Hase \& U. Lehmkuhl (Eds.), Enemy Images in American History (pp. 65-87). Providence, RI: Berghahn Books.

Beckett, K., \& Herbert, S. (2008). Dealing with Disorder: Social Control in the Post-Industrial City. Theoretical Criminology, 12 (1), 5-30.

Beede, B. R. (2008). The Roles of Paramilitary and Militarized Police. Journal of Political and Military Sociology, 36 (1), 53-63.

Beneduce, R. (Ed.) (2008). Violenza. Antropologia, 8 (9-10).

Berger, P. L., \& Luckman T. (1989). The Social Construction of Reality. A Treatise in the Sociology of Knowledge. New York, NY: Doubleday.

Bernstein, S., Lebow, R. N., Stein, J. G., \& Weber, S. (2007). Social Science as Case-Based Diagnostic. In R. N. Lebow \& M. I. Lichbach (Eds.), Theory and Evidence in Comparative Politics and International Relations (pp. 229-260). New York, NY: Palgrave Macmillan.

Bertelli, S. (1990). Il corpo del re. Sacralità del potere nell'Europa medievale e moderna. Florence: Ponte alle Grazie.

Bertelli, S., \& Grottanelli, C. (Eds.) (1990). Gli occhi di Alessandro. Potere sovrano e sacralità del corpo da Alessandro Magno a Ceauçescu. Florence: Ponte alle Grazie.

Bevan, R. (2006). The Destruction of Memory: Architecture at War. London: Reaktion Books. 
Bhatia, M., \& Sedra, M. (2008). Afghanistan, Arms and Conflict: Armed Groups, Disarmament and Security in a Post-War Society. New York, NY: Routledge.

Biersteker, T. J., \& Eckert, S. E. (2008). Countering the Financing of Terrorism. New York, NY: Routledge.

Billingsley, P. (1988). Bandits in Republican China. Stanford, CA: Stanford University Press.

Bilmes, L., \& Stiglitz, J. (2008). The Three Trillion Dollar War: The True Cost of the Iraq Conflict. New York, NY: W. W. Norton \& Company.

Bishop, R., \& Clancy, G. (2004). The City-as-Target, or Perpetuation and Death. In S. Graham (Ed.), Cities, War, and Terrorism. Towards an Urban Geopolitics (pp. 54-74). Oxford: Blackwell.

Black, D. (2004). The Geometry of Terrorism. Sociological Theory, 22 (1), 14-25.

Blainey, G. (1973). The Causes of War. New York, NY: The Free Press.

Blien, U., \& Maier, G. (Eds.) (2008). The Economics of Regional Clusters: Networks, Technology and Policy. Northampton, MA: Edward Elgar.

Bloch, M. (1973). The Royal Touch: Sacred Monarchy and Scrofula in England and France. London: Routledge \& Kegan Paul.

Blomberg, T. G., \& Lucken, K. (2000). American Penology: A History of Control. New York, NY: Aldine De Gruyter.

Bloom, M. (2007). Dying to Kill: The Allure of Suicide Terror. New York, NY: Columbia University Press.

Bobbio, N. (1985). Stato, governo, società. Per una teoria generale della politica. Turin: Einaudi.

Bobbio, N. (1987). The Future of Democracy: A Defence of the Rules of the Game. Minneapolis, MN: University of Minnesota Press.

Bobbit, P. (2003). The Shield of Achilles: War, Peace, and the Course of History. New York, NY: Anchor Books.

Bonanate, L. (1998). La guerra. Rome-Bari: Laterza.

Bonanate, L. (2004). La politica internazionale tra terrorismo e guerra. Rome-Bari: Laterza.

Bonanate, L. (2009). La crisi. Il sistema internazionale vent'anni dopo la caduta del Muro di Berlino. Milan: Bruno Mondadori.

Bonanate, L. (2011). Undicisettembre. Dieci anni dopo. Milan: Bruno Mondadori.

Bonanate, L., Armao, F., \& Tuccari, F. (1997). Le relazioni internazionali. Cinque secoli di storia: 1521-1989. Milan: Bruno Mondadori.

Booth, J. A., Wade, C. J., \& Walker, T. W. (2006). Understanding Central America: Global Forces, Rebellion, and Change. Cambridge, MA: Westview Press.

Booth, M. (1990). The Triads: The Chinese Criminal Fraternity. London: Harper Collins.

Borch, C. (2008). Foam Architecture: Managing Co-Isolated Associations. Economy and Society, 37 (4), 548-571.

Bose, S. (2002). Bosnia after Dayton: Nationalist Partition and International Intervention. Oxford: Oxford University Press.

Bourke, J. (1999). An Intimate History of Killing: Face-to-Face Killing in Twentieth-Century Warfare. New York, NY: Basic.

Bourke, J. (2005). Fear: A Cultural History. London: Virago Press.

Bourne, M. (2007). Arming Conflict: The Proliferation of Small Arms. New York, NY: Palgrave Macmillan.

Bowman, J. (2006). Honor: A History. New York, NY: Encounter Books.

Braudel, F. (1977). Afterthoughts on Material Civilization and Capitalism. Baltimore, MD: The Johns Hopkins University Press.

Braudel, F. (1979). Civilisation matérielle, economie et capitalisme (XVe-XVIIle siècle). 3 vols. Paris: Colin.

Braudel, F. (1980). On History. Chicago, IL: University of Chicago Press. 
Braudy, L. (2003). From Chivalry to Terrorism: War and the Changing Nature of Masculinity. New York, NY: Alfred A. Knopf.

Brauer, J., \& Tuyll, H. van (2008). Castles, Battles \& Bombs: How Economics Explains Military History. Chicago, IL: The University of Chicago Press.

Brenner, N. (2004). New State Spaces: Urban Governance and the Rescaling of Statehood. Oxford: Oxford University Press.

Brewer, M. B. (1999). The Psychology of Prejudice: Ingroup Love or Outgroup Hate? Journal of Social Issues, 55 (3), 429-444.

Brewer, S. A. (2009). Why America Fights: Patriotism and War Propaganda from the Philippines to Iraq. Oxford: Oxford University Press.

Brooker, P. (2010). Modern Stateless Warfare. New York, NY: Palgrave Macmillan.

Brotherton, D. C. (2008). Beyond Social Reproduction: Bringing Resistance Back in Gang Theory. Theoretical Criminology, 12 (1), 55-77.

Brown, W. (2010). Walled States, Waning Sovereignty. New York, NY: Zone Books.

Brzezinski, Z. (1993). Out of Control. Global Turmoil in the Eve of the Twenty-First Century. New York, NY: Scribner.

Budreau, L. M. (2009). Bodies of War: World War I and the Politics of Commemoration in America, 1919-1933. New York, NY: New York University Press.

Buehn, A., \& Schneider, F. (2012). Shadow Economies Around the World: Novel Insights, Accepted Knowledge, and New Estimates. International Tax and Public Finance, 19 (1), 139-171.

Buitenhuis, P. (1987). The Great War of Words: British, American, and Canadian Propaganda and Fiction, 1914-1933. Vancouver: University of British Columbia Press.

Bull, H. (1966). International Theory: The Case for a Classical Approach, World Politics, 18 (3), 361-377.

Bull, H. (1977). The Anarchical Society: A Study of Orders in World Politics. London: Macmillan.

Burchill, S., \& Linklater, A. (1996). Theories of International Relations. London: Macmillan.

Burdman, D. (2003). Education, Indoctrination, and Incitement: Palestinian Children on Their Way to Martyrdom. Terrorism and Political Violence, 15 (1), 96-123.

Burgess, D. R. Jr. (2008). The Pirates' Pact: The Secret Alliances Between History's Most Notorious Buccaneers and Colonial America. New York, NY: McGraw Hill.

Burk, J. (Ed.) (1994). The Military in New Times: Adapting Armed Forces to a Turbulent World. Boulder, CO: Westview.

Burk, J. (Ed.) (1998). The Adaptive Military: Armed Forces in a Turbulent World. New Brunswick, NJ: Transaction Books.

Burton, J. W. (1972). World Society. Cambridge: Cambridge University Press.

Buzan, B. (1995). The Level of Analysis Problem in International Relations Reconsidered. In K. Booth \& S. Smith (Eds.), International Relations Theory Today (pp. 198-216). Cambridge: Polity Press.

Buzan, B., Jones, C., \& Little., R. (1993). The Logic of Anarchy. Neorealism to Structural Realism. New York, NY: Columbia University Press.

Byers, M., \& Johnson, V. M. (2009). The Csi Effect: Television, Crime, and Governance. Lanham, MD: Lexington Books.

Byman, D. L. (2005). Deadly Connections: States that Sponsor Terrorism. Cambridge: Cambridge University Press.

Byman, D. L. (2008). The Changing Nature of State Sponsorship of Terrorism. Washington: Saban Center for Middle East Policy at the Brookings Institution.

Caffarena, A. (2004). A mali estremi. La guerra al terrorismo e la riconfigurazione dell'ordine internazionale. Milan: Guerini.

Caffrey, S., \& Mundy G. (2001). Informal Systems of Justice: The Formation of Law Within Gypsy Communities. In W. O. Weyrauch (Ed.), Gypsy Law. Romani Legal Traditions and Culture (pp. 101-116). Berkeley, CA: University of California Press. 
Caforio, G. (Ed.) (2003). Handbook of the Sociology of the Military. New York, NY: Kluwer Academic/ Plenum.

Caillois, R. (1990). La vertigine della guerra. Roma: Edizioni Lavoro.

Caldeira, T. P. R. (2000). City of Walls: Crime, Segregation, and Citizenship in São Paulo. Berkeley, CA: University of California Press.

Calder, A. (2004). Disaster and Heroes: On War, Memory and Representation. Cardiff: University of Wales Press.

Calder, K. E. (2007). Embattled Garrisons: Comparative Base Politics and American Globalism. Princeton, NJ: Princeton University Press.

Campos, J. H. (2007). The State and Terrorism: National Security and Mobilization of Power. Burlington, VT: Ashgate.

Canetti, E. (1973). Crowds and Power. New York, NY: Continuum.

Cappelletto, F. (2005). Memory and World War II: An Ethnographic Approach. New York, NY: Berg.

Carr, E. H. (1981). The Twenty Years' Crisis 1919-1939. An Introduction to the Study of International Relations. London: Macmillan.

Carr, E. H. (1986). What Is History? London: Macmillan.

Carruthers, S. L. (2000). The Media at War: Communication and Conflict in the Twentieth Century. New York, NY: St. Martin Press.

Carter, J. A., Maher, S., \& Neumann, P. R. (2014). \#Greenbirds: Measuring Importance and Influence in Syrian Foreign Fighters Networks. London: The International Centre for the Study of Radicalisation and Political Violence.

Carvalho, F. J. C. de (2008). Keynes and the Reform of the Capitalist Social Order. Journal of Post Keynesian Economics, 31 (2), 191-211.

Cazeneuve, J. (1971). Sociologie du rite. Paris: Presses Universitaires de France.

Chalk, P. (2003). Non-Military Security in the Wider Middle East. Studies in Conflict \& Terrorism, 26, 197-214.

Chang, I. (1997). The Rape of Nanking: The Forgotten Holocaust of World War II. New York, NY: Basic Books.

Cheloukhine, S. (2008). The Roots of Russian Organized Crime: From Old-Fashioned Professionals to the Organized Criminal Groups of Today. Crime, Law \& Social Change, 50 (4-5), 353-374.

Chen, A. (2005). Secret Societies and Organized Crime in Contemporary China. Modern Asian Studies, 39 (1), 77-107.

Chesterman, S., \& Lehnardt, C. (Eds.) (2007). From Mercenaries to Market: The Rise and Regulation of Private Military Companies. Oxford: Oxford University Press.

Chin, K.-L. (1996). Chinatown Gangs: Extortion, Enterprise, and Ethnicity. Oxford: Oxford University Press.

Chin, K.-L. (2003). Heijin: Organized Crime, Business, and Politics in Taiwan. Armonk, NY: M. E. Sharpe.

Chin, K.-L. (2009). The Golden Triangle: Inside Southeast Asia's Drug Trade. Ithaca, NY: Cornell University Press.

Chin, K.-L., \& Godson, R. (2006). Organized Crime and the Political-Criminal Nexus in China. Trends in Organized Crime, 9 (3), 5-44.

Chirot, D., \& McCauley, C. (2006). Why Not Kill Them All? The Logic and Prevention of Mass Political Murder. Princeton, NJ: Princeton University Press.

Chomsky, N. (2000). Rogue States: The Rule of Force in World Affairs. Cambridge, MA: South End Press.

Chomsky, N. et al. (1997). The Cold War and the University: Toward an Intellectual History of the Postwar Years. New York, NY: The New Press.

Clapp, J. (2001). Toxic Exports: The Traffic of Hazardous Wastes from Rich to Poor Countries. Ithaca, NY: Cornell University Press. 
Clark, I. (2001). The Post-Cold War Order. The Spoils of Peace. Oxford: Oxford University Press.

Clark, M. T. (2006). Does Clausewitz Apply to Criminal-States and Gangs? Global Crime, 7 (3-4), 407-427.

Clarke, M. (2008). China 'War on Terror' in Xinjiang: Human Security and the Causes of Violent Uighur Separatism. Terrorism and Political Violence, 20 (2), 271-301.

Clausewitz, K. von (1976). On War (1832). Princeton, NJ: Princeton University Press.

Coaffee, J. (2009). Terrorism, Risk and the Global City: Toward Urban Resilience. Burlington, VT: Ashgate.

Coaffee, J., Murakami Wood, D., Rogers, P. (2009). The Everyday Resilience of the City: How Cities Respond to Terrorism and Disaster. New York, NY: Palgrave Macmillan.

Codrignani, G. (1994). Ecuba e le altre. La donna, il genere, la guerra. San Domenico di Fiesole: Edizioni Cultura della Pace.

Cohen, D. (2001). The War Come Home: Disabled Veterans in Britain and Germany, 1914-1939. Berkeley, CA: University of California Press.

Cohen, E. A. (1985). Citizens and Soldiers: The Dilemmas of Military Service. Ithaca, NY: Cornell University Press.

Cohen, E. A. (2002). Supreme Command: Soldiers, Statesmen, and Leadership in Wartime. New York, NY: Free Press.

Coker, C. (2002). Waging War Without Warriors? The Changing Culture of Military Conflict. Boulder, CO: Lynne Rienner.

Collins, K. (2006). Clan Politics and Regime Transition in Central Asia. Cambridge: Cambridge University Press.

Commission on the National Guard and Reserves. (2008). Transforming the National Guard and Reserves into a 21st-Century Operational Force. Final Report to Congress and the Secretary of Defense, January 31.

Conroy, J. (2000). Unspeakable Acts, Ordinary People: The Dynamics of Torture. New York, NY: A. A. Knopf.

Contamine, P. (1980). La guerre au Moyen Age. Paris: Presses Universitaires de France.

Cooley, A. (2008). Base Politics: Democratic Change and the U.S. Military Overseas. Ithaca, NY: Cornell University Press.

Cooley, A., \& Spruyt, H. (2009). Contracting States. Sovereign Transfers in International Relations. Princeton, NJ: Princeton University Press.

Cooley, J. K. (2000). Unholy Wars: Afghanistan, America, and International Terrorism. Sterling: Pluto Press.

Cooper, N. (2006). What's the Point of Arms Transfer Controls? Contemporary Security Policy, 27 (1), 118-137.

Cooper, P. J., \& Vargas, C. M. (2008). Sustainable Development in Crisis Conditions: Challenges of War, Terrorism, and Civil Disorder. Lanham, MD: Rowman \& Littlefield.

Cordesman, A. H. (2001). The Lessons and Non-Lessons of the Air and Missile Campaign in Kosovo. Westport, CT: Praeger Security International.

Cordesman, A. H. (2003). The Iraq War: Strategy, Tactics, and Military Lessons. Westport, CT: Praeger Security International.

Cordesman, A. H. (with assistance from E. R. Davies) (2008). Iraq's Insurgency and the Road to Civil Conflict. Westport, CT: Praeger Security International.

Cortright, D. (2005). Soldiers in Revolt: GI Resistance During the Vietnam War. Chicago, IL: Haymarket Books.

Costigan, S. S., \& Gold, D. (Eds.) (2007). Terrornomics. Burlington, VT: Ashgate.

Courtwright, D. T. (2001). Forces of Habit: Drugs and the Making of the Modern World. Cambridge, MA: Harvard University Press.

Cowen, D., \& Gilbert, E. (Eds.) (2008). War, Citizenship, Territory. New York, NY: Routledge. 
Cox, M. D. (2008). State of Corruption, State of Chaos: The Terror of Political Malfeasance. Lanham, MD: Lexington Book.

Cox, R. (1981). Social Forces, States, and World Orders: Beyond International Relations Theory. Millennium, 10 (2), 126-155.

Cragin, K., \& Daly, S. A. (2004). The Dynamic Terrorist Threat: An Assessment of Group Motivations and Capabilities in a Changing World. Santa Monica, CA: Rand Corporation.

Craig, C., \& Logevall, F. (2009). America's Cold War: The Politics of Insecurity. Cambridge, MA: The Belknap Press of Harvard University Press.

Cramer, C. (2007). Violence in Developing Countries: War, Memory, Progress. Bloomington, IN: Indiana University Press.

Crelinsten, R. D., \& Schmid, A. P. (Eds.) (1995). The Politics of Pain, Torturers and Their Masters. Boulder, CO: Westview Press.

Crenshaw, M. (1989). Terrorism and International Cooperation. Boulder, CO: Westview Press.

Crenshaw, M. (2001). Theories of Terrorism: Instrumental and Organizational Approaches. In D. C. Rapoport (Ed.), Inside Terrorist Organizations (pp. 13-31). Portland, OR: Frank Cass.

Crenshaw, M. (Ed.) (1995). Terrorism in Context. University Park, PA: The Pennsylvania State University Press.

Creveld, M. van (1991). The Transformation of War. New York, NY: The Free Press.

Cromer, G. (2001). Narratives of Violence. Aldershot: Ashgate.

Cruz, J. M. (2010). Central American Maras: From Youth Street Gangs to Transnational Protection Rackets. Global Crime, 11 (4), 379-398.

Culberson, W. C. (1990). Vigilantism: Political History of Private Power in America. New York, NY: Greenwood Press.

Cull, N. J. (1995). Selling War: The British Propaganda Campaign Against American Neutrality in World War II. Oxford: Oxford University Press.

Cull, N. J. (2008). The Cold War and the United States Information Agency: American Propaganda and Public Diplomacy, 1945-1989. Cambridge: Cambridge University Press.

Cumings, B. (1992). War and Television. London: Verso.

Cunningham, K. J. (2003). Cross-Regional Trends in Female Terrorism. Studies in Conflict \& Terrorism, 26 (3), 171-195.

Cunningham, S. B. (2002). The Idea of Propaganda: A Reconstruction. Westport, CT: Praeger.

Daniel, E. V. (1996). Charred Lullabies: Chapters in an Anthropography of Violence. Princeton, NJ: Princeton University Press.

Das, V., Arthur, K., Ramphele, M., \& Reynolds, P. (Eds.) (2000). Violence and Subjectivity. Berkeley, CA: University of California Press.

Davis, D. E. (2003). Contemporary Challenges and Historical Reflections on the Study of Militaries, States, and Politics. In D. E. Davis \& A. W. Pereira (Eds.), Irregular Armed Forces and Their Role in Politics and State Formation (pp. 3-34). Cambridge: Cambridge University Press.

Davis, D. E. (2009). Non-State Armed Actors, New Imagined Communities, and Shifting Patterns of Sovereignty and Insecurity in the Modern World. Contemporary Security Policy, 30 (2), 221-245.

Davis, D. E. (2012). Urban Resilience in Situations of Chronic Violence. http://www.urcvproject.org. $(02 / 23 / 2015)$

Davis, F.-L. (1977). Primitive Revolutionaries of China: A Study of Secret Societies in the Late Nineteenth Century. Honolulu: University Press of Hawaii.

Davis, L. E., \& Engerman, S. L. (2006). Naval Blockades in Peace and War: An Economic History Since 1750. Cambridge: Cambridge University Press.

Davis, M. (2004). The Urbanization of Empire. Megacities and the Laws of Chaos. Social Text 81, 22 (4), 9-15.

Davis, M. (2006). Planet of Slums. London: Verso. 
Dawson, L. L., \& Cowan, D. E. (2004). Religion Online: Finding Faith on the Internet. New York, NY: Routledge.

Dear, M., \& Holzer, J. (2007). Altered States: The U.S.-Mexico Borderlands as ‘Third Nation'. In L. Purbrick, J. Aulich \& G. Dawson (Eds.), Contested Spaces: Sites, Representations and Histories of Conflict (pp. 74-93). New York, NY: Palgrave Macmillan.

De Luna, G. (2006). Il corpo del nemico ucciso. Violenza e morte nella guerra contemporanea. Turin: Einaudi.

De Lutiis, G. (1998). I servizi segreti in Italia. Dal Fascismo alla seconda Repubblica. Rome: Editori Riuniti.

De Lutiis, G. (2007). Il golpe di via Fani. Protezioni occulte e connivenze internazionali dietro il delitto Moro. Milan: Sperling \& Kupfer.

Der Derian, J., \& Shapiro, M. (Eds.) (1989). International/Intertextual: Postmodern Readings in World Politics. Lexington, MA: Lexington Books.

Desch, M. C. (1999). Civilian Control of the Military: The Changing Security Environment. Baltimore, MD: The Johns Hopkins University Press.

Diaz, T. (2009). No Boundaries: Transnational Latino Gangs and American Law Enforcement. Ann Arbor, MI: The University of Michigan Press.

Dickinson, L. A. (2011). Outsourcing War \& Peace: Preserving Public Values in a World of Privatized Foreign Affairs. New Haven, CT: Yale University Press.

Dishman, C. (2001). Terrorism, Crime, and Transformation. Studies in Conflict \& Terrorism, 24 (1), 43-58.

Drake, C. J. M. (1998). Terrorists' Target Selection. London: Macmillan.

Drake, R. (1995). The Aldo Moro Murder Case. Cambridge, MA: Harvard University Press.

Dudziak, M. L. (Ed.) (2003). September 11 in History. A Watershed Moment? Durham, NC: Duke University Press.

Dumézil, G. (1985). Heur et Malheur du guerrier. Paris: Flammarion.

Duncan, G. (2006). Los Señores de la Guerra. De paramilitares, mafiosos y autodefensas en Colombia. Bogotá: Planeta.

Earhart, D. C. (2007). Certain Victory: Images of World War II in Japanese Media. Armonk, NY: M. E. Sharpe.

Easton, D. (1965). A System Analysis of Political Life. New York, NY: John Wiley.

Echandía Castilla, C. (2006). Dos décadas de escalamiento del conflicto armado en Colombia 1986-2006. Bogotá: Universidad Externado de Colombia.

Edwards, A., \& Gill, P. (Eds.) (2003). Transnational Organised Crime: Perspectives on Global Security. New York, NY: Routledge.

Ehrenreich, B. (1997). Blood Rites: Origins and History of the Passions of War. New York, NY: Metropolitan Books-Henry Holt Co.

Eibl-Eibesfeldt, I. (1979). The Biology of Peace and War. London: Thames \& Hudson.

Elder-Vass, D. (2012). The Reality of Social Construction. Cambridge: Cambridge University Press.

Eliade, M. (1958). Birth and Rebirth. Rites and Symbols of Initiation. New York, NY: Harper \& Row.

Elias, N. (1991). The Society of Individuals. New York, NY: Continuum.

Elias, N. (1993). The Civilizing Process: The History of Manners and State Formation and Civilization. Oxford: Blackwell.

Ellul, J. (1967). Histoire de la propagande. Paris: Presses Universitaires de France.

Ellul, J. (1973). Propaganda. The Formation of Men's Attitudes. New York, NY: Vintage Book.

Enders, W. \& Sandler, T. (2002). Patterns of Transnational Terrorism, 1970-1999: Alternative Time-Series Estimates. International Studies Quarterly, 46 (2), 145-165.

Engene, J. O. (2004). Terrorism in Western Europe: Explaining the Trends Since 1950. Northampton, MA: Edward Elgar. 
Enloe, C. (2000). Bananas, Beaches and Base: Making Feminist Sense of International Politics. Berkeley, CA: University of California Press.

Enloe, C. (2004). The Curious Feminist: Searching for Women in a New Age of Empire. Berkeley, CA: University of California Press.

Enloe, C. (2007). Globalization and Militarism: Feminists Make the Link. Lanham, MD: Rowman \& Littlefield.

Enzensberger, H. M. (1993). Aussichten auf den Bürgerkrieg. Frankfurt am Main: Suhrkamp Verlag.

Evangelista, M. (2008). Law, Ethics, and the War on Terror. Cambridge: Polity Press.

Evangelista, M. (2011). Gender, Nationalism, and War. Conflict on the Movie Screen. Cambridge: Cambridge University Press.

Evangelista, M. (Ed.) (2005). Peace Studies: Critical Concepts in Political Science. 4 vols. New York, NY: Routledge.

Eyler, G. (2009). Gangs in the Military. The Yale Law Journal, 118 (4), 696-742.

Fabre, G. (2003). Criminal Prosperity: Drug Trafficking, Money Laundering and Financial Crises after the Cold War. New York, NY: Routledge Curzon.

Fair, C. C. (2008a). The Madrassah Challenge: Militancy and Religious Education in Pakistan. Washington DC: United States Institute of Peace Press.

Fair, C. C. (2008b). Who Are Pakistan's Militants and Their Families? Terrorism and Political Violence, 20 (1), 49-65.

Fair, C. C., \& Ganguly, S. (2008). Treading on Hallowed Ground: Counterinsurgency Operations in Sacred Spaces. Oxford: Oxford University Press.

Farcau, B. W. (1994). The Coup: Tactics in the Seizure of Power. Westport, CT: Praeger.

Farcau, B. W. (1996). The Transition to Democracy in Latin America: The Role of the Military. Westport, CT: Praeger.

Farneti, P. (1994). Lineamenti di scienza politica. Milan: Franco Angeli.

Feaver, P. D. (1996). The Civil-Military Problematique: Huntington, Janowitz, and the Question of Civilian Control. Armed Forces \& Society, 23 (2), 149-178.

Feaver, P. D., \& Kohn, R. H. (Eds.) (2001). Soldiers and Civilians: The Civil-Military Gap and American National Security. Cambridge, MA: Mit Press.

Feierabend, I. K., Feierabend, R. L., \& Gurr, T. R. (Eds.) (1972). Anger, Violence and Politics: Theories and Research. Englewood Cliffs, NJ: Prentice-Hall.

Feinstein, A. (2006). Journalists Under Fire: The Psychological Hazards of Covering War. Baltimore, MD: The Johns Hopkins University Press.

Feldman, A. (1991). Formations of Violence: The Narrative of the Body and Political Terror in Northern Ireland. Chicago, IL: The University of Chicago Press.

Fernandez, M., \& Rampal, J.-C. (2005). La ville qui tue les femmes. Paris: Hachette Littératures.

Fieldhouse, D. K. (1966). The Colonial Empires: A Comparative Survey from the Eighteenth Century. London: Weidenfeld \& Nicolson.

Fields, R. M., Elbedour, S., \& Hein, F. A. (2002). The Palestinian Suicide Bombers. In C. E. Stout (Ed.), The Psychology of Terrorism, vol. 2, Clinical Aspects and Responses (pp. 192-223). Westport, CT: Praeger.

Findlay, R., \& O’Rourke, K. H. (2007). Power and Plenty: Trade, War, and the World Economy in the Second Millennium. Princeton, NJ: Princeton University Press.

Fiske, S. T., Cuddy, A. J. C., Glick, P., \& Xu, J. (2002). A Model of (Often Mixed) Stereotype Content: Competence and Warmth Respectively Follow from Perceived Status and Competition. Journal of Personality and Social Psychology, 82 (6), 878-902.

Fletcher, G. P. (2002). Romantics at War: Glory and Guilt in the Age of Terrorism. Princeton, NJ: Princeton University Press.

Fleurant, A., \& Perlo-Freeman, S. (2014). The Sipri Top 100 Arms-Producing and Military Services Companies, 2013. Sipri Fact Sheet, December. 
Foerstel, H. N. (2006). Killing the Messenger: Journalists at Risk in Modern Warfare. Westport, CT: Praeger.

Foerstel, H. N. (2008). The Patriot Act: A Documentary and Reference Guide. Westport, CT: Greenwood Press.

Foote, K. E., \& Azaryahu, M. (2007). Toward a Geography of Memory: Geographical Dimensions of Public Memory and Commemoration. In V. Roudometof (Ed.), Collective Memory and Cultural Politics, Special Issue, Journal of Political and Military Sociology, 35 (1), 125-144.

Forgione, F. (2009). Mafia Export. Come 'Ndrangheta, Cosa Nostra e Camorra hanno colonizzato il mondo. Milan: Baldini Castoldi Dalai.

Fornari, F. (1974). The Psychoanalysis of War. Garden City: Anchor Press.

Forster, A. (2006). Armed Forces and Society in Europe. New York, NY: Palgrave Macmillan.

Foucault, M. (1977). Microfisica del potere. Turin: Einaudi.

Franko Aas, K. (2007). Globalization and Crime (Key Approaches to Criminology). New York, NY: Sage.

Freeman, J., \& Minow, M. (2009). Government by Contract: Outsourcing and American Democracy. Cambridge, MA: Harvard University Press.

Frey, M. (2006). Geschichte des Vietnamkriegs. München: Verlag C. H. Beck oHG.

Friedman, J. (2003). Globalization, the State, and Violence. Walnut Creek, CA: Altamira Press.

Friedrich, C. J. (1972). The Pathology of Politics: Violence, Betrayal, Corruption, Secrecy, and Propaganda. New York, NY: Harper \& Row.

Friman, R. H., \& Andreas, P. (Eds.) (1999). The Illicit Global Economy and State Power. Lanham, MD: Rowman \& Littlefield.

Frisch, H. (2005). Has the Israeli-Palestinian Conflict Become Islamic? Fatah, Islam, and the Al-Aqsa Martyrs' Brigades. Terrorism and Political Violence, 17 (3), 391-406.

Fromm, E. (1973). The Anatomy of Human Destructiveness. New York, NY: Holt, Rinehart and Winston.

Fujita, M., Krugman, P. R., \& Venables, A. (1999). The Spatial Economy: Cities, Regions and International Trade. Cambridge, MA: Mit Press.

Fukuyama, F. (1992). The End of History and the Last Man. New York, NY: Free Press.

Fuller, B., \& Romer P. (2012). Success and the City. How Charter Cities Could Transform the Developing World. http://www.macdonaldlaurier.ca/files/pdf/How-charter-cities-couldtransform-the-developing-world-April-2012.pdf (03/03/2015).

Fussell, P. (1975). The Great War and Modern Memory. Oxford: Oxford University Press.

Fussell, P. (1989). Wartime: Understanding and Behaviour in the Second World War. Oxford: Oxford University Press.

Fyne, R. (2008). Long Ago and Far Away: Hollywood and the Second World War. Lanham, MD: The Scarecrow Press.

Gabriel, R. A. (1988). The Painfuld Field: The Psychiatric Dimension of Modern War. Westport, CT: Greenwood Press.

Gaddis, J. L. (2002). The Landscape of History: How Historians Map the Past. Oxford: Oxford University Press.

Galeotti, M. (2004). The Russian 'Mafiya': Consolidation and Globalization. Global Crime, 6 (1), 54-69.

Gambetta, D. (Ed.) (2005). Making Sense of Suicide Missions. Oxford: Oxford University Press.

Gao (Government Accountability Office) (2008). Contingency Contracting: DOD, State, and Usaid Contracts and Contractor Personnel in Iraq and Afghanistan. http://www.gao.gov/new.items/ d0919.pdf (02/26/2015).

Gates, S. (2002). Recruitment and Allegiance: The Microfoundations of Rebellion. The Journal of Conflict Resolution, 46 (1), 111-130.

Geldenhuys, D. (2004). Deviant Conduct in World Politics. New York, NY: Palgrave Macmillan. 
Gemert, F. van, Peterson, D., \& Lien, I.-L. (Eds.) (2008). Street Gangs, Migration and Ethnicity. Portland, OR: Willan.

Gennep, A. van (1960). The Rites of Passage. Chicago, IL: University of Chicago Press.

Gentry, C. (2004). The Relationship Between New Social Movement Theory and Terrorism Studies: The Role of Leadership, Membership, Ideology and Gender. Terrorism and Political Violence, 16 (2), 274-293.

Gerber, D. A. (Ed.) (2000). Disabled Veterans in History. Ann Arbor, MI: The University of Michigan Press.

Giacomello, G. (2004). Bangs for the Buck: A Cost-Benefit Analysis of Cyberterrorism. Studies in Conflict \& Terrorism, 27 (5), 387-408.

Giacomello, G., Ruzza, S. (2015). Regardless of Clausewitz? Classical Strategic Theory in a Hybrid World. In S. Ruzza, A. P. Jakobi, \& C. Geisler (Eds.), Non-State Challenges in a Re-Ordered World. The Jackals of Westphalia. New York, NY: Routledge.

Gibelli, A. (1991). L'officina della guerra. La Grande Guerra e le trasformazioni del mondo mentale. Turin: Bollati Boringhieri.

Giletti Benso, S., \& Silvestri, L. (Eds.) (2010). Ciudad Juárez. La violenza sulle donne in America Latina, l'impunità, la resistenza delle madri. Milan: Franco Angeli.

Gilpin, R. (1981). War and Change in World Politics. New York, NY: Cambridge University Press.

Gilpin, R. (1987). The Political Economy of International Relations. Princeton, NJ: Princeton University Press.

Gilpin, R. (2011). Global Political Economy: Understanding the International Economic Order. Princeton, NJ: Princeton University Press.

Glantz, A. (2009). The War Comes Home: Washington's Battle Against America's Veterans. Berkeley, CA: University of California Press.

Goldhagen, D. J. (1996). Hitler's Willing Executioners: Ordinary Germans and the Holocaust. London: Little, Brown and Company.

Goldstein, J. S. (1988). Long Cycles. Prosperity and War in the Modern Age. New Haven, CT: Yale University Press.

Goldstein, J. S. (2001). War and Gender: How Gender Shapes the War System and Vice Versa. Cambridge: Cambridge University Press.

Gonzáles Rodríguez, (2002). S. Huesos en el desierto. Barcelona: Edizional Anagramma.

Gonzalez-Perez, M. (2008). Women and Terrorism: Female Activity in Domestic and International Terror Groups. New York, NY: Routledge.

Goodwin, G. (1994). The Janissaries. London: Saqi.

Goodwin, M. (2006). Black Markets: The Supply and Demand of Body Parts. New York, NY: Cambridge University Press.

Gootenberg, P. (2008). Andean Cocaine: The Making of a Global Drug. Chapel Hill, NC: The University of North Carolina Press.

Gordon, I. R., \& McCann, P. (2000). Industrial Clusters: Complexes, Agglomeration and/or Social Networks? Urban Studies, 37 (3), 513-532.

Gorini, U. (2006). La rebelión de las Madres. Historia de las Madres de Plaza de Mayo. Tomo I (1976-1983). Buenos Aires: Grupo Editorial Norma.

Gottshalk, P. (2009). Entrepreneurship and Organised Crime: Entrepreneurs in Illegal Business. Northampton, MA: Edward Elgar.

Gottshalk, P., \& Greenberg, G. (2008). Islamophobia: Making Muslim the Enemy. Lanham, MD: Rowman \& Littlefield.

Govier, T. (Ed.) (1988). Selected Issues in Logic and Communication. Belmont, CA: Wadsworth.

Graham, S. (2006). Cities and the 'War on Terror'. International Journal of Urban and Regional Research, 30 (2), 255-276.

Graham, S. (2010). Cities Under Siege: The New Military Urbanism. London: Verso. 
Graham, S., Marvin, S. (2001). Splintering Urbanism. Networked Infrastructures, Technological Mobilities, and the Urban Condition. New York, NY: Routledge.

Gray, C. S. (1999). Modern Strategy. Oxford: Oxford University Press.

Gray, J. G. (1970). The Warriors: Reflections of Men in Battle. Lincoln and London: University of Nebraska Press.

Greenberg, B. S. (Ed.) (2002). Communication and Terrorism: Public and Media Responses to 9/11. Cresskill, NJ: Hampton Press.

Greenberg, K. J. (Ed.) (2006). The Torture Debate in America. Cambridge: Cambridge University Press.

Greenberg, K. J., \& Dratel, J. L. (2008). The Enemy Combatant Papers: American Justice, the Courts, and the War on Terror. Cambridge: Cambridge University Press.

Greene, B. (1989). Homecoming: When the Soldiers Returned from Vietnam. New York, NY: G. B. Putnam's Sons.

Greif, A. (2005). Commitment, Coercion, and Markets: The Nature and Dynamics of Institutions Supporting Exchange. In C. Ménard \& M. M. Shirley (Eds.), The Handbook of New Institutional Economics (pp. 727-786). New York, NY: Springer.

Greif, A. (2006). Family Structure, Institutions, and Growth: The Origins and Implications of Western Corporations. American Economic Review, 96 (2), 308-312.

Griset, P. L., \& Mahan, S. (Eds.) (2003). Terrorism in Perspective. Thousand Oaks, CA: Sage.

Grossman, D. (1995). On Killing: The Psychological Cost of Learning to Kill in War and Society. Boston, MA: Little, Brown and Company.

Grutzpalk, J. (2002). Blood Feud and Modernity. Max Weber's and Émile Durkheim's Theories. Journal of Classical Sociology, 2 (2), 115-134.

Guelke, A. (2006). Terrorism and Global Disorder. New York, NY: I. B. Tauris.

Guénon, R. (2001). Perspectives on Initiation. Hillsdale: Sophia Perennis.

Guevara, E. Che (2009). Guerrilla Warfare. New York, NY: Classic House Books.

Gunaratna, R. (2002). Inside Al Qaeda: Global Network of Terror. New York, NY: Columbia University Press.

Gupta, D. K. (2008). Understanding Terrorism and Political Violence: The Life Cycle of Birth, Growth, Transformation, and Demise. New York, NY: Routledge.

Gurr, T. R. (1970). Why Men Rebel. Princeton, NJ: Princeton University Press.

Gutman, R., \& Rieff, D. (Eds.) (1999). Crimes of War. New York, NY: W. W. Norton.

Guzzini, S., \& Leander, A. (Eds.) (2006). Constructivism and International Relations: Alexander Wendt and His Critics. New York, NY: Routledge.

Haar, B. J. ter (1998). Ritual and Mythology of the Chinese Triads: Creating an Identity. Leiden: Brill.

Hafez, M. M. (2007). Martyrdom Mythology in Iraq: How Jihadists Frame Suicide Terrorism in Videos and Biographies. Terrorism and Political Violence, 19 (1), 95-115.

Hagedorn, J. M. (2008). World of Gangs: Armed Young Men and Gangsta Culture. Minneapolis, MN: University of Minnesota Press.

Hagedorn, J. M. (Ed.) (2007). Gangs in the Global City: Alternatives to Traditional Criminology. Urbana, IL: University of Illinois Press.

Hagopian, P. (2009). The Vietnam War in American Memory: Veterans, Memorials, and the Politics of Healing. Amherst: University of Massachusetts Press.

Hall, R. B., \& Biersteker, T. J. (Eds.) (2002). The Emergence of Private Authority in Global Governance. Cambridge: Cambridge University Press.

Halloff, F. (Ed.) (2008). Physicians at War: The Dual-Loyalties Challenge. New York, NY: Springer. Hamilton, N. A. (1996). Militias in America: A Reference Handbook. Santa Barbara, CA: Abc-Clio. Hamm, M. S. (2007). Terrorism as Crime: From Oklahoma City to Al Qaeda and Beyond. New York, NY: New York University Press.

Hammond, P. (2007). Framing Post-Cold War Conflicts: The Media and International Intervention. Manchester: Manchester University Press. 
Hancock, P. A., \& Szalma, J. L. (2008). Performance Under Stress. Burlington, VT: Ashgate.

Handelman, S. (1994). Comrade Criminal: The Theft of the Second Russian Revolution. London: Michael Joseph.

Hanson, N. (2006). Unknown Soldiers: The Story of the Missing of the First World War. New York, NY: Knopf.

Harcourt, B. E. (2001). Illusion of Order. The False Promise of Broken Windows Policing. Cambridge, MA: Harvard University Press.

Harding, C. (2006). Aggression and Destructiveness: Psychoanalitical Perspectives. New York, NY: Routledge.

Hasenclever, A., Mayer, P., \& Rittberger, V. (1997). Theories of International Regimes. Cambridge: Cambridge University Press.

Headrick, D. R. (1981). The Tools of Empire: Technology and European Imperialism in the Nineteenth Century. Oxford: Oxford University Press.

Heims, S. J. (1993). Constructing a Social Science for Postwar America: The Cybernetics Group, 1946-1953. Cambridge, MA: Mit Press.

Heinecken, L. (2009). Discontent Within the Ranks? Officers' Attitudes Toward Military Employment and Representation - A Four-Country Comparative Study. Armed Forces \& Society, 35 (3), 477-500.

Held, D., \& Kaya, A. (Eds.) (2007). Global Inequality: Patterns and Explanations. Cambridge: Polity Press.

Held, D., \& McGrew, A. (2007). Globalization/Anti-Globalization. Beyond the Great Divide. Cambridge: Polity Press.

Henriksen, R., \& Vinci, A. (2008). Combat Motivation in Non-State Armed Groups. Terrorism and Political Violence, 20 (1), 87-109.

Herf, J. (2006). The Jewish Enemy: Nazi Propaganda During World War II and the Holocaust. Cambridge, MA: The Belknap Press of Harvard University Press.

Herrmann, R K., \& Fischerkeller, M. P. (1995). Beyond the Enemy Image and Spiral Model: CognitiveStrategic Research after the Cold War. International Organization, 49 (3), 415-450.

Hess, H. (2003). Like Zealots and Romans: Terrorism and Empire in the $21^{\text {st }}$ Century. Crime, Law \& Social Change, 39 (4), 339-357.

Higate, P. R. (Ed.) (2003). Military Masculinities: Identity and the State. Westport, CT: Praeger.

Hilberg, R. (1985). The Destruction of the European Jews. New York, NY: Holmes \& Meier.

Hill, P. B. E. (2003). The Japanese Mafia: Yakuza, Law, and the State. Oxford: Oxford University Press. Hirschman, A. O. (1970). Exit, Voice, and Loyalty: Responses to Decline in Firms, Organizations, and States. Cambridge, MA: Harvard University Press.

Hirst, P. (2005). Space and Power: Politics, War and Architecture. Cambridge: Polity Press. Hobbes, T. (1997). Leviathan (1651). New York, NY: W. W. Norton \& Company.

Hobsbawm, E. J. (1992). Nations and Nationalism Since 1780. Programme, Myth, Reality. Cambridge: Cambridge University Press.

Hobsbawm, E. J. (2000). Bandits. London: Weidenfeld \& Nicolson.

Hoffman, B. (1998). Inside Terrorism. New York, NY: Columbia University Press.

Hoffman, B., \& McCormick, G. H. (2004). Terrorism, Signaling, and Suicide Attack. Studies in Conflict \& Terrorism, 27 (4), 243-281.

Hoffmann, S. (1977). An American Social Science: International Relations. Daedalus, 3, 41-59.

Holmes, L. (Ed.) (2007). Terrorism, Organised Crime and Corruption: Networks and Linkages. Northampton, MA: Edward Elgar.

Holmes, R. (1986). Acts of War: The Behavior of Men in Battle. New York, NY: Free Press.

Holsti, K. J. (1991). Peace and War: Armed Conflicts and International Order 1648-1989. Cambridge: Cambridge University Press.

Honwana, A. M. (2006). Child Soldiers in Africa. Philadelphia, PA: University of Pennsylvania Press. 
Horgan, J. (2006). The Psychology of Terrorism. New York, NY: Routledge.

Horgan, J. \& Taylor, M. (2003). Playing the 'Green Card' - Financing the Provisional IRA: Part 2.

Terrorism and Political Violence, 15 (2), 1-60.

Hoskins, A. (2004). Televising War: From Vietnam to Iraq. New York, NY: Continuum.

Hossein-zadeh, I. (2006). The Political Economy of U.S. Militarism. New York, NY: Palgrave

Macmillan.

Hossein-zadeh, I. (2008). Social vs. Military Spending: How the Escalating Pentagon Budget Crowds out Public Infrastructure and Aggravates Natural Disasters. The Case of Hurricane Katrina.

Review of Social Economy, 67 (2), 149-173.

Huggins, M. K. (1991). Vigilantism and the State in Modern Latin America: Essays on Extralegal Violence. Westport, CT: Praeger.

Huggins, M. K., Haritos-Fatouros, M., \& Zimbardo, P. G. (2002). Violence Workers: Police Torturers and Murderers Reconstruct Brazilian Atrocities. Berkeley, CA: University of California Press.

Huntington, S. P. (1957). The Soldier and the State: The Theory and Politics in Civil-Military Relations. Cambridge, MA: Harvard University Press.

Ikenberry, G. J. (2001). After Victory. Institutions, Strategic Restraints, and the Rebuilding of Order after Major Wars. Princeton, NJ: Princeton University Press.

Ikenberry, G. J. (2011). Liberal Leviathan. The Origins, Crisis, and Tranformation of the American World Order. Princeton, NJ: Princeton University Press.

International Consortium of Investigative Journalists (2003). Making a Killing: The Business of War. Washington DC: Public Integrity Books.

Israeli, R. (2004). Palestinian Women: The Quest for a Voice in the Public Square Through 'Islamikaze Martyrdom'. Terrorism and Political Violence, 16 (1), 66-96.

Jacoby, T. A. (2007). Bridging the Barrier: Israeli Unilateral Disengagement. Burlington, VT: Ashgate. Jankowski, M. S. (1991). Island in the Street: Gangs and American Urban Society. Berkeley, CA: University of California Press.

Janowitz, M. (1960). The Professional Soldier: A Social and Political Portrait. Glencoe: The Free Press. Janowitz, M. (1975). Sociological Theory and Social Control. American Journal of Sociology, 81 (1), 82-108.

Janowitz, M. (1991). Military Institutions and Citizenship in Western Societies. In M. Janowitz, On Social Organization and Social Control (pp. 223-238). Chicago, IL: The University of Chicago Press.

Janowitz, M., \& Little, R. W. (1965). Sociology and the Military Establishment. New York, NY: Russell Sage Foundation.

Jenkins, B. M. (1975). International Terrorism: A Balance Sheet. Survival, 17 (4), 158-164.

Johnson, B., \& Cloonan, M. (2008). Dark Side of the Tune: Popular Music and Violence. Burlington, VT: Ashgate.

Johnson, L. K., \& Wirtz, J. J. (2008). Intelligence and National Security: The Secret World of Spies: An Anthology. Oxford: Oxford University Press.

Joint Publication (JP) 5-0. (2011). Joint Operation Planning. Washington DC: U.S. Joint Chiefs of Staff, August 11, http://www.dtic.mil/doctrine/new_pubs/jp5_0.pdf. (02/23/2015).

Jojarth, C. (2009). Crime, War, and Global Trafficking: Designing International Cooperation.

Cambridge: Cambridge University Press.

Josephson, M. (1934). The Robber Barons. New York, NY: Harcourt, Brace \& Company.

Josselin, D., \& Wallace, W. (Eds.). (2001). Non-State Actors in World Politics. New York, NY: Palgrave. Jowett, G. S., \& O’Donnell, V. (1986). Propaganda and Persuasion. Beverly Hills: Sage.

Juergensmeyer, M. (2000). Terror in the Mind of God: The Global Rise of Religious Violence. Berkeley, CA: University of California Press.

Juergensmeyer, M. (2008). Global Rebellion: Religious Challenges to the Secular State, from Christian Militias to Al Qaeda. Berkeley, CA: University of California Press. 
Junaid, S. (2005). Terrorism and Global Power System. Oxford: Oxford University Press.

Jung, D. (Ed.) (2003). Shadow Globalization, Ethnic Conflicts and New Wars: A Political Economy of Intra-State War. New York, NY: Routledge.

Jungk, R. (1958). Brighter Than a Thousand Suns. A Personal History of the Atomic Scientists. New York, NY: Harcourt Brace.

Jürgs, M. (2003). Der kleine Frieden im grossen Krieg. München: C. Bertelsmann Verlag.

Jütersonke, O., Muggah, R., \& Rodgers, D. (2009). Gangs, Urban Violence, and Security Interventions in Central America. Security Dialogue, 40 (4-5), 373-397.

Kahaner, L. (2007). AK-47: The Weapon that Changed the Face of War. Hoboken, NJ: John Wiley \& Sons.

Kaldor, M. (2012). New and Old Wars: Organized Violence in a Global Era. London: Polity Press.

Kaldor, M. (2013). In Defence of New Wars. Stability, 2 (1), 1-16.

Kaldor, M., \& Vashee, B. (1997). Restructuring the Global Military Sector. New Wars. London: Pinter.

Kallis, A. A. (2005). Nazi Propaganda and the Second World War. New York, NY: Palgrave Macmillan.

Kantorowicz, E. H. (1957). The King's Two Bodies: A Study in Medieval Political Theology. Princeton, NJ: Princeton University Press.

Kaplan, Robert D. (2000). The Coming Anarchy: Shattering the Dreams of the Post Cold War. New York, NY: Random House.

Karnow, S. (1983). Vietnam: A History. New York, NY: Viking.

Karsten, P. (1978). Soldiers and Society: The Effects of Military Service and War on American Life. Westport, CT: Greenwood Press.

Kassimeris, G. (Ed.) (2006a). The Barbarization of Warfare. New York, NY: New York University Press.

Kassimeris, G. (Ed.) (2006b). Warrior's Dishonour: Barbarity, Morality and Torture in Modern Warfare. Burlington, VT: Ashgate.

Kassimeris, G. (Ed.) (2008). Playing Politics with Terrorism: A User’s Guide. New York, NY: Columbia University Press.

Kawata, J. (Ed.). (2006). Comparing Political Corruption and Clientelism. Aldershot: Ashgate.

Keegan, J. (2004). The Iraq War. New York, NY: A. A. Knopf.

Kennedy, C. H., \& Zillmer, E. A. (Eds.) (2006). Military Psychology: Clinical and Operational Applications. New York, NY: The Guilford Press.

Kennedy, D. (2009). The Spectator and the Spectacle: Audiences in Modernity and Postmodernity. Cambridge: Cambridge University Press.

Keohane, R. O. (1984). After Hegemony. Princeton, NJ: Princeton University Press.

Keohane, R. O. (2002). The Globalization of Informal Violence, Theories of World Politics, and the 'Liberalism of Fear'. Dialog-IO, Spring, 29-43.

Kershner, I. (2005). Barrier: The Seam of the Israeli-Palestinian Conflict. New York, NY: Palgrave Macmillan.

Keynes, J. M. (1940). How to Pay for the War: A Radical Plan for the Chancellor of the Exchequer. London: Macmillan.

Khadduri, M. (1955). War and Peace in the Law of Islam. Baltimore, MD: The Johns Hopkins Press.

Kiernan, V. G. (1982). European Empires from Conquest to Collapse, 1815-1960. London: CollinsFontana Paperbacks.

Kiernan, V. G. (1988). The Duel in European History: Honour and the Reign of Aristocracy. Oxford: Oxford University Press.

Kimhi, S., \& Even, S. (2004). Who Are the Palestinian Suicide Bombers? Terrorism and Political Violence, 16 (4), 815-840.

Kinross, S. (2008). Clausewitz and America: Strategic Thought and Practice from Vietnam to Iraq. New York, NY: Routledge.

Kinsella, D. T., Russett, B. M., \& Starr H. (2013). World Politics: The Menu for Choice. Boston, MA: Wadsworth. 
Kinsey, C. (2006). Corporate Soldiers and International Security. The Rise of Private Military Companies. London: Routledge.

Kinsey, C. (2009). Private Contractors and the Reconstruction of Iraq: Transforming Military Logistics. New York, NY: Routledge.

Kirchner, H. (2007). Martyrs, Victims, Friends and Foes: Internet Representations by Palestinian Islamists. In A. Rao, M. Bollig \& M. Böck (Eds.), The Practice of War: Production, Reproduction, and Communication of Armed Violence (pp. 285-304). New York, NY: Berghahn Books.

Kirshner, J. (2007). Appeasing Bankers: Financial Caution on the Road to War. Princeton, NJ: Princeton University Press.

Kirtzman, A. (2009). Betrayal: The Life and Lies of Bernie Madoff. New York, NY: Harper.

Klausen, J. (2015). Tweeting the Jihad: Social Media Networks of Western Foreign Fighters in Syria and Iraq. Studies in Conflict \& Terrorism, 38 (1), 1-22.

Klauser, F. R. (2010). Splintering Spheres of Insecurity: Peter Sloterdijk and the Contemporary Fortress City. Environment and Planning D: Society and Space, 28, 326-340.

Klauser, F. R. (2012). Thinking Through Territoriality: Introducing Claude Raffestin to Anglophone Sociospatial Theory. Environment and Planning D: Society and Space, 30, 106-120.

Klebnikov, P. (2000). Godfather of the Kremlin: Boris Berezovsky and the Looting of Russia. New York, NY: Harcourt.

Knightley, P. (2004). The First Casualty: The War Correspondent as Hero and Myth-Maker from Crimea to Iraq. Baltimore, MD: The Johns Hopkins University Press.

Knowlton, B. (2010). Obama's Nominee for T. S. A. Withdraws. New York Times, January 20.

Kohn, R. H. (2009). The Danger of Militarization in an Endless 'War' on Terrorism. The Journal of Military History, 73 (1), 177-208.

Kolko, G. (1994). Century of War: Politics, Conflict, and Society Since 1914. New York, NY: The New Press.

Kolko, G. (2002). Another Century of War? New York, NY: The New Press.

Koonings, K., \& Kruijt, D. (Eds.) (2004). Armed Actors: Organised Violence and State Failure in Latin America. New York, NY: Zed Books.

Koonings, K., \& Kruijt, D. (Eds.) (2007). Fractured Cities: Social Exclusion, Urban Violence \& Contested Spaces in Latin America. New York, NY: Zed Books.

Koselleck, R. (1988). Critique and Crisis: Enlightenment and the Pathogenesis of Modern Society. Cambridge, MA: Mit Press.

Koskenniemi, M. (2002). The Gentle Civilizer of Nations. The Rise and Fall of International Law 1870-1960. Cambridge: Cambridge University Press.

Krahmann, E. (2010). States, Citizens and the Privatization of Security. Cambridge: Cambridge University Press.

Kramer, A. (2007). Dynamic of Destruction: Culture and Mass Killing in the First World War. Oxford: Oxford University Press.

Kraska, P. B. (Ed.) (2001). Militarizing the American Criminal Justice System: The Changing Roles of the Armed Forces and the Police. Boston, MA: Northeastern University Press.

Krasner, S. D. (Ed.) (1983). International Regimes. Ithaca, NY: Cornell University Press.

Kratochwil, F. (1989). Rules, Norms and Decisions. Cambridge: Cambridge University Press.

Krepinevich, A. F. Jr. (1994). Cavalry to Computer: The Pattern of Military Revolutions. The National Interest, (37), 30-42.

Krishnan, A. (2008). War as Business: Technological Change and Military Service Contracting. Burlington, VT: Ashgate.

Kruijt, D. (2008). Guerrillas, War and Peace in Central America. New York, NY: Zed Books.

Kuklick, B. (2006). Blind Oracles. Intellectuals and War from Kennan to Kissinger. Princeton, NJ: Princeton University Press. 
Kushner, B. (2006). The Thought War: Japanese Imperial Propaganda. Honolulu: University of Hawaii Press.

Kushner, H. W. (Ed.) (2002). Essential Readings on Political Terrorism: Analyses of Problems and Prospects for the $21^{\text {st }}$ Century. New York, NY: Gordian Knot Books.

Kwon, H. (2006). After the Massacre: Commemoration and Consolation in Ha My and My Lai. Berkeley, CA: University of California Press.

LaFree, G., \& Dugan, L. (2007). Introducing the Global Terrorism Database. Terrorism and Political Violence, 19 (2), 181-204.

Landau-Wells, M. (2008), Capital Cities in Civil Wars: The Locational Dimensions of Sovereign Authority. Occasional Paper 6, Crisis States Research Centre, London School of Economics, April, http://web.mit.edu/polisci/people/gradstudents/papers/OP6Landau.pdf (02/24/2015).

Lane, F. C. (1979). Profits from Power: Readings in Protection Rent and Violence-Controlling Enterprises. Albany, NY: State University of New York Press.

Langewiesche, W. (2003). American Ground: Unbuilding the World Trade Center. New York, NY: North Point Press.

Langewiesche, W. (2004). The Outlaw Sea: A World of Freedom, Chaos, and Crime. New York, NY: North Point Press.

Laqueur, W. (1998). Guerrilla Warfare: A Historical and Critical Study. New Brunswick, NJ: Transaction.

Larson, E. V., \& Savych, B. (2007). Misfortunes of War: Press and Public Reactions to Civilian Deaths in Wartime. Santa Monica, CA: Rand Project Air Force.

Lasswell, H. D. (1941). The Garrison State. The American Journal of Sociology, 46 (4), 455-468.

Lasswell, H. D. (1971). Propaganda Technique in World War I. Cambridge, MA: Mit Press.

Lasswell, H. D., Lerner, D., \& Speier, H. (Eds.) (1970-1980). Propaganda and Communication in World History. 3 vols. Honolulu: University of Hawaii Press.

Laurie, C. D. (1996). The Propaganda Warriors: America's Crusade Against Nazi Germany. Lawrence: University Press of Kansas.

Lawson, P. (1993). The East India Company: A History. New York, NY: Longman.

Leal, D. L. (2007). Students in Uniform: Rotc, the Citizen-Soldier, and the Civil-Military Gap. PS: Political Science and Politics, 40 (3), 479-483.

Leander, A. (2005). The Market for Force and Public Security: The Destabilizing Consequences of Private Military Companies. Journal of Peace Research, 42 (5), 605-622.

Leander, A. (Ed.) (2013). Commercialising Security in Europe. Political Consequences for Peace Operations. London: Routledge.

Le Billon, P. (2005). Fuelling War: Natural Resources and Armed Conflict. New York, NY: Routledge.

Lebow, R. N., Kansteiner, W., \& Fogu, C. (Eds.) (2006). The Politics of Memory in Postwar Europe. Durham, NC: Duke University Press.

Leed, E. J. (1979). No Man's Land: Combat \& Identity in World War I. Cambridge: Cambridge University Press.

Lehr, P. (Ed.) (2007). Violence at Sea: Piracy in the Age of Global Terrorism. New York, NY: Routledge.

Leitner, M. (Ed.) (2013). Crime Modeling and Mapping Using Geospatial Technologies. Dordrecht: Springer.

Lennon, A. T. J. (Ed.) (2007). The Epicenter of Crisis: The New Middle East. Cambridge, MA: Mit Press. Lester, D., Yang, B., \& Lindsay, M. (2004). Suicide Bombers: Are Psychological Profiles Possible? Studies in Conflict \& Terrorism, 27 (4), 283-295.

Levi, P. (1988). The Drowned and the Saved. New York, NY: Summit Books.

Levinson, S. (Ed.) (2004). Torture: A Collection. Oxford: Oxford University Press.

Lévi-Strauss, C. (1963). Structural Anthropology. New York, NY: Basic Books.

Lévi-Strauss, C. (1969). The Elementary Structures of Kinship. Boston, MA: Beacon. 
Levy, J. S. (1983). War in the Modern Great Power System, 1495-1975. Lexington, KY: University of Kentucky Press.

Levy, J. S. (1998). The Causes of War and the Conditions of Peace. Annual Review of Political Science, $1,139-166$

Lewis, J. (2005). Language Wars: The Role of the Media and Culture in Global Terror and Political Violence. London: Pluto Press.

Lewis, J. W. (2007). Precision Terror: Suicide Bombings as Control Technology. Terrorism and Political Violence, 19 (2), 223-245.

Liddell Hart, B. H. (1963). The Real War 1914-1918. Boston, MA: Little, Brown and Company.

Liddell Hart, B. H. (1967). Strategy. New York, NY: Praeger.

Linklater, A. (1992). The Question of the Next Stage in International Relations Theory: A CriticalTheoretic Approach. Millennium, 21 (1), 77-98.

Lintner, B. (2002). Blood Brothers: The Criminal Underworld of Asia. New York, NY: Palgrave Macmillan.

Lippert, R., \& Walby, K. (Eds.) (2013). Policing Cities. Urban Securitization and Regulation in a $21^{\text {st }}$ Century World. New York, NY: Routledge.

Lister, C. R. (2015). The Islamic State. A Brief Introduction. Washington, DC: Brooking Institution Press.

Little, R. W. (1964). Buddy Relations and Combat Performance. In M. Janowitz (Ed.), The New Military: Changing Patterns of Organization (pp. 195-224). New York, NY: Russell Sage Foundation.

Lloyd, D. W. (1998). Battlefield Tourism: Pilgrimage and the Commemoration of the Great War in Britain, Australia and Canada, 1913-1939. New York, NY: Berg.

Lodato, S. (2007). La mafia ha vinto. Intervista con Tommaso Buscetta. Milan: Mondadori.

Lorenz, K. (2002). On Aggression. New York, NY: Routledge.

Lowen, R. S. (1997). Creating the Cold War University. The Transformation of Stanford. Berkeley, CA: University of California Press.

Lugo, A. (2008). Fragmented Lives, Assembled Parts: Culture, Capitalism, and Conquest at the

U.S.-Mexico Border. Austin: University of Texas Press.

Luhmann, N. (1995). Social Systems. Stanford, CA: Stanford University Press.

Lyman, M. D., \& Potter G. W. (2006). Organized Crime. Upper Saddle River: Prentice Hall.

Lynch, M., \& Stover, W. (2008). A Turbulent Transition: The Army National Guard and Army Reserve's Movement to an Operational Reserve. Journal of Political and Military Sociology, 36 (2), 65-84.

Machiavelli, N. (2007). The Prince (1515). Rockville, MD: Arc Manor Publishers.

MacNair, R. M. (2002). Perpetration-Induced Traumatic Stress: The Psychological Consequences of Killing. Westport, CT: Praeger.

MacNair, R. M. (2003). The Psychology of Peace: An Introduction. Westport, CT: Praeger.

Mahajan, G., \& Reifeld, H. (Eds.) (2003). The Public and the Private: Issues of Democratic Citizenship. London: Sage.

Mahan, S. (Ed.) (with K. O’Neil) (1998). Beyond the Mafia: Organized Crime in the Americas. Thousand Oaks, CA: Sage.

Maire Vigueur, J.-C. (2003). Cavaliers et citoyens. Guerre, conflits et société dans l'Italie communale, XII'-XIII' siècles. Paris: Éditions de l'École des hautes études en sciences sociales.

Makdisi, S. (2008). Palestine Inside-out: An Everyday Occupation. New York, NY: W. W. Norton.

Malešević, S. (2010). The Sociology of War and Violence. Cambridge: Cambridge University Press.

Maley, W. (2002). The Afghanistan Wars. New York, NY: Palgrave.

Malik, J. (Ed.) (2008). Madrasas in South Asia: Teaching Terror? New York, NY: Routledge.

Mallett, M. (1974). Mercenaries and Their Masters: Warfare in Renaissance Italy. London: The Bodley Head Ltd.

Malloy, S. L. (2008). Atomic Tragedy. Henry L. Stimson and the Decision to Use the Bomb Against Japan. Ithaca, NY: Cornell University Press. 
Maltz, M. D. (1994). Defining Organized Crime. In R. J. Kelly, K.-L. Chin \& R. Schatzberg (Eds.), Handbook of Organized Crime in the United States (pp. 21-37). Westport, CT: Greenwood Press. Mandel, R. (2002). The Privatization of Security. Boulder, CO: Lynne Rienner.

Mann, M. (1988). States, War and Capitalism: Studies in Political Sociology. Oxford: Blackwell.

Manning, P. K. (2008). The Technology of Policing: Crime Mapping, Information Technology, and the Rationality of Crime Control. New York, NY: New York University Press.

Marez, C. (2004). Drug Wars: The Political Economy of Narcotics. Minneapolis, MN: University of Minnesota Press.

Marten, K. (2012). Warlords: Strong-Arm Brokers in Weak States. Ithaca: Cornell University Press.

Martino-Taylor, L. (2008). The Military-Industrial-Academic Complex and a New Social Autism. Journal of Political and Military Sociology, 36 (1), 37-52.

Masciandaro, D., Takáts, E., \& Unger, B. (2007). Black Finance: The Economics of Money Laundering. Northampton, MA: Edward Elgar.

Matheson, D., \& Allan, S. (2009). Digital War Reporting. Cambridge: Polity Press.

Mayer, J. (2008). The Dark Side: The Inside Story of How the War on Terror Turned into a War on American Ideals. New York, NY: Doubleday.

Mazzei, J. (2009). Death Squads or Self-Defense Forces? How Paramilitary Groups Emerge and Challenge Democracy in Latin America. Chapel Hill, NC: The University of North Carolina Press.

McAllister, B. (2004). Al Qaeda and the Innovative Firm: Demythologizing the Network. Studies in Conflict \& Terrorism, 27 (4), 297-319.

McCoy, A. W. (1991). The Politics of Heroin: Cia Complicity in the Global Drug Trade. New York, NY: Lawrence Hill Books.

McDermott, T. (2005). Perfect Soldiers: The Hijackers: Who They Were, Why They Did It. New York, NY: Harper Collins.

McGarty, C., Yzerbyt, V. Y., \& Spears, R. (2002). Social, Cultural and Cognitive Factors in Stereotype Formation. In C. McGarty, V. Y. Yzerbyt \& R. Spears, Stereotypes as Explanations: The Formation of Meaningful Beliefs about Social Groups (pp. 1-15). Cambridge: Cambridge University Press.

McNeill, W. H. (1976). Plagues and Peoples. Garden City: Anchor Book.

McNeill, W. H. (1982). The Pursuit of Power: Technology, Armed Forces, and Society Since A. D. 1000. Chicago, IL: The University of Chicago Press.

Mehta, S. (2004). Maximum City: Bombay Lost and Found. New York, NY: Knopf.

Menjívar, C., \& Rodrìguez, N. (Eds.) (2005). When States Kill: Latin America, the U.S., and Technologies of Terror. Austin: University of Texas Press.

Metelits, C. M. (2009). The Consequences of Rivalry: Explaining Insurgent Violence Using Fuzzy Sets. Political Research Quarterly, 62 (4), 673-684.

Metelits, C. M. (2010). Inside Insurgency: Violence, Civilians, and Revolutionary Group Behavior. New York, NY: New York University Press.

Mettler, S. (2005). Soldiers to Citizens: The G. I. Bill and the Making of the Greatest Generation. Oxford: Oxford University Press.

Midlarsky, M. I. (2004). Nihilism in Political Chaos: Himmler, bin Laden, and Altruistic Punishment. Studies in Conflict \& Terrorism, 27 (3), 187-206.

Milgram, S. (1974). Obedience to Authority. New York, NY: Harper \& Row.

Mills, C. W. (1956). The Power Elite. Oxford: Oxford University Press.

Mills, C. W. (1959). The Sociological Imagination. Oxford: Oxford University Press.

Minc, A. (1993). Le nouveau Moyen Age. Paris: Gallimard.

Mishal, S. (2003). The Pragmatic Dimension of the Palestinian Hamas: A Network Perspective. Armed Forces \& Society, 29 (4), 569-589.

Mishal, S., \& Rosenthal, M. (2005). Al Qaeda as a Dune Organization: Toward a Typology of Islamic Terrorist Organizations. Studies in Conflict \& Terrorism, 28 (4), 275-293. 
Mishal, S., \& Sela, A. (2006). The Palestinian Hamas: Vision, Violence, and Coexistence. New York, NY: Columbia University Press.

Modelski, G. (1987). Long Cycles in World Politics. London: Macmillan.

Moeller, S. D. (1989). Shooting War: Photography and the American Experience of Combat. New York, NY: Basic Books.

Moggi, M. (1992). Straniero due volte: il barbaro e il mondo greco. In M. Bettini (Ed.), Lo straniero. Ovvero l'identità culturale a confronto (pp. 51-76). Rome-Bari: Laterza.

Mol, M. J. (2007). Outsourcing: Design, Process, and Performance. Cambridge: Cambridge University Press.

Monje, S. C. (2008). The Central Intelligence Agency: A Documentary History. Westport, CT: Greenwood Press.

Moorcraft, P. L., \& Taylor, P. M. (2008). Shooting the Messenger: The Political Impact of War Reporting. Washington DC: Potomac Books.

Morgan, M. J. (2005). An Evolving View of Warfare: War and Peace and the American Military Profession. Small Wars and Insurgencies, 16 (2), 147-169.

Morgenthau, H. J., \& Thompson, K. W. (1985). Politics Among Nations. The Struggle for Power and Peace. New York, NY: Alfred A. Knopf.

Morrow, J. D. (2007). When Do States Follow the Laws of War? American Political Science Review, 101 (3), 559-572.

Morrow, J. D., \& Jo, H. (2006). Compliance with the Laws of War: Data Set and Coding Rules. Conflict Management and Peace Science, 23 (1), 91-113.

Moskos, C. C. (1977). From Institution to Occupation: Trends in Military Organizations. Armed Forces \& Society, 4 (1), 41-50.

Moskos, C. C. (1986). Institutional/Occupational Trends in Armed Forces: An Update. Armed Forces \& Society, 12 (3), 377-382.

Moskos, C. C. (1988). Soldiers and Sociology. Alexandria: United States Army Research Institute for the Behavioral and Social Sciences.

Moskos, C. C., Williams, J. A., \& Segal, D. R. (Eds.) (2000). The Postmodern Military: Armed Forces after the Cold War. Oxford: Oxford University Press.

Mosse, G. L. (1974). The Nationalisation of the Masses. Political Symbolism and Mass Movements in Germany from the Napoleonic Wars Through the Third Reich. New York, NY: Howard Ferting.

Mosse, G. L. (1990). Fallen Soldiers: Reshaping the Memory of the World Wars. Oxford: Oxford University Press.

Mosse, G. L. (1996). The Image of Man. Oxford: Oxford University Press.

Mottier, N. (2009). Drug Gangs and Politics in Ciudad Juárez: 1928-1936. Mexican Studies/Estudios Mexicanos, 25 (1), 19-46.

Mueller, J. (1989). Retreat from Doomsday: The Obsolescence of Major War. New York, NY: Basic Books.

Mueller, J. (2004). The Remnants of War. Ithaca, NY: Cornell University Press.

Mulaj, K. (Ed.) (2010). Violent Non-State Actors in World Politics. New York, NY: Columbia University Press.

Munton, D., \& Welch, D. A. (2007). The Cuban Missile Crisis: A Concise History, Oxford: Oxford University Press.

Murray, W., Scales, R. H. Jr. (2003). The Iraq War. Cambridge, MA: The Belknap Press of Harvard University Press.

Nacos, B. L., Bloch-Elkon, Y., \& Shapiro, R. Y. (2008). Prevention of Terrorism in Post-9/11 America: News Coverage, Public Perceptions, and the Politics of Homeland Security. Terrorism and Political Violence, 20 (1), 1-25.

Nadelson, T. (2005). Trained to Kill: Soldiers at War. Baltimore, MD: The Johns Hopkins University Press. 
Nagtzaam, G., \& Lentini, P. (2008). Vigilantes of the High Seas? The Sea Shepherds and Political Violence. Terrorism and Political Violence 20 (1), 110-133.

Nassar, J. R. (2005). Globalization and Terrorism: The Migration of Dreams and Nightmares. Lanham, MD: Rowman \& Littlefield.

Naylor, R. T. (2001). Economic Warfare: Sanctions, Embargo Busting, and Their Human Cost. Boston, MA: Northeastern University Press.

Naylor, R. T. (2002). Wages of Crime: Black Markets, Illegal Finance, and the Underworld Economy. Ithaca, NY: Cornell University Press.

Naylor, R. T. (2009). Violence and Illegal Economic Activity: A Deconstruction. Crime, Law \& Social Change, 52 (3), 231-242.

Neal, A. C. (Ed.) (1942). Introduction to War Economics. Chicago, IL: Richard I. Irwin Inc.

Neiberg, M. S. (2000). Making Citizen-Soldiers: Rotc and the Ideology of American Military Service. Cambridge, MA: Harvard University Press.

Nelson, D. (2008). The War Behind Me: Vietnam Veterans Confront the Truth about U.S. War Crimes. New York, NY: Basic Books.

Ness, C. D. (Ed.) (2008). Female Terrorism and Militancy: Agency, Utility, and Organization. New York, NY: Routledge.

Nesser, P. (2008). How Did Europe's Global Jihadis Obtain Training for the Militant Causes? Terrorism and Political Violence, 20 (2), 234-256.

Neumann, I. B., \& Sending, O. J. (2007). The ‘International’ as Governmentality. Millennium, 3, 677-701.

Neumann, P. R. (2009). Old and New Terrorism: Late Modernity, Globalization and the Transformation of Political Violence. Malden: Polity Press.

Neumann, S. (1965). Permanent Revolution. Totalitarianism in the Age of International Civil War. New York, NY: Praeger.

Nevins, J. (2008). Dying to Live: A Story of U.S. Immigration in an Age of Global Apartheid. San Francisco: Open Media/City Lights Book.

Newman, O. (1996). Creating Defensible Space. Washington DC: U.S. Department of Housing and Urban Development, Office of Policy Development and Research.

Noor, F. A., Sikand, Y., \& Bruinessen, M. van (Eds.) (2008). The Madrasa in Asia: Political Activism and Transnational Linkages. Amsterdam: Amsterdam University Press.

Nordstrom, C. (2004). Shadows of War: Violence, Power, and International Profiteering in the Twenty-First Century. Berkeley, CA: University of California Press.

Norris, P., Kern, M., \& Just, M. R. (2003). Framing Terrorism: The News Media, the Government, and the Public. New York, NY: Routledge.

Nuttal, M. (2000). Choosing Kin: Sharing and Subsistence in a Greenlander Hunting Community. In P. P. Schweitzer (Ed.), Dividends of Kinship: Meaning and Uses of Social Relatedness (pp. 33-60). London: Routledge.

OECD (Organization for Economic Co-operation and Development) (2004). The Security Economy.

Ohnuki-Tierney, E. (2002). Kamikaze, Cherry Blossoms, and Nationalism: The Militarization of Aesthetics in Japanese History. Chicago, IL: The University of Chicago Press.

Ohnuki-Tierney, E. (2006). Kamikaze Diaries: Reflections of Japanese Student Soldiers. Chicago, IL: The University of Chicago Press.

Ojeda, A. E. (Ed.) (2008). The Trauma of Psychological Torture. Westport, CT: Praeger.

Oleinik, A. N. (2003). Organized Crime, Prison and Post-Soviet Societies. Aldershot: Ashgate.

Oliver, A. M., \& Steinberg, P. F. (2005). The Road to Martyrs' Square: A Journey into the World of the Suicide Bomber. Oxford: Oxford University Press.

Oliver, K. (2006). The My Lai Massacre in American History and Memory. Manchester: Manchester University Press. 
Olson, M. (2000). Power and Prosperity: Outgrowing Communist and Capitalist Dictatorships. New York, NY: Basic Books.

Onuf, N. (1989). World of Our Making. Columbia, SC: University of South Carolina Press.

Oppenheimer, L. (2006). The Development of Enemy Images: A Theoretical Contribution. Peace and Conflict: Journal of Peace Psychology, 12 (3), 269-292.

Ouchi, W. G. (1980). Markets, Bureaucracies, and Clans. Administrative Science Quarterly, 25 (1), 129-141.

Ousby, I. (2002). The Road to Verdun: France, Nationalism and the First World War. London: Jonathan Cape.

Paddock, T. R. E. (Ed.) (2004). A Call to Arms: Propaganda, Public Opinion, and Newspapers in the Great War. Westport, CT: Praeger.

Pagès, G. (1970). The Thirty Years War, 1618-1648. New York, NY: Harper.

Paglen, T., \& Thompson, A. C. (2006). Torture Taxi: On the Trail of the Cia's Rendition Flights. New York, NY: Melville House.

Paletz, D. L., \& Schmid, A. P. (Eds.) (1992). Terrorism and the Media. Newbury Park: Sage.

Palmer Harik, J. (2005). Hezbollah: The Changing Face of Terrorism. New York, NY: I. B. Tauris.

Pape, R. (2005). Dying to Win: The Strategic Logic of Suicide Terrorism. New York, NY: Random House.

Paquet, G. (1993). Capital Cities as Symbolic Resources. In J. Taylor, J. G. Lengellé \& C. Andrew (Eds.), Capital Cities: International Perspectives (pp. 271-285). Ottawa: Carleton University Press.

Paret, Pe., Lewis, B. I., \& Paret, Pa. (1992). Persuasive Images: Posters of War and Revolution from the Hoover Institution Archives. Princeton, NJ: Princeton University Press.

Parker, G. (1984). The Thirty Years' War. New York, NY: Routledge \& Kegan Paul.

Parker, G. (1988). The Military Revolution: Military Innovation and the Rise of the West, 1500-1800. Cambridge: Cambridge University Press.

Parker, T. (2007). Fighting an Antaean Enemy: How Democratic States Unintentionally Sustain the Terrorist Movements They Oppose. Terrorism and Political Violence, 19 (2), 155-179.

Parsi, V. E. (2006). The Inevitable Alliance: Europe and the United States Beyond Iraq. New York, NY: Palgrave Macmillan.

Parta, R. E. (2007). Discovering the Hidden Listener: An Assessment of Radio Liberty and Western Broadcasting to the USSR during the Cold War. Stanford, CA: Hoover Institution Press.

Paulsen, D. J. (2013). Crime and Planning: Building Socially Sustainable Communities. Boca Raton, FL: Taylor \& Francis.

Pavone, C. (1991). Una guerra civile. Saggio storico sulla moralità della resistenza. Turin: Bollati Boringhieri.

Paxton, M. (2008). Censorship. Westport, CT: Greenwood Press.

Pearlstein, R. M. (2004). Fatal Future? Transnational Terrorism and the New Global Disorder. Austin: University of Texas Press.

Pedahzur, A., Perliger, A., \& Weinberg, L. (2003). Altruism and Fatalism: The Characteristics of Palestinian Suicide Terrorist. Deviant Behavior: An Interdisciplinary Journal, 24 (4), 405-423.

Pelton, R. Y. (2006). Licensed to Kill: Hired Guns in the War on Terror. New York, NY: Crown.

Peluso, N. L., \& Watts, M. (Eds.) (2001). Violent Environments. Ithaca, NY: Cornell University Press.

Pérez Sáinz, J. P. (1999). From the Finca to the Maquila: Labor and Capitalist Development in Central America. Boulder, CO: Westview Press.

Perlmutter, A. (1977). The Military and Politics in Modern Times: On Professionals, Praetorians, and Revolutionary Soldiers. New Haven, CT: Yale University Press.

Perlmutter, A., \& Plave Bennett, V. (1980). The Political Influence of the Military: A Comparative Reader. New Haven, CT: Yale University Press.

Perlo-Freeman, S., \& Sköns, E. (2008). The Private Military Services Industry. Sipri Insights on Peace and Security, 1. 
Peters, R. A., \& Li, X. (2004). Voices from the Korean War: Personal Stories of American, Korean, and Chinese Soldiers. Lexington: University Press of Kentucky.

Phillips, S. A. (1999). Wallbanging': Graffiti and Gangs in L. A. Chicago, IL: University of Chicago Press.

Pickhardt, M., \& Shinnick, E. (Eds.) (2008). The Shadow Economy, Corruption and Governance. Northampton, MA: Edward Elgar.

Pion-Berlin, D. (Ed.) (2001). Civil-Military Relations in Latin America: New Analytical Perspectives. Chapel Hill, NC: The University of North Carolina Press.

Pirjevec, J. (2001). Le guerre jugoslave. 1991-1999. Turin: Einaudi.

Pitelis, C., Sugden, R., \& Wilson, J. R. (Eds.) (2006). Clusters and Globalisation: The Development of Urban and Regional Economies. Northampton, MA: Edward Elgar.

Polisensky, J. V. (1971). The Thirty Years' War. London: Batsford.

Popitz, H. (1986). Phänomene der Macht. Autorität - Herrschaft - Gewalt - Technik. Tübingen: J. C. B. Mohr (Paul Siebeck).

Porter, M. E. (1990). The Competitive Advantage of Nations. New York, NY: The Free Press.

Porter, M. E. (2003). The Economic Performance of Regions. Regional Studies, 37 (6-7), 549-578.

Portinaro, P. P. (1992). Materiali per una storicizzazione della coppia amico-nemico. In G. Miglio (Ed.), Amicus (inimicus) hostis. Le radici concettuali della conflittualità privata e della conflittualità politica (pp. 221-74). Milan: Giuffrè.

Portinaro, P. P. (1999). Il realismo politico. Rome-Bari: Laterza.

Portinaro, P. P. (Ed.) (2002). I concetti del male. Turin: Einaudi.

Post, J. M. (2007). The Mind of the Terrorist: The Psychology of Terrorism from the Ira to Al Qaeda. New York, NY: Palgrave.

Post, J., Sprinzak, E., \& Denny, L. M. (2003). The Terrorists in Their Own Words: Interviews with 35 Incarcerated Middle Eastern Terrorists. Terrorism and Political Violence, 15 (1), 171-184.

Pratten, D., \& Sen, A. (Eds.) (2008). Global Vigilantes. New York, NY: Columbia University Press.

Prior, R., \& Wilson, T. (2005). The Somme. New Haven, CT: Yale University Press.

Pugh, M., \& Cooper, N. (with J. Goodhand). (2004). War Economies in a Regional Context: Challenges of Transformation. Boulder, CO: Lynne Rienner.

Pullan, W. (2007). Contested Mobilities and the Spatial Topography of Jerusalem. In L. Purbrick, J. Aulich \& G. Dawson (Eds.), Contested Spaces: Sites, Representations and Histories of Conflict, (pp. 49-73). New York, NY: Palgrave Macmillan.

Purbrick, L., Aulich, J., \& Dawson, G. (Eds.) (2007). Contested Spaces: Sites, Representations and Histories of Conflict. New York, NY: Palgrave Macmillan.

Puyana de Palacios, A. (2007). La Maquila en México: Los Desafíos de la Globalización. México D.F.: Flacso-México.

Raffestin, C. (2012). Space, Territory, and Territoriality. Environment and Planning D: Society and Space, 30, 121-141.

Ramsey, D. K. (1987). The Corporate Warriors. Boston, MA: Houghton Mifflin.

Raphaeli, N. (2003). Financing of Terrorism: Sources, Methods, and Channels. Terrorism and Political Violence, 15 (4), 59-82.

Rapoport, D. C. (2008). Before the Bombs There Were the Mobs: American Experience with Terror. Terrorism and Political Violence, 20 (2), 167-194.

Rapoport, D. C. (Ed.) (2001). Inside Terrorist Organizations. Portland, OR: Frank Cass.

Rastello, L. (1998). La guerra in casa. Turin: Einaudi.

Rattray, G. J. (2001). Strategic Warfare in Cyberspace. Cambridge, MA: Mit Press.

Ravenhill, J. (Ed.) (2014). Global Political Economy. Oxford: Oxford University Press.

Rediker, M. (1987). Between the Devil and the Deep Blue Sea: Merchant Seamen, Pirates, and the Anglo-American Maritime World, 1700-1750. Cambridge: Cambridge University Press. 
Reinares, F. (2004). Who Are the Terrorists? Analysing Changes in Sociological Profile Among Members of Eta. Studies in Conflict \& Terrorism, 27 (6), 465-488.

Remmer, K. (1989). Military Rule in Latin America. Boston, MA: Unwin Hyman.

Reno, W. (1998). Warlord Politics and African States. Boulder, CO: Lynne Rienner.

Reno, W. (2009a). Explaining Patterns of Violence in Collapsed States. Contemporary Security Policy, $30(2), 356-374$

Reno, W. (2009b). Illicit Markets, Violence, Warlords, and Governance: West African Cases. Crime, Law \& Social Change, 52 (3), 313-322.

Reno, W. (2011). Warfare in Independent Africa. Cambridge: Cambridge University Press.

Restrepo, J. A., \& Spagat, M. (2005). Colombia's Tipping Point? Survival, 47 (2), 131-152.

Reuter, C. (2004). My Life Is a Weapon: A Modern History of Suicide Bombings. Princeton, NJ: Princeton University Press.

Rich, P. B. (Ed.) (1999). Warlords in International Relations. London: Macmillan.

Richani, N. (2002). Systems of Violence: The Political Economy of War and Peace in Colombia. Albany: State University of New York Press.

Rid, T., \& Hecker M. (2009). War 2.0. Irregular Warfare in the Information Age. Westport, CT: Praeger Security International.

Rieber, R. W., \& Kelly, R. J. (1991). Substance and Shadow: Images of the Enemy. In R. W. Rieber (Ed.), The Psychology of War and Peace: The Image of the Enemy (pp. 3-39). New York, NY: Plenum Press.

Riggs, F. W. (2004). Global Studies Manifesto. Globalizations, 1 (2), 344-350.

Ritchie, R. C. (1986). Captain Kidd and the War Against the Pirates. Cambridge, MA: Harvard University Press.

Rittberger, V. (Ed.) (1993). Regime Theory and International Relations. Oxford: Oxford University Press.

Roberts, A. (2005). The 'War on Terror' in Historical Perspective. Survival, 47 (2), 101-130.

Robin, R. T. (2001). The Making of the Cold War Enemy. Culture and Politics in the Military-Intellectual Complex. Princeton, NJ: Princeton University Press.

Robinson, P. (2002). The CNN Effect: The Myth of News, Foreign Policy, and Intervention. New York, NY: Routledge.

Rodgers, D. (2006). The State as a Gang: Conceptualizing the Governmentality of Violence in Contemporary Nicaragua. Critique of Anthropology, 26 (3), 315-330.

Rodgers, D., \& Muggha, R. (2009). Gangs as Non-State Armed Groups: The Central American Case. Contemporary Security Policy, 30 (2), 301-317.

Rogers, P. (2012). Resilience \& the City: Change, (Dis)order and Disaster. Burlington, VT: Ashgate.

Rohatyn, D. (1988). Propaganda Talk. In T. Govier (Ed.), Selected Issues in Logic and Communication (pp. 73-92). Belmont, CA: Wadsworth.

Rokkan, S. (1999). State Formation, Nation-Building, and Mass Politics in Europe. The Theory of Stein Rokkan. Oxford: Oxford University Press.

Roland, A. (2001). The Military-Industrial Complex. Washington DC: American Historical Association.

Rollins, P. C., \& O'Connor, J. E. (Eds.) (2008). Why We Fought: America's Wars in Film and History. Lexington: The University of Kentucky Press.

Roncarolo, F. (2003). La guerra tra informazione e propaganda. Vecchi e nuovi paradigmi della rappresentazione e del controllo. In A. d'Orsi (Ed.), Guerre globali. Capire i conflitti del XXI secolo (pp. 225-243). Rome: Carocci.

Rosen, D. M. (2005). Armies of the Young: Child Soldiers in War and Terrorism. New Brunswick, NJ: Rutgers University Press.

Rosenau, P. M. (1992). Post-Modernism and the Social Sciences: Insights, Inroads, and Intentions. Princeton, NJ: Princeton University Press. 
Roshwald, A., \& Stites, R. (Eds.) (1999). European Culture in the Great War. The Arts, Entertainment, and Propaganda, 1914-1919. Cambridge: Cambridge University Press.

Ross, J. I. (2003). The Dynamics of Political Crime. Thousand Oaks, CA: Sage.

Rotberg, R. I. (Ed.) (2004). When States Fail: Causes and Consequences. Princeton, NJ: Princeton University Press.

Roth, G. (1987). Politische Herrschaft und persönliche Freiheit, I, Charisma und Patrimonialismus heute. Frankfurt am Main: Suhrkamp Verlag.

Roudometof, V. (Ed.) (2007). Collective Memory and Cultural Politics. Special Issue, Journal of Political and Military Sociology, 35 (1).

Rousseau, J.-J. (1984). A Discourse on Inequality (1754). New York, NY: Penguin Books.

Rousset, D. (1965). L'univers concentrationnaire. Paris: Les Editions de Minuit.

Roxborough, I. (2003). The Ghost of Vietnam: America Confronts the New World Disorder. In D. E. Davis \& A. W. Pereira (Eds.), Irregular Armed Forces and Their Role in Politics and State Formation (pp. 346-384). Cambridge: Cambridge University Press.

Roy, S. (2011). Hamas and Civil Society in Gaza. Engaging the Islamist Social Sector. Princeton, NJ: Princeton University Press.

Ruble, R. S. (2009). Round Up the Usual Suspects: Criminal Investigation in Law \& Order, Cold Case, and Csi. Westport, CT: Praeger.

Ruddick, S. (1989). Maternal Thinking. New York, NY: Ballantine Books.

Ruggiero, V. (1999). Delitti dei deboli e dei potenti. Esercizi di anticriminologia. Turin: Bollati Boringhieri.

Ruggiero, V. (2000). Transnational Crime: Official and Alternative Fears. International Journal of the Sociology of Law, 28 (3), 187-199.

Ruggiero, V. (2003). Terrorism: Cloning the Enemy? International Journal of the Sociology of Law, 31 (1), 23-34.

Ruggiero, V. (2007). Privatizing International Conflict: War as Corporate Crime. Social Justice, 34 (3-4), 132-147.

Ruggiero, V. (2009). Transnational Crime and Global Illicit Economies. In E. Wilson (Ed.), Government of the Shadow. Parapolitics and Criminal Sovereignty (pp. 117-129). London: Pluto Press.

Ruzza, S. (2007). Chi combatterà le guerre del futuro? L'avvento delle private military firms. Biblioteca della libertà, 42 (188), 19-44.

Ruzza, S. (2008). Nisour Square, Baghdad: la privatizzazione del conflitto iracheno e il caso Blackwater. Biblioteca della libertà, 43 (190), 17-28.

Ruzza, S. (2010). Combattere. I dilemmi delle democrazie. Acireale-Rome: Bonanno Editore.

Ruzza, S. (2011). Guerre conto terzi: aziende di sicurezza e privatizzazione della funzione militare. Bologna: il Mulino.

Ruzza, S., Jakobi, A. P., \& Geisler, C. (Eds.) (2015). Non-State Challenges in a Re-Ordered World. The Jackals of Westphalia. New York, NY: Routledge.

Sageman, M. (2004). Understanding Terror Networks. Philadelphia, PA: University of Pennsylvania Press.

Sageman, M. (2006). The Psychology of Al Qaeda Terrorists: The Evolution of the Global Selafi Jihad. In C. H. Kennedy \& E. A. Zillmer (Eds.), Military Psychology: Clinical and Operational Applications (pp. 281-294). New York, NY: The Guilford Press.

Sahlins, M. (2013). What Kinship Is - and Is Not. Chicago, IL: University of Chicago Press.

Sànchez-Cuenca, I. (2007). The Dynamics of Nationalist Terrorism: Eta and the Ira. Terrorism and Political Violence, 19 (3), 289-306.

Sarkesian, S. C., \& Connor, R. E. Jr. (2006). The U.S. Military Profession into the Twenty-First Century: War, Peace and Politics. New York, NY: Routledge.

Sassen, S. (1994). Cities in a World Economy. Thousands Oaks, CA: Pine Forge Press. 
Sassen, S. (2006). Territory, Authority, Rights. From Medieval to Global Assemblages. Princeton, NJ: Princeton University Press.

Sassen, S. (2007). A Sociology of Globalization. New York, NY: W. W. Norton \& Company.

Satter, D. (2003). Darkness at Dawn: The Rise of the Russian Criminal State. New Haven, CT: Yale University Press.

Savitch, H. V. (2008). Cities in a Time of Terror: Space, Territory, and Local Resilience. Armonk, NY: M. E. Sharpe.

Scahill, J. (2010). U.S. Mercenaries Set Sights in Haiti. The Nation, January 19.

Scarry, E. (1985). The Body in Pain: The Making and Unmaking of the World. Oxford: Oxford University Press.

Schaffert, R. W. (1992). Media Coverage and Political Terrorists: A Quantitative Analysis. Westport, CT: Praeger.

Schelling, T. C. (1966). Arms and Influence. New Haven, CT: Yale University Press.

Schlesinger, A. M. (2005). War and the American Presidency. New York, NY: W. W. Norton.

Schlichte, K. (2009). With the State Against the State? The Formation of Armed Groups. Contemporary Security Policy, 30 (2), 246-264.

Schmid, A. P. (2004). Framework for Conceptualising Terrorism. Terrorism and Political Violence, 16 (2), 197-221.

Schmid, A. P., \& Graaf, J. de (1982). Violence as Communication: Insurgent Terrorism and the Western News Media. Beverly Hills: Sage.

Schmid, A. P., Jongman, A. J., et al. (2005). Political Terrorism: A New Guide to Actors, Authors, Concepts, Data Bases, Theories, and Literature. New Brunswick, NJ: Transaction.

Schmitt, C. (1972). Le categorie del politico. Bologna: il Mulino.

Schmitt, C. (2007). Theory of the Partisan: Intermediate Commentary on the Concept of the Political. New York, NY: Telos Press Pub.

Schneider, F. (2005). Shadow Economies Around the World: What Do We Really Know? European Journal of Political Economy, 21 (3), 598-642.

Schneider, F., \& Enste, D. (2007). The Shadow Economy: An International Survey. Cambridge: Cambridge University Press.

Schulte-Bockholt, A. (2006). The Politics of Organized Crime and the Organized Crime of Politics: A Study in Criminal Power. Lanham, MD: Lexington Books.

Schumacher, G. (2006). A Bloody Business: America's War Zone Contractors and the Occupation of Iraq. St. Paul: Zenith Press.

Schwartz, Mi. (2007). Neo-Liberalism on Crack. Cities Under Siege in Iraq. City, 11 (1), 21-69.

Schwartz, Mo. (2009). Department of Defense Contractors in Iraq and Afghanistan: Background and Analysis. Congressional Research Service, August 13.

Schwartz, M., \& Church, J. (2013). Department of Defense's Use of Contractors to Support Military Operations: Background, Analysis, and Issues for Congress. Congressional Research Service, May 17.

Schwartz, M., \& Swain, J. (2011). Department of Defense Contractors in Afghanistan and Iraq: Background and Analysis. Congressional Research Service, May 13.

Schweitzer, R. (2003). The Cross and the Trenches: Religions Faith and Doubt Among British and American Great War Soldiers. Westport, CT: Praeger.

Schwoch, J. (2009). Global TV: New Media and the Cold War, 1946-1969. Chicago, IL: University of Illinois Press.

Searle, J. R. (1995). The Construction of Social Reality. New York, NY: The Free Press.

Searle, J. R. (2010). Making the Social World. The Structure of Human Civilization. Oxford: Oxford University Press.

Seaton, J. (2005). Carnage and the Media: The Making and Breaking of News about Violence. London: Allen Lane. 
Sebald, W. G. (1999). On the Natural History of Destruction. New York, NY: Random House.

Secunda, E., \& Moran, T. P. (2007). Selling War to America: From the Spanish American War to the Global War on Terror. Westport, CT: Praeger Security International.

Seib, P. (2004). Beyond the Front Lines: How the News Media Cover a World Shaped by War. New York, NY: Palgrave Macmillan.

Seib, P. (2007). New Media and the New Middle East. New York, NY: Palgrave Macmillan.

Seib, P. (2008). The Al Jazeera Effect: How the New Global Media Are Reshaping World Politics. Washington DC: Potomac Books.

Sen, A., \& Pratten, D. (2008). Global Vigilantes: Perspectives on Justice and Violence. In D. Pratten \& A. Sen (Eds.), Global Vigilantes (pp. 1-24). New York, NY: Columbia University Press.

Shambaugh, J., Oglethorpe, J., \& Ham, R. (with contributions from S. Tognetti) (2001). Trampled Grass: Mitigating the Impacts of Armed Conflict on the Environment. Washington DC: Biodiversity Support Program.

Shapiro, J. F. (2002). Atomic Bomb Cinema: The Apocalyptic Imagination on Film. New York, NY: Routledge.

Shay, S. (2005). The Axis of Evil: Iran, Hizballah, and the Palestinian Terror. New Brunswick, NJ: Transaction.

Shelley, L., Scott, E. R., \& Letta, A. (Eds.) (2007). Organized Crime and Corruption in Georgia. New York, NY: Routledge.

Shibutani, T. (1966). Improvised News: A Sociological Study of Rumor. Indianapolis: The BobbsMerrill Company.

Shiu-Hing Lo, S. (2009). The Politics of Cross-Border Crime in Greater China. Armonk, NY: M. E. Sharpe.

Siegel, D., Bunt, H. van de, \& Zaitch, D. (2003). Global Organized Crime: Trends and Developments. Dordrecht: Kluwer Academic.

Siegel, D., \& Nelen, H. (Eds.) (2008). Organized Crime: Culture, Markets and Policies. New York, NY: Springer.

Silke, A. (2000). Drink, Drugs, and Rock'n'Roll: Financing Loyalist Terrorism in Northern Ireland-Part Two. Studies in Conflict \& Terrorism, 23 (2), 107-127.

Silke, A. (2003a). Becoming a Terrorist. In A. Silke (Ed.), Terrorists, Victims and Society: Psychological Perspectives on Terrorism and its Consequences (pp. 29-53). Southern Gate: Wiley.

Silke, A. (Ed.) (2003b). Terrorists, Victims and Society: Psychological Perspectives on Terrorism and its Consequences. Southern Gate: Wiley.

Simmel, G. (1906). The Sociology of Secrecy and of Secret Societies. The American Journal of Sociology, 11 (4), 441-498.

Simon, J. (2007). Governing Through Crime: How the War on Crime Transformed American Democracy and Created a Culture of Fear. Oxford: Oxford University Press.

Simon, J. D. (2008). The Forgotten Terrorists: Lessons from the History of Terrorism. Terrorism and Political Violence, 20 (2), 195-214.

Simons, G. (2009). Mass Media and Modern Warfare: Reporting on the Russian War on Terrorism. Burlington, VT: Ashgate.

Simpson, C. (Ed.) (1998). Universities and Empire: Money and Politics in the Social Sciences During the Cold War. New York, NY: The New Press.

Simpson, R., \& Coté, W. E. (2006). Covering Violence: A Guide to Ethical Reporting about Victims and Trauma. New York, NY: Columbia University Press.

Singer, P. W. (2003). Corporate Warriors: The Rise of the Privatized Military Industry. Ithaca, NY: Cornell University Press.

Singer, P. W. (2005a). Children at War. New York, NY: Pantheon Books.

Singer, P. W. (2005b). Outsourcing War. Foreign Affairs, 84 (2), 119-132.

Singer, P. W. (2008). Outsourcing the Fight. Forbes, June 5. 
Singh Deepali, G. (2007). Drugs Production and Trafficking in Afghanistan. New Delhi: Pentagon Press.

Siniawer Maruko, E. (2008). Ruffians, Yakuza, Nationalists: The Violent Politics of Modern Japan, 1860-1960. Ithaca, NY: Cornell University Press.

Sipri (Stockholm International Peace Research Institute) (2009). Sipri Yearbook: Armaments, Disarmament and International Security. Oxford: Oxford University Press.

Sironi, F. (1999). Bourreaux et victimes. Psychologie de la torture. Paris: Editions Odile Jacob.

Sironi, F. (2007). Psychopathologie des violences collectives. Essai de psychologie géopolitique clinique. Paris: Editions Odile Jacob.

Sledge, M. (2005). Soldier Dead: How We Recover, Identify, Bury, and Honor Our Military Fallen. New York, NY: Columbia University Press.

Sloan, E. (2008). Military Transformation and Modern Warfare: A Reference Handbook. Westport, CT: Praeger Security International.

Sloterdijk, P. (1998, 1999, and 2004). Sphären. 3 voll. Frankfurt am Main: Suhrkamp.

Sluka, J. A. (Ed.) (2000). Death Squad: The Anthropology of State Terror. Philadelphia, PA: University of Pennsylvania Press.

Small Arms Survey (2009). Shadows of War. Oxford: Oxford University Press.

Smith, J. A. (1991). The Idea Brokers. Think Tanks and the Rise of the New Policy Elite. New York, NY: The Free Press.

Smith, P. J. (2008). The Terrorism Ahead: Confronting Transnational Violence in the Twenty-First Century. Armonk, NY: M. E. Sharpe.

Smith, S. (1995). The Self-Images of a Discipline: A Genealogy of International Relations Theory. In K. Booth \& S. Smith (Eds.), International Relations Theory Today (pp. 1-37). Cambridge: Polity Press.

Smith, S. (1996). Positivism and Beyond. In S. Smith, K. Booth \& M. Zalewski (Eds.), International Theory: Positivism and Beyond (pp. 11-44). Cambridge: Cambridge University Press.

Smith, S., Booth, K., \& Zalewski, M. (1996) (Eds.). International Theory: Positivism and Beyond. Cambridge: Cambridge University Press.

Smith, T. B. (2008). The Golden Age of Battlefield Preservation: The Decade of the 1890 s and the Establishment of America's First Five Military Parks. Knoxville: The University of Tennessee Press.

Snape, M. (2005). God and the British Soldier: Religion and the British Army in the First and Second World Wars. New York, NY: Routledge.

Snow, R. L. (1999). The Militia Threat: Terrorists Among Us. New York, NY: Plenum Trade.

Snyder, C. A. (Ed.) (2008), Contemporary Security and Strategy. New York, NY: Palgrave.

Sofsky, W. (1996). Traktat über die Gewalt. Frankfurt am Main: Fischer Verlag.

Sofsky, W. (1997). The Order of Terror: The Concentration Camp. Princeton, NJ: Princeton University Press.

Sontag, S. (1977). On Photography. New York, NY: Farrar, Straus and Giroux.

Sontag, S. (2003). Regarding the Pain of Others. New York, NY: Farrar, Straus and Giroux.

Sorenson, D. S. (2007). Military Base Closure: A Reference Handbook. Westport, CT: Praeger Security International.

Spearin, C. (2004). The Emperor's Leased Clothes: Military Contractors and Their Implications in Combating International Terrorism. International Politics, 41 (2), 243-264.

Spicer, T. (1999). An Unorthodox Soldier: Peace and War and the Sandline Affair. Edinburgh: Mainstream Publishing Company.

Sproule, J. M. (1997). Propaganda and Democracy: The American Experience of Media and Mass Persuasion. Cambridge: Cambridge University Press.

Spruyt, H. (1994). The Sovereign State and Its Competitors: An Analysis of System Change. Princeton, NJ: Princeton University Press. 
Stajano, C. (1991). Un eroe borghese. Turin: Einaudi.

Stanger, A. (2009). One Nation Under Contract: The Outsourcing of American Power and the Future of Foreign Policy. New Haven, CT: Yale University Press.

Stanley, L. (2006). Mourning Becomes...:Post/Memory, Commemoration and the Concentration Camps of the South African War. Manchester: Manchester University Press.

Starr, P. (2004). The Creation of the Media: Political Origins of Modern Communications. New York, NY: Basic Books.

Staub, E. (1989). The Roots of Evil: The Origins of Genocide and Other Group Violence. Cambridge: Cambridge University Press.

Staudt, K. (2008). Violence and Activism at the Border: Gender, Fear, and Everyday Life in Ciudad Juárez. Austin: University of Texas Press.

Steensgaard, N. (1975). The Asian Trade Revolution of the 17th Century: The East India Companies and the Decline of the Caravan Trade. Chicago, IL: The University of Chicago Press.

Steensgaard, N. (1981). Violence and the Rise of Capitalism: Frederic C. Lane's Theory of Protection and Tribute. Review, 5 (2), 247-273.

Stenersen, A. (2008). The Internet: A Virtual Training Camp? Terrorism and Political Violence, 20 (2), 215-233.

Stern, S. M. (2005). The Week the World Stood Still: Inside the Secret Cuban Missile Crisis. Stanford, CA: Stanford University Press.

Stewart, F. H. (1994). Honor. Chicago, IL: The University of Chicago Press.

Stouffer, S. A., et al. (1949). The American Soldier. 5 vols. Princeton, NJ: Princeton University Press.

Stout, C. E. (Ed.) (2002). The Psychology of Terrorism. 4 vols. Westport, CT: Praeger.

Strachan, H., \& Herberg-Rothe, A. (2007). Clausewitz in the Twenty-First Century. Oxford: Oxford University Press.

Strachan, H., \& Scheipers, S. (2011). The Changing Character of War. Oxford: Oxford University Press.

Strange, S. (1986). Casino Capitalism. Oxford: Blackwell.

Strange, S. (1996). The Retreat of the State: The Diffusion of Power in the World Economy. Cambridge: Cambridge University Press.

Strasser, S. (Ed.) (2004). The Abu Ghraib Investigations: The Official Reports of the Independent Panel and the Pentagon on the Shocking Prisoner Abuse in Iraq. New York, NY: Public Affairs.

Straus, S. (2007). What Is the Relationship Between Hate Radio and Violence? Rethinking Rwanda's 'Radio Machete'. Politics \& Society, 35 (4), 609-637.

Strazzari, F. (2008). Notte balcanica. Guerre, crimine, stati falliti alle soglie d’Europa. Bologna: il Mulino.

Strenski, I. (2003). Sacrifice, Gift and the Social Logic of Muslim 'Human Bombers'. Terrorism and Political Violence, 15 (3), 1-34.

Stulberg, A. N., \& Salamone, M. D. (with A. G. Long) (2007). Managing Defense Transformation: Agency, Culture and Service Change. Burlington, VT: Ashgate.

Sullivan, J. P., \& Bunker, R. J. (2002). Drug Cartels, Street Gangs, and Warlords. Small Wars and Insurgencies, 13 (2), 40-53.

Sweeney, M. S. (2006). The Military and the Press: An Uneasy Truce. Evanston, IL: Northwestern University Press.

Sylvester, C. (2001). Feminist International Relations: An Unfinished Journey. Cambridge: Cambridge University Press.

Szymkowiak, K. (2002). Sokaiya: Extortion, Protection, and the Japanese Corporation. Armonk, NY: M. E. Sharpe.

Tabarrok, A. (2007). The Rise, Fall, and Rise Again of Privateers. The Independent Review, 11 (4), 565-577.

Tanaka, Y., \& Young, M. B. (Eds.) (2009). Bombing Civilians. A Twentieth-Century History. New York, NY: The New Press. 
Tanielian, T., \& Jaycox, L. H. (Eds.) (2008). Invisible Wounds of War: Psychological and Cognitive Injuries, Their Consequences, and Services to Assist Recovery. Santa Monica, CA: Rand.

Tarrow, S. (1994). Power in Movement: Social Movements, Collective Action and Politics. Cambridge: Cambridge University Press.

Tarrow, S. (2015). War, States, \& Contention. A Comparative Historical Study. Ithaca, NY: Cornell University Press.

Taylor, T. (1992). The Anatomy of the Nuremberg Trials. New York, NY: Alfred A. Knopf.

Tefft, S. K. (Ed.) (1980). Secrecy: A Cross-Cultural Perspective. New York, NY: Human Science Press.

The 9/11 Commission Report (2004). New York, NY: W. W. Norton \& Company.

Thomas, G. M. (2009). Treating the Trauma of the Great War: Soldiers, Civilians, and Psychiatry in France, 1914-1940. Baton Rouge: Lousiana State University Press.

Thomas, W. H. Jr. (2008). Unsafe for Democracy: Wold War I and the U.S. Justice Department's Covert Campaign to Suppress Dissent. Madison: The University of Wisconsin Press.

Thompson, W. R. (1988). On Global War: Historical-Structural Approaches to World Politics. Columbia, SC: University of South Carolina.

Thomson, J. E. (1994). Mercenaries, Pirates, and Sovereigns: State-Building and Extraterritorial Violence in Early Modern Europe. Princeton, NJ: Princeton University Press.

Thoumi, F. E. (2003). Illegal Drugs, Economy, and Society in the Andes. Baltimore, MD: The Johns Hopkins University Press.

Thussu, D. K., \& Freedman, D. (Eds.) (2003). War and the Media: Reporting Conflict 24/7. Thousand Oaks Sage.

Tilly, C. (1975a). Reflections on the History of the European State Making. In C. Tilly (Ed.), The Formation of National States in Western Europe (pp. 3-83). Princeton, NJ: Princeton University Press.

Tilly, C. (Ed.) (1975b). The Formation of National States in Western Europe. Princeton, NJ: Princeton University Press.

Tilly, C. (1985). War Making and State Making as Organized Crime. In P. B. Evans, D. Rueschemeyer \& T. Skocpol (Eds.), Bringing the State Back In (pp. 169-191). Cambridge: Cambridge University Press.

Tilly, C. (1990). Coercion, Capital, and European States: AD 990-1992. Oxford: Blackwell.

Tilly, C. (2003). The Politics of Collective Violence. Cambridge: Cambridge University Press.

Tilly, C. (2008). Contentious Performances. Cambridge: Cambridge University Press.

Tilly, C. (2010). Cities, States, and Trust Networks: Chapter 1 of Cities and States in World History. Theory and Society, 39 (3-4), 265-280.

Torgovnick, M. (2005). The War Complex: World War II in Our Time. Chicago, IL: The University of Chicago Press.

Troy, S. T., Kiser, S. D., \& Casebeer, W. D. (2005). Warlord Rising: Confronting Violent Non-State Actors. Lanham, MD: Lexington Books.

Tucker, R. P., Russell, E. (Eds.) (2004). Natural Enemy, Natural Ally: Toward an Environmental History of Warfare. Corvallis: Oregon State University Press.

Tuman, J. S. (2010). Communicating Terror: The Rhetorical Dimensions of Terrorism. Thousand Oaks, CA: Sage.

Tumber, H., \& Webster, F. (2006). Journalists Under Fire: Information War and Journalistic Practices. Thousand Oaks, CA: Sage.

Ulrich, C. J., \& Kivimäki, T. A. (2002). Uncertain Security: Confronting Transnational Crime in the Baltic Sea Region and Russia. Lanham, MD: Lexington Books.

Unger, B. (2007). The Scale and Impacts of Money Laudering. Northampton, MA: Edward Elgar.

United Nations Department of Economic and Social Affairs (2014). World Urbanization Prospects: The 2014 Revision. New York, NY. 
Unodc (United Nations Office on Drugs and Crime) (2009). Addiction, Crime and Insurgency: The Transnational Threat of Afghan Opium. Wien.

Uziel, D. (2008). The Propaganda Warriors: The Wehrmacht and the Consolidation of the German Home Front. Oxford: Peter Lang.

Vagts, A. (1967). A History of Militarism: Civilian and Military. Glencoe: The Free Press.

Valentine, B. (2000). Gangs and Their Tattoos: Identifying Gangbangers on the Street and in Prison. Boulder, CO: Paladin Press.

Varese, F. (2001). The Russian Mafia: Private Protection in a New Market Economy. Oxford: Oxford University Press.

Vasquez, J. A. (1995). The Post-Positivist Debate: Reconstructing Scientific Enquire and International Relations Theory after Enlightenment's Fall. In K. Booth \& S. Smith (Eds.), International Relations Theory Today (pp. 217-240). Cambridge: Polity Press.

Veer, P. van der, \& Munshi, S. (Eds.) (2004). Media, War, and Terrorism: Responses from the Middle East and Asia. New York, NY: Routledge Curzon.

Verbitsky, H. (1996). The Flight: Confessions of an Argentine Dirty Warrior. New York, NY: New Press.

Verkuil, P. R. (2007). Outsourcing Sovereignty: Why Privatization of Government Functions Threatens Democracy and What We Can Do about It. Cambridge: Cambridge University Press.

Victor, B. (2003). Army of Roses: Inside the World of Palestinian Women Suicide Bombers. New York, NY: Rodale-St. Martin Press.

Victoroff, J. (2005). The Mind of the Terrorist: A Review and Critique of Psychological Approaches. The Journal of Conflict Resolution, 49 (1), 3-42.

Vokes, R. (2007). Charisma, Creativity, and Cosmopolitanism: A Perspective on the Power of the New Radio Broadcasting in Uganda and Rwanda. The Journal of Anthropological Institute, 13 (4), 805-824.

Volkov, V. (2002). Violent Entrepreneurs: The Use of Force in the Making of Russian Capitalism. Ithaca, NY: Cornell University Press.

Volkov, V. (2004). Hostile Enterprise Takeovers: Russia's Economy in 1998-2002. Review of Central and East European Law, 29 (4), 527-548.

Voltaire, (1962). Philosophical Dictionary (1764). New York, NY: Basic Books.

Vovelle, M. (1983). La mort et l'Occident de 1300 à nos jours. Paris: Editions Gallimard.

Wacquant, L. (2000). The New ‘Peculiar Institution’: On the Prison as Surrogate Ghetto. Theoretical Criminology, 4 (3), 377-389.

Wacquant, L. (2008). The Militarization of Urban Marginality: Lessons from the Brazilian Metropolis. International Political Sociology, 2 (1), 56-74.

Walker, I., \& Smith, H. J. (Eds.) (2002). Relative Deprivation: Specification, Development, and Integration. Cambridge: Cambridge University Press.

Wallerstein, I. (1974-1980-1989). The Modern World-System. 3 vols. New York, NY: Academic Press.

Waltz, K. (1954). Man, the State, and War. A Theoretical Analysis. New York, NY: Columbia University Press.

Waltz, K. (1979). Theory of International Politics. Reading, MA: Addison-Wesley.

Walzer, M. (1977). Just and Unjust Wars: A Moral Argument with Historical Illustrations. London: Allen Lane.

Washington Valdez, D. (2006). Harvest of Women: Safari in Mexico. Los Angeles: Peace at the Border.

Wasserstein, B. (2008). Divided Jerusalem: The Struggle for the Holy City. New Haven, CT: Yale University Press.

Watson, A. (2008). Enduring the Great War: Combat, Morale and Collapse in the German and British Armies, 1914-1918. Cambridge: Cambridge University Press.

Webber, C. (2007). Revaluating Relative Deprivation Theory. Theoretical Criminology, 11 (1), 97-120. 
Weber, M. (1978). Economy and Society: An Outline of Interpretive Sociology (1922). Berkeley, CA: University of California Press.

Webster, D. (1996). Aftermath: The Remnants of War. New York, NY: Pantheon Books.

Wedgwood, C. V. (1981). The Thirty Years' War. London: Routledge Chapman.

Weiner, M. S. (2013). The Rule of the Clan. New York, NY: Farrar, Straus \& Giroux.

Weinstein, J. M. (2007). Inside Rebellion: The Politics of Insurgent Violence. Cambridge: Cambridge University Press.

Weiss, L. (1998). The Myth of the Powerless State. Ithaca, NY: Cornell University Press.

Weiss, M., \& Hassan, H. (2015). Isis. Inside the Army of Terror. New York, NY: Regan Arts.

Weizman, E. (2007). Hollow Land: Israel's Architecture of Occupation. London: Verso.

Welch, D. (2000). Germany, Propaganda and Total War, 1914-1918: The Sins of Omission. New Brunswick, NJ: Rutgers University Press.

Wendt, A. (1987). The Agent/Structure Problem in International Relations Theory. International Organization, 41 (3), 335-370.

Wendt, A. (1992). Anarchy Is What States Make of It: The Social Construction of Power Politics. International Organization, 46 (2), 391-425.

Wendt, A. (1999). Social Theory of International Politics. Cambridge: Cambridge University Press.

Whaley Eager, P. (2008). From Freedom Fighters to Terrorists: Women and Political Violence. Burlington, VT: Ashgate.

White, R. (2008). Depleted Uranium, State Crime and the Politics of Knowing. Theoretical Criminology, 12 (1), 31-54.

Wickham-Crowley, T. P. (1992). Guerrillas and Revolution in Latin America: A Comparative Study of Insurgents and Regimes Since 1956. Princeton, NJ: Princeton University Press.

Wieviorka, M. (1988). The Making of Terrorism. Chicago, IL: The University of Chicago Press.

Wieviorka, M. (2003). The New Paradigm of Violence. In J. Friedman (Ed.), Globalization, the State, and Violence (pp. 107-139). Walnut Creek, CA: Altamira Press.

Wieviorka, O. (2008). Normandy, The Landings to the Liberation of Paris. Cambridge, MA: The Belknap Press of Harvard University Press.

Wight, C. (2006). Agents, Structures and International Relations: Politics as Ontology. Cambridge: Cambridge University Press.

Wight, M. (1991). International Theory: The Three Traditions. Leicester: Leicester University Press.

Wilford, H. (2008). The Mighty Wurlitzer. How the Cia Played America. Cambridge, MA: Harvard University Press.

Willbanks, J. H. (2007). The Tet Offensive: A Concise History. New York, NY: Columbia University Press.

Williams, J. A. (2008). The Military and Society Beyond the Postmodern Era. Orbis, 52 (2), 199-216.

Williams, P. (2009). Illicit Markets, Weak States and Violence: Iraq and Mexico. Crime, Law \& Social Change, 52 (3), 323-336.

Wilson, E. (Ed.) (2009). Government of the Shadow: Parapolitics and Criminal Sovereignty. London: Pluto Press.

Winter, J. (1995). Sites of Memory, Sites of Mourning: The Great War in European Cultural History. Cambridge: Cambridge University Press.

Winter, J. (2006). Remembering War: The Great War Between Memory and History in the Twentieth Century. New Haven, CT: Yale University Press.

Wixted, B. (2009). Innovation System Frontiers: Cluster Networks and Global Value. Berlin: Springer. Wolfe, A. (1977). The Limits of Legitimacy: Political Contradictions of Contemporary Capitalism. New York, NY: The Free Press.

Wolfe, D. A., \& Lucas, M. (Eds.) (2005). Global Networks and Local Linkages: The Paradox of Cluster Development in an Open Economy. Ithaca, NY: McGill-Queen's University Press.

Wolfendale, J. (2007). Torture and the Military Profession. New York, NY: Palgrave Macmillan. 
Wolin, S. S. (2010). Democracy Incorporated: Managed Democracy and the Specter of Inverted Totalitarianism. Princeton, NJ: Princeton University Press.

Worcester, K., Bermanzohn, S. A., \& Ungar, M. (Eds.) (2002). Violence and Politics: Globalization's Paradox. New York, NY: Routledge.

World Bank (2013). Building Urban Resilience. Principles, Tools, and Practice. Washington DC.

Wright, Q. (1964). A Study of War. Chicago, IL: The University of Chicago Press.

Wright, T. C. (2007). State Terrorism in Latin America: Chile, Argentina, and International Human Rights. Lanham, MD: Rowman \& Littlefield.

Xia, M. (2008). Organizational Formations of Organized Crime in China: Perspectives from the State, Markets, and Networks. Journal of Contemporary China, 17 (54), 1-23.

Yang, B. (1987). Golden Triangle: Frontier and Wilderness. Hong Kong: Joint Publishing Co.

Youngers, C., \& Rosin, E. (2005). Drugs and Democracy in Latin America: The Impact of U.S. Policy. Boulder, CO: Lynne Rienner.

Yurdusev, A. N. (1993). 'Level of Analysis' and 'Unit of Analysis': A Case for Distinction. Millennium, 22 (1), 77-88.

Zaman, S.-uz (2015). Rise of the Non-State Actors in Middle East: Regional Dimensions. Ipri Journal, 15 (1), 51-65.

Žarkov, D. (2007). The Body of War: Media, Ethnicity, and Gender in the Break-up of Yugoslavia. Durham, NC: Duke University Press.

Zelizer, B. (2004). When War Is Reduced to a Photograph. In S. Allan and B. Zelizer (Eds.), Reporting War: Journalism in Wartime (pp. 115-135). New York, NY: Routledge.

Zertal, I., \& Eldar, A. (2007). Lords of Land: The War Over Israel's Settlements in the Occupied Territories, 1967-2007. New York, NY: Nation Books.

Zimbardo, P. G. (2007). The Lucifer Effect: Understanding How Good People Turn Evil. New York, NY: Random House.

Zimmermann, E. (1983). Political Violence, Crises, and Revolutions: Theories and Research. Boston, MA: G. K. Hall \& Co.

Zoja, L. (2001). The Father: Historical, Psychological, and Cultural Perspectives. Philadelphia, PA: Brunner-Routledge.

Zoja, L. (2009). Contro Ismene. Considerazioni sulla violenza. Turin: Bollati Boringhieri. 


\section{Index}

Abrahams, R. 52

Abu Ghraib 34, 146

Acharya, A. 133

Acton, C. 106

aerial bombings $39,43,45,68,137$

Afflerbach, H. 28

Afghanistan 50, 51, 73, 80, 103, 131

Afghanistan War 39, 55, 56, 68, 102, 108, 127, 130

Africa 40, 69, 71, 72, 75, 77, 92, 124

Agent Orange 43

Agnew, J. 141

Alexander, M. G. 96

Algeria 79

Al Jazeera 102

Allan, S. 104

Allende, S. 76, 81

Allen, M. 99

Allen, M. J. 108

Allison, W. T. 68

Allport, G. W. 94

Almerighi, M. 121

Al Qaeda 50, 53, 92

Altschuler, G. C. 108

American Civil War 49, 101, 106

Amnesty International 42

Anders, G. 43

Anderson, D. L. 68, 76, 77

Andersson, R. 71

Andreas, P. 121

Angola 79

Arab-Israeli wars 38, 103

Arab spring 104

Ardrey, R. 3

Arendt, H. 13, 33, 35, 36, 74, 89, 110

Argentina 36, 81, 94

Arlacchi, P. 109

Armao, F. 31, 33, 52, 65, 90, 96, 142, 143, 144

Armenian genocide 94

Armstrong and Vickers 116

Aron, R. 6, 16

Arriagada, G. 76

Ashplant, T. G. 106

Asia 40, 77, 82, 152

Atkinson, R. 156

atomic bomb 6, 43, 116, 117
Aulich, J. 70, 78

Auschwitz-Birkenau 38

Austria 115

Avant, D. D. 16, 46, 57, 79

Axelrod, A. 87

Azaryahu, M. 106

Azerbaijan 79

Bacevich, A. J. 56

Bagaeen, S. 156

Baker, C. E. 104

Ballentine, K. 119

Bangladesh 71

Barbier, M. K. 67

Barkawi, T. 3

Bartle, R. 58

Base Realignment and Closure Process (BRAC) 69

Baum, D. 39

Baylis, J. 67

Beah, I. 109

Beare, M. E. 127

Beckett, K. 72

Beck, U. 93, 97

behaviourism 7, 14

Bellocchio, M. 32

Beneduce, R. 40

Berger, P. L. 13

Bernstein, S. 13, 15

Bertelli, S. 29

Bevan, R. 78

Bhatia, M. 80

Biersteker, T. J. 133

Bilmes, L. 130

bin Laden, 0. 109

Bishop, R. 78

black market 70, 84, 126, 127

Black Sea region 69

Blandy, S. 156

Blien, U. 143

Bloch, M. 29

Blomberg, T. G. 145

Bloom, M. 65

Blumin, S. M. 108

Bobbio, N. 80, 147

Bolivia 80

Bonanate, L. 17, 44 
Booth, J. A. 76

Booth, K. 5

Booth, M. 80

Borch, C. 153, 154

Borghese, J. V. 76

Bosnia 103

Bosnian war 42

Bosnian War 4, 101, 106

Bourke, J. 105

Bourne, M. 75

Bowman, J. 62

Braudel, F. 16, 18

Brauer, J. 119

Brazil 79

Bretton Woods system 84, 128

Brewer, M. B. 95,96

Brewer, S. A. 58, 95

Brigate rosse (BR) 59

Brighton, S. 3

Brodie, B. 8

Brown, W. 71, 141

Bruinessen, $M$. van 91

Brzezinski, Z. 19

Budreau, L. M. 106

Buehn, A. 125, 126

Buitenhuis, P. 87

Bull, H. 14

Burchill, S. 14

Burk, J. 58, 64

Burma 71, 79

Burton, J. W. 6

Buscetta, T. 109

Bush, G. W. 55, 58, 81, 95, 131, 132, 137

Buzan, B. 14

Byers, M. 99

Byman, D. L. 60, 133

Cable News Network (CNN) 101, 104

Caffrey, S. 149

Caforio, G. 58

Caillois, R. 4

Calder, K. E. 69, 105

Calvi, R. 121

Cambodia 38, 82, 94

Camorra 93

Canada 123

Canetti, E. 41, 61, 99

Capa, R. 103, 104

capitalism $23,128,137,142,147,148,151$. see also market of violence

Cappelletto, F. 108
Carr, E. H. 5

Carruthers, S. L. 101

Carter, J. A. 92

Carvalho, F. J. C. de 129

Cazeneuve, J. 53, 63

Central Asia 69, 71, 125

Central Intelligence Agency (CIA) 7, 80, 82

Chang, I. 42

Charles VIII of France 112

Charles V of Spain 112

Charlie Hebdo 103

chartered companies 114, 129, 130, 140

Chen, A. 53

Cheney, D. 131

Chicago 78

child soldiers 40, 49, 51, 109

Chile 81

Chilean coup 76

China 52, 70, 72, 79, 122, 127

Chinese Revolution 127

Chin, K.-L. 127

Church, J. 56

citizen-soldiers 55, 95, 104, 108

civilians

and propaganda 88,91

as personnel in the military $48,57,58$

as victims $39,40,42,50,51,73,75,82,97$,

$107,117,137$

involvement in wars $24,66,68,74,106$,

118, 136

relationship with the military 56

clan

and neopatrimonial relationships 149

and the administration of justice 148

and the family 147

definition of 146

Clancy, G. 78

Clapp, J. 125

Clark, I. 17

Clausewitz, K. von 24, 25, 67, 136

cleavage structures. see state and the new cleavage structure

Clinton, B. 131

Cloonan, M. 93

Coaffee J. 155

Codrignani, G. 42

coercive commercial enterprises $47,50,51,53$, 63,64

coercive non-profit organisations $46,50,51,52$, $53,59,63,64$ 
Cohen, D. 108

Cohen, E. A. 54

Cold War 6, 7, 47, 55, 68, 75, 82, 120

and the media 91

ending of $16,30,47,57,62,63,67,70,109$,

$117,119,123,126,127,128,130,149$

legacy $10,69,78,138,139,140$

periodisation of 17

propaganda apparatuses 87,98

Collins, K. 146, 147

Colombia 42, 52, 73, 74, 78, 80

Commission on the National Guard and Reserves 56,58

condottiere 111

Congo 79

Conroy, J. 36

conscription $30,35,46,54,55,56,57,63,112$, $129,130,136$

constitutive theory 11

conservative 12

constructivist $12,13,15$

critical 12

emancipative 12

feminist 13

postmodernist 12,13

contractors 50, 52, 56, 95, 124, 130, 131, 139

and clusters of sovereignty 144

and globalisation 142

and professionalism 49, 51

and strategies for recruitment 60

and strategies of coercion 145

self-representation of 109

Cooley, A. 69

Cooley, J. K. 146

Cooper, N. 119, 126

Cooper, P. J. 77

Cordesman, A. H. 43, 75

Cosa Nostra 31, 93, 121

Costigan, S. S. 133

Coté, W. E. 104

coup d'état 28, 76, 81

Courtwright, D. T. 127

Cowan, D. E. 93

Cox, M. D. 127

Cox, R. 12

Craig, C. 119

Creel, G. 87

Crelinsten, R. D. 41

Creveld, M. van 41

Crimean War 100
Croatia 4

Cruz, J. M. 52

Cuban Missile Crisis 82

Cuddy, A. J. C. 96

Cull, N. J. 87

Cumings, B. 101

Cunningham, K. J. 65, 89, 90

Cunningham, S. B. 86

cyberterrorism 93

cyberwar 101

Davies, D. 5

Davis, D. E. 72, 140, 155, 156

Davis, F.-L. 54

Davis, L. E. 119

Davis, M. 23, 72

Dawson, G. 70, 78, 106

Dawson, L. L. 93

Dear, M. 71

Declaration of Paris 115

deduction 14

Defensible Space Programs 155

dehumanisation process 35, 36, 50, 51

De Luna, G. 104

De Lutiis, G. 76, 82

democratic regimes $9,18,29,46,54,55,58$,

$118,139,148$

and armed forces 64, 112, 139

and clusters of sovereignty 142, 145

and permanent global civil war 151

and preventive war 18

and privatisation of violence 118

and propaganda 91, 94, 95

and secrecy 81

and totalitarianism 98

and war 2

triumph of 17,97

democratisation 62, 137

democratisation of memory 105

Der Derian, J. 12

Desch, M. C. 47

Dickinson, L. A. 131

Dirección Nacional de Inteligencia (DINA) 81

Dishman, C. 60

Drake, R. 82

Dratel, J. L. 97

Dudziak, M. L. 137

Dumézil, G. 49

Duncan, G. 52, 73

Dutch East India Company 115

Earhart, D. C. 91 
Easton, D. 153

Eatherly, C. 43

Echandía Castilla, C. 73, 80

Eckert, S. E. 133

Egypt 38, 74

Ehrenreich, B. 41, 105

Eibl-Eibesfeldt, I. 35

Eichmann, A. 33

Ejército de Liberación Nacional (ELN) 73

Ejército Popular de Liberación (EPL) 73

Eldar, A. 106

Elder-Vass, D. 13

Eliade, M. 32, 53

Elias, N. 110

Ellul, J. 89

embedded journalists 101

Engerman, S. L. 119

English East India Company 115, 129

Enloe, C. 13, 56

Enste, D. 126

Ernst, J. 68, 76

Escobar, P. 78

ethnic cleansing 28, 42

ethnic conflicts $16,100,120$

ethnic groups 15, 21, 42, 64, 139, 142, 147

ethnicity $24,46,64,97,141$

ethnic rape 42

Europe 5, 18, 47, 68, 69, 79, 83, 105, 117, 125 and arms production and sales 120, 122 and chartered companies 115 and conscription 55 and extraordinary rendition 36 and global jihadis 50 and partisan war 82 and police forces militarisation 48 and privateering 113, 115

and securitisation of the urban spaces 79 and state formation 20, 31, 140, 144, 145 and technological revolution in weaponry 116

and the military-industrial complex 123 and World War I 136

European Union 11, 20, 64, 71

Evangelista, M. 146

Even, S. 61

Executive Committee of the National Security Council 82

explanatory theory 11 empiricist 12

pragmatist 12 rationalist 12

extraordinary rendition 36,146

Eyler, G. 60

Fabre, G. 127

Fair, C. C. 61, 91

Farcau, B. W. 76

Feaver, P. D. 46

Feinstein, A. 102

Findlay, R. 119

Finnemore, M. 16

Fischerkeller, M. P. 96, 98

Fiske, S. T. 96

Fleurant, A. 123

foam theory 153

Foerstel, H. N. 82, 102

Fogu, C. 106

Foote, K. E. 106

Fornari, F. 89

Forster, A. 47, 57

Foucault, M. 29

France 55, 69, 70, 103, 115, 116, 122

Frederick the Great of Prussia 112

Freedman, D. 102

Freeman, J. 131

French Revolution 22, 105

fringe armies 47, 50, 51, 53, 59, 63, 64

Fromm, E. 4

Fuerzas Armadas Revolucionarias de Colombia (FARC) 73, 80

Fujita, M. 142

Fukuyama, F. 17

Fuller, B. 156

Fussell, P. 108, 137

Fyne, R. 91

Gabriel, R. A. 38, 39

Galeotti, M. 127

gangs $20,21,30,33,45,50,51,52,59,64$, $72,79,93,95,97,103,132,154$. see also violent non-state actors (VNSAs) and career prospects 60 and globalisation 141 and honour code 63 and initiation 53 and masculinity 42 and professionalism 49 and socialisation to violence 32 and sources of legitimacy 78 and strategies for recruitment 55 and the city $75,141,154$ and the market of violence 124 
as fringe armies 47

Ganguly, S. 91

gated communities 71, 91, 153, 156

Gaza 59, 106

Geisler, C. 25

gender. see women

Geneva Conventions 97

Gennep, A. van 32, 99

Gerber, D. A. 108

Germany 43, 45, 48, 55, 59, 69, 87, 111, 116, 122

Giacomello, G. 93

Giap Vo Nguyen 68

Gibelli, A. 108

Gilpin, R. 10, 84

Glantz, A. 108

Glick, P. 96

globalisation 22, 65, 70, 72, 94, 106, 137, 140, 142,151

and centre-periphery transactions 20 and privatisation of violence 118 and states de-construction 19 and the city 23, 152

and the military-industrial complex 126

and war 2, 16, 24

Global War on Terror (GWOT) 18, 55, 69, 82, 97

Godson, R. 127

Gold, D. 133

Golden Crescent 127

Golden Triangle 79, 127

Goldhagen, D. J. 49

Goldstein, J. S. 10, 17, 42, 64

Gonzalez-Perez, M. 65

Goodwin, M. 128

Gootenberg, P. 127

Gordon, I. R. 143

Gorini, U. 81

Gottshalk, P. 97, 125

Graaf, J. de 44

Graham, S. 152, 153

Gray, C. S. 66, 67, 74

Great Britain 55, 69, 86, 87, 115, 116, 122

Great Mutiny 115

Greece 13, 122

Greenberg, B. S. 44

Greenberg, G. 97

Greenberg, K. J. 41, 97

Greif, A. 147

Grossman, D. 34, 49, 61

Grottanelli, C. 29

Grutzpalk, J. 147
Guantánamo 146

Guénon, R. 32, 54

guerrillas $50,73,76$. see also violent non-state actors (VNSAs)

and career prospects 60

and clusters of sovereignty 144

and honour code 63

and professionalism 49

and social environment 50

and strategies for recruitment 64

and the city 75,76

and women 65

as coercive non-profit organisations 46

guerrilla warfare 59, 138

Guevara, E. Che 82, 104

Gutman, R. 38

Guzzini, S. 14

Haar, B. J. ter 62

Hafez, M. M. 88

Hagedorn, J. M. 33, 52

Hagopian, P. 107

Halliburton 131

Halloff, F. 41

Hamas 59, 143

Hammond, P. 103

Ham, R. 77

Hancock, P. A. 39

Hanson, N. 108

Harcourt, B. E. 156

Harding, C. 34

Haritos-Fatouros, M. 36

Hasenclever, A. 10

Hassan, H. 124

Headrick, D. R. 116

Heims, S. J. 95

Heinecken, L. 58

Held, D. 23, 151

Henriksen, R. 61

Herberg-Rothe, A. 24

Herbert, S. 72

Herf, J. 87

heroism 28, 30, 38, 44, 88, 105, 108, 140

Herrmann, R. K. 96, 98

Hezbollah 80

Hilberg, R. 38

Hill, P. B. E. 60

Hiroshima atom bomb attack 43

Hirschman, A. 0. 59

Hobbes, T. 3

Hobsbawm, E. J. 31, 141 
Ho Chi Min 107

Hoffmann, S. 5

Holmes, L. 127

Holocaust 94

Holzer, J. 71

honour code 31, 62, 65, 97, 138, 146, 149

Honwana, A. M. 109

Horgan, J. 53, 59, 62

Hoskins, A. 100

Hossein-zadeh, I. 123, 132

Huggins, M. K. 36

Hundred Years' War 113

Huntington, S. P. 28, 62, 113

Ikenberry, G. J. 17

India 71, 72, 115, 122

India Bill 115

Indian Army 115

Indochina 103

induction 14

Industrial Revolution 22, 129

Information and Communication Technologies (ICTs) 156

information warfare 101

initiation 32, 35, 36, 40, 51, 63

insurgents 46, 51, 91

international anarchy 5, 9, 11, 13, 24, 143

International Criminal Tribunal for the Former Yugoslavia 33

International Monetary Fund 20

international order $9,13,17,18,140$

International Relations (IR) 5, 10, 11, 13, 14, 15, 16,18

Inter-Services Intelligence (ISI) 80

Iran 104

Iran-Iraq War 62

Iraq 51, 55, 71, 75, 87, 103, 131, 132

Iraq War 39, 55, 56, 58, 102, 104, 106, 108, 130

Irish Republican Army (IRA) 59

Islamic schools 91

Islamic State (IS) 92, 109, 124

Islamists 21, 22, 50

Israel 38, 70, 71, 74, 106

Italy 35, 48, 55, 59, 76, 111, 143

Jacobi, A. P. 25

Jacoby, T. A. 71

Jankowski, M. S. 60, 65

Janowitz, M. 28, 46, 49, 54, 62, 148

Japan 43, 69, 87, 117

Japanese army 42

Japanese kamikaze 37
Jaycox, L. H. 39

Jenkins, B. M. 44

jihad 50, 59, 92, 105

Jo, H. 118

Johnson, B. 93

Johnson, L. K. 81

Johnson, V. M. 99

Jojarth, C. 124

Jongman, A. J. 44

Jordan 74

Jowett, G. S. 86

Jung, D. 119

Jungk, R. 6

Jürgs, M. 68

Just, M. R. 103

Kahaner, L. 123

Kaldor, M. 23, 24

Kallis, A. A. 87

Kansteiner, W. 106

Kantorowicz, E. H. 29

Karnow, S. 76

Kashmir 71

Kassimeris, G. 28

Kawata, J. 148

Kaya, A. 23

Keegan, J. 75

Kelly, R. J. 94

Kennedy, C. H. 39

Kennedy, J. F. 82

Kennedy, R. 82

Keohane, R. 0. 10

Kern, M. 103

Kershner, I. 71

Keynes, J. M. 129

Kiernan, V. G. 97

Kimhi, S. 61

Kinross, S. 67

Kinsella, D. T. 9

Kirchner, H. 105

Kirshner, J. 129

Kirtzman, A. 121

Kissinger, H. 7

Klausen, J. 92

Klauser, F. R. 153, 154

Knightley, P. 100

Knowlton, B. 58

Kohn, R. H. 46, 56

Koselleck, R. 54

Koskenniemi, M. 28

Kosovo 43, 103 
Kramer, A. 108

Kraska, P. B. 48

Krasner, S. D. 10

Kratochwil, F. 12

Krepinevich, A. F. Jr. 67

Krishnan, A. 123

Krugman, P. R. 142

Kruijt, D. 76

Krupp 116

Kubrick, S. 32

Kuklick, B. 8

Kushner, B. 87

Kwon, H. 108

Landau-Wells, M. 76

Lane, F. C. 111, 114, 128

Laos 79, 82

Laqueur, W. 82

Lasswell, H. D. 56, 86, 90

Latin America 40, 72, 82, 103, 127, 146

Laurie, C. D. 87

Lawson, P. 115, 130

Leal, D. L. 54

Leander, A. 14

Lebanon 38

Le Billon, P. 125

Lebow, R. N. 13, 15, 106

Leed, E. J. 38, 68

Leitner, M. 156

Lerner, D. 86

levels of analysis. see scenarios and level of analysis

Levinson, S. 41

Levi, P. 44

Levy, J. S. 10

Lévy-Strauss, C. 149

Lewis, B. I. 91

Lewis, J. W. 36

Liddell Hart, B. H. 66, 136

Linklater, A. 12, 14

Lippert, R. 156

Lister, C. R. 92

Little, R. W. 41

Livingston, R. W. 96

Li, X. 108

Lloyd, D. W. 106

Lodato, S. 109

Logevall, F. 119

Lorenz, K. 3

Louis XIV of France 112

Lowen, R. S. 7, 8
Lucken, K. 145

Luckman, T. 13

Luhmann, N. 153

Lynch, M. 56

Machiavelli, N. 112

MacNair, R. M. 39

mafias 21, 23, 45, 52, 72, 95, 103, 125, 132 , 149. see also violent non-state actors (VNSAs)

and career prospects 60

and clusters of sovereignty $142,143,144$

and globalisation 141

and initiation 53

and masculinity 42

and professionalism 49, 51

and secrecy 54,120

and socialisation to violence 33

and sources of legitimacy 31, 78

and strategies for recruitment 55, 60, 64

and strategies of coercion 144, 145

and the city $75,141,154$

and the market of violence 124

and welfare 83

as coercive commercial enterprises 47 self-representation of 109

Maher, S. 92

Maier, G. 143

Maire Vigueur, J.-C. 111

Makdisi, S. 71

Malešević, S. 24

Malik, J. 91

Mallett, M. 111

Malloy, S. L. 7

Manhattan Project 6, 117

Manning, P. K. 156

maras 51, 103

market of violence 53, 56, 117 and arms production 122

and illegal trafficking 126

characteristics of 119

Martino-Taylor, L. 6

martyrdom 28, 37, 50, 53, 65, 80, 87, 105, 106, 140

Marvin, S. 153

Masciandaro, D. 128

masculinity 41,64

massacre of Nanking 42

Matheson, D. 104

Mayer, J. 36

Mayer, P. 10 
Mazzei, J. 52

McCann, P. 143

McCoy, A. W. 80

McGarty, C. 90

McGrew, A. 151

McNeill, W. H. 43, 116, 117, 123, 136

Medellín Cartel 78

Mehta, S. 23

mercenaries $68,74,109,111,112,113,114,115$, $129,130,140$

Mettler, S. 108

Mexican-American War 101

Mexico 70

Middle Ages 112, 118

Middle East 102

Milgram, S. 34

militarism 41, 56, 93

military-industrial complex 116, 123, 126, 131, 138

military profession 3, 30, 46, 47, 48, 49, 60, 139

military professional revolution 113

militias 46, 64, 79, 112

Minow, M. 131

Mishal, S. 53, 143

Modelski, G. 10, 17

Moeller, S. D. 100, 104

Moggi, M. 97

Monje, S. C. 82

Moorcraft, P. L. 100

Moran, T. P. 95

Morgenthau, H. J. 9

Moro, A. 82

Morocco 71

Morrow, J. D. 118

Moskos, C. C. 42, 47, 57, 63

Mosse, G. L. 21, 41, 105

Muammar Gaddafi 104

Mueller, J. 78

Muggha, R. 63

Mundy, G. 149

Munshi, S. 103

Munton, D. 82

Murakami Wood, D. 155

Murray, W. 75

Mussolini, B. 104

My Lai massacre 107

Nagasaki atom bomb attack 43

Napoleon Bonaparte 75

Napoleonic Wars 41

narcocorridos 93 narco-dictatorships 79, 139

narco-terrorism 133

narco-traffickers 132, 144

narco-trafficking 124, 126, 127, 128, 141

nationalism 9, 24, 86, 148

Naylor, R. T. 84, 119

Neal, A. C. 119

Neiberg, M. S. 54

Nelson, D. 107

neopatrimonialism 147,150

Ness, C. D. 65

Nesser, P. 50

net war. see revolution in military affairs (RMA)

Neumann, I. B. 10

Neumann, P. R. 92

Neumann, S. 151

Nevins, J. 71

new imagined communities 141, 146

Newman, 0. 155

New Mexico 107

Nicaragua 76

Nitzschke, H. 119

Noor, F. A. 91

Norris, P. 103

Northern Ireland 59, 103

North Vietnamese People's Army 76

Nuremberg trials 33

Nuttal, M. 147

O’Connor, J. E. 91

O’Donnell, V. 86

officer corps 30, 49, 62, 105, 136, 139 and career prospects 57 and honour code 62 and state formation 111, 112 and the military-industrial complex 116 and the professional revolution 113 and war crimes justification 33 as military elite 49 evolution in the role of 48 information warfare 101 professionalisation 46 selling of commissions 30

Oglethorpe, J. 77

Ohnuki-Tierney, E. 37

Ojeda, A. E. 41

Oliver, K. 107

Olson, M. 110

Onuf, N. 12

operation Overlord 66

Oppenheimer, L. 94 
Organisation for Economic Cooperation and Development (OECD) 125

organised crime $20,33,71,84,126,128,146$, 154, 155

O’Rourke, K. H. 119

Ouchi, W. G. 147

Ousby, I. 136

outsourcing $30,50,56,70,79,109,113,128$, $130,131,145,149$

Paddock, T. R. E. 91

Pagès, G. 68

Paglen, T. 36, 146

Pakistan 71, 80

Palestinians 71

Paletz, D. L. 44

Palmer Harik, J. 83

Paquet, G. 76

paramilitaries 42, 47, 52, 64

Paret, Pa. 91

Paret, Pe. 91

Parker, G. 68, 74, 117

Parsi, V. E. 17

Parta, R. E. 92

partisans 75,82

partisan warfare 68,136

Patriot Act 81

patriotism $50,57,93,102$

Paulsen, D. J. 78, 155

Paxton, M. 101

Pearl Harbor 137

Peluso, N. L. 125

Perlmutter, A. 113

Perlo-Freeman, S. 123, 124, 130, 131

perpetration-induced traumatic stress (PITS) 39

Persian Gulf 101

Peru 80

Peters, R. A. 108

Peter the Great of Russia 18

Phillips, S. A. 93

Pion-Berlin, D. 76

pirates 111, 115, 140

Pirjevec, J. 43

Pitelis, C. 142

Police Paramilitary Units (PPU) 48

Polisensky, J. V. 68

Politkovskaya, A. 103

Porter, M. E. 142

post-traumatic stress disorder (PTSD) 39, 102

Poveda, C. 63, 103

Pratten, D. 52, 118 prisons $46,77,79,93,139$

privateering 113,115

private military corporations (PMCs) $50,56,57$, $59,70,72,79,118,124,126,131$. see also violent non-state actors (VNSAs) and globalisation 142 and masculinity 42 and professionalism 49, 51 and secrecy 83 and sources of legitimacy 30,31 and strategies for recruitment 55, 60, 64 and the city 75 and the market of violence 132 as coercive commercial enterprises 47 privatisation of violence $62,63,64,72,102$, $109,120,122,131,140,141$

propaganda and enemy-making 93,96 and overexposure to images 100 and stereotypes 89 and the politics of memory 105 and the propagandee 89 definition of 86 protection rent 114

Prussia 112, 115

Pugh, M. 119

Pullan, W. 71

Purbrick, L. 70, 78

Raffestin, C. 152

Rand Corporation 7, 8

Rastello, L. 75

Rattray, G. J. 101

Ravenhill, J. 10

Reagan, R. 107

realism $5,6,8,9,10,14$

Remmer, K. 76

Reno, W. 124

Reserve Officers' Training Corps (ROTC) 54

Reuter, C. 51, 60

revolution in military affairs (RMA) 2, 55, 67

Richani, N. 73

Rieber, R. W. 94

Rieff, D. 38

Riggs, F. W. 8

Rittberger, V. 10

Robin, R. T. 7

Robinson, P. 101

Rodgers, D. 63

Rogers, P. 155

Rohatyn, D. 89 
Rokkan, S. 19

Roland, A. 123

Rollins, P. C. 91

Romer, P. 156

Roper, M. 106

Rosenau, P. M. 12

Rosen, D. M. 40, 51

Rosenthal, M. 53

Rosin, E. 127, 146

Rote Armee Fraktion (RAF) 59

Roth, G. 149, 150

Rousseau, J.-J. 3

Rousset, D. 35

Roxborough, I. 47

Ruble, R. S. 99

Ruggiero, V. 119, 132

Russell, E. 77

Russett, B. M. 9

Russia 18, 55, 60, 65, 68, 115, 122, 127

Russian-Japanese war 38

Russian mafiya 31, 143

Ruzza, S. 25

Rwanda 38, 92, 103

Saddam Hussein 104

Sahlins, M. 147

Salamone, M. D. 67

San Salvador 103

Sarajevo siege 43, 75, 106, 121

Sardinia 115

Sassen, S. 22, 23

Saudi Arabia 71

Scahill, J. 51

Scales, R. H. Jr. 75

Scarry, E. 38, 40, 43

scenarios $25,90,95,118,138,140$

and degree of abstraction 15

and levels of analysis 14, 15, 16, 19, 21, 23

and levels of comprehension 16

and time 16

Schaffert, R. W. 44

Scheipers, S. 25

Schelling, T. C. 19

Schlesinger, A. M. 98

Schlichte, K. 46

Schlieffen Plan 74

Schmid, A. P. 41, 44, 88

Schmitt, C. 82

Schneider-Creusot 116

Schneider, F. 125, 126

Schumacher, G. 51
Schwartz, Mi. 132

Schwartz, Mo. 56

Schweitzer, R. 86

Schwoch, J. 92

Searle, J. R. 13

Seaton, J. 99

Sebald, W. G. 45

Secunda, E. 95

Sedra, M. 80

Segal, D. R. 47, 57

Seib, P. 102, 104

Sela, A. 143

Sell, S. K. 16

Sen, A. 52, 118

Sending, O. J. 10

September 11 attack 17, 18, 38, 56, 88, 95, 137, 151

shadow economy 125

shadow finance 128

Shambaugh, J. 77

Shapiro, J. F. 92

Shapiro, M. 12

Sherman, J. 119

Shibutani, T. 96

Shiu-Hing Lo, S. 127

Sierra Leone 51, 79

Sikand, Y. 91

Silke, A. 59, 64

Simmel, G. 54

Simon, J. 146

Simons, G. 103

Simpson, C. 7

Simpson, R. 104

Sindona, M. 121

Singer, P. W. 40, 68, 70, 79, 109, 130

Singh Deepali, G. 73, 80

Sironi, F. 36, 40, 41

Six Days War 74

Sköns, E. 124, 130, 131

Sledge, M. 106

Sloan, E. 67

Sloterdijk, P. 153

Slovenia 4

Sluka, J. A. 52

Small Arms Survey 123

Smith, J. A. 7

Smith, S. 5, 8, 11, 12, 15

Smith, T. B. 106

Snape, M. 86

Snyder, C. A. 67 
Sofsky, W. 36

Somalia 103

Sontag, S. 101

Sorenson, D. S. 69

South Africa 71

South Korea 69, 122, 156

sovereignty $9,18,20,109,114,118,140$

and capital city 75

and new imagined communities 146

and the state 4,9

clusters of 142

sacredness of 29

Spain 55

Spears, R. 90

Special Weapons and Tactics Teams (SWAT) 48

Speier, H. 86

Spicer, T. 109

Sproule, J. M. 95

Stajano, C. 121

Stalingrad siege 75

Stanford Prison Experiment 34

Stanger, A. 131

Starr, H. 9

Starr, P. 101

state armed forces $32,56,58,60,61,64,120$, 139

and masculinity 64

and revolution in military affairs 67

and strategies for recruitment 55

and the crisis in the military vocation 58

and the end of conscription 57

and the military elite 49

and the warrior spirit 63

as coercive non-profit organisations 46

hybrid role of 47,49

states $18,141,147,148$

and fragmentation of power 10

and international anarchy 3

and propaganda 85

and strategies of coercion 144

and the market of violence 129

and the new cleavage structure 22

and war 24, 66, 68, 112, 136, 140

de-construction 19

formation 4, 20, 31, 110, 113, 149

Staub, E. 94

Steensgaard, N. 114

Stein, J. G. 13, 15

Stenersen, A. 92

Stern, S. M. 82
Stewart, F. H. 62

Stiglitz, J. 130

Stimson, H. L. 7

Stouffer, S. A. 61

Stover, W. 56

Strachan, H. 24, 25, 28

Strange, S. 18, 84, 128

Strasser, S. 34

Straus, S. 92

Strazzari, F. 121

Stulberg, A. N. 67

subcontracting. see outsourcing

Sub-Saharan Africa 125

Sugden, R. 142

suicide terrorists $36,38,62,75$

Swain, J. 56

Sweeney, M. S. 101

Sylvester, C. 13

Syria 74

Szalma, J. L. 39

Takáts, E. 128

Taliban 73, 80, 146

Tanaka, Y. 43

Tanielian, T. 39

Tavernier, B. 105

Taylor, P. M. 100

Taylor, T. 33

terrorist attacks 18, 41, 44, 47, 103, 137, 138, 154

terrorists $20,21,23,30,37,48,50,61,62,71$, $84,95,97,124,132,143$. see also violent non-state actors (VNSAs)

and career prospects 60

and clusters of sovereignty 143

and extraordinary rendition 36

and globalisation 141

and initiation 53

and masculinity 42

and professionalism 49

and propaganda 88

and secrecy 54,120

and social environment 50, 59

and socialisation to violence 33

and sources of legitimacy 31

and strategies for recruitment 60,64

and strategies of coercion 144, 145

and the city 75

and the market of violence 124

and the risks of a new militarism 56

and welfare 83

and women 65 
as coercive non-profit organisations 46

self-representation of 109

terrorists and Islamic school 91

Texas 70

Thailand 79

theater strategy 66

The Hague trials 33

Thirty Years War 68

Thomas, G. M. 39

Thomas, W. H. Jr. 88

Thompson, A. C. 36,146

Thompson, K. W. 9

Thomson, J. E. 113, 114, 115, 145

Thoumi, F. E. 127

Thussu, D. K. 102

Tilly, C. 111, 129, 144, 145, 157

torture $28,34,35,36,40,41,43,50,77,80,81$

totalitarianism $36,49,64,72,74,91,98,132$, $136,137,139,148,151$

Triads 31

Tucker, R. P. 77

Tuman, J. S. 44, 88

Tumber, H. 102

Turkey 94, 115

Tuyll, H. van 119

Tyndall Report 102

Uduku, 0. 156

Unger, B. 128

United Arab Emirates 122, 156

United Nations Development Program (UNDP) 23

United Nations peacekeepers 121

United Nations Register of Conventional Arms 123

United Nations World Urbanisation Prospects 72 universal draft. see conscription

URSS 68, 119

USA $39,49,57,58,87,95,99,106,117,121,137$

and academic institutions 5

and aerial bombing in Vietnam War 43

and arms production and sales 122,123

and conscription 54,55

and extraordinary rendition 36

and multilateralism 11

and police forces militarisation 48

and privatisation of security 130, 145

and propaganda 86

and securitisation of the urban spaces 78 , 155

and Texas border fence 70 and the Base Realignment and Closure

Process (BRAC) 69

and the crisis in the military vocation 58

and the military-industrial complex 119, 123

and the Patriot Act 81

and the risks of a new militarism 56

and the role of the media in war 104

and the space of prisons 79

and the valorisation of war sites 106

and the veterans debate 108

as penal state 146

reorganisation of the military 69

US Army 38, 55, 63, 76

US Department of Defense (DOD) 56, 130

US Executive Committee of the National Security

Council 82

US National Guard and the Reserves 55

US Shock and Awe doctrine 154

Uziel, D. 87

Vagts, A. 28,136

Valentine, B. 93

Valmy, battle of (1792) 112

Varese, F. 60

Vargas, C. M. 77

Vasquez, J. A. 11

Veer, P. van der 103

Venables, A. 142

Verbitsky, H. 36

Verdun 105

Verdun, battle of (1916) 136

veterans $39,83,102,107,108$

victims 99

Vietnam 69, 79, 107

Vietnam Veterans Memorial 107

Vietnam Veterans Peace and Brotherhood Chapel 107

Vietnam War 38, 43, 54, 55, 67, 76, 80, 82, 106, $107,108,127$

vigilantes $47,64,72$

vigilantism 118

Vinci, A. 61

violent non-state actors (VNSAs) 24, 46, 49, 63, 73, 95, 110, 117, 128, 137, 138, 151, 157

and clusters of sovereignty 142

and enemy-making 90

and honour code 62,97

and new imagined communities 141

and propaganda apparatuses 87

and rural environment 79

and secrecy 83,126 
and small arms 123

and social environment 59, 64, 72, 78

and the duty to kill 35

and the market of violence $119,120,132$

and the media 92, 93

and the state $31,58,61$

and urban resilience to violence 155, 156

institutionalisation 83

Vokes, R. 92

Volkov, V. 60, 127

Voltaire 3

Vovelle, M. 105

Wacquant, L. 79

Wade, C. J. 76

Walby, K. 156

Walker, T. W. 76

Wallenstein, A. von 111

Wallerstein, I. 21

walls 70

Waltz, K. 11, 15

war

and enemy-making 97

and evolution in the role of the officer 47

and hegemony 10

and internal cohesion of the primary group

61,63

and psychiatric pathologies 38

and the abolition of conscription 54

and the consequences of outsourcing 55

and the evolution of privateering 113

and the evolution of state armed forces 111

and the evolution of weapons

manufacturing 116

and the media 91,101

and the politics of memory 105

and the problem of legitimacy 28

and the process of socialisation to violence

32

and the state of nature 3

crimes of $33,97,118$

outsourcing 130

propaganda apparatuses 86

spiral 25

theaters 66, 74

tourism 106

warlords 47, 51, 64, 118, 124, 132, 138, 142

war on drugs 77,154

war studies

and economic factors 119

and human nature 3 and the new wars debate 23, 138

and the role of American academic

institutions 5

epistemology 10,11

methodology $8,10,12,14,25$

ontology $8,13,17,24$

Watson, A. 39

Watts, M. 125

Weber, M. 29, 31, 147, 149

Weber, S. 13, 15

Webster, D. 77

Webster, F. 102

Wedgwood, C. V. 68

Weiner, M. S. 149

Weinstein, J. M. 51

Weiss, M. 124

Welch, D. 87

Welch, D. A. 82

Wendt, A. 12, 14

West Bank 59, 70, 71

Westphall, V. 107

Whaley Eager, P. 65

White, R. 77

Wieviorka, 0.67

Wight, M. 9

Wilbanks, J. H. 68

Wilford, H. 7

Williams, J. A. 47, 48, 57

Wilson, J. R. 142

Winter, J. 106

Wirtz, J. J. 67, 81

Wixted, B. 142

Wolfe, D. A. 143

Wolin, S. S. 151

women

as soldiers 56,64

as victims 40, 41, 81, 108

World Bank 20

World Trade Center 137

World War I 5, 37, 39, 66, 70, 74, 83, 106, 108, 136

and democratisation of memory 105

and internal cohesion of the primary group

62

and masculinity 41

and psychiatric pathologies 38

and the media 91

environmental consequences of 77

international administrative agencies 117

no man's land 68 
propaganda apparatuses 86

victims 117

World War II 5, 6, 7, 37, 43, 45, 63, 70, 76, 82, $86,95,108,117,118,128,129,136,137$ aerial bombings 43, 68 and embedded journalists 101 and internal cohesion of the primary group 61

and psychiatric pathologies 38

and the media 91

and war crimes 33

centralised economy 117

propaganda apparatuses 98 victims 117

Wright, Q. 2

Wright, T. C. 81

$\mathrm{Xu}$, J. 96

Yakuza 31, 60
Yang, B. 80

Yemen 71

Youngers, C. 127, 146

Young, M. B. 43

Yugoslavia 4, 38, 75, 100, 130

Yurdusev, A. N. 14

Yzerbyt, V. Y. 90

Zalewski, M. 5

Zaman, S. uz 92

Žarkov, D. 100

Zelizer, B. 100

Zertal, I. 106

Zillmer, E. A. 39

Zimbabwe 71

Zimbardo, P. G. 34, 36

Zimmern, A. 5

Zoja, L. 42 
